Federal Reserve Bank of Dallas

Globalization and Monetary Policy Institute

Working Paper No. 11

http://www.dallasfed.org/assets/documents/institute/wpapers/2008/0011.pdf

\title{
Globalization and Monetary Policy: An Introduction*
}

\author{
Enrique Martinez-Garcia \\ Federal Reserve Bank of Dallas
}

April 2008

\begin{abstract}
Greater openness has become an almost universal feature of modern, developed economies. This paper develops a workhorse international model, and explores the role of standard monetary policy rules applied to an open economy. For this purpose, I build a two-country DSGE model with monopolistic competition, sticky prices, and pricing-to-market. I also derive the steady state and a log-linear approximation of the equilibrium conditions. The paper provides a lengthy explanation of the steps required to derive this benchmark model, and a discussion of: (a) how to account for certain well-known anomalies in the international literature, and (b) how to start 'thinking' about monetary policy in this environment.
\end{abstract}

JEL codes: F3, F4

\footnotetext{
Enrique Martinez-Garcia, Research Department, Federal Reserve Bank of Dallas, $2200 \mathrm{~N}$. Pearl Street, Dallas, TX 75201. 214-922-5262. enrique.martinez-garcia@dal.frb.org. http://www.dallasfed.org/research/economists/martinez-garcia.cfm. This paper was originally prepared for a course on Topics of International Macroeconomics and Monetary Theory at the University of Alicante on December 17-19, 2007. I would like to thank Mark Wynne, Charles Engel, Rodolfo Manuelli, and the grad students and faculty at the University of Alicante for helpful discussions. All remaining errors are mine alone. The views in this paper do not necessarily reflect those of the Federal Reserve Bank of Dallas or the Federal Reserve System.
} 
"By way of background, two developments fundamentally distinguish modern monetary theory from its predecessors: first, the embedding of forward-looking (rational) expectations and microeconomic-based theories of wage/price formation into classical monetary models, and, second, the use of optimal monetary policy rules to describe and analyze policy" (Taylor, 2006, p. 1).

\section{Introduction}

A milestone in the international business cycle literature came with the work of Backus, Kehoe and Kydland $(1992,1994,1995)$. The new open economy macro literature (NOEM) was launched by Obstfeld and Rogoff (1995, 2002) shortly after that ${ }^{1}$. It can be argued that its precursors go back at least to Svensson and van Wijnbergen (1989), who worked out a model with NOEM features as an open economy development of Blanchard and Kiyotaki (1987). The recent treatise on the theory of monetary policy by Woodford (2003) is a common reference point for the NOEM literature too, even if it is concerned primarily with closed economies. Woodford (2003) has formalized the modern view that monetary policy is relevant even in a cashless economy.

The purpose of this paper is to introduce the benchmark NOEM model and to discuss the role for monetary policy in it. I study the neoclassical synthesis which incorporates commonly-used frictions in the literature (i.e., monopolistic competition, staggered prices and pricing-to-market) into an otherwise simplified version of the standard two-country international business cycle model. The analysis is conducted largely on theoretical grounds. The analysis is framed around a number of stylized facts that are thought to be robust in major industrialized countries for the post-Bretton Woods period and characteristic of open economies (see, e.g., Obstfeld and Rogoff, 2000). The paper also emphasizes differences with the frictionless models.

The Concept of Openness. Globalization in its most basic meaning is just openness to trade (whether in goods, inputs or assets). The NOEM literature, therefore, concerns itself with the effects that openness has on the domestic economy. As we go along, I will try to make this point as clear as possible. But, how do we quantify the effects of globalization anyway?

First, the magnitude and effects of openness cannot be unequivocally determined by the volumes of trade. It is possible to write models in which countries are fully open to trade (without frictions) and yet optimally decide not to exchange anything. We cannot infer from the lack of trade that the economies are closed. Most importantly, we cannot infer that openness is irrelevant. Let me give a simple example for illustrative purposes. Suppose that production of a certain variety is controlled by a domestic monopolist. The local government decides to eliminate all trade barriers and foreign competitors begin to challenge the incumbent domestic monopolist. It is possible to end up in a new equilibrium where the incumbent defeats the challengers by aggressively changing their pricing policy. Trade does not occur, and yet the impact of greater openness on prices can be quite significative.

\footnotetext{
${ }^{1}$ As Galí and Gertler (2007) note, "Goodfriend and King employ the term 'New Neoclassical Synthesis', while Woodford uses 'NeoWicksellian'. At the insistence of a referee, in our (Galí and Gertler's) 1999 paper with Richard Clarida, we used 'New Keynesian'. The latter term has probably become the most popular, though it does not adequately reflect the influence of real business cycle theory".
} 
Second, openness is a relative concept best defined in opposition to the closed economy equilibrium. Its effects, however, are conditional on a certain characterization of the model economy. The trade volumes are endogenously determined, and depend on the market structure, but also on other features of the model (preferences, technologies, taxes, trading costs, etc.). Hence, a decline in trade volumes alone cannot be shown as proof of decreasing openness or argued as evidence of greater insulation from foreign shocks.

Third, there is no guarantee that monetary policy is welfare-enhancing or that monetary policy is more or less 'effective' with greater openness. It is always possible to write a frictionless model where money is neutral. Hence, in that environment no monetary policy rule is welfare-enhancing whether the economy is open or closed, because money itself has no real effects. Whether monetary policy is welfare-enhancing critically depends on the market structure preventing an optimal allocation from occurring naturally. Nominal rigidities or other frictions are necessary to make sense of monetary policy.

How to conduct monetary policy optimally in an open economy is still an open question, but the answer very much hinges upon the set of frictions that one assumes. The benchmark NOEM model posits a market structure characterized by costless and instantaneous trading in goods markets ${ }^{2}$, complete asset markets, and fully segregated markets for inputs (particularly, labor). Openness operates fundamentally on the goods market and the asset markets, while frictions on both markets are expected to account for a number of stylized facts and puzzles. The literature emphasizes the importance of pricing decisions, and has developed a framework to do so based on nominal rigidities, monopolistic competition and the effects of local-currency pricing (henceforth, LCP) and producer-currency pricing (henceforth, PCP). It has also given much attention to the role of monetary policy on the demand-side.

In summary, the increased mobility and interdependence of the world's financial and goods markets, may be due to improvements of the information technology, the reduction in government barriers to doing business internationally, preference changes, financial innovations, etc. The interest on globalization driven by a trend for increased trade across countries may decay in the future if these patterns reverse themselves, even though these evolution may have little to do with market openness per se. But openness, or lack thereof, is a topic that has accompanied mankind since the dawn of time and it will continue to preoccupy scholars long after this paper has come out of fashion. Naturally, the only thing left to do is to devote ourselves to the subject as best as we can given the tools at our disposal in hopes that our efforts will enhance our general understanding of economics.

\section{The Six Fundamental Puzzles in International Macroeconomics}

At a basic level, I attempt to model and understand the basic primitives of an economy. The model of reference is the frictionless international real business cycle model (or a simplified version of it), while the benchmark for the NOEM literature adds some key frictions (nominal rigidities, pricing-to-market and monopolistic competition). I also discuss the role of frictions in the asset markets. The ultimate goal is to obtain a unified framework that captures a number of relevant stylized facts of the external sector. Having a unified framework gives us a null hypothesis to think about issues of international macroeconomics and finance with a point of reference. Parsimony is always preferred in modelling.

\footnotetext{
${ }^{2}$ See Obstfeld and Rogoff (2000) for a discussion of the role that costly international trading can play.
} 
The stylized facts that inform my discussion, at least partially, are summarized in the form of six puzzles. These six puzzles come with the seal of approval of Obstfeld and Rogoff (2000a). The six puzzles, which I briefly describe here, are viewed as tell-tale signs of modelling failures which require deeper thought. The six stylized facts described by Obstfeld and Rogoff (2000a) are:

- The Home Bias in Trade Puzzle. The evidence in McCallum (1995) and Evans (2003) suggests that trade within a country is substantially greater than across the border and, therefore, international goods markets appear to be quite segmented. The main focus of this paper is the international finance puzzles. However, it is worth noticing that there are other related real trade puzzles. For example, Trefler's (1995) 'missing trade' puzzle arising because the imputed factor content of trade does not seem to reflect comparative advantage, or the empirical failure of the Heckscher-Ohlin prediction of factor-price equalization. The home bias in trade should be viewed as part of this larger set of trade anomalies.

- The Savings-Investment (or Feldstein-Horioka) Puzzle. Feldstein and Horioka (1980) demonstrate that long period averages of national savings rates are highly correlated with the same averages of domestic investment rates among OECD countries. Obstfeld and Rogoff (2000a) show that the correlations have decreased over time, but they remain surprisingly higher than one might expect in a world with fully integrated asset markets.

- The Home Bias in Equity Portfolios Puzzle. French and Poterba (1991) observe that investors maintain a perplexing preference for home assets in spite of the rapid expansion of international asset markets experienced over the past decades. Over time, portfolios have become more diversified. But the pervasive effects of the bias remain and have been documented across many (small and large) economies. See Lewis (1999) for a detailed survey of the literature.

- The International Consumption Correlations Puzzle. The evidence on consumption growth correlations is often hard to reconcile with the much higher correlations predicted in models with complete international asset markets. Under complete asset markets, country-specific risks are easily pooled and shared across countries making consumption growth less dependent on them. As noted by Obstfeld and Rogoff (2000a), the consumption correlation puzzle is intimately connected to the Feldstein-Horioka and the home equity bias puzzles: "Given that the most transparent of market means of consumption smoothing -debt and equity trade- are far less operative across borders than within them, it should not come as any great surprise that international consumption correlations are low".

Backus, Kehoe and Kydland (1992) note that, moreover, international output growth rates appear to be more correlated than consumption. Backus and Smith (1993) show that fluctuations in consumption ratios and bilateral real exchange rates ought to be highly correlated whenever international asset markets are complete, and yet there is little empirical evidence for this relationship in the data. Ultimately, consumption correlation puzzles play a prominent role in distinguishing among alternative models, so the discussion often revolves around them.

- The Purchasing Power Parity Puzzle. Rogoff (1996) explore the tenuous connection between nominal exchange rates and consumption price indexes, resulting into highly volatile and persistent real exchange rates $^{3}$. The slow mean reversion of the real exchange rate, however, does not appear to depend on the contribution of nontraded goods as documented most strikingly by Engel (1999) and Chari, Kehoe and

\footnotetext{
${ }^{3}$ As a note of caution, estimates of the persistence of the real exchange rates can be missleading. For example, in the presence of transaction costs or other nonlinearities, the real exchange rate can move slowly within a band and more quickly outside of it.
} 
McGrattan (2002).

There are also other stylized facts to keep in mind related to this puzzle. Goldberg and Knetter (1997) survey the empirical literature and conclude that the pass-through of nominal exchange rates relative to international prices is much faster at the importer level than at the consumer level. They also provide evidence of pricing-to-market behavior (and price discrimination). Obstfeld and Rogoff (2000b) argue that terms of trade worsen in response to an exchange rate depreciation. This fact, however, is hard to account for with very sluggish import prices. The purchasing power parity (henceforth, PPP) puzzle is, therefore, a broad reflection of the trouble that conventional general equilibrium models have to rationalize the observed patterns of international pricing.

- The Exchange Rate Disconnect Puzzle. This puzzle refers to the weak relationship found empirically between the nominal exchange rate and most macro variables of interest, except for long horizons. Meese and Rogoff (1983) show that standard present-value models of the nominal exchange rate are regularly beaten by a naive random walk whenever forecasting short- and medium-horizons. Baxter and Stockman (1989) and Flood and Rose (1995) argue about the neutrality of the exchange rate regime based on the fact that transitions to floating exchange rates tend to generate increases in nominal and real exchange rate volatility without corresponding changes in the fundamentals. All these papers are manifestations of the same puzzle, anyway. They point out the difficulties of explaining exchange rate dynamics in terms of macroeconomic fundamentals as general equilibrium models attempt to do.

The power purchasing parity puzzle and the exchange rate disconnect puzzle (the so-called pricing puzzles) focus our attention on the pricing behavior, including the dynamic covariation between prices and other macro variables. However, as Obstfeld and Rogoff (2000a) already indicate, these puzzles are also more prevalent in the short- to medium-run, while all other puzzles (the so-called quantity puzzles) are more important in the long-run. In this paper, let that be clear, I concentrate most of the discussion on the pricing puzzles.

\section{The Workhorse Open Economy Macro Model}

I specify a stochastic, two-country general equilibrium model in the spirit of Clarida, Galí and Gertler (2002), Obstfeld and Rogoff (2002), Chari, Kehoe and McGrattan (2002), and Woodford (2007), among others. The home country has a mass of $n$ identical households, the foreign country (denoted with an asterisk) has a mass of $1-n$ identical households. There is also a continuum of monopolistically competitive firms located in each country, which produce a differentiated, tradable good. Firms in the home country produce varieties in the range $[0, n]$, while foreign firms produce in the range $(n, 1]$. The population size of each country matches with the range of produced varieties. Hence, the number of firms in each country equals the number of households.

Under complete asset markets, households in both countries have access to a full set of Arrow-Debreu securities (or state-contingent bonds) which are quoted in both the domestic and foreign currencies. Under incomplete asset markets, households in both countries have access to two uncontingent bonds (each quoted in a different currency). A frictionless goods market is modelled with flexible prices and no trading costs. Frictions in the goods market are introduced in the form of nominal price stickiness à la Calvo (1983) and pricing-to-market. Deviations from PPP occur because nominal prices are sticky in the local currency of the buyer, and firms can effectively price discriminate across markets. 
Both countries are essentially symmetric, although shocks are not always perfectly correlated. I allow for two important deviations from symmetry. I assume a home bias in consumption preferences (see Warnock, 2003), and I conjecture that the degree of price stickiness may vary depending on whether the firm is located in one country or the other ${ }^{4}$.

\subsection{Preliminary Concepts}

The law of one price (henceforth, LOOP) states that barring frictional or complicating factors such as tariffs, taxes, and transportation costs, the price of an internationally traded good in one country should be equal to the identical price in another country, once the price is expressed in the same currency. Absolute purchasing power parity (henceforth, absolute PPP) extends the concept to a common basket of goods. It simply states that a basket of goods which are frictionlessly and instantaneously traded must have an identical price in every country once the corresponding price index is expressed in the same currency.

If the basket of consumption goods contains some goods that are non-tradeable, some goods for which trading costs are non-negligible or the composition of the basket differs across countries, absolute PPP is likely fail even if the LOOP holds for all (frictionlessly) tradable goods. It is quite common to compare the CPI across countries expressed in the same currency with the help of the nominal exchange rate, and this evidence suggests that absolute PPP fails. However, this is neither proof that the LOOP fails nor a proper comparison because CPI baskets are not homogeneous across countries and often contain goods that are not internationally traded ${ }^{5}$.

Relative Purchasing Power Parity (henceforth, relative PPP) states that a basket of goods must have the same aggregate price in each pair of countries, if the price indexes are expressed in the same currency, up to a constant. Absolute PPP can be viewed as a special case of relative PPP. The LOOP may fail to hold because there is only limited pass-through. But if the pass-through rate is constant and identical for all goods, then the aggregation over all goods displays a similar pattern. Differences in prices may also be due to distribution costs or mark-ups that are country specific, if they exhibit little time variation. Furthermore, as noted before, pricing differences across CPIs could also be due to trading costs and compositional effects.

Systematic differences in those components of the observable price can explain the failure of absolute PPP. However, if those differences are constant over time, then relative PPP should still hold.

Fluctuations of the Real Exchange Rate under the LOOP. The real exchange rate, $R S_{t}$, can be computed as the nominal exchange rate, $S_{t}$, times the ratio of the CPI in the foreign country, $P_{t}^{*}$, over the CPI in the domestic country, $P_{t}$, i.e.

$$
R S_{t} \equiv \frac{S_{t} P_{t}^{*}}{P_{t}}
$$

If relative PPP holds, the real exchange rate should be equal to a constant, and equal to one if PPP is absolute. The empirical evidence suggests that relative PPP fails (at least in the short- and mediumhorizons), so fluctuations of the real exchange rate are very volatile and persistent. Not surprisingly, the

\footnotetext{
${ }^{4}$ For other types of asymmetry in the degree of price rigidity, see G. Benigno (2004) and Martínez-García (2007).

${ }^{5}$ In this paper, I abstract from nontraded goods entirely. However, I shall explore deviations from absolute PPP due to differences in the underlying basket of consumption goods across countries.
} 
interpretation of these real exchange rate fluctuations has become one of the most relevant topics in the international macro literature these days.

A number of researchers emphasize the presence of nominal rigidities and local-currency pricing in the goods market as an explanation for the failure of the $\mathrm{LOOP}^{6}$, based on the existing evidence that suggests most goods adjust their prices infrequently while changes in the nominal exchange rate occur almost continually. However, the failure of the LOOP is not required to induce fluctuations on the real exchange rate and violations of PPP. For simplicity, let me assume that prices are fully flexible, then the following alternative explanations exist,

Compositional Differences. Warnock's (2003) model of consumption bias in preferences gives me a natural candidate. I can use the definition of the real exchange rate and the CPIs implied by the workhorse model, which I describe in subsection 3.2, to argue that,

$$
\begin{aligned}
R S_{t} & =\frac{S_{t}\left[\xi^{*}\left(P_{t}^{H *}\right)^{1-\sigma}+\left(1-\xi^{*}\right)\left(P_{t}^{F *}\right)^{1-\sigma}\right]^{\frac{1}{1-\sigma}}}{\left[\xi\left(P_{t}^{H}\right)^{1-\sigma}+(1-\xi)\left(P_{t}^{F}\right)^{1-\sigma}\right]^{\frac{1}{1-\sigma}}} \\
& =\frac{\left[\xi^{*}\left(P_{t}^{H}\right)^{1-\sigma}+\left(1-\xi^{*}\right)\left(P_{t}^{F}\right)^{1-\sigma}\right]^{\frac{1}{1-\sigma}}}{\left[\xi\left(P_{t}^{H}\right)^{1-\sigma}+(1-\xi)\left(P_{t}^{F}\right)^{1-\sigma}\right]^{\frac{1}{1-\sigma}}} \neq 1 .
\end{aligned}
$$

Under flexible prices. it follows that terms of trade are defined as $T o T_{t} \equiv \frac{P_{t}^{F}}{S_{t} P_{t}^{H *}}=\frac{P_{t}^{F}}{P_{t}^{H}}$. Hence, it is possible to express the real exchange rate as a function of terms of trade,

$$
R S_{t}=\left\{\begin{array}{l}
{\left[1+\left(\xi^{*}-\xi\right) \frac{1-\left(T o T_{t}\right)^{1-\sigma}}{\xi+(1-\xi)\left(T o T_{t}\right)^{1-\sigma}}\right]^{\frac{1}{1-\sigma}}, \text { if } \xi^{*} \neq \xi} \\
1, \text { if } \xi^{*}=\xi
\end{array}\right.
$$

Absolute and relative PPP fail in this setting, even if the LOOP holds, except in the case where the terms of trade endogenously turn out to be time-invariant or preferences are identical across countries. In the long-run, however, it is likely to find support for relative PPP assuming that the real exchange rate and the terms of trade converge towards a deterministic steady state.

Trading Costs. Let me assume 'iceberg' shipping costs as in Obstfeld and Rogoff (2000a) such that for every unit of home and foreign good shipped abroad, only a fraction $1-\tau^{c}$ arrives at destination. These trading costs are identical for all varieties and across countries. I denote $P_{t}^{H}$ and $P_{t}^{F}$ the domestic price of the home and foreign goods, while $P_{t}^{H *}$ and $P_{t}^{F *}$ denote the corresponding foreign prices. Then, if markets are competitive and prices fully flexible, arbitrage would imply that,

$$
\begin{aligned}
P_{t}^{F *} & =\frac{1}{1-\tau^{c}} \frac{1}{S_{t}} P_{t}^{F}, \\
P_{t}^{H} & =\left(1-\tau^{c}\right) S_{t} P_{t}^{H *} .
\end{aligned}
$$

\footnotetext{
${ }^{6}$ I follow the same logic in these notes. However, as noted in my prior observations, fluctuations of the real exchange rate may occur even if the LOOP holds. This point is of great importance because it affects how we think about monetary monetary policy. If nominal rigidities are the primary channel, then optimal monetary policy may have real effects and a role to play in response to relative price distortions. If the LOOP holds and the real exchange rate fluctuates purely due to compositional effects in the basket of goods or trading costs, optimal monetary policy has no real effects in the model.
} 
For any $0 \leq \tau^{c}<1$, I can use again the definition of the real exchange rate and the CPI indexes implied by the workhorse model to show that,

$$
\begin{aligned}
& R S_{t}=\frac{S_{t}\left[\xi^{*}\left(P_{t}^{H *}\right)^{1-\sigma}+\left(1-\xi^{*}\right)\left(P_{t}^{F *}\right)^{1-\sigma}\right]^{\frac{1}{1-\sigma}}}{\left[\xi\left(P_{t}^{H}\right)^{1-\sigma}+(1-\xi)\left(P_{t}^{F}\right)^{1-\sigma}\right]^{\frac{1}{1-\sigma}}} \\
& =\frac{1}{1-\tau^{c}} \frac{\left[\xi^{*}\left(P_{t}^{H}\right)^{1-\sigma}+\left(1-\xi^{*}\right)\left(P_{t}^{F}\right)^{1-\sigma}\right]^{\frac{1}{1-\sigma}}}{\left[\xi\left(P_{t}^{H}\right)^{1-\sigma}+(1-\xi)\left(P_{t}^{F}\right)^{1-\sigma}\right]^{\frac{1}{1-\sigma}}} \neq 1,
\end{aligned}
$$

which can be expressed as a function of terms of trade, $T o T_{t} \equiv \frac{P_{t}^{F}}{S_{t} P_{t}^{H *}}=\left(1-\tau^{c}\right) \frac{P_{t}^{F}}{P_{t}^{H}}$, as follows,

$$
R S_{t}=\left\{\begin{array}{l}
\frac{1}{1-\tau^{c}}\left[1+\left(\xi^{*}-\xi\right) \frac{1-\left(\frac{1}{1-\tau^{c}} T o T_{t}\right)^{1-\sigma}}{\xi+(1-\xi)\left(\frac{1}{1-\tau^{c}} T o T_{t}\right)^{1-\sigma}}\right]^{\frac{1}{1-\sigma}}, \text { if } \xi^{*} \neq \xi \\
\frac{1}{1-\tau^{c}}, \text { if } \xi^{*}=\xi
\end{array}\right.
$$

Again, absolute and relative PPP fail in this setting even though the LOOP holds. However, relative PPP (but not absolute PPP) is a possible outcome if terms of trade are time invariant or preferences are identical across countries. This is no longer true if I assume that the trading costs are either time-varying or different across varieties and countries.

Non-traded Goods. Non-traded varieties can be viewed as a special case where the 'iceberg' shipping costs are equal to one, i.e. $\tau^{c}=1$. Therefore, prices abroad for domestic non-traded varieties are always infinity and demand for them is zero. A similar statement can be made regarding the domestic prices of foreign non-traded varieties. I denote $P_{t}^{H, T}$ and $P_{t}^{H, N T}$ the domestic price of the traded and non-traded home goods, and $P_{t}^{F, T}$ the domestic price of the traded foreign good. Similarly for the foreign prices $P_{t}^{F, T *}$, $P_{t}^{F, N T *}$ and $P_{t}^{H, T *}$. Then, if markets are competitive and prices fully flexible, arbitrage would imply that,

$$
\begin{aligned}
P_{t}^{F, T *} & =\frac{1}{1-\tau^{c}} \frac{1}{S_{t}} P_{t}^{F, T}, \\
P_{t}^{H, T} & =\left(1-\tau^{c}\right) S_{t} P_{t}^{H, T *} .
\end{aligned}
$$

A simple and straightforward extension of the consumption price indexes in the workhorse model allows me to write the real exchange rate as,

$$
\begin{aligned}
& R S_{t}=\frac{S_{t}\left[\xi^{T *}\left(P_{t}^{H, T *}\right)^{1-\sigma}+\xi^{N T *}\left(P_{t}^{F, N T *}\right)^{1-\sigma}+\left(1-\xi^{T *}-\xi^{N T *}\right)\left(P_{t}^{F, T *}\right)^{1-\sigma}\right]^{\frac{1}{1-\sigma}}}{\left[\xi^{T}\left(P_{t}^{H, T}\right)^{1-\sigma}+\xi^{N T}\left(P_{t}^{H, N T}\right)^{1-\sigma}+\left(1-\xi^{T}-\xi^{N T}\right)\left(P_{t}^{F, T}\right)^{1-\sigma}\right]^{\frac{1}{1-\sigma}}} \\
&=\frac{1}{1-\tau^{c}} \frac{\left[\xi^{T *}\left(P_{t}^{H, T}\right)^{1-\sigma}+\xi^{N T *}\left(\left(1-\tau^{c}\right) S_{t} P_{t}^{F, N T *}\right)^{1-\sigma}+\left(1-\xi^{T *}-\xi^{N T *}\right)\left(P_{t}^{F, T}\right)^{1-\sigma}\right]^{\frac{1}{1-\sigma}}}{\left[\xi^{T}\left(P_{t}^{H, T}\right)^{1-\sigma}+\xi^{N T}\left(P_{t}^{H, N T}\right)^{1-\sigma}+\left(1-\xi^{T}-\xi^{N T}\right)\left(P_{t}^{F, T}\right)^{1-\sigma}\right]^{1-\sigma}} \neq 1
\end{aligned}
$$

Hence, if I redefine terms of trade for tradable goods only as $T o T_{t}^{T} \equiv \frac{P_{t}^{F, T}}{S_{t} P_{t}^{H, T *}}=\left(1-\tau^{c}\right) \frac{P_{t}^{F, T}}{P_{t}^{H, T}}$, it can be 
said that,

$$
R S_{t}=\left\{\begin{array}{l}
\frac{1}{1-\tau^{c}}\left[1+\frac{\left(\xi^{T *}-\xi^{T}\right)\left(1-\left(\frac{1}{1-\tau^{c}} T o T_{t}^{T}\right)^{1-\sigma}\right)+\xi^{N T}\left(\left(\frac{1}{1-\tau^{c}} T o T_{t}^{T}\right)^{1-\sigma}-\left(P_{t}^{N T, T}\right)^{1-\sigma}\right)-\xi^{N T *}\left(\frac{1}{1-\tau^{c}} T o T_{t}^{T}\right)^{1-\sigma}\left(1-\left(P_{t}^{N T, T *}\right)^{1-\sigma}\right)}{\xi^{T}+\left(1-\xi^{T}\right)\left(\frac{1}{1-\tau^{c}} T o T_{t}^{T}\right)^{1-\sigma}-\xi^{N T}\left(\left(\frac{1}{1-\tau^{c}} T o T_{t}^{T}\right)^{1-\sigma}-\left(P_{t}^{N T, T}\right)^{1-\sigma}\right)}\right]^{\frac{1}{1-\sigma}} \\
\text { if } \xi^{T *} \neq \xi^{T} \text { and } \xi^{N T *} \neq \xi^{N T} \\
\frac{1}{1-\tau^{c}}\left[1+\frac{\left(\xi^{T *}-\xi^{T}\right)\left(1-\left(\frac{1}{1-\tau^{c}} T o T_{t}^{T}\right)^{1-\sigma}\right)+\xi^{N T}\left(\left(\frac{1}{1-\tau^{c}} T o T_{t}^{T}\right)^{1-\sigma}\left(P_{t}^{N T, T *}\right)^{1-\sigma}-\left(P_{t}^{N T, T}\right)^{1-\sigma}\right)}{\xi^{T}+\left(1-\xi^{T}\right)\left(\frac{1}{1-\tau^{c}} T o T_{t}^{T}\right)^{1-\sigma}-\xi^{N T}\left(\left(\frac{1}{1-\tau^{c}} T o T_{t}^{T}\right)^{1-\sigma}-\left(P_{t}^{N T, T}\right)^{1-\sigma}\right)}\right]^{\frac{1}{1-\sigma}} \\
\text { if } \xi^{T *} \neq \xi^{T} \text { and } \xi^{N T *}=\xi^{N T} \\
\frac{1}{1-\tau^{c}}\left[1+\frac{\xi^{N T}\left(\left(\frac{1}{1-\tau} \tau o T_{t}^{T}\right)^{1-\sigma}\left(P_{t}^{N T, T *}\right)^{1-\sigma}-\left(P_{t}^{N T, T}\right)^{1-\sigma}\right)}{\xi^{T}+\left(1-\xi^{T}\right)\left(\frac{1}{1-\tau^{c}} T o T_{t}^{T}\right)^{1-\sigma}-\xi^{N T}\left(\left(\frac{1}{1-\tau^{c}} T o T_{t}^{T}\right)^{1-\sigma}-\left(P_{t}^{N T, T}\right)^{1-\sigma}\right)}\right]^{\frac{1}{1-\sigma}} \\
\text { if } \xi^{T *}=\xi^{T} \text { and } \xi^{N T *}=\xi^{N T}
\end{array}\right.
$$

where $P_{t}^{N T, T} \equiv \frac{P_{t}^{H, N T}}{P_{t}^{H, T}}$ and $P_{t}^{N T, T *} \equiv \frac{P_{t}^{F, N T *}}{P_{t}^{F, T *}}$ denote the ratio of prices between non-traded and traded quoted in the local currency for the domestic and foreign goods, respectively. In the case where the elasticity of intratemporal substitution between the home and foreign bundles is one, i.e. $\sigma=1$, the expression for the real exchange rate takes the well-known form of,

$$
R S_{t}=\frac{1}{1-\tau^{c}}\left[\left(\frac{1}{1-\tau^{c}} T o T_{t}^{T}\right)^{\xi^{T}+\xi^{N T}-\xi^{T *}} \frac{\left(P_{t}^{N T, T *}\right)^{\xi^{N T *}}}{\left(P_{t}^{N T, T}\right)^{\xi^{N T}}}\right]
$$

which depends exclusively on $P_{t}^{N T, T}$ and $P_{t}^{N T, T *}$ if $\xi^{T *}=\xi^{T}+\xi^{N T}$. Absolute and relative PPP fail in this setting once again, even though the LOOP holds. However, not even relative PPP is a possibility except in the unlikely event where terms of trade and the ratios of non-traded to traded goods are all time invariant.

Even though fluctuations can arise from any of these channels, the evidence shows that consumptionbased real exchange rates fluctuate a lot over the short- to medium-horizon. Seemingly more than can be accounted for with fluctuations of the terms of trade, the trading costs or non-traded goods ${ }^{7}$. This has been interpreted as concurring evidence that violations of the LOOP are necessary to explain important features of the data. This has also supported a strong interest on nominal rigidities and other goods market frictions (e.g., pricing-to-market) in the international macro literature. I build on this idea too.

\subsection{The Households' Problem}

For tractability, I abstract from a number of relevant features like capital and investment (see, e.g., Chari, Kehoe and McGrattan, 2002, or Martínez-García and Sondergaard, 2008) and durable goods (see, e.g., Engel and Wang, 2007). All consumption is in terms of perishable consumption goods. The lifetime utility for the representative household in the home country is additively separable in aggregate consumption, $C_{t}$, real

\footnotetext{
${ }^{7}$ Trading costs are thought to be slow-moving and more relevant for the long-run horizon. See Engel (1999) and Chari, Kehoe and McGrattan (2002) for a discussion of the importance of non-traded goods fluctuations on the real exchange rate.
} 
money balances, $\frac{M_{t}^{d}}{P_{t}}$, and labor supply, $L_{t}^{s}$. The representative domestic household maximizes,

$$
\sum_{\tau=0}^{\infty} \beta^{\tau} \mathbb{E}_{t}\left[\frac{1}{1-\gamma}\left(C_{t+\tau}\right)^{1-\gamma}+\frac{\chi}{1-\zeta}\left(\frac{M_{t+\tau}^{d}}{P_{t+\tau}}\right)^{1-\zeta}-\frac{\kappa}{1+\varphi}\left(L_{t+\tau}^{s}\right)^{1+\varphi}\right]
$$

where $\beta \in(0,1)$ is the subjective intertemporal discount factor ${ }^{8}$. The inverse of the intertemporal elasticity of substitution, the risk aversion on real balances, and the inverse of the Frisch elasticity of labor supply satisfy that $\gamma>0(\gamma \neq 1), \zeta>0(\zeta \neq 1)$ and $\varphi>0$, respectively. The coefficients $\chi$ and $\kappa$ are nonnegative. Similarly, the lifetime utility of the representative foreign household is,

$$
\sum_{\tau=0}^{\infty} \beta^{\tau} \mathbb{E}_{t}\left[\frac{1}{1-\gamma}\left(C_{t+\tau}^{*}\right)^{1-\gamma}+\frac{\chi}{1-\zeta}\left(\frac{M_{t+\tau}^{d *}}{P_{t+\tau}^{*}}\right)^{1-\zeta}-\frac{\kappa}{1+\varphi}\left(L_{t+\tau}^{s *}\right)^{1+\varphi}\right]
$$

Hence, the lifetime utility is symmetric in both countries.

The Budget Constraints. In each period $t$ the world economy confronts one of infinitely many events $\omega_{t} \in \Omega$ in the state space $\Omega$. The initial realization $\omega_{0}$ is given, $h_{t}$ denotes the history of events up to time $t$, and $\mu\left(\omega_{t+1} \mid h_{t}\right) \equiv \mu_{t}\left(\omega_{t+1}\right)$ the conditional probability at time $t$. The representative household in the home country allocates his wealth between three different asset types: domestic currency, $M_{t}^{d}$; either a set of Arrow-Debreu securities or an uncontingent bond expressed in the domestic currency, $B_{t}^{H}\left(\omega_{t+1}\right)$ or $B_{t}^{H}$; and, either a set of Arrow-Debreu securities or an uncontingent bond quoted in the foreign currency, $B_{t}^{F}\left(\omega_{t+1}\right)$ or $B_{t}^{F}$.

Similarly, the foreign household demands foreign currency, $M_{t}^{d}$, a set of Arrow-Debreu securities or a bond expressed in the domestic currency, $B_{t}^{H *}\left(\omega_{t+1}\right)$ or $B_{t}^{H *}$, and a set of Arrow-Debreu securities or a bond quoted in the foreign currency, $B_{t}^{F *}\left(\omega_{t+1}\right)$ or $B_{t}^{F *}$. As a convention, the time subscript indicates the period at which the security is issued and sold to the households. Also each household only holds money issued in the local currency. Local money is issued exclusively by the local monetary authority, and assumed to be a one-period liability on their balance sheet.

Complete Asset Markets. Arrow-Debreu securities (or claims) are modelled as one-period contingent bonds in zero net-supply. At each period $t$ they involve the promise to pay one unit of the local currency if state $\omega_{t+1}$ occurs and 0 otherwise. The domestic-currency price of one unit of the domestic contingent bond at time $t$ is denoted $Q\left(\omega_{t+1} \mid h_{t}\right) \equiv Q_{t}\left(\omega_{t+1}\right)$, while the foreign-currency price of one unit of the foreign contingent bond is $Q^{*}\left(\omega_{t+1} \mid h_{t}\right) \equiv Q_{t}^{*}\left(\omega_{t+1}\right)$. The continued existence of a full set of one-period ArrowDebreu securities suffices to complete the asset markets recursively. If this contingent bonds are available in the asset markets and asset trading is otherwise frictionless, I say that the economy has 'complete asset markets'.

The domestic household maximizes its lifetime utility in (3.2.1) subject to the sequence of budget con-

\footnotetext{
${ }^{8}$ For a similar version of the workhorse model with external habits, see Martínez-García (2007).
} 
straints,

$$
\begin{aligned}
& P_{t} C_{t}+M_{t}^{d}+\int_{\omega_{t+1} \in \Omega} Q_{t}\left(\omega_{t+1}\right) B_{t}^{H}\left(\omega_{t+1}\right)+S_{t} \int_{\omega_{t+1} \in \Omega} Q_{t}^{*}\left(\omega_{t+1}\right) B_{t}^{F}\left(\omega_{t+1}\right) \\
& \leq M_{t-1}^{d}+B_{t-1}^{H}\left(\omega_{t}\right)+S_{t} B_{t-1}^{F}\left(\omega_{t}\right)+W_{t} L_{t}^{s}+\Pi_{t}-T_{t},
\end{aligned}
$$

where $W_{t}$ is the domestic nominal wage, $P_{t}$ is the domestic consumption price index or CPI, $S_{t}$ is the nominal exchange rate, $T_{t}$ is the nominal lump-sum tax (or transfer) from the domestic government, and $\Pi_{t}$ are nominal domestic profits. Similarly, the foreign household maximizes its lifetime utility in (3.2.2) subject to the sequence of budget constraints,

$$
\begin{aligned}
& P_{t}^{*} C_{t}^{*}+M_{t}^{d *}+\frac{1}{S_{t}} \int_{\omega_{t+1} \in \Omega} Q_{t}\left(\omega_{t+1}\right) B_{t}^{H *}\left(\omega_{t+1}\right)+\int_{\omega_{t+1} \in \Omega} Q_{t}^{*}\left(\omega_{t+1}\right) B_{t}^{F *}\left(\omega_{t+1}\right) \\
& \quad \leq M_{t-1}^{d *}+\frac{1}{S_{t}} B_{t-1}^{H *}\left(\omega_{t}\right)+B_{t-1}^{F *}\left(\omega_{t}\right)+W_{t}^{*} L_{t}^{s *}+\Pi_{t}^{*}-T_{t}^{*},
\end{aligned}
$$

where $W_{t}^{*}$ is the foreign nominal wage, $P_{t}^{*}$ is the foreign CPI, $T_{t}^{*}$ is the nominal lump-sum tax (or transfer) received from the foreign government, and $\Pi_{t}^{*}$ are nominal foreign profits.

I assume that there is no trade in either domestic or foreign shares. Moreover, I also impose a strict home bias in portfolios by giving sole ownership of the local firms to the local households. For asset markets to be complete it is not necessary to have each Arrow-Debreu claim quoted in both currencies. One of these two claims is redundant. In fact, most models with complete asset markets only have securities quoted in one of the currencies. However, having both of them is very convenient to compare the 'complete' versus the 'incomplete' asset markets.

Incomplete Asset Markets. I still maintain that trading in assets is frictionless, but I assume instead that households only have access to uncontingent bonds to define an alternative economy with 'incomplete asset markets'. That is, households can only invest their wealth in two bonds (each one of them quoted in a different currency). The domestic bond promises one unit of the domestic currency at time $t+1$ (independently of the event $\omega_{t+1}$ ) in exchange for $Q_{t} \equiv \frac{1}{1+i_{t}}$ units of the domestic currency at time $t$. Similarly, the foreign bond promises one unit of the foreign currency tomorrow in exchange for $Q_{t}^{*} \equiv \frac{1}{1+i_{t}^{*}}$ units of the foreign currency today. The one-period riskless nominal interest rates in the domestic and foreign country are $i_{t}$ and $i_{t}^{*}$, respectively.

Given my description of the asset markets with two sets of Arrow-Debreu claims quoted in each currency, it naturally follows that the incomplete asset market model with uncontingent bonds is equivalent to imposing the following restrictions on the demand,

$$
\begin{aligned}
B_{t}^{H}\left(\omega_{t+1}\right) & =B_{t}^{H}, B_{t}^{F}\left(\omega_{t+1}\right)=B_{t}^{F}, \\
B_{t}^{H *}\left(\omega_{t+1}\right) & =B_{t}^{H *}, B_{t}^{F *}\left(\omega_{t+1}\right)=B_{t}^{F *},
\end{aligned}
$$

for all $\omega_{t+1} \in \Omega$. In other words, the demand for bonds is uncontingent because that's the nature of the assets traded. In this situation, the uncontingent bonds are not sufficient in general to complete the asset markets (unless there are only two states of nature in each period, or the asset markets are irrelevant as in Cole and Obstfeld, 1991, and Corsetti and Pesenti, 2001), and are not redundant. This structure is particularly convenient because it makes easier to visualize the difference between complete and incomplete asset markets.

The returns on the uncontingent bonds can be replicated with Arrow-Debreu claims. Therefore, the 
prices of the uncontingent bonds must satisfy that,

$$
\int_{\omega_{t+1} \in \Omega} Q_{t}\left(\omega_{t+1}\right)=Q_{t} \equiv \frac{1}{1+i_{t}}, \int_{\omega_{t+1} \in \Omega} Q_{t}^{*}\left(\omega_{t+1}\right)=Q_{t}^{*} \equiv \frac{1}{1+i_{t}^{*}}
$$

The sequence of budget constraints for the domestic and foreign households can be re-written in the following terms,

$$
\begin{aligned}
P_{t} C_{t}+M_{t}^{d}+\frac{1}{1+i_{t}} B_{t}^{H}+S_{t} \frac{1}{1+i_{t}^{*}} B_{t}^{F} & \leq M_{t-1}^{d}+B_{t-1}^{H}+S_{t} B_{t-1}^{F}+W_{t} L_{t}^{s}+\Pi_{t}-T_{t}, \\
P_{t}^{*} C_{t}^{*}+M_{t}^{d *}+\frac{1}{S_{t}} \frac{1}{1+i_{t}} B_{t}^{H *}+\frac{1}{1+i_{t}^{*}} B_{t}^{F *} & \leq M_{t-1}^{d *}+\frac{1}{S_{t}} B_{t-1}^{H *}+B_{t-1}^{F *}+W_{t}^{*} L_{t}^{s *}+\Pi_{t}^{*}-T_{t}^{*} .
\end{aligned}
$$

This type of asset market structure is often referred to in the literature as a bond economy. I can write the budget constraints of the domestic and foreign households (equations (3.2.3) - (3.2.4)) in the following form,

$$
\begin{aligned}
& P_{t} C_{t}+\Delta_{t} M_{t}^{d}+\int_{\omega_{t+1} \in \Omega} Q_{t}\left(\omega_{t+1}\right) A_{t}^{H}\left(\omega_{t+1}\right)+S_{t} \int_{\omega_{t+1} \in \Omega} Q_{t}^{*}\left(\omega_{t+1}\right) B_{t}^{F}\left(\omega_{t+1}\right) \\
& \quad \leq A_{t-1}^{H}\left(\omega_{t}\right)+S_{t} B_{t-1}^{F}\left(\omega_{t}\right)+W_{t} L_{t}^{s}+\Pi_{t}-T_{t}, \\
& P_{t}^{*} C_{t}^{*}+\Delta_{t}^{*} M_{t}^{d *}+\frac{1}{S_{t}} \int_{\omega_{t+1} \in \Omega} Q_{t}\left(\omega_{t+1}\right) B_{t}^{H *}\left(\omega_{t+1}\right)+\int_{\omega_{t+1} \in \Omega} Q_{t}^{*}\left(\omega_{t+1}\right) A_{t}^{F *}\left(\omega_{t+1}\right) \\
& \quad \leq \frac{1}{S_{t}} B_{t-1}^{H *}\left(\omega_{t}\right)+A_{t-1}^{F *}\left(\omega_{t}\right)+W_{t}^{*} L_{t}^{s *}+\Pi_{t}^{*}-T_{t}^{*},
\end{aligned}
$$

where $A_{t-1}^{H}\left(\omega_{t}\right) \equiv M_{t-1}^{d}+B_{t-1}^{H}\left(\omega_{t}\right)$ and $A_{t-1}^{F *} \equiv M_{t-1}^{d *}+B_{t-1}^{F *}\left(\omega_{t}\right)$ represent the total value of nominal wealth in the local currency at the beginning of period $t$. The interest rate differential between a riskless, one-period, non-monetary asset and money (which yields liquidity services) is,

$$
\Delta_{t} \equiv \frac{i_{t}}{1+i_{t}}, \Delta_{t}^{*} \equiv \frac{i_{t}^{*}}{1+i_{t}^{*}}
$$

It is evident from (3.2.8) - (3.2.9) that these terms measure the opportunity cost of holding part of one's wealth in monetary form.

Preference for Varieties and the Price Indexes. The home and foreign consumption bundles of the domestic household, $C_{t}^{H}$ and $C_{t}^{F}$, are aggregated by means of a CES preference index as,

$$
C_{t}^{H}=\left[\left(\frac{1}{n}\right)^{\frac{1}{\theta}} \int_{0}^{n} C_{t}(h)^{\frac{\theta-1}{\theta}} d h\right]^{\frac{\theta}{\theta-1}}, C_{t}^{F}=\left[\left(\frac{1}{1-n}\right)^{\frac{1}{\theta}} \int_{n}^{1} C_{t}(f)^{\frac{\theta-1}{\theta}} d f\right]^{\frac{\theta}{\theta-1}}
$$

while aggregate consumption, $C_{t}$, is defined with another CES preference index as,

$$
C_{t}=\left\{\begin{array}{l}
{\left[\xi^{\frac{1}{\sigma}}\left(C_{t}^{H}\right)^{\frac{\sigma-1}{\sigma}}+(1-\xi)^{\frac{1}{\sigma}}\left(C_{t}^{F}\right)^{\frac{\sigma-1}{\sigma}}\right]^{\frac{\sigma}{\sigma-1}}, \text { if } \sigma>0, \sigma \neq 1} \\
\frac{\left(C_{t}^{H}\right)^{\xi}\left(C_{t}^{F}\right)^{1-\xi}}{\xi^{\xi}(1-\xi)^{1-\xi}}, \text { if } \sigma=1
\end{array}\right.
$$

The elasticity of substitution across varieties produced within a country is $\theta>1$, the elasticity of intratemporal substitution between the home and foreign bundles of varieties is $\sigma>0$, and the share of the home 
goods in the preference of the domestic consumer is $\xi$. The superscripts $H$ and $F$ refer to purchases of goods produced in the home and foreign country, respectively. The lower case $h$ and $f$ indicate domestic and foreign varieties, respectively.

Similarly, the representative foreign household has preferences defined by,

$$
\begin{aligned}
C_{t}^{H *} & =\left[\left(\frac{1}{n}\right)^{\frac{1}{\theta}} \int_{0}^{n} C_{t}^{*}(h)^{\frac{\theta-1}{\theta}} d h\right]^{\frac{\theta}{\theta-1}}, C_{t}^{F *}=\left[\left(\frac{1}{1-n}\right)^{\frac{1}{\theta}} \int_{n}^{1} C_{t}^{*}(f)^{\frac{\theta-1}{\theta}} d f\right]^{\frac{\theta}{\theta-1}}, \\
C_{t}^{*} & =\left\{\begin{array}{l}
{\left[\left(\xi^{*}\right)^{\frac{1}{\sigma}}\left(C_{t}^{H *}\right)^{\frac{\sigma-1}{\sigma}}+\left(1-\xi^{*}\right)^{\frac{1}{\sigma}}\left(C_{t}^{F *}\right)^{\frac{\sigma-1}{\sigma}}\right]^{\frac{\sigma}{\sigma-1}}, \text { if } \sigma>0, \sigma \neq 1,} \\
\frac{\left(C_{t}^{H *}\right)^{\xi^{*}}\left(C_{t}^{F *}\right)^{1-\xi^{*}}}{\left(\xi^{*}\right)^{*}\left(1-\xi^{*}\right)^{1-\xi^{*}}}, \text { if } \sigma=1 .
\end{array}\right.
\end{aligned}
$$

Preferences are identical for households in both countries, except for the share of home and foreign goods in the preference of each consumer. The parameter $\xi^{*}$ denotes the share of domestic goods for the foreign household. These definitions allow for home bias in consumption as in Warnock (2003). A convenient simplification is to assume that $\xi=\xi^{*}=n$.

The domestic CPI, $P_{t}$, is defined as the minimum expenditure needed to buy one unit of the consumption index, $C_{t}$. Similarly for $P_{t}^{*}$ and $C_{t}^{*}$. Under standard results on functional separability, the indexes which correspond to this specification of preferences $\operatorname{are}^{9}$,

$$
\begin{aligned}
& P_{t}=\left\{\begin{array}{l}
{\left[\xi\left(P_{t}^{H}\right)^{1-\sigma}+(1-\xi)\left(P_{t}^{F}\right)^{1-\sigma}\right]^{\frac{1}{1-\sigma}}, \text { if } \sigma>0, \sigma \neq 1,} \\
\left(P_{t}^{H}\right)^{\xi}\left(P_{t}^{F}\right)^{1-\xi}, \text { if } \sigma=1,
\end{array}\right. \\
& P_{t}^{*}=\left\{\begin{array}{l}
{\left[\xi^{*}\left(P_{t}^{H *}\right)^{1-\sigma}+\left(1-\xi^{*}\right)\left(P_{t}^{F *}\right)^{1-\sigma}\right]^{\frac{1}{1-\sigma}}, \text { if } \sigma>0, \sigma \neq 1,} \\
\left(P_{t}^{H *}\right)^{\xi^{*}}\left(P_{t}^{F *}\right)^{1-\xi^{*}}, \text { if } \sigma=1,
\end{array}\right.
\end{aligned}
$$

and

$$
\begin{aligned}
P_{t}^{H} & =\left[\frac{1}{n} \int_{0}^{n} P_{t}(h)^{1-\theta} d h\right]^{\frac{1}{1-\theta}}, P_{t}^{F}=\left[\frac{1}{1-n} \int_{n}^{1} P_{t}(f)^{1-\theta} d f\right]^{\frac{1}{1-\theta}}, \\
P_{t}^{H *} & =\left[\frac{1}{n} \int_{0}^{n} P_{t}^{*}(h)^{1-\theta} d h\right]^{\frac{1}{1-\theta}}, P_{t}^{F *}=\left[\frac{1}{1-n} \int_{n}^{1} P_{t}^{*}(f)^{1-\theta} d f\right]^{\frac{1}{1-\theta}},
\end{aligned}
$$

where $P_{t}^{H}$ and $P_{t}^{F}$ are the price sub-indexes for the home- and foreign-produced bundles of goods in units of the home currency. Similarly for $P_{t}^{H *}$ and $P_{t}^{F *}$. Home and foreign households have identical tastes and, therefore, the respective price indexes are identical. Moreover, I define the terms of trade in both countries as,

$$
T o T_{t} \equiv \frac{P_{t}^{F}}{S_{t} P_{t}^{H *}}, T o T_{t}^{*} \equiv \frac{S_{t} P_{t}^{H *}}{P_{t}^{F}}=\frac{1}{T o T_{t}}
$$

\footnotetext{
${ }^{9}$ Clarida, Galí and Gertler (2002) only explore the case where the elasticity of intratemporal substitution between the home and foreign bundles of varieties is $\sigma=1$. But preferences are not scaled and, therefore, the CPI must be pre-multiplied by $\left[n^{n}(1-n)^{1-n}\right]^{-1}$.
} 
and the real exchange rate as,

$$
R S_{t} \equiv \frac{S_{t} P_{t}^{*}}{P_{t}}
$$

where $S_{t}$ denotes the nominal exchange rate.

I represent the relative exchange price in each country by ${ }^{10}$,

$$
R P_{t} \equiv \frac{P_{t}^{F}}{P_{t}^{H}}, R P_{t}^{*} \equiv \frac{P_{t}^{H *}}{P_{t}^{F *}}
$$

The relative exchange price, $R P_{t}$, represents the value of imported goods (quoted in the domestic market) relative to the value of the domestic good supplied locally. This ratio is the 'local market' cost of replacing one unit of imports with one unit of the domestically-produced good. Instead, terms of trade $T o T_{t}$ represents the value of imported goods (quoted in the domestic market) relative to the value of the domestic good exported to the foreign market, but expressed in units of the local currency. This ratio measures the 'foreign market' cost of replacing one unit of imports with one unit of exports. Similarly for $R P_{t}^{*}$ and $T o T_{t}^{*}$.

The Demand Function for each Variety. Each household decides how much to allocate to the different varieties of home and foreign goods. Given the structure of preferences, the solution to the sub-utility maximization problem implies that the home and foreign households' demands for each variety are given by,

$$
\begin{aligned}
& C_{t}(h)=\frac{1}{n}\left(\frac{P_{t}(h)}{P_{t}^{H}}\right)^{-\theta} C_{t}^{H}, C_{t}^{*}(h)=\frac{1}{n}\left(\frac{P_{t}^{*}(h)}{P_{t}^{H *}}\right)^{-\theta} C_{t}^{H *}, \text { if } h \in[0, n], \\
& C_{t}(f)=\frac{1}{1-n}\left(\frac{P_{t}(f)}{P_{t}^{F}}\right)^{-\theta} C_{t}^{F}, C_{t}^{*}(f)=\frac{1}{1-n}\left(\frac{P_{t}^{*}(f)}{P_{t}^{F *}}\right)^{-\theta} C_{t}^{F *}, \text { if } f \in(n, 1],
\end{aligned}
$$

while the demands for the bundles of home and foreign goods are simply equal to,

$$
\begin{aligned}
C_{t}^{H} & =\xi\left(\frac{P_{t}^{H}}{P_{t}}\right)^{-\sigma} C_{t}, C_{t}^{H *}=\xi^{*}\left(\frac{P_{t}^{H *}}{P_{t}^{*}}\right)^{-\sigma} C_{t}^{*} \\
C_{t}^{F} & =(1-\xi)\left(\frac{P_{t}^{F}}{P_{t}}\right)^{-\sigma} C_{t}, C_{t}^{F *}=\left(1-\xi^{*}\right)\left(\frac{P_{t}^{F *}}{P_{t}^{*}}\right)^{-\sigma} C_{t}^{*} .
\end{aligned}
$$

These equations indicate that the domestic demand for each variety, whether domestic or foreign, is a function of total domestic consumption. Similarly, the foreign demand for each variety, whether domestic or foreign, is a function of total foreign consumption.

The First-Order Conditions of the Households' Problem. Under complete asset markets, the (interior) optimal allocation of consumption expenditures in each country over time and across states implies

\footnotetext{
${ }^{10}$ Terms of trade and relative prices are identical and the real exchange rate is equal to one only if the LOOP holds in both countries. Since the LOOP condition fails in the workhorse model, fluctuations of the real exchange rate arise and the distinction between terms of trade and relative prices matters.
} 
that,

$$
\begin{aligned}
& Q_{t}\left(\omega_{t+1}\right)=\beta\left(\frac{C_{t+1}\left(\omega_{t+1}\right)}{C_{t}}\right)^{-\gamma} \frac{P_{t}}{P_{t+1}\left(\omega_{t+1}\right)} \mu_{t}\left(\omega_{t+1}\right), \\
& Q_{t}^{*}\left(\omega_{t+1}\right)=\beta\left(\frac{C_{t+1}^{*}\left(\omega_{t+1}\right)}{C_{t}^{*}}\right)^{-\gamma} \frac{P_{t}^{*}}{P_{t+1}^{*}\left(\omega_{t+1}\right)} \mu_{t}\left(\omega_{t+1}\right), \\
& \frac{S_{t}}{S_{t+1}\left(\omega_{t+1}\right)} \frac{Q_{t}^{*}\left(\omega_{t+1}\right)}{Q_{t}\left(\omega_{t+1}\right)}=1,
\end{aligned}
$$

which must hold for all $\omega_{t+1} \in \Omega$. These are the intertemporal conditions that characterize the optimal allocation of resources, and perfect international risk-sharing. The combination of equations (3.2.25) (3.2.27) results in the following equilibrium condition expressed compactly (and, for ease of notation, without reference to the state of the world) as,

$$
\frac{R S_{t+1}}{R S_{t}}=\left(\frac{C_{t+1}^{*}}{C_{t}^{*}} \frac{C_{t}}{C_{t+1}}\right)^{-\gamma}
$$

where the real exchange rate is defined in (3.2.19).

Backward recursion allows me to express the real exchange rate as follows,

$$
R S_{t}=v\left(\frac{C_{t}^{*}}{C_{t}}\right)^{-\gamma}
$$

where $v \equiv \frac{S_{0} P_{0}^{*}}{P_{0}}\left(\frac{C_{0}^{*}}{C_{0}}\right)^{\gamma}$ is a constant that depends on the initial conditions ${ }^{11}$. This equation is central to the so-called Backus-Smith Puzzle, also known as the real exchange rate-relative consumption anomaly, and is at the core of what the international consumption correlations puzzle is all about. The puzzle arises because the complete asset markets model clearly ties the real exchange rate to the relative consumption, while the empirical evidence suggests that the correlation between the two is weak and often negative. The choice of a functional form for the preferences is obviously not trivial in this result. However, most of the literature has argued that the empirical evidence is symptomatic of lack of international risk-sharing, and has concentrated on theories of asset market incompleteness (or other frictions in asset trading) to seek an explanation.

Under incomplete asset markets, I obtain a conventional set of stochastic Euler equations,

$$
\begin{aligned}
& \frac{1}{1+i_{t}}=Q_{t}=\beta \mathbb{E}_{t}\left[\left(\frac{C_{t+1}}{C_{t}}\right)^{-\gamma} \frac{P_{t}}{P_{t+1}}\right], \\
& \frac{1}{1+i_{t}^{*}}=Q_{t}^{*}=\beta \mathbb{E}_{t}\left[\left(\frac{C_{t+1}^{*}}{C_{t}^{*}}\right)^{-\gamma} \frac{P_{t}^{*}}{P_{t+1}^{*}}\right], \\
& \mathbb{E}_{t}\left[\frac{S_{t}}{S_{t+1}} \frac{m_{t, t+1}^{*}}{m_{t, t+1}}\right]=1,
\end{aligned}
$$

which is equivalent to taking conditional expectations on both sides of (3.2.25) - (3.2.27) and re-arranging

\footnotetext{
${ }^{11}$ In a symmetric world and after a convenient normalization of the steady state, which I discuss later, home and foreign consumption are identical and the real interest rate is equal to one. Hence, if the initial conditions correspond to those of the normalized steady state, the constant $v$ in the above expression is equal to one.
} 
terms. Here, I define the one-period ahead intertemporal marginal rates of substitution (IMRS) as,

$$
\begin{aligned}
& m_{t, t+1} \equiv \beta\left(\frac{C_{t+1}}{C_{t}}\right)^{-\gamma} \frac{P_{t}}{P_{t+1}} \\
& m_{t, t+1}^{*} \equiv \beta\left(\frac{C_{t+1}^{*}}{C_{t}^{*}}\right)^{-\gamma} \frac{P_{t}^{*}}{P_{t+1}^{*}}
\end{aligned}
$$

It holds true that the IMRS and the price of the Arrow-Debreu securities are related as follows,

$$
m_{t, t+1} \equiv m_{t}\left(\omega_{t+1}\right)=\frac{Q_{t}\left(\omega_{t+1}\right)}{\mu_{t}\left(\omega_{t+1}\right)}, m_{t, t+1}^{*} \equiv m_{t}^{*}\left(\omega_{t+1}\right)=\frac{Q_{t}^{*}\left(\omega_{t+1}\right)}{\mu_{t}\left(\omega_{t+1}\right)}
$$

for all $\omega_{t+1} \in \Omega$. In other words, the price of an Arrow-Debreu claim can be interpreted as the product of the IMRS at a given state of nature times the conditional probability of that event actually occurring. If investors were risk-neutral, then they would be willing to buy insurance through Arrow-Debreu claims at a cost equal to the conditional probability of each possible event. The IMRS, therefore, could be viewed as the premium (or discount) that investors are ready to pay over the risk-neutral price of a claim in order to be indifferent between buying the claim and 'tolerating the risk'.

Finally, the equilibrium conditions of the households' problem also include a pair of stable money demand and a pair of labor supply functions which can be expressed as,

$$
\begin{aligned}
& \chi\left(\frac{M_{t}^{d}}{P_{t}\left(C_{t}\right)^{\frac{\gamma}{\zeta}}}\right)^{-\zeta}=\Delta_{t} \\
& \chi\left(\frac{M_{t}^{d *}}{P_{t}^{*}\left(C_{t}^{*}\right)^{\frac{\gamma}{\zeta}}}\right)^{-\zeta}=\Delta_{t}^{*} \\
& \frac{W_{t}}{P_{t}}=\kappa\left(C_{t}\right)^{\gamma}\left(L_{t}^{s}\right)^{\varphi} \\
& \frac{W_{t}^{*}}{P_{t}^{*}}=\kappa\left(C_{t}^{*}\right)^{\gamma}\left(L_{t}^{s *}\right)^{\varphi}
\end{aligned}
$$

plus the appropriate no-Ponzi games, transversality conditions and the budget constraint of both representative households. Equations (3.2.36) - (3.2.39) are the intratemporal equilibrium conditions. The labor supply and the money demand functions in this framework do not depend on the assumption of complete asset markets. These first-order conditions are the same whether households have access to a full set of Arrow-Debreu securities or just a pair of one-period riskless bonds.

Balanced Growth: A Brief Comment. Let me abstract from all stochastic uncertainty, and from monetary policy regime changes that would shift the opportunity cost of holding money. I require that in the market sector the labor-augmenting productivity, $g_{t}$, grows at an exogenous and constant net rate of $g$. In other words, $L_{t}^{s}\left(=L_{t}\right)$ units of time produce $g_{t} L_{t}$ units of labor for production purposes. Chari, Kehoe and McGrattan (2002) assume that the non-market sectors grow at the same rate $g$.

Adapting their idea to the workhorse model implies that technical progress raises the effort of time allocated to market production, so that $L_{t}^{s}\left(=L_{t}\right)$ units of time produce $g_{t} L_{t}$ units of labor output as well as $g_{t} L_{t}$ units of labor disutility. In fact, technical progress raises the time allocated for transaction or liquidity 
services (which is a function of real balances), such that $\frac{M_{t}^{d}}{P_{t}}\left(=\frac{M_{t}}{P_{t}}\right)$ units of real balances buy $\left(g_{t}\right)^{z} \frac{M_{t}}{P_{t}}$ of transaction services ${ }^{12}$.

Given the specification of preferences adopted in this paper, whenever consumption, $C_{t}$, and real balances, $\frac{M_{t}}{P_{t}}$, grow at the same rate as $g_{t}$, but labor $L_{t}$ is constant, then it must hold true in equilibrium that,

$$
\begin{aligned}
& \chi(1+g)^{z(1-\zeta) t}\left(\frac{(1+g)^{t}}{(1+g)^{\frac{\gamma}{\zeta} t}}\right)^{-\zeta}=\Delta_{t}, \\
& \frac{W_{t}}{P_{t}}=\kappa\left(L^{s}\right)^{\varphi}(1+g)^{(1+\varphi) t}(1+g)^{\gamma t},
\end{aligned}
$$

which follows naturally from the first-order conditions in equations (3.2.36) and (3.2.38). Similarly for the foreign country. Along the balanced growth path, real wages must grow at the same rate as $g_{t}$, and the opportunity cost of holding money should be constant (unless a policy regime change occurs). Hence, ensuring a balanced growth in this model with additively separable utility functions requires that $\gamma=-\varphi$ and $\gamma=\zeta-z(1-\zeta)$. These parametric conditions are most often not satisfied in the literature (specially the restriction on the inverse of the Frisch elasticity of labor supply $\left.{ }^{13}\right)$.

\subsection{The Firms' Problem}

Each firm supplies the home and foreign markets. I impose competitive markets for inputs (labor), that are fully segregated across countries. That is, cross-border labor migrations are not feasible. Frictions in the goods market are modelled with nominal price stickiness à la Calvo (1983) and pricing-to-market ${ }^{14}$. Firms set prices in the local currency (LCP pricing) and, consequently, invoice exports in the currency of the importer. Furthermore, firms engage in third-degree price discrimination across markets and enjoy monopolistic power in their own variety. Re-selling must be precluded so that the optimal pricing policy is not reversed by re-sellers exploiting the arising arbitrage opportunities in the goods market.

These assumptions require a degree of international market segmentation which prevents the equalization of prices across borders, and opens up an important channel for deviations from the LOOP (and, therefore, from absolute PPP). This paper focuses on fluctuations in real exchange rates arising solely from deviations of the LOOP on traded goods or home bias in consumption (see Warnock, 2003). I abstract from non-traded goods altogether to be consistent with the evidence documented by Engel (1999) and Chari, Kehoe and McGrattan $(2002)^{15}$. I also sidestep distribution costs on tradable goods even though these assumption adds

\footnotetext{
${ }^{12}$ The utility function used by Chari, Kehoe and McGrattan (2002) is not additively separable in real balances. However, they make the sensible assumption that $z=0$.

${ }^{13}$ Chari, Kehoe and McGrattan (2002) propose that leisure utility instead of labor disutility appear in the utility function as,

$$
\frac{\kappa}{1-\varphi}\left(1-L_{t}^{s}\right)^{1-\varphi}
$$

The parametric restriction for balanced growth path with this alternative utility is $\gamma=\varphi$. Balanced growth is easier to reconcile with this restriction than the one used in the paper.

${ }^{14} \mathrm{I}$ do not discuss state-dependent pricing in spite of its increasing relevance in the debate about international pricing. For more details on state-dependent pricing, see Dotsey, King and Wolman (1999) and Landry (2007). For details on the impact of sticky information on the dynamics of inflation, see Mankiw and Reis (2002, 2006).

${ }^{15}$ This evidence, however, is not undisputed. For instance, Crucini, Telmer and Zachariadis (2005) use retail goods and services prices between all EU countries to conclude that "good-by-good measures of cross-sectional price dispersion are negatively related
} 
a non-tradeable component to local prices that could explain the pricing differences across markets. I also ignore the iceberg-type trading costs proposed by Obstfeld and Rogoff (2000a).

The Technology. With probability $\alpha \in[0,1]$, at time $t$ the domestic firm producing variety $h$ is forced to maintain its previous period prices in the domestic and foreign markets ${ }^{16}$. With probability $(1-\alpha)$, the firm receives a signal to optimally reset each price. Firm $h \in[0, n]$ produces a differentiated (and tradable) variety with a linear-in-labor technology ${ }^{17}$, i.e.

$$
Y_{t}^{s}(h)=A_{t} L_{t}^{d}(h)
$$

where $A_{t}$ is the domestic productivity shock. Analogously, the probability of re-setting prices for the foreign firm $f \in(n, 1]$ is given by $\left(1-\alpha^{*}\right)$, and the linear-in-labor technology is,

$$
Y_{t}^{s *}(f)=A_{t}^{*} L_{t}^{d *}(f)
$$

where $A_{t}^{*}$ is the foreign productivity shock.

The labor force is homogenous within a country and immobile across borders, and the national labor markets are perfectly competitive. Hence, wages equalize in each country but not necessarily across countries, i.e. $W_{t}(h)=W_{t}$ for all $h \in[0, n], W_{t}^{*}(f)=W_{t}^{*}$ for all $f \in(n, 1]$, and usually $W_{t} \neq W_{t}^{*}$. Otherwise, only the firms with the largest wages would be supplied in a competitive labor market. As a consequence, the nominal cost function is multiplicatively separable in output and the nominal unit-cost is equal to the nominal marginal cost. I define the nominal marginal costs after taxes (or subsidies) as,

$$
M C_{t} \equiv\left(\frac{\left(1+\phi_{t}\right) W_{t}}{A_{t}}\right), M C_{t}^{*} \equiv\left(\frac{\left(1+\phi_{t}^{*}\right) W_{t}^{*}}{A_{t}^{*}}\right)
$$

where $\phi_{t}$ and $\phi_{t}^{*}$ are a pair of taxes (or subsidies) charged by the fiscal authority in each country in order to influence wage costs and the conditions in the labor market.

The Net Discounted Profits. Households are charged a different price in each country for the same variety, but they still face a constant price within a country for all units of output purchased. Re-selling across borders is either banned or infeasible due to high costs. A domestic firm $h$ has to choose the price charged domestically (in units of the domestic currency), $\widetilde{P}_{t}(h)$, and the price charged abroad (in units of the foreign currency), $\widetilde{P}_{t}^{*}(h)$. The objective is to maximize the expected discounted value of its net profits

to the tradeability of the good, and positively related to the share of non-traded inputs required to produce the good". They also argue that their findings are supportive of a model where the retail goods sold to consumers include a significative share of non-traded input (which e.g. could be interpreted as distribution services).

\footnotetext{
${ }^{16}$ Under the Calvo specification, the probability of setting a new price, $1-\alpha$, is the same for all firms and is independent of the time elapsed since the last price change. Hence, the average time under fixed prices is equal to $\frac{1}{1-\alpha}$.

${ }^{17} \mathrm{I}$ abstract from capital accumulation in the problem of the firm. For an analysis of the impact of capital investment, see Chari, Kehoe and McGrattan (2002) and Martínez-García and Sondergaard (2008).
} 
subject to a demand constraint in each goods market,

$$
\sum_{\tau=0}^{\infty} \mathbb{E}_{t}\left\{\alpha^{\tau} m_{t, t+\tau}\left[\begin{array}{c}
n \widetilde{Y}_{t, t+\tau}^{d}(h)\left(\widetilde{P}_{t}(h)-\frac{\left(1+\phi_{t+\tau}\right) W_{t+\tau}}{A_{t+\tau}}\right)+ \\
+(1-n) \widetilde{Y}_{t, t+\tau}^{d *}(h)\left(S_{t+\tau} \widetilde{P}_{t}^{*}(h)-\frac{\left(1+\phi_{t+\tau}\right) W_{t+\tau}}{A_{t+\tau}}\right)
\end{array}\right]\right\}
$$

where $m_{t, t}=1$ and $m_{t, t+\tau} \equiv \beta^{\tau}\left(\frac{C_{t+\tau}}{C_{t}}\right)^{-\gamma} \frac{P_{t}}{P_{t+\tau}}$ is an extension of the one-period ahead IMRS introduced in (3.2.33). I derive the demand for variety $h$ in the home and foreign markets by combining equations $(3.2 .21)-(3.2 .24)$. As a result, $\widetilde{Y}_{t, t+\tau}^{d}(h)$ and $\widetilde{Y}_{t, t+\tau}^{d *}(h)$ indicate the per capita demand for any variety $h$ at home and abroad respectively, given that prices $\widetilde{P}_{t}(h)$ and $\widetilde{P}_{t}^{*}(h)$ remain unchanged between time $t$ and $t+\tau$, i.e.

$$
\begin{aligned}
& \widetilde{Y}_{t, t+\tau}^{d}(h)=\frac{\xi}{n}\left(\frac{\widetilde{P}_{t}(h)}{P_{t+\tau}^{H}}\right)^{-\theta}\left(\frac{P_{t+\tau}^{H}}{P_{t+\tau}}\right)^{-\sigma} C_{t+\tau}, \\
& \widetilde{Y}_{t, t+\tau}^{d *}(h)=\frac{\xi^{*}}{n}\left(\frac{\widetilde{P}_{t}^{*}(h)}{P_{t+\tau}^{H *}}\right)^{-\theta}\left(\frac{P_{t+\tau}^{H *}}{P_{t+\tau}^{*}}\right)^{-\sigma} C_{t+\tau}^{*} .
\end{aligned}
$$

Similarly, I characterize the problem of the foreign firm with the objective of maximizing the expected discounted value of its net profits subject to a demand constraint,

$$
\sum_{\tau=0}^{\infty} \mathbb{E}_{t}\left\{\left(\alpha^{*}\right)^{\tau} m_{t, t+\tau}^{*}\left[\begin{array}{c}
n \widetilde{Y}_{t, t+\tau}^{d}(f)\left(\frac{1}{S_{t+\tau}} \widetilde{P}_{t}(f)-\frac{\left(1+\phi_{t+\tau}^{*}\right) W_{t+\tau}^{*}}{A_{t+\tau}^{*}}\right)+ \\
+(1-n) \widetilde{Y}_{t, t+\tau}^{d *}(f)\left(\widetilde{P}_{t}^{*}(f)-\frac{\left(1+\phi_{t+\tau}^{*}\right) W_{t+\tau}^{*}}{A_{t+\tau}^{*}}\right)
\end{array}\right]\right\}
$$

where $m_{t, t}^{*}=1$ and $m_{t, t+\tau}^{*} \equiv \beta\left(\frac{C_{t+\tau}^{*}}{C_{t}^{*}}\right)^{-\gamma} \frac{P_{t}^{*}}{P_{t+\tau}^{*}}$ is an extension of the one-period IMRS introduced in (3.2.34). I obtain that $\widetilde{Y}_{t, t+\tau}^{d}(f)$ and $\widetilde{Y}_{t, t+\tau}^{d *}(f)$ describe the demand constraints of the foreign firms as,

$$
\begin{aligned}
& \widetilde{Y}_{t, t+\tau}^{d}(f)=\frac{1-\xi}{1-n}\left(\frac{\widetilde{P}_{t}(f)}{P_{t+\tau}^{F}}\right)^{-\theta}\left(\frac{P_{t+\tau}^{F}}{P_{t+\tau}}\right)^{-\sigma} C_{t+\tau}, \\
& \widetilde{Y}_{t, t+\tau}^{d *}(f)=\frac{1-\xi^{*}}{1-n}\left(\frac{\widetilde{P}_{t}^{*}(f)}{P_{t+\tau}^{F *}}\right)^{-\theta}\left(\frac{P_{t+\tau}^{F *}}{P_{t+\tau}^{*}}\right)^{-\sigma} C_{t+\tau}^{*},
\end{aligned}
$$

given that prices $\widetilde{P}_{t}(h)$ and $\widetilde{P}_{t}^{*}(h)$ remain unchanged between time $t$ and $t+\tau$.

Finally, the per capita profits of the domestic firms can be expressed in the domestic currency as,

$$
\Pi_{t}=\frac{1}{n}\left[\int_{0}^{n}\left[P_{t}(h) n C_{t}(h)+S_{t} P_{t}^{*}(h)(1-n) C_{t}^{*}(h)\right] d h-\left(1+\phi_{t}\right) W_{t} \int_{0}^{n} L_{t}^{d}(h) d h\right],
$$

while the per capita profits of the foreign firms quoted in the foreign currency are,

$$
\Pi_{t}^{*}=\frac{1}{1-n}\left[\int_{n}^{1}\left[\frac{1}{S_{t}} P_{t}(f) n C_{t}(f)+P_{t}^{*}(f)(1-n) C_{t}^{*}(f)\right] d f-\left(1+\phi_{t}^{*}\right) W_{t}^{*} \int_{n}^{1} L_{t}^{d *}(f) d f\right] .
$$


The labor demand functions of the domestic firms, $L_{t}^{d}(h)$ for all $h \in[0, n]$, and the foreign firms, $L_{t}^{d *}(f)$ for all $f \in(n, 1]$, are implicit in the cost function of the firms. The labor markets are fully segmented across countries, so the market clearing conditions merely require that,

$$
\begin{aligned}
n L_{t}^{s} & =\int_{0}^{n} L_{t}^{d}(h) d h, \\
(1-n) L_{t}^{s *} & =\int_{n}^{1} L_{t}^{d *}(f) d f .
\end{aligned}
$$

where $L_{t}^{s}$ is the labor supply of the representative domestic household, and $L_{t}^{s *}$ is the labor supply of the representative foreign household.

The First-Order Conditions. The Dixit-Stiglitz Pricing Equations. In the polar case where all prices are adjusted in each period (i.e., $\alpha=0$ ) and trade in goods is frictionless, the pricing equations imply that,

$$
\begin{aligned}
P_{t}^{H} & =P_{t}(h)=\frac{\theta}{\theta-1}\left(\frac{\left(1+\phi_{t}\right) W_{t}}{A_{t}}\right)=P_{t}^{*}(h) S_{t}=P_{t}^{H *} S_{t}, \\
P_{t}^{F *} & =P_{t}^{*}(f)=\frac{\theta}{\theta-1}\left(\frac{\left(1+\phi_{t}^{*}\right) W_{t}^{*}}{A_{t}^{*}}\right)=P_{t}(f) \frac{1}{S_{t}}=P_{t}^{F} \frac{1}{S_{t}},
\end{aligned}
$$

which is the outcome expected under monopolistic competition. These formulas are often known as the Dixit-Stiglitz pricing equations. The LOOP, then, holds in each variety and the pricing decision in either market is equal to a mark-up times the nominal marginal cost (whenever expressed in units of the same currency). The gross mark-up, $\mu \equiv \frac{\theta}{\theta-1}$, is clearly a function of the elasticity of substitution across varieties, i.e. $\theta$. Often the literature assumes that the elasticity of substitution across varieties is greater than one. This parametric assumption is meant to insure that the gross mark-up is always above one, as we would expect it to be.

The Optimal Pricing Equations. The necessary and sufficient first-order conditions for the domestic firm producing variety $h$ give me the following pair of price-setting formulas,

$$
\begin{aligned}
& \widetilde{P}_{t}(h)=\frac{\theta}{\theta-1} \frac{\sum_{\tau=0}^{\infty} \alpha^{\tau} \mathbb{E}_{t}\left[m_{t, t+\tau} \widetilde{Y}_{t, t+\tau}^{d}(h)\left(\frac{\left(1+\phi_{t+\tau}\right) W_{t+\tau}}{A_{t+\tau}}\right)\right]}{\sum_{\tau=0}^{\infty} \alpha^{\tau} \mathbb{E}_{t}\left[m_{t, t+\tau} \widetilde{Y}_{t, t+\tau}^{d}(h)\right]}, \\
& \widetilde{P}_{t}^{*}(h)=\frac{\theta}{\theta-1} \frac{\sum_{\tau=0}^{\infty} \alpha^{\tau} \mathbb{E}_{t}\left[m_{t, t+\tau} \widetilde{Y}_{t, t+\tau}^{d *}(h)\left(\frac{\left(1+\phi_{t+\tau}\right) W_{t+\tau}}{A_{t+\tau}}\right)\right]}{\sum_{\tau=0}^{\infty} \alpha^{\tau} \mathbb{E}_{t}\left[m_{t, t+\tau} \widetilde{Y}_{t, t+\tau}^{d *}(h) S_{t+\tau}\right]} .
\end{aligned}
$$

Under proper aggregation rules (using the law of large numbers), the price sub-indexes under sticky prices on domestic varieties, $P_{t}^{H}$ and $P_{t}^{H *}$, are,

$$
\begin{aligned}
P_{t}^{H} & =\left[\alpha\left(P_{t-1}^{H}\right)^{1-\theta}+(1-\alpha)\left(\widetilde{P}_{t}(h)\right)^{1-\theta}\right]^{\frac{1}{1-\theta}}, \\
P_{t}^{H *} & =\left[\alpha\left(P_{t-1}^{H *}\right)^{1-\theta}+(1-\alpha)\left(\widetilde{P}_{t}^{*}(h)\right)^{1-\theta}\right]^{\frac{1}{1-\theta}} .
\end{aligned}
$$


Equations (3.3.18) - (3.3.19) are a convenient way to reformulate (3.2.16). The price-setting rule is symmetric for all firms who can re-optimize at time $t$. The lagged term reflects the aggregate behavior of all domestic firms who cannot re-set prices. Equations (3.3.16) - (3.3.17) can also be re-expressed as,

$$
\begin{array}{r}
\mathbb{E}_{t}\left[\sum_{\tau=0}^{\infty} \alpha^{\tau} m_{t, t+\tau} \widetilde{Y}_{t, t+\tau}^{d}(h)\left(\frac{\widetilde{P}_{t}(h)}{P_{t+\tau}^{H}}-\frac{\theta\left(1+\phi_{t+\tau}\right)}{\theta-1}\left(\frac{W_{t+\tau}}{P_{t+\tau} A_{t+\tau}}\right) \frac{P_{t+\tau}}{P_{t+\tau}^{H}}\right)\right]= \\
\mathbb{E}_{t}\left[\sum_{\tau=0}^{\infty} \alpha^{\tau} m_{t, t+\tau} \widetilde{Y}_{t, t+\tau}^{d *}(h)\left(\frac{\widetilde{P}_{t}^{*}(h)}{P_{t+\tau}^{H *}} \frac{S_{t+\tau} P_{t+\tau}^{H *}}{P_{t+\tau}^{H}}-\frac{\theta\left(1+\phi_{t+\tau}\right)}{\theta-1}\left(\frac{W_{t+\tau}}{P_{t+\tau} A_{t+\tau}}\right) \frac{P_{t+\tau}}{P_{t+\tau}^{H}}\right)\right]
\end{array}
$$

One way to interpret these equations is that the weighted average of current and future deviations around the Dixit-Stiglitz pricing rule is expected to be equal to zero.

Similar conditions, pricing rules and price sub-indexes hold for the foreign firms. The first-order conditions for the foreign firm producing variety $f$ give me the following price-setting formulas,

$$
\begin{aligned}
\widetilde{P}_{t}(f) & =\frac{\theta}{\theta-1} \frac{\sum_{\tau=0}^{\infty}\left(\alpha^{*}\right)^{\tau} \mathbb{E}_{t}\left[m_{t, t+\tau}^{*} \widetilde{Y}_{t, t+\tau}^{d}(f)\left(\frac{\left(1+\phi_{t+\tau}^{*}\right) W_{t+\tau}^{*}}{A_{t+\tau}^{*}}\right)\right]}{\sum_{\tau=0}^{\infty}\left(\alpha^{*}\right)^{\tau} \mathbb{E}_{t}\left[m_{t, t+\tau}^{*} \widetilde{Y}_{t, t+\tau}^{d}(f) \frac{1}{S_{t+\tau}}\right]}, \\
\widetilde{P}_{t}^{*}(f) & =\frac{\theta}{\theta-1} \frac{\sum_{\tau=0}^{\infty}\left(\alpha^{*}\right)^{\tau} \mathbb{E}_{t}\left[m_{t, t+\tau}^{*} \widetilde{Y}_{t, t+\tau}^{d *}(f)\left(\frac{\left(1+\phi_{t+\tau}^{*}\right) W_{t+\tau}^{*}}{A_{t+\tau}^{*}}\right)\right]}{\sum_{\tau=0}^{\infty}\left(\alpha^{*}\right)^{\tau} \mathbb{E}_{t}\left[m_{t, t+\tau}^{*} \widetilde{Y}_{t, t+\tau}^{d *}(f)\right]},
\end{aligned}
$$

while the price sub-indexes under sticky prices on foreign varieties, $P_{t}^{F}$ and $P_{t}^{F *}$, are,

$$
\begin{aligned}
P_{t}^{F} & =\left[\alpha^{*}\left(P_{t-1}^{F}\right)^{1-\theta}+\left(1-\alpha^{*}\right)\left(\widetilde{P}_{t}(f)\right)^{1-\theta}\right]^{\frac{1}{1-\theta}}, \\
P_{t}^{F *} & =\left[\alpha^{*}\left(P_{t-1}^{F *}\right)^{1-\theta}+\left(1-\alpha^{*}\right)\left(\widetilde{P}_{t}^{*}(f)\right)^{1-\theta}\right]^{\frac{1}{1-\theta}} .
\end{aligned}
$$

Equations (3.3.24) - (3.3.25) are a convenient way to reformulate (3.2.17). Naturally, equations (3.3.22) (3.3.23) can be conveniently re-written in the following terms,

$$
\begin{aligned}
\mathbb{E}_{t}\left[\sum_{\tau=0}^{\infty}\left(\alpha^{*}\right)^{\tau} m_{t, t+\tau}^{*} \widetilde{Y}_{t, t+\tau}^{d}(f)\left(\frac{\widetilde{P}_{t}(f)}{P_{t+\tau}^{F}} \frac{P_{t+\tau}^{F}}{S_{t+\tau} P_{t+\tau}^{F *}}-\frac{\theta\left(1+\phi_{t+\tau}^{*}\right)}{\theta-1}\left(\frac{W_{t+\tau}^{*}}{P_{t+\tau}^{*} A_{t+\tau}^{*}}\right) \frac{P_{t+\tau}^{*}}{P_{t+\tau}^{F *}}\right)\right] & = \\
\mathbb{E}_{t}\left[\sum_{\tau=0}^{\infty}\left(\alpha^{*}\right)^{\tau} m_{t, t+\tau}^{*} \widetilde{Y}_{t, t+\tau}^{d *}(f)\left(\frac{\widetilde{P}_{t}^{*}(f)}{P_{t+\tau}^{F *}}-\frac{\theta\left(1+\phi_{t+\tau}^{*}\right)}{\theta-1}\left(\frac{W_{t+\tau}^{*}}{P_{t+\tau}^{*} A_{t+\tau}^{*}}\right) \frac{P_{t+\tau}^{*}}{P_{t+\tau}^{F *}}\right)\right] & =
\end{aligned}
$$

with the same interpretation as (3.3.20) - (3.3.21). It is worthwhile to always remember that in the workhorse model the prices of the varieties traded in the goods markets may be sticky, but the nominal exchange rate is still a purely flexible price (floats freely).

Clarida, Galí and Gertler (2002) assume PCP and complete pass-through. Then, the LOOP holds in their model. Furthermore, in the absence of other features like home bias in preferences or trading costs, their model also implies absolute PPP. Instead, the workhorse model explored in this paper relies on LCP pricing as emphasized among others by Devereux and Engel (2003). Widespread local-currency pricing behavior is 
documented among others by Knetter (1993) and Gopinath and Rigobon (2007). Local-currency pricing is, however, not sufficient to guarantee that the LOOP fails. Some degree of nominal rigidities is also necessary for that to happen.

Wages and Aggregate Output. Wages are a fundamental part of the marginal cost faced by the firms in the context of this model as seen in (3.3.3). Wages are determined in a segmented, but otherwise competitive, labor market. The labor market clearing conditions can be expressed as follows (see also equations (3.3.12) $(3.3 .13))$,

$$
\begin{aligned}
n L_{t}^{s} & =\int_{0}^{n} L_{t}^{d}(h) d h=\frac{1}{A_{t}} \int_{0}^{n} Y_{t}^{s}(h) d h, \\
(1-n) L_{t}^{s *} & =\int_{n}^{1} L_{t}^{d *}(f) d f=\frac{1}{A_{t}^{*}} \int_{n}^{1} Y_{t}^{s *}(f) d f,
\end{aligned}
$$

where the second equality comes from the fact that technologies are linear-in-labor as described by equations (3.3.1) - (3.3.2). I define aggregate output in either the domestic or foreign country as $n Y_{t}=\int_{0}^{n} Y_{t}^{s}(h) d h$ and $(1-n) Y_{t}^{*}=\int_{n}^{1} Y_{t}^{s *}(f) d f^{18}$. Using the labor supply function derived from the first-order conditions of the household in equations (3.2.38) - (3.2.39), I can argue that real wages should be equal to,

$$
\begin{aligned}
\frac{W_{t}}{P_{t}} & =\kappa\left(A_{t}\right)^{-\varphi}\left(C_{t}\right)^{\gamma}\left(Y_{t}\right)^{\varphi}, \\
\frac{W_{t}^{*}}{P_{t}^{*}} & =\kappa\left(A_{t}^{*}\right)^{-\varphi}\left(C_{t}^{*}\right)^{\gamma}\left(Y_{t}^{*}\right)^{\varphi} .
\end{aligned}
$$

These equilibrium conditions define how wages and marginal costs evolve in the economy. However, real wages as well as consumption and output are all determined endogenously.

Equations (3.2.21) - (3.2.24) determine the demand function for each variety. That coupled with the market clearing condition at the variety level allows me to calculate the aggregate output as follows,

$$
\begin{aligned}
& n Y_{t}=\int_{0}^{n} Y_{t}^{s}(h) d h=\int_{0}^{n}\left[n C_{t}(h)+(1-n) C_{t}^{*}(h)\right] d h \\
&=n \underbrace{\left[\int_{0}^{n}\left(\frac{P_{t}(h)}{P_{t}^{H}}\right)^{-\theta} d h\right]}_{\text {Relative price dispersion }}\left(\frac{\xi}{n}\left(\frac{P_{t}^{H}}{P_{t}}\right)^{-\sigma} C_{t}\right)+(1-n) \underbrace{\left[\int_{0}^{n}\left(\frac{P_{t}^{*}(h)}{P_{t}^{H *}}\right)^{-\theta} d h\right]}_{\text {Relative price dispersion }}\left(\frac{\xi^{*}}{n}\left(\frac{P_{t}^{H *}}{P_{t}^{*}}\right)^{-\sigma} C_{t}^{*}\right)(3.3 .32) \\
&(1-n) Y_{t}^{*}=\int_{n}^{1} Y_{t}^{s *}(f) d f=\int_{n}^{1}\left[n C_{t}(f)+(1-n) C_{t}^{*}(f)\right] d f \\
&=n \underbrace{\left[\int_{n}^{1}\left(\frac{P_{t}(f)}{P_{t}^{F}}\right)^{-\theta} d f\right]}_{\text {Relative price dispersion }}\left(\frac{1-\xi}{1-n}\left(\frac{P_{t}^{F}}{P_{t}}\right)^{-\sigma} C_{t}\right)+(1-n) \underbrace{\left[\int_{n}^{1}\left(\frac{P_{t}^{*}(f)}{P_{t}^{F *}}\right)^{-\theta} d f\right]}_{\text {Relative price dispersion }}\left(\frac{1-\xi^{*}}{1-n}\left(\frac{P_{t}^{F *}}{P_{t}^{*}}\right)^{-\sigma}\left(3 C_{t}^{* 3}\right)^{\beta}\right) \\
&{ }^{18} \text { Equations (3.3.28)-(3.3.29), naturally, imply that, } \\
& Y_{t}=A_{t} L_{t}^{s}, Y_{t}^{*}=A_{t}^{*} L_{t}^{s *} .
\end{aligned}
$$

Aggregate output is a linear function of aggregate labor. 
In equilibrium, aggregate output is affected by a measure of relative price dispersion as can be see from the equations above. Relative price dispersion and the failure of the LOOP are the consequence of having introduced nominal rigidities in the model. However, relative price dispersion would appear in the model whether firms relied on LCP or PCP pricing, while the LOOP is violated only if firms price-to-market (LCP pricing). Anyway, the relative price dispersion wedges are of second-order importance for aggregate output in the model. Put it differently, these wedges do not enter into a first-order approximation of the aggregate output equations in (3.3.32) and (3.3.33).

If prices were fully flexible, aggregate output in a (symmetric) equilibrium should be,

$$
\begin{aligned}
n Y_{t} & =\int_{0}^{n} Y_{t}^{s}(h) d h=n\left(\frac{\xi}{n}\left(\frac{P_{t}^{H}}{P_{t}}\right)^{-\sigma} C_{t}\right)+(1-n)\left(\frac{\xi^{*}}{n}\left(\frac{P_{t}^{H *}}{P_{t}^{*}}\right)^{-\sigma} C_{t}^{*}\right) \\
(1-n) Y_{t}^{*} & =\int_{n}^{1} Y_{t}^{s *}(f) d f=n\left(\frac{1-\xi}{1-n}\left(\frac{P_{t}^{F}}{P_{t}}\right)^{-\sigma} C_{t}\right)+(1-n)\left(\frac{1-\xi^{*}}{1-n}\left(\frac{P_{t}^{F *}}{P_{t}^{*}}\right)^{-\sigma} C_{t}^{*}\right)
\end{aligned}
$$

In fact, given that the LOOP holds under flexible prices (see (3.3.14) - (3.3.15)), it is possible to re-write these equations as,

$$
\begin{aligned}
n Y_{t} & =\int_{0}^{n} Y_{t}^{s}(h) d h=\left(\frac{P_{t}^{H}}{P_{t}}\right)^{-\sigma}\left[n\left(\frac{\xi}{n} C_{t}\right)+(1-n)\left(\frac{\xi^{*}}{n}\left(\frac{1}{R S_{t}}\right)^{-\sigma} C_{t}^{*}\right)\right] \\
(1-n) Y_{t}^{*} & =\int_{n}^{1} Y_{t}^{s *}(f) d f=\left(\frac{P_{t}^{F *}}{P_{t}^{*}}\right)^{-\sigma}\left[n\left(\frac{1-\xi}{1-n}\left(R S_{t}\right)^{-\sigma} C_{t}\right)+(1-n)\left(\frac{1-\xi^{*}}{1-n} C_{t}^{*}\right)\right]
\end{aligned}
$$

In a symmetric equilibrium with flexible prices, the relative price of all varieties is identical and price dispersion has no role in aggregate output. In this sense, it can be said that relative price dispersion at the variety level defines the degree of real-side distortions on aggregate output and the impact of misallocated expenditures caused by the presence of nominal rigidities. These real-side effects, in turn, give a different motivation to monetary policy: money is no longer neutral, at least in the short-run.

\subsection{The Fiscal and Monetary Policy}

In the spirit of the positive theory of monetary and fiscal policy of Mankiw (1987), the government chooses tax rates and interest rates to 'reduce' the welfare loss associated with the underlying distortions of the economy. In Woodford's (2003) benchmark model the economy is closed, and asset markets are complete. The only two distortions are nominal rigidities and monopolistic competition. The government, therefore, requires at least two instruments to be effective: a labor subsidy (fiscal policy) and a short-term interest rate (monetary policy). As I will argue in this section, the international workhorse model is by no means so straightforward for policy-makers.

The monetary and fiscal policies of the domestic government must satisfy a consolidated budget constraint of the following form,

$$
n\left[P_{t} G_{t}+B_{t-1}-\frac{B_{t}}{1+i_{t}}\right]=R_{t}
$$

where $G_{t}$ denotes per capita real government expenditure, $B_{t}$ is the per capita nominal amount of debt issued at time $t$ which promises one unit of the local currency tomorrow, and $R_{t}$ is the nominal total revenues raised 
by the domestic government. All variables are expressed in per capita terms by convenience, except for total government revenues. I abstract completely from different debt maturities and, for simplicity, I impose that the government does not issue bonds ${ }^{19}$ and that government spending (whether for consumption purposes or for investment) is zero. That is, I assume that $G_{t}=B_{t}=0$ for all $t \geq 1$ and $B_{0}=0$.

Fiat money is an unbacked asset that serves as a unit of account. Each currency serves as the numeraire in the country where it is issued, and the nominal exchange rate is the relative price between the two currencies ${ }^{20}$. Money promises one unit of the local currency in period $t+1$ in exchange for one unit of the local currency in period $t$. The government raises a lump-sum tax on household and a proportional tax on the wage receipts. Therefore, the total revenue is,

$$
R_{t}=n[\underbrace{T_{t}+\phi_{t} W_{t} L_{t}^{s}}_{\text {per capita direct taxation }}+\underbrace{\left(M_{t}-M_{t-1}\right)}_{\text {per capita seigniorage revenues }}],
$$

where $M_{t}$ is the per capita money supply, and $L_{t}^{s}$ the per capita labor supply. Taxes on households and wages imply that $T_{t}>0$ and $\phi_{t}>0$, while a households transfer and a wage subsidy occur if $T_{t}<0$ and $\phi_{t}<0$.

Similarly, the foreign government consolidated budget constraint can be expressed as follows,

$$
\begin{aligned}
& (1-n)\left[P_{t}^{*} G_{t}^{*}+B_{t-1}^{*}-\frac{B_{t}^{*}}{1+i_{t}^{*}}\right]=R_{t}^{*}, \\
& R_{t}^{*}=(1-n)[\underbrace{T_{t}^{*}+\phi_{t}^{*} W_{t}^{*} L_{t}^{s *}}_{\text {per capita direct taxation }}+\underbrace{\left(M_{t}^{*}-M_{t-1}^{*}\right)}_{\text {per capita seigniorage revenues }}],
\end{aligned}
$$

where $G_{t}^{*}$ denotes per capita real government expenditure, $B_{t}^{*}$ is the per capita nominal amount of debt issued at time $t$ which promises one unit of the foreign currency tomorrow, and $R_{t}^{*}$ are the nominal total revenues raised by the foreign government. $M_{t}$ is the per capita money supply, $L_{t}^{s}$ the per capita labor supply, while $T_{t}$ and $\phi_{t}$ are the household and wage taxes (or subsidies) respectively. I also assume that $G_{t}^{*}=B_{t}^{*}=0$ for all $t \geq 1$ and $B_{0}^{*}=0$.

Total revenues are the sum of the receipts from direct taxation and seigniorage. First, I ignore the possibility of independent budgets for the monetary authority and the fiscal authority. Nevertheless, the joint consolidated budget of the fiscal authority and the monetary authority must satisfy the constraints described above. Second, I summarize all possible instruments of fiscal policy into a lump-sum tax and a wage tax (or a wage subsidy). There may be many other taxes as well as a role to be played by government

\footnotetext{
${ }^{19} \mathrm{I}$ characterize government bonds as uncontingent claims. I could alternatively re-write equation (3.4.1) assuming that bonds are contingent, but only for the case where asset markets are complete. For the purpose of this paper, the distinction is of lesser importance because I keep the assumption that all traded assets are in zero-net supply independently of whether they are government-issued or not and independently of whether they are contingent or uncontingent. I recognize that there are not many examples of contingent government bonds to speak off. However, what truly matters is whether households can write contingent or uncontingent lending contracts between themselves and whether these contracts are open to international investors (that is, to foreign households).

${ }^{20} \mathrm{In}$ a pure float regime, monetary policy is set independently from developments in the foreign exchange market. Here, I assume that the exchange rate floats freely and I do not discuss the role that monetary policy may have under a 'managed' exchange rate regime. For a discussion of alternative policy regimes (target zones, fixed exchange rates, etc.) and their implications for exchange rate volatility, see for instance Jeanne and Rose (2002).
} 
spending and borrowing. However, these instruments suffice for the purposes of the model and my focus on monetary policy. They are also key ingredients in Woodford's (2003) closed economy model.

While Taylor (1993) introduced one of the staples of monetary theory, Woodford (2003) set the standard of reference. The aim of monetary and fiscal policy in Woodford (2003) is always the frictionless, competitive allocation. Policy is understood as a set rules implemented by the policy-makers with the aim of driving the economy towards the frictionless allocation. Whether policy rules are optimal or not depends to a great extent on the options available to policy-makers, and the welfare costs associated with the policy choice intended to approximate the frictionless allocation. The literature has placed great emphasis on the properties of certain rules and their impact on the dynamics of the economy. For instance, short-term interest rate Taylor rules have become mainstream for monetary policy analysis and very helpful to forecast the behavior of this policy instrument. Here, I also focus my attention on policy rules.

Fiscal Policy Rules. Woodford (2003) works with a closed-economy framework where there are two basic frictions arising from nominal rigidities and monopolistic competition. The choice of a labor tax/subsidy in either country is simple,

$$
\phi_{t}=\phi_{t}^{*}=\frac{1-\mu}{\mu}=\frac{-1}{\theta},
$$

where $\mu \equiv \frac{\theta}{\theta-1}$ is the mark-up charged by the monopolistic firms, and $\theta$ is the elasticity of substitution across varieties produced within a country. The fiscal authority, therefore, subsidizes labor wages to eliminate the mark-up. If prices were fully flexible, firms would set them equal to their marginal costs. Hence, if the fiscal authority takes care of the mark-up, the monetary policy is left with the task of dealing with the distortion introduced by nominal rigidities alone. In other words, the monetary authority is entrusted with the responsibility of driving the economy towards the allocation that would prevail if prices were flexible and firms perfectly competitive.

The lump-sum taxes/transfers on households, $T_{t}$ and $T_{t}^{*}$, simply guarantee that the government budget constraints are satisfied in each period. If seigniorage revenues offset the cost of the wage subsidy, the lumpsum transfer re-distributes whatever is left to households. If seigniorage revenues are insufficient, then the lump-sum tax will raise enough resources to finance the subsidy. This tax/transfer scheme on households is purely non-distortionary. Such idea naturally carries over to a world populated by two countries which are open to trade in some markets. I adopt it in this paper without much more comment.

However, the simplicity of this fiscal policy rule is somewhat misleading. If the elasticity of substitution across varieties is time-varying (because preferences are not well-approximated with CES aggregators) or the mark-ups are time-varying for some other reason, then the subsidies may have to be time-varying too. Other assumptions that may complicate the role of fiscal policy if lifted are the following: segregated national labor markets, flexible and competitive wages, symmetric firms and households, etc. If mark-ups were timevarying and firm- or industry-specific, that would require the fiscal authority to have in place a very complex time-varying and firm- or industry-specific labor subsidy scheme. But evidence of such subsidies is hard to find in the data. 
Monetary Policy Rules. The money market is fully segregated across countries and the market clearing conditions require that,

$$
\begin{aligned}
n M_{t} & =n M_{t}^{d}, \\
(1-n) M_{t}^{*} & =(1-n) M_{t}^{d *}
\end{aligned}
$$

where $M_{t}$ and $M_{t}^{*}$ are the money supply in the domestic and foreign country, respectively. The money market clearing conditions in equations (3.4.6) - (3.4.7) combined with the money demand functions in (3.2.36) - (3.2.37) indicate that in equilibrium,

$$
\begin{aligned}
M_{t} & =\left(\frac{1}{\chi} \frac{i_{t}}{1+i_{t}}\right)^{-\frac{1}{\zeta}} P_{t}\left(C_{t}\right)^{\frac{\gamma}{\zeta}} \\
M_{t}^{*} & =\left(\frac{1}{\chi} \frac{i_{t}^{*}}{1+i_{t}^{*}}\right)^{-\frac{1}{\zeta}} P_{t}^{*}\left(C_{t}^{*}\right)^{\frac{\gamma}{\zeta}},
\end{aligned}
$$

Monetary policy relies on two instruments in practice: the money supply, $M_{t}$ or $M_{t}^{*}$, and the short-term nominal interest rate, $i_{t}$ or $i_{t}^{*}$. From these equations, it follows immediately that of the two monetary instruments available to the domestic monetary authority, i.e. $\left(M_{t}, i_{t}\right)$, one of them is redundant. Similarly, for the instruments of the foreign monetary authority. Woodford's (2003) implicit argument is that having money or not is completely irrelevant for modelling purposes as long as money itself is non-distortionary. Relevant monetary policy questions can be addressed without having to refer to the money markets at all.

Monetary policy is determined by the choice of a target rule on the short-term nominal interest rate in the tradition of Taylor (1993) as advocated in Woodford's $(2003,2007)$ research. Then, the monetary authority simply promises to supply the money market with as much currency as it is required given the interest rate chosen. Money is supplied locally by the monetary authority and demanded locally too. Money supply evolves over time, generates seigniorage revenues, and is used to finance the fiscal authority's budget. Seigniorage revenues are non-distortionary because the fiscal authority does not set its optimal wage subsidy on the basis of these revenues and whatever is distributed to the households comes in the form of lump-sum transfers. Moreover, the utility function is additively separable in real balances.

The Taylor rule is often defined as the trademark of modern monetary policy. I assume that the monetary authority sets short-term nominal interest rates according to Taylor (1993) type rules,

$$
\begin{aligned}
\frac{1+i_{t}}{1+\bar{i}} & =\frac{Z_{t}}{Z}\left(\frac{1+i_{t-1}}{1+\bar{i}}\right)^{\rho}\left[\left(\Pi_{t}\right)^{\psi_{1}}\left(\frac{Y_{t}}{\bar{Y}_{t}}\right)^{\psi_{2}}\right]^{1-\rho}, \\
\frac{1+i_{t}^{*}}{1+\bar{i}^{*}} & =\frac{Z_{t}^{*}}{Z^{*}}\left(\frac{1+i_{t-1}^{*}}{1+\bar{i}^{*}}\right)^{\rho^{*}}\left[\left(\Pi_{t}^{*}\right)^{\psi_{1}^{*}}\left(\frac{Y_{t}^{*}}{\bar{Y}_{t}^{*}}\right)^{\psi_{2}^{*}}\right]^{1-\rho^{*}},
\end{aligned}
$$

where $Z_{t}$ and $Z_{t}^{*}$ are the monetary policy shocks, $\Pi_{t} \equiv \frac{P_{t}}{P_{t-1}}$ and $\Pi_{t}^{*} \equiv \frac{P_{t}^{*}}{P_{t-1}^{*}}$ are the (gross) CPI inflation rates, $Y_{t}$ and $Y_{t}^{*}$ are the per capita output levels, and $\bar{Y}_{t}$ and $\bar{Y}_{t}^{*}$ are the per capita potential output levels. The ratios $\frac{Y_{t}}{\bar{Y}_{t}}$ and $\frac{Y_{t}^{*}}{\bar{Y}_{t}^{*}}$ are the output gaps in levels for the domestic and foreign country, respectively. Potential output is defined as the output level that would prevail in the economy if all frictions could be eliminated, that is in a frictionless economy with competitive firms and flexible prices. This index specification of the 
Taylor rule takes the standard form once it is log-linearized. The monetary policy index captures both a smoothing term and a policy component.

Fiscal policy takes care of the mark-up charged by firms, so monetary policy becomes the tool of choice to offset the 'distortions' caused by nominal rigidities. Disparities in relative prices arise due to price stickiness. In fact, the more rapid inflation grows, the larger are the relative price differences between otherwise symmetric firms. The resulting misallocation of expenditures is thought to be costly in terms of welfare for the consumers. Price stability, therefore, guarantees that relative price differences are contained, that the misallocation of expenditures is limited and that the welfare loss is 'small'.

With perfect foresight and no uncertainty, it should be possible to set the nominal interest rate in such a way that prices are stable over time. Therefore, the distortion introduced by nominal rigidities is completely eliminated. That coupled with the fiscal policy suffices to attain the desired optimal allocation. With rational expectations and uncertainty, there is no simple way to implement a monetary policy that guarantees price stability in every state of nature. Hence, Taylor rules cannot guarantee price stability at every state of the world anyway. However, Taylor rules are a convenient specification for monetary policy because: (a) they set an objective of price stability in order to force inflation and output to revert to their desired targets, and (b) they explicitly account for a trade-off between inflation and the output gap to balance the benefits of price stability against the costs of attaining that goal.

Finally, it is worth commenting on the monetarist view that sound monetary policy should be grounded in stable money supply growth rules as advocated by Friedman (1960). In Poole's (2008) own words I must recognize that: "If the money-demand functions were stable, a central bank that pursued such an interest rate policy (a Taylor rule) would find that the growth rate of the money stock would fall when inflation rose above target. Similarly, under the Taylor rule money growth would tend to rise when inflation fell below the target. If a central bank is successful in maintaining a relatively low rate of inflation, the resulting average growth in the money stock will be relatively low and stable. Hence, a central bank following an appropriately specified Taylor rule with an invariant inflation target would induce the pattern of money growth that the monetarists argued was required for a nominal anchor in the economy. The Taylor rule reconciles somewhat different theoretical approaches of economists who emphasize the money stock in their analysis of monetary policy and those who emphasize interest rates in their analysis."

An 'Open' Discussion about Monetary Policy and Openness. My previous discussion is essentially borrowed from the literature on closed-economies. It follows the treatment in Woodford (2003, chap. 2, sec. 3.3 ) and Woodford (2007) based on the simple idea that fiscal and monetary policy should be implemented in the presence of frictions in such a way that the effects of those frictions are minimized (to approximate the outcome of the frictionless allocation). It is not immediately obvious, however, how to extend this logic to a two-country economy with nominal rigidities, monopolistic firms and LCP. The role of fiscal policy is still to eliminate the distortion caused by the mark-up. However, the role of monetary policy becomes more obscure and complex.

If trade is allowed between these two economies it is not clear that a Taylor rule that targets price stability and the domestic output gap would suffice. For example,

- Domestic output gap should not be the only measure of real marginal costs tracked by the domestic monetary authority, because the foreign output gap also has value as proxy for foreign real marginal costs (and hence imported inflation). 
- The potential output in both countries changes as a result of trade openness, and generally depends on external factors too. As a result, measuring the potential for the domestic economy can be more complex.

- Market clearing requires that domestic consumption be equal to domestic output in a closed economy, but this equality does not necessarily hold true for an open economy. If the monetary authority cares about the welfare of the domestic households, it could be better to balance the benefits of pursuing price stability against the costs in terms of a consumption gap rather than an output gap.

Furthermore, even after taking away the mark-up with fiscal policy, the distortions of the workhorse international model are more than the relative price distortions introduced by nominal rigidities. First of all, there is an implicit assumption that all firms are specialized in their own varieties and can neither relocate nor tap into the international inputs market (inputs are non-traded across countries). It is not obvious to me that specialization in this type of models is due to the competitive advantage of one country over the other. In fact, it seems to me that if it can be shown that specialization is not due to competitive advantage, a model build around this restriction on the location of firms could lead to a sub-optimal allocation. Hence, if monetary policy is used to 'push' the allocation closer to its optimal level, it could come into conflict with its goal of price stability.

Secondly, the workhorse model also implies that firms rely on pricing-to-market (LCP). In this environment, movements in the nominal exchange rate -which is assumed to be a flexible price- can induce large misallocations of expenditure across countries because the LOOP fails to hold. It is not clear how monetary policy should respond to this type of relative price distortions in the external sector (if at all). This is just another worry that policy-makers should have because of openness and international pricing behavior which is completely alien to the closed-economy literature.

Finally, a common variant of the workhorse model allows for frictions in the asset markets to be considered. This is the case of the bond economy described in this paper. But, what monetary policy is or ought to be if asset markets are incomplete is not clear either. Incomplete asset markets implies that households in each country have only limited opportunities to pool risks among themselves. Conceivably models could be written in which the fiscal and monetary authorities can provide some degree of insurance for households. However, manipulating monetary policy for risk-sharing purposes may come into conflict with the objective of price stability too.

\subsection{The Resource Constraint}

The structure of asset markets has obvious implications for the degree of risk-sharing that can be attained across countries and for financing the trade balance. But the results presented here are general enough, so I focus on the complete asset specification (unless otherwise noted). If I aggregate the budget constraint of the domestic household in (3.2.3) with the consolidated domestic government budget constraint in (3.4.1) (3.4.2), I obtain,

$$
\begin{aligned}
& P_{t} C_{t}+\left(M_{t}^{d}-M_{t}\right)+\int_{\omega_{t+1} \in \Omega} Q_{t}\left(\omega_{t+1}\right) B_{t}^{H}\left(\omega_{t+1}\right)+S_{t} \int_{\omega_{t+1} \in \Omega} Q_{t}^{*}\left(\omega_{t+1}\right) B_{t}^{F}\left(\omega_{t+1}\right) \\
& \leq\left(M_{t-1}^{d}-M_{t-1}\right)+B_{t-1}^{H}\left(\omega_{t}\right)+S_{t} B_{t-1}^{F}\left(\omega_{t}\right)+\Pi_{t}+\left(1+\phi_{t}\right) W_{t} L_{t}^{s} .
\end{aligned}
$$


Similarly, it follows that if I aggregate the budget constraint of the foreign household in (3.2.4) with the consolidated foreign government budget constraint in (3.4.3) - (3.4.4), I obtain,

$$
\begin{aligned}
& P_{t}^{*} C_{t}^{*}+\left(M_{t}^{d *}-M_{t}^{*}\right)+\frac{1}{S_{t}} \int_{\omega_{t+1} \in \Omega} Q_{t}\left(\omega_{t+1}\right) B_{t}^{H *}\left(\omega_{t+1}\right)+\int_{\omega_{t+1} \in \Omega} Q_{t}^{*}\left(\omega_{t+1}\right) B_{t}^{F *}\left(\omega_{t+1}\right) \\
& \quad \leq\left(M_{t-1}^{d *}-M_{t-1}^{*}\right)+\frac{1}{S_{t}} B_{t-1}^{H *}\left(\omega_{t}\right)+B_{t-1}^{F *}\left(\omega_{t}\right)+\Pi_{t}^{*}+\left(1+\phi_{t}^{*}\right) W_{t}^{*} L_{t}^{s *} .
\end{aligned}
$$

Equations (3.5.1) and (3.5.2) hold with equality in equilibrium. Using the money market clearing conditions described in (3.4.6) - (3.4.7), the definitions of per capita profits distributed to the representative household in each country as given by (3.3.10) and (3.3.11), and the labor market clearing conditions in equations (3.3.12) - (3.3.13), I immediately infer that,

$$
\begin{aligned}
& P_{t} C_{t}+\int_{\omega_{t+1} \in \Omega} Q_{t}\left(\omega_{t+1}\right) B_{t}^{H}\left(\omega_{t+1}\right)+S_{t} \int_{\omega_{t+1} \in \Omega} Q_{t}^{*}\left(\omega_{t+1}\right) B_{t}^{F}\left(\omega_{t+1}\right) \\
& \quad=B_{t-1}^{H}\left(\omega_{t}\right)+S_{t} B_{t-1}^{F}\left(\omega_{t}\right)+\frac{1}{n} \int_{0}^{n}\left[P_{t}(h) n C_{t}(h)+S_{t} P_{t}^{*}(h)(1-n) C_{t}^{*}(h)\right] d h, \\
& P_{t}^{*} C_{t}^{*}+\frac{1}{S_{t}} \int_{\omega_{t+1} \in \Omega} Q_{t}\left(\omega_{t+1}\right) B_{t}^{H *}\left(\omega_{t+1}\right)+\int_{\omega_{t+1} \in \Omega} Q_{t}^{*}\left(\omega_{t+1}\right) B_{t}^{F *}\left(\omega_{t+1}\right) \\
& \quad=\frac{1}{S_{t}} B_{t-1}^{H *}\left(\omega_{t}\right)+B_{t-1}^{F *}\left(\omega_{t}\right)+\frac{1}{1-n} \int_{n}^{1}\left[\frac{1}{S_{t}} P_{t}(f) n C_{t}(f)+P_{t}^{*}(f)(1-n) C_{t}^{*}(f)\right] d f .
\end{aligned}
$$

Equations (3.5.3) and (3.5.4) can easily be adapted to reflect that only trade in uncontingent bonds is possible, as posited in the incomplete asset markets setting discussed in this paper.

Real and Nominal Goods Market Clearing Conditions. Given the fact that all firms are committed to satisfy the household demands at the given prices, the market clearing condition for any given variety in either location can be computed as,

$$
\begin{aligned}
Y_{t}(h) & =n C_{t}(h)+(1-n) C_{t}^{*}(h), \forall h \in[0, n], \\
Y_{t}^{*}(f) & =n C_{t}(f)+(1-n) C_{t}^{*}(f), \forall f \in(n, 1] .
\end{aligned}
$$

The demand functions for each variety of goods are analyzed in equations (3.2.21) - (3.2.24). The implicit assumption that preferences over different varieties within a bundle (either domestic or foreign) are identical implies that the nominal market clearing conditions for each bundle of varieties can be aggregated as follows,

$$
\begin{aligned}
P P I_{t}^{H} Y_{t} & =\frac{1}{n} \int_{0}^{n}\left[P_{t}(h) n C_{t}(h)+S_{t} P_{t}^{*}(h)(1-n) C_{t}^{*}(h)\right] d h \\
& =\frac{1}{n}\left[\frac{1}{n} \int_{0}^{n}\left(\frac{P_{t}(h)}{P_{t}^{H}}\right)^{1-\theta} d h\right] n P_{t}^{H} C_{t}^{H}+\frac{1}{n}\left[\frac{1}{n} \int_{0}^{n}\left(\frac{P_{t}^{*}(h)}{P_{t}^{H *}}\right)^{1-\theta} d h\right](1-n) S_{t} P_{t}^{H *} C_{t}^{H *}, \\
P P I_{t}^{F *} Y_{t}^{*} & =\frac{1}{1-n} \int_{n}^{1}\left[\frac{1}{S_{t}} P_{t}(f) n C_{t}(f)+P_{t}^{*}(f)(1-n) C_{t}^{*}(f)\right] d f \\
& \left.=\frac{1}{1-n}\left[\frac{1}{1-n} \int_{n}^{1}\left(\frac{P_{t}(f)}{P_{t}^{F}}\right)^{1-\theta} d f\right] n \frac{1}{S_{t}} P_{t}^{F} C_{t}^{F}+\frac{1}{1-n}\left[\frac{1}{1-n} \int_{n}^{1}\left(\frac{P_{t}^{*}(f)}{P_{t}^{F *}}\right)^{1-\theta} d f\right](1-n) P_{t}^{F\left(3 C_{t}^{F} .8 *\right.}\right)
\end{aligned}
$$

where $Y_{t}$ are the units of output produced per firm in the home country, $Y_{t}^{*}$ are the units of output produced per firm in the foreign country, and $P P I_{t}^{H}$ and $P P I_{t}^{F *}$ are the corresponding producer price indexes (PPI) 
expressed in the local currency of the domestic and foreign country, respectively.

The expressions within brackets in the previous equations are a measure of relative price dispersion across firms within a given location. From the definitions of the price indexes for the bundles of domestic and foreign varieties in (3.2.16) - (3.2.17), it immediately follows that these measures of dispersion aggregate to one. Therefore, I obtain that,

$$
\begin{aligned}
n P P I_{t}^{H} Y_{t} & =n P_{t}^{H} C_{t}^{H}+(1-n) S_{t} P_{t}^{H *} C_{t}^{H *}, \\
(1-n) P P I_{t}^{F *} Y_{t}^{*} & =n \frac{1}{S_{t}} P_{t}^{F} C_{t}^{F}+(1-n) P_{t}^{F *} C_{t}^{F *},
\end{aligned}
$$

while the market clearing condition for each country can be expressed in real terms as,

$$
\begin{aligned}
n Y_{t} & =n C_{t}^{H}+(1-n) C_{t}^{H *} \\
(1-n) Y_{t}^{*} & =n C_{t}^{F}+(1-n) C_{t}^{F *}
\end{aligned}
$$

The producer price indexes (PPIs) are identical to the consumption price sub-indexes for each bundle of goods, i.e. $P P I_{t}^{H}=P_{t}^{H}$ and $P P I_{t}^{F *}=P_{t}^{F *}$, whenever the LOOP holds. Otherwise, the PPI can be derived as,

$$
\begin{aligned}
P P I_{t}^{H} & =\frac{n C_{t}^{H}}{n C_{t}^{H}+(1-n) C_{t}^{H *}} P_{t}^{H}+\frac{(1-n) C_{t}^{H *}}{n C_{t}^{H}+(1-n) C_{t}^{H *}} S_{t} P_{t}^{H *}, \\
P P I_{t}^{F *} & =\frac{n C_{t}^{F}}{n C_{t}^{F}+(1-n) C_{t}^{F *}} \frac{1}{S_{t}} P_{t}^{F}+\frac{(1-n) C_{t}^{F *}}{n C_{t}^{F}+(1-n) C_{t}^{F *}} P_{t}^{F *} .
\end{aligned}
$$

In other words, each PPI is a weighted sum of the aggregate prices of the bundle of goods in both the local and the foreign markets expressed in the nominal currency of the producer. The weights are the shares of output produced to be sold in each market.

Using the demand functions for each variety of goods in equations (3.2.21) - (3.2.24) one more time, I re-write the nominal market clearing conditions in (3.5.9) - (3.5.10) in terms of aggregate consumption as follows,

$$
\begin{aligned}
n P P I_{t} Y_{t} & =n \xi\left(\frac{P_{t}^{H}}{P_{t}}\right)^{1-\sigma} P_{t} C_{t}+(1-n) \xi^{*}\left(\frac{P_{t}^{H *}}{P_{t}^{*}}\right)^{1-\sigma} S_{t} P_{t}^{*} C_{t}^{*} \\
(1-n) P P I_{t}^{*} Y_{t}^{*} & =n(1-\xi)\left(\frac{P_{t}^{F}}{P_{t}}\right)^{1-\sigma} \frac{1}{S_{t}} P_{t} C_{t}+(1-n)\left(1-\xi^{*}\right)\left(\frac{P_{t}^{F *}}{P_{t}^{*}}\right)^{1-\sigma} P_{t}^{*} C_{t}^{*}
\end{aligned}
$$

while the market clearing conditions are expressed in real terms as,

$$
\begin{aligned}
n Y_{t} & =n \xi\left(\frac{P_{t}^{H}}{P_{t}}\right)^{1-\sigma} C_{t}+(1-n) \xi^{*}\left(\frac{P_{t}^{H *}}{P_{t}^{*}}\right)^{1-\sigma} C_{t}^{*} \\
(1-n) Y_{t}^{*} & =n(1-\xi)\left(\frac{P_{t}^{F}}{P_{t}}\right)^{1-\sigma} C_{t}+(1-n)\left(1-\xi^{*}\right)\left(\frac{P_{t}^{F *}}{P_{t}^{*}}\right)^{1-\sigma} C_{t}^{*} .
\end{aligned}
$$

Naturally, the sum of the real aggregate output in both countries equals the sum of the real aggregate 
consumption,

$$
n Y_{t}+(1-n) Y_{t}^{*}=n C_{t}+(1-n) C_{t}^{*},
$$

which follows from the market clearing conditions above. I can also derive an alternative characterization of the PPI computed in terms of the CPI of each country which takes up the form,

$$
\begin{aligned}
P P I_{t} & =\frac{n \xi\left(\frac{P_{t}^{H}}{P_{t}}\right)^{1-\sigma} C_{t}}{n \xi\left(\frac{P_{t}^{H}}{P_{t}}\right)^{1-\sigma} C_{t}+(1-n) \xi^{*}\left(\frac{P_{t}^{H *}}{P_{t}^{*}}\right)^{1-\sigma} C_{t}^{*}} P_{t}+\frac{(1-n) \xi^{*}\left(\frac{P_{t}^{H *}}{P_{t}^{*}}\right)^{1-\sigma} C_{t}^{*}}{n \xi\left(\frac{P_{t}^{H}}{P_{t}}\right)^{1-\sigma} C_{t}+(1-n) \xi^{*}\left(\frac{P_{t}^{H *}}{P_{t}^{*}}\right)^{1-\sigma} C_{t}^{*}} S_{t} P_{t}^{*}, \\
P P I_{t}^{*} & =\frac{n(1-\xi)\left(\frac{P_{t}^{F}}{P_{t}}\right)^{1-\sigma} C_{t}}{n(1-\xi)\left(\frac{P_{t}^{F}}{P_{t}}\right)^{1-\sigma} C_{t}+(1-n)\left(1-\xi^{*}\right)\left(\frac{P_{t}^{F *}}{P_{t}^{*}}\right)^{1-\sigma} C_{t}^{*}} \frac{1}{S_{t}} P_{t}+\frac{(1-n)\left(1-\xi^{*}\right)\left(\frac{P_{t}^{F *}}{P_{t}^{*}}\right)^{1-\sigma} C_{t}^{*}}{n(1-\xi)\left(\frac{P_{t}^{F}}{P_{t}}\right)^{1-\sigma} C_{t}+(1-n)\left(1-\xi^{*}\right)\left(\frac{P_{t}^{F *}}{P_{t}^{*}}\right)^{1-\sigma} C_{t}^{*}} P_{t}^{*} .
\end{aligned}
$$

If absolute PPP were to hold, which in the context of the workhorse model requires the LOOP to hold and no home bias in consumption (i.e., $\xi=\xi^{*}$ ), then the local PPI corresponds exactly to the local CPI. In other words, it is true that $P P I_{t}=P_{t}$ and $P P I_{t}^{*}=P_{t}^{*}$.

This long digression on the differences between the CPI and the PPI, or consumption-based and producerbased prices, is also meant to reinforce the idea that it is necessary to distinguish between the nominal resource constraint of each country and the market clearing conditions in real terms. It is also important to realize that my definition of the PPI is not necessarily equivalent to the CPI. This is a subject that has received some attention specially in policy circles because not everybody agrees that targeting the CPI is the best strategy for monetary policy. I do not cover the discussion in this paper for lack of space.

The Current Account, the Capital Account and the Trade Balance. Following on the previous results, it is possible to argue that the nominal resource constraint in each country is equal to,

$$
\begin{aligned}
& \int_{\omega_{t+1} \in \Omega} Q_{t}\left(\omega_{t+1}\right) B_{t}^{H}\left(\omega_{t+1}\right)+S_{t} \int_{\omega_{t+1} \in \Omega} Q_{t}^{*}\left(\omega_{t+1}\right) B_{t}^{F}\left(\omega_{t+1}\right)=B_{t-1}^{H}\left(\omega_{t}\right)+S_{t} B_{t-1}^{F}\left(\omega_{t}\right)+ \\
& \quad+P_{t} \frac{1}{n}\left[\xi\left(\frac{P_{t}^{H}}{P_{t}}\right)^{1-\sigma} n C_{t}+\xi^{*}\left(\frac{P_{t}^{H *}}{P_{t}^{*}}\right)^{1-\sigma} R S_{t}(1-n) C_{t}^{*}-n C_{t}\right] \\
& \frac{1}{S_{t}} \int_{\omega_{t+1} \in \Omega} Q_{t}\left(\omega_{t+1}\right) B_{t}^{H *}\left(\omega_{t+1}\right)+\int_{\omega_{t+1} \in \Omega} Q_{t}^{*}\left(\omega_{t+1}\right) B_{t}^{F *}\left(\omega_{t+1}\right)=\frac{1}{S_{t}} B_{t-1}^{H *}\left(\omega_{t}\right)+B_{t-1}^{F *}\left(\omega_{t}\right)+ \\
& \quad+P_{t}^{*} \frac{1}{1-n}\left[(1-\xi)\left(\frac{P_{t}^{F}}{P_{t}}\right)^{1-\sigma} \frac{1}{R S_{t}} n C_{t}+\left(1-\xi^{*}\right)\left(\frac{P_{t}^{F *}}{P_{t}^{*}}\right)^{1-\sigma}(1-n) C_{t}^{*}-(1-n) C_{t}^{*}\right],
\end{aligned}
$$

where the real exchange rate is defined as in equation (3.2.19). These pair of equations in per capita terms hold true independently of whether the prices are flexible or sticky. The per capita current account equations 
in (3.5.21) and (3.5.22) can be expressed more conveniently as,

$$
\begin{aligned}
& \underbrace{P_{t} \frac{1}{n}\left[\xi\left(\frac{P_{t}^{H}}{P_{t}}\right)^{1-\sigma} n C_{t}+\xi^{*}\left(\frac{P_{t}^{H *}}{P_{t}^{*}}\right)^{1-\sigma}(1-n) R S_{t} C_{t}^{*}-n C_{t}\right]}+ \\
& \text { Nominal Trade Balance of Country } H \\
& +\underbrace{\left[B_{t-1}^{H}\left(\omega_{t}\right)-\int_{\omega_{t+1} \in \Omega} Q_{t-1}\left(\omega_{t}\right) B_{t-1}^{H}\left(\omega_{t}\right)\right]+S_{t}\left[B_{t-1}^{F}\left(\omega_{t}\right)-\int_{\omega_{t+1} \in \Omega} Q_{t-1}^{*}\left(\omega_{t}\right) B_{t-1}^{F}\left(\omega_{t}\right)\right]} \\
& \text { Nominal Service Balance of Country } H \\
& =\left[\int_{\omega_{t+1} \in \Omega} Q_{t}\left(\omega_{t+1}\right) B_{t}^{H}\left(\omega_{t+1}\right)-\int_{\omega_{t+1} \in \Omega} Q_{t-1}\left(\omega_{t}\right) B_{t-1}^{H}\left(\omega_{t}\right)\right]+ \\
& \underbrace{+S_{t}\left[\int_{\omega_{t+1} \in \Omega} Q_{t}^{*}\left(\omega_{t+1}\right) B_{t}^{F}\left(\omega_{t+1}\right)-\int_{\omega_{t+1} \in \Omega} Q_{t-1}^{*}\left(\omega_{t}\right) B_{t-1}^{F}\left(\omega_{t}\right)\right]}
\end{aligned}
$$

and

$$
\begin{aligned}
& \underbrace{P_{t}^{*} \frac{1}{1-n}\left[(1-\xi)\left(\frac{P_{t}^{F}}{P_{t}}\right)^{1-\sigma} n \frac{1}{R S_{t}} C_{t}+\left(1-\xi^{*}\right)\left(\frac{P_{t}^{F *}}{P_{t}^{*}}\right)^{1-\sigma}(1-n) C_{t}^{*}-(1-n) C_{t}^{*}\right]}+ \\
& +\underbrace{\frac{1}{S_{t}}\left[B_{t-1}^{H *}\left(\omega_{t}\right)-\int_{\omega_{t+1} \in \Omega}^{\text {Nominal Trade Balance of Country } F} Q_{t-1}\left(\omega_{t}\right) B_{t-1}^{H *}\left(\omega_{t}\right)\right]+\left[B_{t-1}^{F *}\left(\omega_{t}\right)-\int_{\omega_{t+1} \in \Omega} Q_{t-1}^{*}\left(\omega_{t}\right) B_{t-1}^{F *}\left(\omega_{t}\right)\right]} \\
& \begin{aligned}
=\begin{array}{l}
\frac{1}{S_{t}}\left[\int_{\omega_{t+1} \in \Omega} Q_{t}\left(\omega_{t+1}\right) B_{t}^{H *}\left(\omega_{t+1}\right)-\int_{\omega_{t+1} \in \Omega} Q_{t-1}\left(\omega_{t}\right) B_{t-1}^{H *}\left(\omega_{t}\right)\right]+ \\
+\left[\int_{\omega_{t+1} \in \Omega} Q_{t}^{*}\left(\omega_{t+1}\right) B_{t}^{F *}\left(\omega_{t+1}\right)-\int_{\omega_{t+1} \in \Omega} Q_{t-1}^{*}\left(\omega_{t}\right) B_{t-1}^{F *}\left(\omega_{t}\right)\right]
\end{array}
\end{aligned}
\end{aligned}
$$

Equations (3.5.23) and (3.5.24) are expressed in nominal terms using their respective local currencies as numeraire. The first term inside brackets in the left-hand side is the nominal trade balance of each country. The second term inside brackets in the left-hand side is the service balance. The sum of the trade balance and the service balance is the current account. The terms in the right-hand side represent the capital account, that is the inflow or outflow of capital. A current account deficit (surplus) automatically equates to a capital account surplus (deficit).

The current account of the balance of payments $(\mathrm{BoP})$ is the sum of the trade balance (exports minus imports of goods and services) and the services balance (which includes net factor incomes such as interests and dividends, and net transfer payments such as foreign aid). The trade balance is typically the most important part of the current account. The BoP in the official statistics often includes an accounting item to balance net errors and omissions which, for obvious reasons, must be ignored in the model.

The official reserves (including foreign exchange reserves, official gold reserves, and IMF Special Drawing Rights, all denominated in foreign currency) should also be added to the BoP. In this paper I abstract from foreign reserves entirely, which means that the monetary authority looses a policy instrument often used for 
interventions in the foreign exchange market. This is consistent with my focus on a free-floating exchange rate regime. As noted previously, I also abstract from the possibility that private agents would demand foreign currency. Hence, money supply does not enter neither the capital account nor the financial services account in the workhorse model.

The World Nominal Trade Balance. The Arrow-Debreu securities can be simply interpreted as borrowing and lending short-term contracts between the households in both countries, since the government neither borrows nor lends in the model. The market clearing condition for the Arrow-Debreu securities requires that,

$$
\begin{aligned}
n B_{t}^{H}\left(\omega_{t+1}\right)+(1-n) B_{t}^{H *}\left(\omega_{t+1}\right) & =n B_{t}^{s}\left(\omega_{t+1}\right)=0, \\
n B_{t}^{F}\left(\omega_{t+1}\right)+(1-n) B_{t}^{F *}\left(\omega_{t+1}\right) & =(1-n) B_{t}^{s *}\left(\omega_{t+1}\right)=0,
\end{aligned}
$$

where $B_{t}^{s}\left(\omega_{t+1}\right)$ and $B_{t}^{s *}\left(\omega_{t+1}\right)$ are the per capita supply of each claim. All claims are in zero net supply. The asset market clearing conditions must hold true for all period $t$ and for all events in the space $\omega_{t+1} \in \Omega$. Furthermore, the intertemporal first-order condition on the household's problem given in equation (3.2.27) tells me that in equilibrium $Q_{t}\left(\omega_{t+1}\right)=Q_{t}^{*}\left(\omega_{t+1}\right) \frac{S_{t}}{S_{t+1}\left(\omega_{t+1}\right)}$. Let me aggregate the current account equations of both countries as given by (3.5.21) and (3.5.22) across all households, transform the equations to be quoted in units of the same currency with the help of the nominal exchange rate, and add them up. Then, it must follow that,

$$
\begin{aligned}
& \int_{\omega_{t+1} \in \Omega} Q_{t}\left(\omega_{t+1}\right)\left[n B_{t}^{H}\left(\omega_{t+1}\right)+(1-n) B_{t}^{H *}\left(\omega_{t+1}\right)\right]+S_{t} \int_{\omega_{t+1} \in \Omega} Q_{t}^{*}\left(\omega_{t+1}\right)\left[n B_{t}^{F}\left(\omega_{t+1}\right)+(1-n) B_{t}^{F *}\left(\omega_{t+1}\right)\right] \\
& \quad=\left[n B_{t-1}^{H}\left(\omega_{t}\right)+(1-n) B_{t-1}^{H *}\left(\omega_{t}\right)\right]+S_{t}\left[n B_{t-1}^{F}\left(\omega_{t}\right)+(1-n) B_{t-1}^{F *}\left(\omega_{t}\right)\right]+ \\
& \quad+P_{t}\left(\xi\left(\frac{P_{t}^{H}}{P_{t}}\right)^{1-\sigma} n C_{t}+\xi^{*} R S_{t}\left(\frac{P_{t}^{H *}}{P_{t}^{*}}\right)^{1-\sigma}(1-n) C_{t}^{*}-n C_{t}\right)+ \\
& \quad+P_{t}\left((1-\xi)\left(\frac{P_{t}^{F}}{P_{t}}\right)^{1-\sigma} n C_{t}+\left(1-\xi^{*}\right) R S_{t}\left(\frac{P_{t}^{F *}}{P_{t}^{*}}\right)^{1-\sigma}(1-n) C_{t}^{*}-(1-n) R S_{t} C_{t}^{*}\right)
\end{aligned}
$$

Alternatively, I can simply write that,

$$
\begin{aligned}
& P_{t}\left(\xi\left(\frac{P_{t}^{H}}{P_{t}}\right)^{1-\sigma} n C_{t}+\xi^{*} R S_{t}\left(\frac{P_{t}^{H *}}{P_{t}^{*}}\right)^{1-\sigma}(1-n) C_{t}^{*}-n C_{t}\right)+ \\
& \quad+S_{t} P_{t}^{*}\left((1-\xi) \frac{1}{R S_{t}}\left(\frac{P_{t}^{F}}{P_{t}}\right)^{1-\sigma} n C_{t}+\left(1-\xi^{*}\right)\left(\frac{P_{t}^{F *}}{P_{t}^{*}}\right)^{1-\sigma}(1-n) C_{t}^{*}-(1-n) C_{t}^{*}\right)=0,
\end{aligned}
$$

which implies that the nominal trade balance surplus in one country has to be equal to the nominal trade balance deficit in the other country whenever expressed in the same currency (as expected).

In other words, the nominal trade balance of the entire world has to be equal to zero when expressed in the same currency. I can re-express this equation one more time as follows,

$$
\left(\frac{P P I_{t}}{P_{t}} n Y_{t}-n C_{t}\right)+R S_{t}\left(\frac{P P I_{t}^{*}}{P_{t}^{*}}(1-n) Y_{t}^{*}-(1-n) C_{t}^{*}\right)=0
$$


while in real terms it holds true that ${ }^{21}$,

$$
\left(n Y_{t}+(1-n) Y_{t}^{*}\right)-\left(n C_{t}+(1-n) C_{t}^{*}\right)=0
$$

from the goods market clearing conditions in (3.5.17) - (3.5.18). These pair of equations shows that differences in the equilibrium conditions between the nominal and the real values arise from fluctuations in the real exchange rate and from discrepancies between PPIs and CPIs. Both of which are the result of home bias in preferences and violations of the LOOP due to sticky prices and LCP pricing.

The Current Account Equation with Incomplete Asset Markets. From equation (3.5.21) and the intertemporal first-order condition in (3.2.27), it follows that the domestic nominal current account equation can be expressed as,

$$
\int_{\omega_{t+1} \in \Omega} Q_{t}\left(\omega_{t+1}\right) B_{t}\left(\omega_{t+1}\right)=B_{t-1}\left(\omega_{t}\right)+P_{t} \frac{1}{n}\left[\xi\left(\frac{P_{t}^{H}}{P_{t}}\right)^{1-\sigma} n C_{t}+\xi^{*}\left(\frac{P_{t}^{H *}}{P_{t}^{*}}\right)^{1-\sigma} R S_{t}(1-n) C_{t}^{*}-n C_{t}\right],
$$

where I define the net borrowing as $B_{t}\left(\omega_{t+1}\right) \equiv B_{t}^{H}\left(\omega_{t+1}\right)+S_{t+1}\left(\omega_{t+1}\right) B_{t}^{F}\left(\omega_{t+1}\right)$. Alternatively, I could also redefine the current account equation for the foreign country in (3.5.22) by noting that foreign net borrowing can be expressed as $B_{t}^{*}\left(\omega_{t+1}\right) \equiv \frac{1}{S_{t+1}\left(\omega_{t+1}\right)} B_{t}^{H *}\left(\omega_{t+1}\right)+B_{t}^{F *}\left(\omega_{t+1}\right)$. That is,

$$
\begin{aligned}
& \int_{\omega_{t+1} \in \Omega} Q_{t}^{*}\left(\omega_{t+1}\right) B_{t}^{*}\left(\omega_{t+1}\right) \\
& \quad=B_{t-1}^{*}\left(\omega_{t}\right)+P_{t}^{*} \frac{1}{1-n}\left[(1-\xi)\left(\frac{P_{t}^{F}}{P_{t}}\right)^{1-\sigma} \frac{1}{R S_{t}} n C_{t}+\left(1-\xi^{*}\right)\left(\frac{P_{t}^{F *}}{P_{t}^{*}}\right)^{1-\sigma}(1-n) C_{t}^{*}-(1-n) C_{t}^{*}\right] .
\end{aligned}
$$

In the case where asset market are incomplete, the domestic current account equation can be expressed as,

$$
\left[1+\left(\frac{S_{t}}{S_{t+1}} \frac{1+i_{t}}{1+i_{t}^{*}}-1\right) \alpha_{t}\right] \frac{1}{1+i_{t}} B_{t}=B_{t-1}+P_{t} \frac{1}{n}\left[\xi\left(\frac{P_{t}^{H}}{P_{t}}\right)^{1-\sigma} n C_{t}+\xi^{*}\left(\frac{P_{t}^{H *}}{P_{t}^{*}}\right)^{1-\sigma} R S_{t}(1-n) C_{t}^{*}-n C_{t}\right]
$$

where $B_{t} \equiv B_{t}^{H}+S_{t+1} B_{t}^{F}$ and $\alpha_{t} \equiv \frac{S_{t+1} B_{t}^{F}}{B_{t}}$. In turn, the foreign current account equation is equivalent to,

$$
\begin{aligned}
& {\left[1+\left(\frac{S_{t+1}}{S_{t}} \frac{1+i_{t}^{*}}{1+i_{t}}-1\right) \alpha_{t}^{*}\right] \frac{1}{1+i_{t}^{*}} B_{t}^{*}} \\
& \quad=B_{t-1}^{*}+P_{t}^{*} \frac{1}{1-n}\left[(1-\xi)\left(\frac{P_{t}^{F}}{P_{t}}\right)^{1-\sigma} \frac{1}{R S_{t}} n C_{t}+\left(1-\xi^{*}\right)\left(\frac{P_{t}^{F *}}{P_{t}^{*}}\right)^{1-\sigma}(1-n) C_{t}^{*}-(1-n) C_{t}^{*}\right],
\end{aligned}
$$

where $B_{t}^{*} \equiv \frac{1}{S_{t+1}} B_{t}^{H *}+B_{t}^{F *}$ and $\alpha_{t}^{*} \equiv \frac{B_{t}^{H *}}{S_{t+1} B_{t}}$.

\footnotetext{
${ }^{21}$ This is a condition that holds true no matter what assets are available for trade, or which nominal rigidities are present, and so on. In the end, nominal output must be equal to nominal consumption in the world. This expression, however, reflects some of the simplifications of the workhorse model. On one hand, the government may also demand a share of each variety of goods. On the other hand, the complexity of adding either durable goods or investment goods to the mix of international trade is particularly important given the share of these goods in total trade. But, neither one of those is considered here explicitly.
} 
The Real Exports, Real Imports and Real Net Exports. The aggregate imports of the domestic country in real terms are defined from equations (3.2.22) and (3.2.24) as follows,

$$
I M_{t}=n \int_{n}^{1} C_{t}(f) d f=(1-\xi)\left[\frac{1}{1-n} \int_{n}^{1}\left(\frac{P_{t}(f)}{P_{t}^{F}}\right)^{-\theta} d f\right]\left(\frac{P_{t}^{F}}{P_{t}}\right)^{-\sigma} n C_{t},
$$

while the aggregate exports of the domestic country in real terms are derived from (3.2.21) and (3.2.23) as,

$$
E X_{t}=(1-n) \int_{0}^{n} C_{t}^{*}(h) d h=\xi^{*}\left[\frac{1}{n} \int_{0}^{n}\left(\frac{P_{t}^{*}(h)}{P_{t}^{H *}}\right)^{-\theta} d h\right]\left(\frac{P_{t}^{H *}}{P_{t}^{*}}\right)^{-\sigma}(1-n) C_{t}^{*}
$$

In a two-country model it must be the case that aggregate imports (exports) of the domestic country correspond to aggregate exports (imports) of the foreign country. In other words, $I M_{t}=E X_{t}^{*}$ and $E X_{t}=$ $I M_{t}^{*}$. There is no need to emphasize that point further. Naturally, the real net exports per capita in the domestic country, $N X_{t}$, can be computed as,

$$
\begin{aligned}
n N X_{t} & \equiv E X_{t}-I M_{t} \\
& =\xi^{*}\left[\frac{1}{n} \int_{0}^{n}\left(\frac{P_{t}^{*}(h)}{P_{t}^{H *}}\right)^{-\theta} d h\right]\left(\frac{P_{t}^{H *}}{P_{t}^{*}}\right)^{-\sigma}(1-n) C_{t}^{*}-(1-\xi)\left[\frac{1}{1-n} \int_{n}^{1}\left(\frac{P_{t}(f)}{P_{t}^{F}}\right)^{-\theta} d f\right]\left(\frac{P_{t}^{F}}{P_{t}}\right)^{-\sigma}(3.5 n \boldsymbol{B} \vec{t})
\end{aligned}
$$

The domestic aggregate real net exports, $n N X_{t}$, is equal to the aggregate real net exports of the foreign country with the opposite sign. Using equation (3.3.32) for aggregate output, it follows that the real net exports can be re-expressed as,

$$
\begin{aligned}
n N X_{t} & \equiv n Y_{t}-\xi\left[\frac{1}{n} \int_{0}^{n}\left(\frac{P_{t}(h)}{P_{t}^{H}}\right)^{-\theta} d h\right]\left(\frac{P_{t}^{H}}{P_{t}}\right)^{-\sigma} n C_{t}-(1-\xi)\left[\frac{1}{1-n} \int_{n}^{1}\left(\frac{P_{t}(f)}{P_{t}^{F}}\right)^{-\theta} d f\right]\left(\frac{P_{t}^{F}}{P_{t}}\right)^{-\sigma} n C_{t} \\
& =n Y_{t}-\left[\xi\left(\frac{1}{n} \int_{0}^{n}\left(\frac{P_{t}(h)}{P_{t}^{H}}\right)^{-\theta} d h\right)\left(\frac{P_{t}^{H}}{P_{t}}\right)^{-\sigma}+(1-\xi)\left(\frac{1}{1-n} \int_{n}^{1}\left(\frac{P_{t}(f)}{P_{t}^{F}}\right)^{-\theta} d f\right)\left(\frac{P_{t}^{F}}{P_{t}}\right)^{-\sigma}(3] .5 n B(t)\right.
\end{aligned}
$$

in terms of domestic aggregate output and consumption, as well as relative prices.

The nominal trade balance in (3.5.23) for the home country is, by comparison,

$$
\begin{aligned}
n T B_{t} & =P_{t}\left[\xi\left(\frac{P_{t}^{H}}{P_{t}}\right)^{1-\sigma} n C_{t}+\xi^{*}\left(\frac{P_{t}^{H *}}{P_{t}^{*}}\right)^{1-\sigma}(1-n) R S_{t} C_{t}^{*}-n C_{t}\right] \\
& =S_{t} P_{t}^{H *}\left[\xi^{*}\left(\frac{P_{t}^{H *}}{P_{t}^{*}}\right)^{-\sigma}(1-n) C_{t}^{*}\right]-P_{t}\left(1-\xi\left(\frac{P_{t}^{H}}{P_{t}}\right)^{1-\sigma}\right) n C_{t} \\
& =S_{t} P_{t}^{H *}\left[\xi^{*}\left(\frac{P_{t}^{H *}}{P_{t}^{*}}\right)^{-\sigma}(1-n) C_{t}^{*}\right]-P_{t}^{F}\left[(1-\xi)\left(\frac{P_{t}^{F}}{P_{t}}\right)^{-\sigma} n C_{t}\right],
\end{aligned}
$$

and comes also expressed in per capita terms. The third equality follows from manipulating the domestic CPI formula in (3.2.14). As noted before, the aggregate nominal trade balance in the domestic country, $n T B_{t}$, is equal to the aggregate nominal trade balance of the foreign country with the opposite sign. The 
nominal trade balance can be combined with (3.5.15) to obtain that,

$$
n T B_{t}=n P P I_{t} Y_{t}-n P_{t} C_{t}
$$

Usually, the definition of the real trade balance in units of the consumption good that we compute is $\frac{T B_{t}}{P_{t}}$, instead of the real net exports, $N X_{t}$.

\subsection{The Six Puzzles: Revisited}

By now, it should be evident that the workhorse model either avoids or exogenously imposes certain features designed to side-step the modelling hurdles of a fully integrated theory of the six puzzles. The model is naturally positioned to become the benchmark for the international correlations puzzle, the PPP puzzle and to some extent the exchange rate disconnect puzzle.

The assumption of home bias in preferences proposed by Warnock (2003) allows me to exogenously replicate the real trade patterns noted in the home bias in trade puzzle. It certainly allows me to regulate the amount of imports and exports in steady state to account for the observation that cross-border trade seems to be more limited than we would anticipate. I have already pointed out that these preference specification introduces compositional effects that can explain fluctuations of the real exchange rate even if the LOOP condition holds. Some compositional effects may be relevant to explain movements in real exchange rates and a pervasive bias in trade. However, this is unlikely to be the whole story on both accounts.

The workhorse model also assumes that there are neither capital investment goods nor durable goods. Moreover, the production function is linear in labor. This makes the model ill-equipped to convincingly account for the savings-investment (or Feldstein-Horioka) puzzle. It also limits the ability of the model to replicate certain features on net exports and exchange rates (e.g., Martínez-García and Sondergaard, 2008) and exports and imports (e.g., Engel and Wang, 2007). Moreover, it eliminates certain margins of great interest like investing in capital to move production intertemporally.

Finally, the assumption that portfolios of the local firms are solely owned by the local households imposes exogenously a strict home bias that is consistent with the home bias in equity portfolios puzzle. The model still allows for either contingent or uncontingent bonds to be traded internationally. Hence, it can say something about the degree of home bias in bonds instead (under incomplete asset markets). Nonetheless, the model cannot account endogenously for and explain the overwhelming evidence of 'insufficient' portfolio diversification.

The question that we should always keep in mind is to what extent these simplifications and exogenous restrictions are also distorting our understanding of the three puzzles around which much of the current international business cycle literature has developed. It is not obvious to me that these simplifications are just 'innocuous'.

\section{The Frictionless Allocation}

Here, I re-write the basic building blocks of the model by assuming that the economy is fully flexible, frictionless and competitive. The result characterizes the frictionless allocation and, more concretely, identifies

the potential output of each country, i.e. $\bar{Y}_{t}$ and $\bar{Y}_{t}^{*}$. Potential output is necessary to define the output gap 
measure that enters into the monetary policy rules in (3.4.12) - (3.4.13). In order to notationally distinguish this frictionless equilibrium I denote the variables with an upper bar. Productivity shocks are unaffected by the presence of frictions in the model or lack thereof, hence they do not require a different notation.

Using the equilibrium conditions in the labor market as discussed in (3.3.30) - (3.3.31), I express the marginal cost in both countries in the following compact form under flexible prices,

$$
\begin{aligned}
& \frac{\theta-1}{\theta}=\frac{\overline{M C}_{t}}{\bar{P}_{t}^{H}}=\left(1+\bar{\phi}_{t}\right)\left(\frac{\bar{W}_{t}}{\bar{P}_{t}^{H} A_{t}}\right)=\left(1+\bar{\phi}_{t}\right)\left(\kappa\left(A_{t}\right)^{-\varphi-1}\left(\bar{C}_{t}\right)^{\gamma}\left(\bar{Y}_{t}\right)^{\varphi}\left(\frac{\bar{P}_{t}}{\bar{P}_{t}^{H}}\right)\right) \\
& \frac{\theta-1}{\theta}=\frac{\overline{M C}_{t}^{*}}{\bar{P}_{t}^{F *}}=\left(1+\bar{\phi}_{t}^{*}\right)\left(\frac{\bar{W}_{t}^{*}}{\bar{P}_{t}^{F *} A_{t}^{*}}\right)=\left(1+\bar{\phi}_{t}^{*}\right)\left(\kappa\left(A_{t}^{*}\right)^{-\varphi-1}\left(\bar{C}_{t}^{*}\right)^{\gamma}\left(\bar{Y}_{t}^{*}\right)^{\varphi}\left(\frac{\bar{P}_{t}^{*}}{\bar{P}_{t}^{F *}}\right)\right) .
\end{aligned}
$$

Fiscal policy is optimally implemented and completely eliminates the distortion caused by the mark-up as in (3.4.5), i.e. $\bar{\phi}_{t}=\bar{\phi}_{t}^{*}=\frac{-1}{\theta}$. Alternatively, I could have assumed that prices are competitive and equal to marginal costs. Therefore, each individual firm charges a price equal to marginal costs and, by symmetry, the same is true in the aggregate. The labor market equilibrium conditions can be naturally reduced to,

$$
\begin{aligned}
\kappa\left(A_{t}\right)^{-\varphi-1}\left(\bar{C}_{t}\right)^{\gamma}\left(\bar{Y}_{t}\right)^{\varphi}\left(\frac{\bar{P}_{t}}{\bar{P}_{t}^{H}}\right) & =1, \\
\kappa\left(A_{t}^{*}\right)^{-\varphi-1}\left(\bar{C}_{t}^{*}\right)^{\gamma}\left(\bar{Y}_{t}^{*}\right)^{\varphi}\left(\frac{\bar{P}_{t}^{*}}{\bar{P}_{t}^{F *}}\right) & =1 .
\end{aligned}
$$

These pair of equations, however, depends on consumption, output and prices (all of which are endogenously determined).

By assuming that fiscal policy in this fashion, I eliminate the mark-up which is the distortion introduced by monopolistic competition. The economy behaves as if it was populated by perfectly competitive firms. I also assume complete asset markets to avoid the distortions due to incompleteness. As a result, the perfect international risk-sharing condition under complete asset markets described in equation (3.2.29) tells me that,

$$
v \bar{C}_{t}=\left(\overline{R S}_{t}\right)^{\frac{1}{\gamma}} \bar{C}_{t}^{*}
$$

where $v=1$ after normalization of the steady state. Moreover, I assume that prices are fully flexible, which immediately implies that the LOOP holds (independently of whether firms price-to-market or not). Eliminating this friction, however, does not mean the real exchange rate should be constant because I still maintain the assumption that households have home bias on consumption. The real exchange rate can be related to terms of trade as in equation (3.1.2),

$$
\overline{R S}_{t}=\frac{\left[\xi^{*}+\left(1-\xi^{*}\right)\left(\overline{T o T}_{t}\right)^{1-\sigma}\right]^{\frac{1}{1-\sigma}}}{\left[\xi+(1-\xi)\left(\overline{T o T}_{t}\right)^{1-\sigma}\right]^{\frac{1}{1-\sigma}}} .
$$

The model under these conditions is, therefore, equivalent to one where prices are fully flexible, firms are perfectly competitive, and asset markets are complete.

If I take the ratio of aggregate output in both countries as given by equations (3.3.36) - (3.3.37), it follows 
that,

$$
\begin{aligned}
\frac{n \bar{Y}_{t}}{(1-n) \bar{Y}_{t}^{*}} & =\frac{\left(\frac{\bar{P}_{t}^{H}}{\bar{P}_{t}}\right)^{-\sigma}\left[n\left(\frac{\xi}{n} \bar{C}_{t}\right)+(1-n)\left(\frac{\xi^{*}}{n}\left(\frac{1}{\overline{R S}_{t}}\right)^{-\sigma} \bar{C}_{t}^{*}\right)\right]}{\left(\frac{\bar{P}_{t}^{F *}}{\bar{P}_{t}^{*}}\right)^{-\sigma}\left[n\left(\frac{1-\xi}{1-n}\left(\overline{R S}_{t}\right)^{-\sigma} \bar{C}_{t}\right)+(1-n)\left(\frac{1-\xi^{*}}{1-n} \bar{C}_{t}^{*}\right)\right]} \\
& =\left(\frac{\bar{P}_{t}^{H} \bar{P}_{t}^{*}}{\bar{P}_{t}^{F *}} \bar{P}_{t}\right)^{-\sigma}\left[\frac{n\left(\frac{\xi}{n} \frac{1}{v}\left(\overline{R S}_{t}\right)^{\frac{1}{\gamma}}\right)+(1-n)\left(\frac{\xi^{*}}{n}\left(\overline{R S}_{t}\right)^{\sigma}\right)}{n\left(\frac{1-\xi}{1-n} \frac{1}{v}\left(\overline{R S}_{t}\right)^{-\sigma+\frac{1}{\gamma}}\right)+(1-n)\left(\frac{1-\xi^{*}}{1-n}\right)}\right] \\
& =\left(\frac{\overline{R S}_{t}}{\overline{T o T}_{t}}\right)^{-\sigma}\left[\frac{n\left(\frac{\xi}{n} \frac{1}{v}\left(\overline{R S}_{t}\right)^{\frac{1}{\gamma}}\right)+(1-n)\left(\frac{\xi^{*}}{n}\left(\overline{R S}_{t}\right)^{\sigma}\right)}{\left.n\left(\frac{1-\xi}{1-n} \frac{1}{v}\left(\overline{R S}_{t}\right)^{-\sigma+\frac{1}{\gamma}}\right)+(1-n)\left(\frac{1-\xi^{*}}{1-n}\right)\right]}\right]
\end{aligned}
$$

where the second equality comes from the perfect international risk-sharing condition in (3.2.29). Equations (4.6) - (4.7) for the real exchange rate and the terms of trade can be naturally interpreted as two non-linear functions of the ratio of aggregate output between the two countries. Generically, I can say that,

$$
\begin{aligned}
\overline{R S}_{t} & =R\left(\frac{n \bar{Y}_{t}}{(1-n) \bar{Y}_{t}^{*}}\right) \\
\overline{T o T}_{t} & =T\left(\frac{n \bar{Y}_{t}}{(1-n) \bar{Y}_{t}^{*}}\right) .
\end{aligned}
$$

In other words, both the real exchange rate and the terms of trade are functions of the output ratio. Based on the structure of the consumption price indexes in (3.2.14) - (3.2.15), I can argue that the following price ratios,

$$
\begin{aligned}
& \frac{\bar{P}_{t}^{H}}{\bar{P}_{t}}=\left[\frac{1}{\xi+(1-\xi)\left(\frac{\bar{P}_{t}^{F}}{\bar{P}_{t}^{H}}\right)^{1-\sigma}}\right]^{\frac{1}{1-\sigma}}=\left[\frac{1}{\xi+(1-\xi)\left(\overline{T O T}_{t}\right)^{1-\sigma}}\right]^{\frac{1}{1-\sigma}}=X\left(\frac{n \bar{Y}_{t}}{(1-n) \bar{Y}_{t}^{*}}\right) \\
& \frac{\bar{P}_{t}^{F *}}{\bar{P}_{t}^{*}}=\left[\frac{1}{\xi^{*}\left(\frac{\bar{P}_{t}^{H *}}{\bar{P}_{t}^{F *}}\right)^{1-\sigma}+\left(1-\xi^{*}\right)}\right]^{\frac{1}{1-\sigma}}=\left[\frac{1}{\xi^{*}\left(\frac{1}{\overline{T o T}_{t}}\right)^{1-\sigma}+\left(1-\xi^{*}\right)}\right]^{\frac{1}{1-\sigma}}=X^{*}\left(\frac{n \bar{Y}_{t}}{(1-n) \bar{Y}_{t}^{*}}\right)(4.11)
\end{aligned}
$$

are a function of terms of trade and therefore also connected to the aggregate output ratio.

Using this information about the structure of the economy and the aggregate output equations in (3.3.36) - (3.3.37), I can re-write the aggregate consumption in terms of aggregate output (appropriately 
using the perfect risk-sharing condition in (3.2.29)),

$$
\begin{aligned}
n \bar{Y}_{t} & =\left(X\left(\frac{n \bar{Y}_{t}}{(1-n) \bar{Y}_{t}^{*}}\right)\right)^{-\sigma}\left[n\left(\frac{\xi}{n}\right)+(1-n)\left(\frac{\xi^{*}}{n} v\left(R\left(\frac{n \bar{Y}_{t}}{(1-n) \bar{Y}_{t}^{*}}\right)\right)^{\sigma-\frac{1}{\gamma}}\right)\right] \bar{C}_{t}, \\
(1-n) \bar{Y}_{t}^{*} & =\left(X^{*}\left(\frac{n \bar{Y}_{t}}{(1-n) \bar{Y}_{t}^{*}}\right)\right)^{-\sigma}\left[n\left(\frac{1-\xi}{1-n} \frac{1}{v}\left(R\left(\frac{n \bar{Y}_{t}}{(1-n) \bar{Y}_{t}^{*}}\right)\right)^{-\sigma+\frac{1}{\gamma}}\right)+(1-n)\left(\frac{1-\xi^{*}}{1-n}\right)\left(4 . \overline{\mathbb{C}}_{3}^{*}\right)\right.
\end{aligned}
$$

These equations clearly imply that the aggregate consumption in equilibrium follows from,

$$
\begin{aligned}
& \bar{C}_{t}=C\left(\bar{Y}_{t}, \bar{Y}_{t}^{*}\right), \\
& \bar{C}_{t}^{*}=C^{*}\left(\bar{Y}_{t}, \bar{Y}_{t}^{*}\right),
\end{aligned}
$$

which are functional forms that depend exclusively on the output in both countries. The model shows that aggregate consumption is a function of output in both countries. This relationship can be derived easily from the goods market clearing conditions. Finally, if I replace the equations for optimal aggregate consumption (i.e., $C\left(\bar{Y}_{t}, \bar{Y}_{t}^{*}\right)$ and $\left.C^{*}\left(\bar{Y}_{t}, \bar{Y}_{t}^{*}\right)\right)$ and the equations for the price ratios (i.e., $X\left(\frac{n \bar{Y}_{t}}{(1-n) \bar{Y}_{t}^{*}}\right)$ and $\left.X^{*}\left(\frac{n \bar{Y}_{t}}{(1-n) \bar{Y}_{t}^{*}}\right)\right)$ inside the equilibrium labor market clearing conditions in $(4.3)-(4.4)$, I immediately derive a pair of equilibrium conditions that link output in both countries to productivity shocks,

$$
\begin{aligned}
\kappa\left(A_{t}\right)^{-\varphi-1}\left(C\left(\bar{Y}_{t}, \bar{Y}_{t}^{*}\right)\right)^{\gamma}\left(\bar{Y}_{t}\right)^{\varphi} & =X\left(\frac{n \bar{Y}_{t}}{(1-n) \bar{Y}_{t}^{*}}\right), \\
\kappa\left(A_{t}^{*}\right)^{-\varphi-1}\left(C^{*}\left(\bar{Y}_{t}, \bar{Y}_{t}^{*}\right)\right)^{\gamma}\left(\bar{Y}_{t}^{*}\right)^{\varphi} & =X^{*}\left(\frac{n \bar{Y}_{t}}{(1-n) \bar{Y}_{t}^{*}}\right) .
\end{aligned}
$$

This is a system of two equations in two unknowns that can be resolved.

Finding a solution for the system in (4.16) - (4.17) implies, in general, that output in each country is a function of productivity shocks in both countries. To be more precise, the equilibrium level of employment varies (non-linearly) with the productivity shocks in both countries and, as a result, local output also responds to the foreign productivity shocks. The formulas take a highly non-linear form, which I do not derive explicitly, but nevertheless convey two important ideas. First, that monetary policy is neutral under flexible prices, perfect competition and complete asset markets. So, money affects the nominal variables (wages and prices), but it has no real-side effects (on employment and output). Second, openness has a direct effect on the real-side of the economy because, unlike in the case of autarky, it implies that equilibrium aggregate employment responds to foreign shocks.

I define the functional forms for output and employment generically as,

$$
\begin{aligned}
& \bar{Y}_{t}=A_{t} \bar{L}_{t}, \bar{L}_{t}=\bar{L}\left(A_{t}, A_{t}^{*}\right), \\
& \bar{Y}_{t}^{*}=A_{t}^{*} \bar{L}_{t}^{*}, \bar{L}_{t}^{*}=\bar{L}^{*}\left(A_{t}, A_{t}^{*}\right),
\end{aligned}
$$

and I assume that these expressions represent and reflect the true 'potential' of the economy (in terms of output and employment). If monetary policy targets deviations of output from its potential, as posited by 
the Taylor rule, it can no longer ignore the foreign productivity shocks (except in special cases as in Corsetti and Pesenti, 2001). Therefore, it becomes ever more clear that monetary policy cannot be conducted looking at domestic sources or domestic shocks in isolation.

A Special Case: Corsetti and Pesenti (2001). As in Corsetti and Pesenti (2001), let me assume that the preferences are logarithmic in aggregate consumption (i.e., $\gamma=1$ ) and that the elasticity of substitution across bundles of goods is equal to one (i.e., $\sigma=1$ ), then I argue that the real exchange rate and terms of trade can be expressed as,

$$
\begin{aligned}
\overline{R S}_{t} & =R\left(\frac{n \bar{Y}_{t}}{(1-n) \bar{Y}_{t}^{*}}\right)=\left(\overline{T o T}_{t}\right)^{\xi-\xi^{*}} \\
\overline{T o T}_{t} & =T\left(\frac{n \bar{Y}_{t}}{(1-n) \bar{Y}_{t}^{*}}\right)=\left[\frac{n\left(\frac{1-\xi}{1-n} \frac{1}{v}\right)+(1-n)\left(\frac{1-\xi^{*}}{1-n}\right)}{n\left(\frac{\xi}{n} \frac{1}{v}\right)+(1-n)\left(\frac{\xi^{*}}{n}\right)}\right]\left(\frac{n \bar{Y}_{t}}{(1-n) \bar{Y}_{t}^{*}}\right) .
\end{aligned}
$$

In other words, both the real exchange rate and the terms of trade are very simple functions of the output ratio properly adjusted to take into account the home bias in consumption. If the elasticity of substitution across bundles of goods is equal to one (i.e., $\sigma=1)$, then the consumption price indexes in (3.2.14) - (3.2.15) become,

$$
\begin{aligned}
\frac{\bar{P}_{t}^{H}}{\bar{P}_{t}} & =X\left(\frac{n \bar{Y}_{t}}{(1-n) \bar{Y}_{t}^{*}}\right)=\left(\frac{1}{\overline{T o T}_{t}}\right)^{1-\xi}, \\
\frac{\bar{P}_{t}^{F *}}{\bar{P}_{t}^{*}} & =X^{*}\left(\frac{n \bar{Y}_{t}}{(1-n) \bar{Y}_{t}^{*}}\right)=\left(\overline{T o T}_{t}\right)^{\xi^{*}} .
\end{aligned}
$$

Using this information about the structure of the economy and the aggregate output equations in (3.3.36) (3.3.37), I can naturally re-write the aggregate consumption in terms of aggregate output (appropriately using the perfect risk-sharing condition in (3.2.29)) as,

$$
\begin{aligned}
& \bar{C}_{t}=C\left(\bar{Y}_{t}, \bar{Y}_{t}^{*}\right)=\frac{\left(n \bar{Y}_{t}\right)^{\xi}\left((1-n) \bar{Y}_{t}^{*}\right)^{1-\xi}}{v\left(n\left(\frac{\xi}{n} \frac{1}{v}\right)+(1-n)\left(\frac{\xi^{*}}{n}\right)\right)^{\xi}\left(n\left(\frac{1-\xi}{1-n} \frac{1}{v}\right)+(1-n)\left(\frac{1-\xi^{*}}{1-n}\right)\right)^{1-\xi}}, \\
& \bar{C}_{t}^{*}=C^{*}\left(\bar{Y}_{t}, \bar{Y}_{t}^{*}\right)=\frac{\left(n \bar{Y}_{t}\right)^{\xi^{*}}\left((1-n) \bar{Y}_{t}^{*}\right)^{1-\xi^{*}}}{\left(n\left(\frac{\xi}{n} \frac{1}{v}\right)+(1-n)\left(\frac{\xi^{*}}{n}\right)\right)^{\xi^{*}}\left(n\left(\frac{1-\xi}{1-n} \frac{1}{v}\right)+(1-n)\left(\frac{1-\xi^{*}}{1-n}\right)\right)^{1-\xi^{*}}} .
\end{aligned}
$$

In this particular example, the aggregate consumption is proportional to the aggregate world output computed using the consumption aggregator. This reflects the fact that each household consumes a constant fraction of the total output produced locally and a different (but still constant) fraction of the output produced abroad. However, this is only a special case. In general, the model shows that aggregate consumption ought to be a more complex function of output in both countries.

Finally, if I replace the equations for optimal aggregate consumption (i.e., $C\left(\bar{Y}_{t}, \bar{Y}_{t}^{*}\right)$ and $C^{*}\left(\bar{Y}_{t}, \bar{Y}_{t}^{*}\right)$ ) and the equations for the price ratios (i.e., $X\left(\frac{n \bar{Y}_{t}}{(1-n) \bar{Y}_{t}^{*}}\right)$ and $\left.X^{*}\left(\frac{n \bar{Y}_{t}}{(1-n) \bar{Y}_{t}^{*}}\right)\right)$ inside the equilibrium labor 
market clearing conditions in (4.3) - (4.4), I immediately derive an explicit pair of equilibrium conditions that link output in both countries to productivity shocks,

$$
\begin{aligned}
n \bar{Y}_{t} & =\left[\frac{v}{\kappa} n^{\varphi}\left(n\left(\frac{\xi}{n} \frac{1}{v}\right)+(1-n)\left(\frac{\xi^{*}}{n}\right)\right)\right]^{\frac{1}{1+\varphi}} A_{t}, \\
(1-n) \bar{Y}_{t}^{*} & =\left[\frac{1}{\kappa}(1-n)^{\varphi}\left(n\left(\frac{1-\xi}{1-n} \frac{1}{v}\right)+(1-n)\left(\frac{1-\xi^{*}}{1-n}\right)\right)\right]^{\frac{1}{1+\varphi}} A_{t}^{*} .
\end{aligned}
$$

This is a very special case in which aggregate output only depends on the local productivity shock. Another way of interpreting the result is by saying that labor in the economy is constant, i.e.

$$
\begin{aligned}
n \bar{L}_{t} & =\left[\frac{v}{\kappa} n^{\varphi}\left(n\left(\frac{\xi}{n} \frac{1}{v}\right)+(1-n)\left(\frac{\xi^{*}}{n}\right)\right)\right]^{\frac{1}{1+\varphi}} \\
(1-n) \bar{L}_{t}^{*} & =\left[\frac{1}{\kappa}(1-n)^{\varphi}\left(n\left(\frac{1-\xi}{1-n} \frac{1}{v}\right)+(1-n)\left(\frac{1-\xi^{*}}{1-n}\right)\right)\right]^{\frac{1}{1+\varphi}} .
\end{aligned}
$$

Openness has only a limited impact. It only varies the size of the constant labor employment and the aggregate output level because output must be produced now to satisfy the foreign demand. In this context, potential output depends only on domestic shocks and, therefore, monetary policy can be conducted as usual: by targeting a measure of potential output that is purely domestic, and depends on domestic shocks only.

The Nominal Exchange Rate in the Frictionless Economy. Money is neutral in a frictionless economy. CPI inflation is induced by the monetary authority's willingness to interfere with the nominal interest rate. Although, monetary policy can act as a conduit that allows real-shocks (and probably other shocks too) to have an impact on the price level and inflation, it is still true that the domestic inflation is determined and can be regulated by the domestic monetary policy. Openness to trade on goods and assets has no effect whatsoever on the ability of the domestic monetary authority to control domestic inflation.

The real exchange rate described in (4.6) is known to be a function of the productivity shocks. Using the definition of the real exchange rate it is possible to write the nominal exchange rate as the product of this function and the ratio of the CPIs in both countries ${ }^{22}$, i.e.

$$
\bar{S}_{t}=R\left(\frac{n \bar{Y}\left(A_{t}, A_{t}^{*}\right)}{(1-n) \bar{Y}^{*}\left(A_{t}, A_{t}^{*}\right)}\right) \frac{\bar{P}_{t}}{\bar{P}_{t}^{*}} .
$$

Even in an elementary model like this one, monetary policy is not the only source of fundamental shocks driving the nominal exchange rate. As a matter of fact, it is arguably possible to write a model where the monetary policy is such that CPIs are very stable in both countries. The outcome of that model would be that very little of the fluctuations of the nominal exchange rate has to do with monetary shocks in either country. Hence, the nominal exchange rate mostly reflects the impact of productivity shocks. This could be related to the exchange rate disconnect puzzle since it gives little role to monetary policy shocks in the

\footnotetext{
${ }^{22}$ This nominal exchange rate should be consistent with the intertemporal first-order condition of the household's problem in either (3.2.27) or (3.2.32).
} 
nominal exchange rate, but it certainly does not help us explain the high volatility observed in the data. The crucial lesson here, anyway, is that real shocks can affect the nominal exchange rate because PPP fails. However, the sensitivity of the nominal exchange rate to real shocks depends on what determines the failure of PPP. In other words, the effects due to non-traded goods or LOOP violations may be very different.

\section{The Irrelevance of Asset Markets}

The irrelevance of asset markets is a result often cited, but one that needs further exploration. Cole and Obstfeld (1991) are credited with having pointed out this result, which has been subsequently studied by Corsetti and Pesenti (2001, 2005a, 2005b, 2006). It states that under certain assumptions, the structure of the asset markets has no impact on the allocation of the economy. I have demonstrated already that if prices are flexible and firms are competitive, then monetary policy is neutral. Now, I shall demonstrate that in certain cases asset markets are irrelevant. Therefore, financial openness may have no impact on the allocation and, therefore, should not enter as a consideration in monetary policy decisions.

I assume that the preferences are logarithmic (and additively separable) in consumption, i.e. $\gamma=1$, and the elasticity of substitution between the domestic and foreign bundle of goods is equal to one, i.e. $\sigma=1$. I know from the demand functions in equations (3.2.23) - (3.2.24) that,

$$
\begin{aligned}
P_{t}^{H} C_{t}^{H} & =\xi P_{t} C_{t}, P_{t}^{H *} C_{t}^{H *}=\xi^{*} P_{t}^{*} C_{t}^{*}, \\
P_{t}^{F} C_{t}^{F} & =(1-\xi) P_{t} C_{t}, P_{t}^{F *} C_{t}^{F *}=\left(1-\xi^{*}\right) P_{t}^{*} C_{t}^{*},
\end{aligned}
$$

which naturally implies that the nominal value of the demand for households in both countries has to satisfy that,

$$
\begin{aligned}
n P_{t}^{H} C_{t}^{H}+n P_{t}^{F} C_{t}^{F} & =n P_{t} C_{t}, \\
(1-n) P_{t}^{H *} C_{t}^{H *}+(1-n) P_{t}^{F *} C_{t}^{F *} & =(1-n) P_{t}^{*} C_{t}^{*},
\end{aligned}
$$

while the aggregate income described in equations (3.5.9) - (3.5.10) is equal to,

$$
\begin{aligned}
n P P I_{t}^{H} Y_{t} & =n \xi P_{t} C_{t}+(1-n) \xi^{*} S_{t} P_{t}^{*} C_{t}^{*}, \\
(1-n) P P I_{t}^{F *} Y_{t}^{*} & =n(1-\xi) \frac{1}{S_{t}} P_{t} C_{t}+(1-n)\left(1-\xi^{*}\right) P_{t}^{*} C_{t}^{*}
\end{aligned}
$$

Hence, the aggregate nominal trade balance expressed in the same currency should be equal to,

$$
\begin{aligned}
n T B_{t} & =n P P I_{t}^{H} Y_{t}-n P_{t} C_{t}, \\
-\frac{(1-n) T B_{t}^{*}}{S_{t}} & =(1-n) P P I_{t}^{F *} Y_{t}^{*}-(1-n) P_{t}^{*} C_{t}^{*},
\end{aligned}
$$

where $T B_{t}$ and $T B_{t}^{*}$ are nominal quantities in per capita terms. Equation (3.5.29) clearly establishes a relationship between the nominal trade balance in both countries which is given by,

$$
\left(n P P I_{t} Y_{t}-n P_{t} C_{t}\right)+S_{t}\left((1-n) P P I_{t}^{*} Y_{t}^{*}-(1-n) P_{t}^{*} C_{t}^{*}\right)=0
$$


or simply by,

$$
n T B_{t}=(1-n) T B_{t}^{*}
$$

I can use the nominal trade balance as expressed in equations (5.7) - (5.8) and the aggregate income value derived in equations $(5.5)-(5.6)$ to write that,

$$
\begin{aligned}
n P_{t} C_{t}+n T B_{t} & =n P P I_{t}^{H} Y_{t}=n \xi P_{t} C_{t}+(1-n) \xi^{*} S_{t} P_{t}^{*} C_{t}^{*} \\
(1-n) P_{t}^{*} C_{t}^{*}-\frac{n T B_{t}}{S_{t}} & =(1-n) P P I_{t}^{F *} Y_{t}^{*}=n(1-\xi) \frac{1}{S_{t}} P_{t} C_{t}+(1-n)\left(1-\xi^{*}\right) P_{t}^{*} C_{t}^{*}
\end{aligned}
$$

Taking the ratio of both equations,

$$
\frac{n P_{t} C_{t}+n T B_{t}}{(1-n) S_{t} P_{t}^{*} C_{t}^{*}-n T B_{t}}=\frac{n \xi P_{t} C_{t}+(1-n) \xi^{*} S_{t} P_{t}^{*} C_{t}^{*}}{n(1-\xi) P_{t} C_{t}+(1-n)\left(1-\xi^{*}\right) S_{t} P_{t}^{*} C_{t}^{*}}
$$

and re-arranging terms appropriately, I derive the following expression,

$$
\begin{aligned}
& n T B_{t}=\left(\frac{n \xi P_{t} C_{t}+(1-n) \xi^{*} S_{t} P_{t}^{*} C_{t}^{*}}{n P_{t} C_{t}+(1-n) S_{t} P_{t}^{*} C_{t}^{*}}\right)(1-n) S_{t} P_{t}^{*} C_{t}^{*}- \\
& -\left(\frac{n(1-\xi) P_{t} C_{t}+(1-n)\left(1-\xi^{*}\right) S_{t} P_{t}^{*} C_{t}^{*}}{n P_{t} C_{t}+(1-n) S_{t} P_{t}^{*} C_{t}^{*}}\right) n P_{t} C_{t} .
\end{aligned}
$$

Let me assume the polar case where the asset markets are complete. Under complete asset markets, the perfect international risk-sharing condition given by (3.2.29) holds, so I can write the domestic nominal trade balance in the following terms,

$$
n T B_{t}=\left[\left(\frac{n \xi+(1-n) \xi^{*} v}{n+(1-n) v}\right)(1-n) v-\left(\frac{n(1-\xi)+(1-n)\left(1-\xi^{*}\right) v}{n+(1-n) v}\right) n\right] P_{t} C_{t}
$$

where $v=1$ after normalization of the steady state. Further algebra allows me to compute the following formula for the nominal trade balance,

$$
n T B_{t}=\left[(1-n) \xi^{*}-n(1-\xi)\right] P_{t} C_{t} .
$$

The way the model is written, it follows that the nominal trade balance is equal to zero if and only if,

$$
(1-n) \xi^{*}=n(1-\xi) \Longleftrightarrow \xi=1-\left(\frac{1-n}{n}\right) \xi^{*}
$$

This condition is at the center of the irrelevance result.

Let me assume the polar opposite case where the asset markets are fully separated and no cross-country asset trading is permitted. This case is also discussed in Woodford (2007). I do not take a stand on the number of assets available within each local market, so there may be less than a full set of Arrow-Debreu securities. If asset trading does not occur in the international markets, then the nominal trade balance must be equal to zero in every period. International borrowing and lending is simply impossible. Based on 
equation (5.14), I can argue that,

$$
\begin{aligned}
& \left(\frac{n \xi P_{t} C_{t}+(1-n) \xi^{*} S_{t} P_{t}^{*} C_{t}^{*}}{n P_{t} C_{t}+(1-n) S_{t} P_{t}^{*} C_{t}^{*}}\right)(1-n) S_{t} P_{t}^{*} C_{t}^{*}- \\
& \quad-\left(\frac{n(1-\xi) P_{t} C_{t}+(1-n)\left(1-\xi^{*}\right) S_{t} P_{t}^{*} C_{t}^{*}}{n P_{t} C_{t}+(1-n) S_{t} P_{t}^{*} C_{t}^{*}}\right) n P_{t} C_{t}=0
\end{aligned}
$$

and naturally it follows that,

$$
\left(n \xi C_{t}+(1-n) \xi^{*} R S_{t} C_{t}^{*}\right) R S_{t}(1-n) C_{t}^{*}=\left(n(1-\xi) C_{t}+(1-n)\left(1-\xi^{*}\right) R S_{t} C_{t}^{*}\right) n C_{t} .
$$

Simple algebra tells me that the real exchange rate can be pin down as a second-order equation,

$$
\xi^{*}\left((1-n) C_{t}^{*}\right)^{2}\left(R S_{t}\right)^{2}+\left[\xi-\left(1-\xi^{*}\right)\right]\left((1-n) C_{t}^{*}\right)\left(n C_{t}\right) R S_{t}-(1-\xi)\left(n C_{t}\right)^{2}=0 .
$$

I observe that the solution to the second-order equation on the real exchange rate takes the following form,

$$
R S_{t}=\left[\frac{-\left[\xi-\left(1-\xi^{*}\right)\right]+\sqrt[2]{\left[\xi-\left(1-\xi^{*}\right)\right]^{2}+4 \xi^{*}(1-\xi)}}{2 \xi^{*}}\right] \frac{n C_{t}}{(1-n) C_{t}^{*}}
$$

where only the positive root gives a solution that is consistent with the real exchange rate being positive. I suppose that the preference parameters satisfy the condition in (5.17), then it follows that the real exchange rate is equal to,

$$
R S_{t}=\left[\frac{-\left(\frac{2 n-1}{n}\right)+\sqrt[2]{\left(\frac{2 n-1}{n}\right)^{2}-4\left(\frac{1-n}{n}\right)}}{2}\right] \frac{n C_{t}}{(1-n) C_{t}^{*}}=\frac{C_{t}}{C_{t}^{*}},
$$

which again coincides with the real exchange rate that would prevail if the asset markets were complete and both countries were able to perfectly share their risks.

The point of these calculations is that an optimal allocation can be attained with no trade at all in assets. Trading in the goods market suffices to attain the optimal allocation. In fact, the allocation attained should be the same independently of whether I allow for unrestricted asset trading internationally and have a complete set of Arrow-Debreu securities to do so or I impose that international trade is infeasible and the local asset markets have only a limited number of assets to trade on. The same logic applies to other intermediate cases where international asset trading is possible, but asset markets are not complete. It is always possible to attain the perfect risk-sharing allocation without having to resort to the asset markets at all. Therefore, the availability of more or less assets should not make a difference.

Let me review the implicit and explicit assumptions of these exercise. First, I have explicitly required logarithmic (and additively separable) preferences on consumption, i.e. $\gamma=1$. Second, I have required that the elasticity of substitution between the domestic and the foreign bundle of goods be equal to one in both countries (Cobb-Douglas aggregator), i.e. $\sigma=1$. Third, I have to impose that the combination of the population size in each country and the shares of local consumption satisfy that $(1-n) \xi^{*}=n(1-\xi)$. Forth, implicitly I have made the assumption that the initial condition on the net foreign asset position of each country be equal to zero. Obviously, if I assume that one country starts as a net debtor (and the other as a net creditor), the trade balance can not be zero from that point onwards because the debtor country needs to either trade goods with the other country to repay its debts or simply needs to borrow more. 
The irrelevance of the asset market structure is a very powerful an interesting result and it has been widely exploited to simplify the model in cases where asset trading or the nominal trade balance are deemed of secondary importance for the questions being asked. Of course, in this particular case, increased financial openness has no consequences whatsoever for the determination of the aggregate demand under any monetary policy rule. Woodford (2007, p. 8) argues that "the fact that complete irrelevance is possible (and does not even require an 'extreme' preference specification) indicates that the effects of financial globalization need not be large". This irrelevance result is a very special case, convenient as it may be, so I would caution from reading too much into Woodford's (2007) argument. This paper tries to shed some light on the very complex phenomenon of financial globalization. For the more advanced readers, I would suggest to start with the papers of Evans and Hnatkovska (2005, 2007).

As relevant as portfolio allocations can be in order to address certain specific questions, like what explains the fact that some countries have very large capital account surpluses (for example, Spain and the U.S.) while others do not, the issue is of secondary importance in this paper. What matters is how the set of available assets affects the risk-sharing opportunities of households and their consumption-savings margin. Beyond that, as I will discuss later, portfolio allocations are not needed to close the model. In this sense, portfolio allocations could be derived endogenously as a 'residual' after first having determined the optimal allocation of resources. Following in the spirit of Evans and Hnatkovska (2005, 2007) that only requires a second-order approximation of the asset pricing equations and either the optimal allocation of resources or a number of conditions that would characterize it appropriately.

\section{The Deterministic Steady State $^{23}$}

\subsection{The Zero-Inflation Steady State}

I require that all shocks be evaluated at their unconditional mean in steady state. The steady state productivity shocks are denoted, $A$ and $A^{*}$, while the monetary policy shocks are denoted, $Z$ and $Z^{*}$. I also conjecture the existence of a (symmetric) deterministic steady state in which prices, consumption and the nominal exchange rate are constant, i.e.

$$
\begin{aligned}
P_{t+1} & =P_{t}=\bar{P}, P_{t+1}^{*}=P_{t}^{*}=\bar{P}^{*}, \\
C_{t+1} & =C_{t}=\bar{C}, C_{t+1}^{*}=C_{t}^{*}=\bar{C}^{*}, \\
S_{t+1} & =S_{t}=\bar{S} .
\end{aligned}
$$

I often refer to this steady state as the zero-inflation steady state.

Given my steady state conjecture and the Euler equations in (3.2.31) and (3.2.32), it follows that the steady state nominal interest rate in both countries is identical and equal to the inverse of the rate of the subjective intertemporal discount factor,

$$
\beta=\frac{1}{1+\bar{i}}=\frac{1}{1+\bar{i}^{*}},
$$

\footnotetext{
${ }^{23}$ The initial conditions of the model at time $t=0$ should naturally correspond to the steady state values.
} 
which holds true for the case of incomplete asset markets. Under complete asset markets, I can also argue based on the intertemporal first-order conditions in (3.2.25) - (3.2.26), that the Arrow-Debreu security prices are,

$$
\begin{aligned}
\bar{Q}(\omega) & =\beta \bar{\mu}(\omega), \frac{1}{1+\bar{i}}=\int_{\omega \in \Omega} \bar{Q}(\omega)=\beta, \\
\bar{Q}^{*}(\omega) & =\beta \bar{\mu}(\omega), \frac{1}{1+\bar{i}^{*}}=\int_{\omega \in \Omega} \bar{Q}^{*}(\omega)=\beta,
\end{aligned}
$$

which is consistent with my findings on the steady state interest rate. The invariant distribution function is denoted $\bar{\mu}(\omega)$. The assumption that the nominal exchange rate is constant satisfies also the intertemporal first-order conditions in either (3.2.27) or (3.2.32).

From the firm's first-order conditions in (3.3.16) - (3.3.17) and (3.3.22) - (3.3.23), I obtain that the LOOP holds in steady state, i.e.

$$
\begin{aligned}
\overline{\widetilde{P}}(h) & =\bar{S} \overline{\widetilde{P}}^{*}(h)=\frac{\theta}{\theta-1}\left(\frac{(1+\bar{\phi}) \bar{W}}{A}\right), \\
\frac{1}{\bar{S}} \overline{\widetilde{P}}(f) & =\overline{\widetilde{P}}^{*}(f)=\frac{\theta}{\theta-1}\left(\frac{\left(1+\bar{\phi}^{*}\right) \bar{W}^{*}}{A^{*}}\right) .
\end{aligned}
$$

The fiscal policy rule in this model is time-invariant, as described in (3.4.5). Furthermore, it cancels out the effect of the mark-up charged by firms and results in a competitive Dixit-Stiglitz price-setting rule for all varieties in steady state, i.e.

$$
\begin{aligned}
\overline{\widetilde{P}}(h) & =\bar{S} \overline{\widetilde{P}}^{*}(h)=\left(\frac{\bar{W}}{A}\right), \\
\frac{1}{\bar{S}} \overline{\widetilde{P}}(f) & =\overline{\widetilde{P}}^{*}(f)=\left(\frac{\bar{W}^{*}}{A^{*}}\right),
\end{aligned}
$$

where the price equals the marginal cost. In other words, the pricing behavior of these monopolistic competitors is observationally equivalent to the behavior of perfectly competitive firms. The steady state price sub-indexes in equations (3.3.18) - (3.3.19) and (3.3.24) - (3.3.25) simply become,

$$
\begin{aligned}
& \bar{P}^{H}=\overline{\widetilde{P}}(h), \bar{P}^{H *}=\overline{\widetilde{P}}^{*}(h), \\
& \bar{P}^{F}=\overline{\widetilde{P}}(f), \bar{P}^{F *}=\overline{\widetilde{P}}^{*}(f),
\end{aligned}
$$

and, naturally,

$$
\bar{P}^{H}=\overline{S P}^{H *}, \bar{P}^{F}=\overline{S P}^{F *} .
$$

The LOOP holds also at the level of the aggregate bundles of goods produced at home and abroad. Using the price indexes in equations (3.2.14) and (3.2.15) evaluated at their steady state, I also infer that the real 
exchange rate should be equal to,

$$
\bar{P}=\left[\frac{\xi+(1-\xi)(\overline{T o T})^{1-\sigma}}{\xi^{*}+\left(1-\xi^{*}\right)(\overline{T o T})^{1-\sigma}}\right]^{\frac{1}{1-\sigma}} \overline{S P}^{*} \Rightarrow \overline{R S} \equiv \frac{\overline{S P}^{*}}{\bar{P}}=\left[\frac{\xi^{*}+\left(1-\xi^{*}\right)(\overline{T o T})^{1-\sigma}}{\xi+(1-\xi)(\overline{T o T})^{1-\sigma}}\right]^{\frac{1}{1-\sigma}}
$$

where $\overline{T o T} \equiv \frac{\bar{P}^{F}}{\overline{S P}^{H *}}=\frac{\bar{P}^{F}}{\bar{P}^{H}}$ denotes the steady state terms of trade. Absolute PPP holds in steady state (and the real exchange rate equals to one) only if preferences on consumption are identical across countries, i.e. $\xi=\xi^{*}$, or the terms of trade are equal to one in steady state. Relative PPP holds in steady state, but not absolute PPP, whenever the preferences differ across countries due to home-bias in consumption and terms of trade are not equal to zero. In the workhorse model, the difference between the long-run price of a basket of goods in either country expressed in terms of the same currency is a function of the steady state value of the terms of trade.

These findings prove that, if a zero-inflation steady state exists as conjectured, the LOOP holds and the pricing decisions of firms are equivalent to those of (symmetric) competitive firms under flexible prices. The steady state is also observationally equivalent whether asset markets are complete or not, as I shall discuss shortly. In other words, the steady state for any variant of the workhorse model that I explore here (with nominal rigidities, LCP pricing and/or incomplete asset markets) is equivalent to the steady state of the frictionless allocation described in subsection 4. That explains the notational convention of describing all endogenous steady state variables by dropping the time subscript and marking them with an 'upper bar' (as in the frictionless model).

The Other Real Steady State Variables. The analytic results reported in subsection 4 serve me to argue that the steady state real exchange rate, i.e. $\overline{R S}$, the steady state terms of trade, i.e. $\overline{T O T}$, the steady state total consumption, i.e. $\bar{C}$ and $\bar{C}^{*}$, the steady state output, i.e. $\bar{Y}$ and $\bar{Y}^{*}$, and the steady state employment, i.e. $\bar{L}$ and $\bar{L}^{*}$, are all functions of the steady state productivity shocks in both countries (and the structural parameters of the model). Taking that as given, I can infer real wages from the first-order conditions on labor supply given by (3.2.38) - (3.2.39), or from the labor market clearing conditions discussed in $(3.3 .30)-(3.3 .31)$, i.e.

$$
\begin{aligned}
\frac{\bar{W}}{\bar{P}} & =\kappa(A)^{-\varphi}\left(\bar{C}\left(A, A^{*}\right)\right)^{\gamma}\left(\bar{Y}\left(A, A^{*}\right)\right)^{\varphi}, \\
\frac{\bar{W}^{*}}{\bar{P}^{*}} & =\kappa\left(A^{*}\right)^{-\varphi}\left(\bar{C}^{*}\left(A, A^{*}\right)\right)^{\gamma}\left(\bar{Y}^{*}\left(A, A^{*}\right)\right)^{\varphi},
\end{aligned}
$$

noting that in steady state both labor and output are functions of the steady state productivity shocks only.

The demand for each variety and for the entire bundle of goods in each country can be obtained from equations (3.2.21) - (3.2.24) as,

$$
\begin{aligned}
& \bar{C}(h)=\frac{1}{n} \bar{C}^{H}\left(A, A^{*}\right), \bar{C}^{*}(h)=\frac{1}{n} \bar{C}^{H *}\left(A, A^{*}\right), \text { if } h \in[0, n], \\
& \bar{C}(f)=\frac{1}{1-n} \bar{C}^{F}\left(A, A^{*}\right), \bar{C}^{*}(f)=\frac{1}{1-n} \bar{C}^{F *}\left(A, A^{*}\right), \text { if } f \in(n, 1],
\end{aligned}
$$


and

$$
\begin{aligned}
& \bar{C}^{H}=\xi\left(\frac{1}{\xi+(1-\xi)\left(\overline{T O T}\left(A, A^{*}\right)\right)^{1-\sigma}}\right)^{\frac{-\sigma}{1-\sigma}} \bar{C}\left(A, A^{*}\right), \\
& \bar{C}^{H *}=\xi^{*}\left(\frac{1}{\xi^{*}+\left(1-\xi^{*}\right)\left(\overline{T o T}\left(A, A^{*}\right)\right)^{1-\sigma}}\right)^{\frac{-\sigma}{1-\sigma}} \bar{C}^{*}\left(A, A^{*}\right), \\
& \bar{C}^{F}=(1-\xi)\left(\frac{1}{\xi\left(\overline{T O T}\left(A, A^{*}\right)\right)^{\sigma-1}+(1-\xi)}\right)^{\frac{-\sigma}{1-\sigma}} \bar{C}\left(A, A^{*}\right), \\
& \bar{C}^{F *}=\left(1-\xi^{*}\right)\left(\frac{1}{\xi^{*}\left(\overline{T o T}\left(A, A^{*}\right)\right)^{\sigma-1}+\left(1-\xi^{*}\right)}\right)^{\frac{-\sigma}{1-\sigma}} \bar{C}^{*}\left(A, A^{*}\right) .
\end{aligned}
$$

The pricing for each variety and for the bundle of goods in each country comes from the optimal pricing equations in (3.3.14) - (3.3.15) and can be expressed relative to the CPI, by manipulating the indexes in (3.2.14) and (3.2.15), as follows,

$$
\begin{aligned}
\frac{\bar{P}^{H}}{\bar{P}} & =\left[\frac{1}{\xi+(1-\xi)\left(\overline{T O T}\left(A, A^{*}\right)\right)^{1-\sigma}}\right]^{\frac{1}{1-\sigma}}, \frac{\bar{P}^{F}}{\bar{P}}=\left[\frac{1}{\xi\left(\overline{T O T}\left(A, A^{*}\right)\right)^{\sigma-1}+(1-\xi)}\right]^{\frac{1}{1-\sigma}}, \\
\frac{\bar{P}^{F *}}{\bar{P}^{*}} & =\left[\frac{1}{\xi^{*}\left(\overline{T o T}\left(A, A^{*}\right)\right)^{\sigma-1}+\left(1-\xi^{*}\right)}\right]^{\frac{1}{1-\sigma}}, \frac{\bar{P}^{H *}}{\bar{P}^{*}}=\left[\frac{1}{\xi^{*}+\left(1-\xi^{*}\right)\left(\overline{T o T}\left(A, A^{*}\right)\right)^{1-\sigma}}\right]^{\frac{1}{1-\sigma}}
\end{aligned}
$$

These prices ratios are, not surprisingly, purely determined by real variables even in steady state.

The Nominal Steady State Variables. I should point out that the Taylor rules in the spirit of equations (3.4.12) - (3.4.13), and the Euler equations in (3.2.30) - (3.2.31) are not sufficient to pin down the steady state price level. Although the system is consistent with the conjecture that the inflation should be zero in steady state. To be more specific, the Euler equations imply that,

$$
\frac{1}{1+\bar{i}}=\frac{1}{1+\bar{i}^{*}}=\beta
$$

while the Taylor rules ensure that,

$$
\begin{aligned}
\frac{1+\bar{i}}{1+\bar{i}} & =\frac{Z}{Z}\left(\frac{1+\bar{i}}{1+\bar{i}}\right)^{\rho}\left[(\bar{\Pi})^{\psi_{1}}\left(\frac{\bar{Y}}{\bar{Y}}\right)^{\psi_{2}}\right]^{1-\rho} \Leftrightarrow \bar{\Pi}=1, \\
\frac{1+\bar{i}^{*}}{1+\bar{i}^{*}} & =\frac{Z^{*}}{Z^{*}}\left(\frac{1+\bar{i}^{*}}{1+\bar{i}^{*}}\right)^{\rho^{*}}\left[\left(\bar{\Pi}^{*}\right)^{\psi_{1}^{*}}\left(\frac{\bar{Y}^{*}}{\bar{Y}^{*}}\right)^{\psi_{2}^{*}}\right]^{1-\rho^{*}} \Leftrightarrow \bar{\Pi}^{*}=1 .
\end{aligned}
$$

This means that by enforcing a Taylor rule the long-run inflation target of the monetary authority becomes the steady state level. By construction, therefore, price stability is guaranteed in the steady state. However, this is not sufficient to determine the price level in steady state. It only guarantees that the price level is unchanged in steady state. Under price stability, the Euler equations also imply that the steady state nominal and real interest rates are determined by the subjective discount factor, $\beta$.

The determination of the price level may seem of little practical value since the log-linearized version of 
the workhorse model that I explore in this paper depends on the inflation dynamics and not on the price level itself. Relative prices do matter, however, but those are determined by real shocks in the steady state. However, as it turns out neither the nominal wages nor the nominal exchange rate (or any other nominal price) can be identified in steady state without knowing the price level first. Hence, I cannot simply ignore the issue.

The steady state version of the money market clearing conditions given by (3.4.8) - (3.4.9) characterizes the real balances in real terms. It can also be re-interpreted as a function for the steady state CPI level, i.e.

$$
\begin{aligned}
\bar{P} & =\left(\frac{1-\beta}{\chi}\right)^{\frac{1}{\zeta}}\left(\bar{C}\left(A, A^{*}\right)\right)^{-\frac{\gamma}{\zeta}} \bar{M}, \\
\bar{P}^{*} & =\left(\frac{1-\beta}{\chi}\right)^{\frac{1}{\zeta}}\left(\bar{C}^{*}\left(A, A^{*}\right)\right)^{-\frac{\gamma}{\zeta}} \bar{M}^{*},
\end{aligned}
$$

which is arranged to reflect that the monetary authority can alter the price level in steady state by manipulating the steady state money supply. While in the short-run money supply is endogenously determined by the model after the monetary authority sets a Taylor interest rate rule, in the long-run (more specifically in steady state) it is not. As a result, the monetary authority could set the long-run money supply and determine the price level in steady state.

Moreover, what this entails for monetary policy is that: (a) the short-term interest rate that the monetary authority tries to manipulate in response to short-term deviations of the inflation rate must be consistent with its long-run gross rate, $\beta^{-1}$ (which in the context of the model is completely independent of policy choice), and (b) the long-run inflation rate is zero, but the long-run CPI level depends on the long-run money supply of the economy. Therefore, if monetary policy is going to determine the price level in the long-run it has to be the case that long-run money supply is being used to determine the price level.

In other words, there is a case to be made as to why the monetary authority may care about the long-run trends of money supply. Imagine an economy that lies on a steady state. If money supply is increased because the monetary authority decides to allow more liquidity in the markets than its average trend it may create inflation and a transition towards a new steady state with higher price levels. If money is not neutral, this may come at a cost in the short-run. In any event, letting the long-run money supply loose introduces unnecessary noise in the system.

In summary, the monetary authority controls the nominal interest rates in the short-run, but cannot control the long-run interest rates. In steady state, those depend on the time preference of households. Monetary policy commonly relies on a Taylor interest rule to deal with the inflation dynamics (and to some extent with the fluctuations over the business cycle) and this rule, in turn, endogenously defines the shortrun path of the money supply. In the long-run, however, the Taylor rule does not constraint the price level or the money supply, and the steady state interest rates cannot be controlled by policy-makers. Hence, policy-makers could still exercise some control over the price level by regulating the money supply (but only over the long-run).

The Steady State of the External Sector. Using the definition of the real exchange rate in (3.2.19), which is a function of the steady state values of the productivity shock in both countries (as implied in subsection 4), it is possible to write the nominal exchange rate as the product of this function and the ratio 
of the CPIs in both countries, i.e.

$$
\bar{S}=\overline{R S}\left(A, A^{*}\right) \frac{\bar{P}}{\bar{P}^{*}},
$$

which is consistent with the intertemporal first-order condition of the households' problem in either (3.2.27) or (3.2.32). I can also use the domestic current account equation in (3.5.31) for the complete asset markets case and equation (3.5.33) for the incomplete asset markets case in order to identify the steady state trade balance.

There are a few comments that deserve to be noted explicitly here. First, I have considered all along that the deterministic steady state should correspond to that of the frictionless allocation independently of whether the model in its full complexity has nominal rigidities and/or incomplete asset markets features. Naturally, if a deterministic steady state does exist, whether the workhorse model has multiple Arrow-Debreu securities traded internationally or just one bond is completely irrelevant. As can be seen from the current account equation: whatever the optimal trade balance is for the steady state frictionless economy, it can be implemented in steady for an economy where only one asset is available. Because the steady state is deterministic there is no uncertainty and, therefore, having more assets is irrelevant. In this steady state, the outcome should be observationally equivalent to that under complete asset markets ${ }^{24}$.

Second, I argue that the portfolio allocation is indeterminate in this steady state. But I also maintain that it is not necessary to take a stand about portfolio allocations in this paper because we are concerned with the resource allocation instead. And, as I discuss later on, portfolio allocations are not needed to pin down the resource allocations of the workhorse model. Finally, independent of the portfolio structure, the only thing that really matters in steady state is the net borrowing that is attained in real terms. Alternatively, I could say that the only fixture of importance is the domestic real trade balance which can be computed as,

$$
\begin{aligned}
& \frac{\overline{T B}}{\bar{P}}=\frac{\xi}{n}\left(\frac{1}{\xi+(1-\xi)\left(\overline{T O T}\left(A, A^{*}\right)\right)^{1-\sigma}}\right) n \bar{C}\left(A, A^{*}\right)+ \\
& \quad+\frac{\xi^{*}}{n}\left(\frac{1}{\xi^{*}+\left(1-\xi^{*}\right)\left(\overline{T o T}\left(A, A^{*}\right)\right)^{1-\sigma}}\right) \overline{R S}\left(A, A^{*}\right)(1-n) \bar{C}^{*}\left(A, A^{*}\right)-\bar{C}\left(A, A^{*}\right) .
\end{aligned}
$$

Not surprisingly, the real trade balance is a function of the steady state productivity shock levels in both countries.

I can determine the steady state of real wages, real balances and the real trade balance. However, obtaining the steady state for nominal wages, the nominal trade balance, the nominal exchange rate or even the price of domestic and foreign goods requires that I pin down the steady state level of the CPI in both countries. Hence, the relevance of my previous discussion on the subject.

\subsection{The Normalization of the Steady State ${ }^{25}$}

I shall impose a number of normalizations that make the linearization exercise much easier. It is worthwhile to be explicit about these choices, because they are very common in the literature but not always trivial.

\footnotetext{
${ }^{24}$ I have shown that in steady state asset market incompleteness and nominal rigidities coupled with LCP pricing don't matter at all. The steady state of any model that combines either one of these frictions in the goods market and the assets market is the same as the steady state that can be found for the case of complete asset markets, flexible prices and competitive firms. Therefore, the steady state follows directly from the results that I already discussed in subsection 4 .

${ }^{25}$ Under this normalization of the steady state, it can be verified that $v \equiv \frac{S_{0} P_{0}^{*}}{P_{0}}\left(\frac{C_{0}^{*}}{C_{0}}\right)^{\gamma}=1$.
} 
First, I assume that the long-run level for the monetary shocks to the Taylor rule is equal to one. In other words, without loss of generality $Z=Z^{*}=1$. I could assume that the long-run money supply (i.e., the initial condition on the money supply regime) needed to pin down the price level is also equal to one, i.e. $\bar{M}=\bar{M}^{*}=1$. However, the steady state of the workhorse model corresponds to the steady state of the frictionless model. In that scenario, money is neutral and it seems reasonable to assume that the consumption good plays the role of numeraire (as it is often done in the RBC literature), i.e. $\bar{P}=\bar{P}^{*}=1$. For this normalization to hold, the money supply regime implemented by the monetary authority must satisfy that,

$$
\begin{aligned}
\bar{M} & =\left(\frac{\chi}{1-\beta}\right)^{\frac{1}{\zeta}}(\bar{C})^{\frac{\gamma}{\zeta}}, \\
\bar{M}^{*} & =\left(\frac{\chi}{1-\beta}\right)^{\frac{1}{\zeta}}\left(\bar{C}^{*}\right)^{\frac{\gamma}{\zeta}} .
\end{aligned}
$$

This comes from the money market clearing conditions. I adopt this particular normalization, which seems more natural to me, in this paper.

Second, I make the assumption that the steady state productivity shocks are chosen to ensure that terms of trade in steady state are equal to one, i.e. $\overline{T o T}=1$. I know from (4.6) and (4.7) that, if the steady state terms of trade are equal to one, then the real exchange rate is also equal to one,

$$
\overline{R S}=1 .
$$

Furthermore, the ratio of aggregate output in both countries is given by,

$$
\frac{n \bar{Y}}{(1-n) \bar{Y}^{*}}=\left[\frac{n\left(\frac{\xi}{n}\right)+(1-n)\left(\frac{\xi^{*}}{n}\right)}{n\left(\frac{1-\xi}{1-n}\right)+(1-n)\left(\frac{1-\xi^{*}}{1-n}\right)}\right],
$$

which implies that it is a constant fraction. Using this information about the structure of the economy and the aggregate output equations in (3.3.36) - (3.3.37), I can re-write the steady state consumption in terms of aggregate output (appropriately using the perfect risk-sharing condition in (3.2.29)) as,

$$
\begin{aligned}
n \bar{Y} & =\left[n\left(\frac{\xi}{n}\right)+(1-n)\left(\frac{\xi^{*}}{n}\right)\right] \bar{C} \\
(1-n) \bar{Y}^{*} & =\left[n\left(\frac{1-\xi}{1-n}\right)+(1-n)\left(\frac{1-\xi^{*}}{1-n}\right)\right] \bar{C}^{*} .
\end{aligned}
$$

Naturally, it follows that these relationships are consistent with the ratio described above only if consumption is perfectly shared across countries,

$$
\bar{C}=\bar{C}^{*}
$$

Given that the real exchange rate is equal to one, this result also follows directly from the perfect risksharing condition in (3.2.29). The money supply used to normalize the price level to one in steady state is analogously equalized, i.e. $\bar{M}=\bar{M}^{*}$.

The expressions above show that aggregate consumption in each country is proportional to the local aggregate output. From the equilibrium labor market clearing conditions in (4.3) - (4.4), I immediately 
derive a pair of steady state conditions that link output in both countries to productivity shocks under this normalization, i.e.

$$
\begin{aligned}
\kappa(A)^{-\varphi-1}(\bar{C})^{\gamma}(\bar{Y})^{\varphi} & =1 \Leftrightarrow \kappa(A)^{-\varphi-1}(n \bar{Y})^{\gamma}(\bar{Y})^{\varphi}=\left(n\left(\frac{\xi}{n}\right)+(1-n)\left(\frac{\xi^{*}}{n}\right)\right)^{\gamma}, \\
\kappa\left(A^{*}\right)^{-\varphi-1}\left(\bar{C}^{*}\right)^{\gamma}\left(\bar{Y}^{*}\right)^{\varphi} & =1 \Leftrightarrow \kappa\left(A^{*}\right)^{-\varphi-1}\left((1-n) \bar{Y}^{*}\right)^{\gamma}\left(\bar{Y}^{*}\right)^{\varphi}=\left(n\left(\frac{1-\xi}{1-n}\right)+(1-n)\left(\frac{1-\xi^{*}}{1-n}(6) \cdot 2.9\right) .9\right)
\end{aligned}
$$

This is a system of two equations in two unknowns that can be resolved. If I re-write everything appropriately, I obtain that,

$$
\begin{aligned}
n \bar{Y} & =\left[\frac{n^{\varphi}}{\kappa}\left(n\left(\frac{\xi}{n}\right)+(1-n)\left(\frac{\xi^{*}}{n}\right)\right)^{\gamma}\right]^{\frac{1}{\gamma+\varphi}}(A)^{\frac{1+\varphi}{\gamma+\varphi}} \\
(1-n) \bar{Y}^{*} & =\left[\frac{(1-n)^{\varphi}}{\kappa}\left(n\left(\frac{1-\xi}{1-n}\right)+(1-n)\left(\frac{1-\xi^{*}}{1-n}\right)\right)^{\gamma}\right]^{\frac{1}{\gamma+\varphi}}\left(A^{*}\right)^{\frac{1+\varphi}{\gamma+\varphi}} .
\end{aligned}
$$

If I take the ratio of both expressions and re-write everything according to equation (6.2.4), it should follow that,

$$
\frac{n\left(\frac{\xi}{n}\right)+(1-n)\left(\frac{\xi^{*}}{n}\right)}{n\left(\frac{1-\xi}{1-n}\right)+(1-n)\left(\frac{1-\xi^{*}}{1-n}\right)}=\frac{n \bar{Y}}{(1-n) \bar{Y}^{*}}=\frac{n^{\frac{\varphi}{\gamma+\varphi}}\left(n\left(\frac{\xi}{n}\right)+(1-n)\left(\frac{\xi^{*}}{n}\right)\right)^{\frac{\gamma}{\gamma+\varphi}}(A)^{\frac{1+\varphi}{\gamma+\varphi}}}{(1-n)^{\frac{\varphi}{\gamma+\varphi}}\left(n\left(\frac{1-\xi}{1-n}\right)+(1-n)\left(\frac{1-\xi^{*}}{1-n}\right)\right)^{\frac{\gamma}{\gamma+\varphi}}\left(A^{*}\right)^{\frac{1+\varphi}{\gamma+\varphi}}}
$$

and this implies that the ratio of the steady state productivity shocks is,

$$
\frac{A}{A^{*}}=\left(\frac{1-n}{n}\right)^{\frac{\varphi}{1+\varphi}}\left[\frac{n\left(\frac{\xi}{n}\right)+(1-n)\left(\frac{\xi^{*}}{n}\right)}{n\left(\frac{1-\xi}{1-n}\right)+(1-n)\left(\frac{1-\xi^{*}}{1-n}\right)}\right]^{\frac{\varphi}{1+\varphi}} .
$$

This is the most critical condition on the normalization of the steady state productivity shocks because it is needed to guarantee that the terms of trade and the real exchange rate are both equal to one.

This normalization is very convenient to determine the basic log-linearized set of equilibrium conditions that has become so popular in the international macro literature. However, this normalization is not innocuous because it constraints the parameters of the model and may force us to rely on a fundamental difference between the two countries. In other words, it is not always possible to assume that the steady state productivity level in both countries is identical. So even if I normalize the steady state productivity in the foreign country to be equal to one, I cannot make the same normalization for the domestic country. Let me suppose that preferences are identical across countries, i.e. $\xi=\xi^{*}$, then the restriction in (6.2.13) still implies that,

$$
\frac{A}{A^{*}}=\left(\frac{1-n}{n}\right)^{\frac{2 \varphi}{1+\varphi}}\left[\frac{\xi}{1-\xi}\right]^{\frac{\varphi}{1+\varphi}} .
$$

This means that identical preferences are not sufficient to restore the conventional view that the productivity 
shocks in each country are identical in steady state. Instead, I would need also that,

$$
\xi=\frac{n^{2}}{(1-n)^{2}+n^{2}}=\frac{n^{2}}{1+2 n^{2}-2 n} .
$$

The assumption that $\xi=\xi^{*}=n=\frac{1}{2}$ is consistent with this restriction.

Instead, let me consider the possibility that the following restriction applies on the parameters of consumption bias, i.e.

$$
(1-n) \xi^{*}=n(1-\xi)
$$

This is the same condition derived for the irrelevance of asset markets. Then, it is possible to re-write the normalization condition on the steady state productivity levels as,

$$
\frac{A}{A^{*}}=\left(\frac{n}{1-n}\right)^{-\frac{\varphi}{1+\varphi}}
$$

This equation indicates that under a particular specification of the home bias parameters it should follow that the differences in the productivity levels in steady state are inversely related to the relative population size of both countries. This condition is consistent with equal productivity levels, i.e. $A=A^{*}=1$, if I assume that either $n=\frac{1}{2}$ (equal population sizes) or $\varphi=0$ (linear labor disutility).

Other Implications of the Normalization. Assuming this normalization of the productivity shocks turns out to be very convenient. In the standard normalization that I propose in this paper the price level is equalized across countries by construction, i.e.

$$
\frac{\bar{P}}{\bar{P}^{*}}=\frac{\bar{M}}{\bar{M}^{*}}=1,
$$

given that $\bar{C}=\bar{C}^{*}$. In a very intuitive fashion, this shows that the long-run differences in price levels across countries can only be due to long-run differences in the money supply regime under which each country's monetary authority is operating. Given this simplification of the initial condition on money supply I know that the CPI price level must be equalized across countries, i.e. $\bar{P}=\bar{P}^{*}$.

Since the real exchange rate is equal to one given the normalization of the steady state productivity shocks that I explore here, then, it must be the case that the nominal exchange rate is equal to one too, i.e.

$$
\bar{S}=\frac{\bar{P}}{\bar{P}^{*}}=\frac{\bar{M}}{\bar{M}^{*}}=1
$$

In principle the nominal exchange rate reflects the different steady state values (or the initial conditions) of the money supply. It could be said that the nominal exchange rate is a purely monetary phenomenon in the long-run, while this is not the case in the short-run if PPP fails. However, it must be noted that this is true under the particular normalization of the productivity shocks that I discussed before ${ }^{26}$. In any event, it is

\footnotetext{
${ }^{26}$ Another normalization in which the real exchange rate is different than one and the consumption levels do not equalize across countries would result in a long-run nominal exchange rate that depends on steady state money supply but also on steady state productivity levels.
} 
obvious that if the monetary authority switches towards a different regime with a different long-run level of money supply, the long-run CPI indexes as well as the nominal exchange rate will reflect the change.

Given the optimal Dixit-Stiglitz pricing rule in steady state in equations (6.1.9) - (6.1.12), the labor market clearing conditions in steady state in equations (6.1.13) - (6.1.14), and the fact that $\bar{P}=\bar{P}^{H}$ and $\bar{P}^{*}=\bar{P}^{F *}$ whenever $\overline{T O T}=1$, I obtain that,

$$
\begin{aligned}
& 1=\frac{\bar{P}^{H}}{\bar{P}}=\frac{\bar{W}}{\bar{P} A}=\kappa(A)^{-\varphi-1}(\bar{C})^{\gamma}(\bar{Y})^{\varphi}, \\
& 1=\frac{\bar{P}^{F *}}{\bar{P}^{*}}=\frac{\bar{W}^{*}}{\bar{P}^{*} A^{*}}=\kappa\left(A^{*}\right)^{-\varphi-1}\left(\bar{C}^{*}\right)^{\gamma}\left(\bar{Y}^{*}\right)^{\varphi} .
\end{aligned}
$$

Using equations $(6.2 .10)-(6.2 .11)$ to pin down the steady state levels of output, it should follow that aggregate consumption is equal to,

$$
\begin{aligned}
\bar{C} & =\left(\frac{1}{\kappa}\right)^{\frac{1}{\gamma}}(\bar{Y})^{-\frac{\varphi}{\gamma}}(A)^{\frac{1+\varphi}{\gamma}}=\left(\frac{1}{\kappa}\right)^{\frac{1}{\gamma+\varphi}}\left(\frac{1}{n}\right)^{-\frac{\varphi}{\gamma+\varphi}}\left(n\left(\frac{\xi}{n}\right)+(1-n)\left(\frac{\xi^{*}}{n}\right)\right)^{-\frac{\varphi}{\gamma+\varphi}}(A)^{\frac{1+\varphi}{\gamma+\varphi}}, \\
\bar{C}^{*} & \left.=\left(\frac{1}{\kappa}\right)^{\frac{1}{\gamma}}\left(\bar{Y}^{*}\right)^{-\frac{\varphi}{\gamma}}\left(A^{*}\right)^{\frac{1+\varphi}{\gamma}}=\left(\frac{1}{\kappa}\right)^{\frac{1}{\gamma+\varphi}}\left(\frac{1}{1-n}\right)^{-\frac{\varphi}{\gamma+\varphi}}\left(n\left(\frac{1-\xi}{1-n}\right)+(1-n)\left(\frac{1-\xi^{*}}{1-n}\right)\right)^{-\frac{\varphi}{\gamma+\varphi}}\left(A()^{6}\right), \frac{1+\varphi}{2.22}\right)
\end{aligned}
$$

At any rate, consumption must be identical in both countries given the conditions I impose to normalize the steady state productivity levels. Considering that $\overline{T O T}=1$, the demand of each bundle of goods given by (6.1.17) - (6.1.16) is simply,

$$
\begin{aligned}
\bar{C}(h) & =\frac{1}{n} \bar{C}^{H}, \bar{C}^{*}(h)=\frac{1}{n} \bar{C}^{H *}, \text { if } h \in[0, n], \\
\bar{C}(f) & =\frac{1}{1-n} \bar{C}^{F}, \bar{C}^{*}(f)=\frac{1}{1-n} \bar{C}^{F *}, \text { if } f \in(n, 1], \\
\bar{C}^{H} & =\xi \bar{C}, \bar{C}^{H *}=\xi^{*} \bar{C}^{*}, \bar{C}^{F}=(1-\xi) \bar{C}^{*}, \bar{C}^{F *}=\left(1-\xi^{*}\right) \bar{C}^{*},
\end{aligned}
$$

which is the same allocation that would prevail if I assume that the aggregator for the domestic and foreign bundle of goods is of the Cobb-Douglas type. Given my normalization on prices, it should follow that the steady CPI levels are,

$$
\begin{aligned}
\overline{\widetilde{P}}(h) & =\bar{P}^{H}=\bar{P}=1, \\
\bar{P}^{*}(f) & =\bar{P}^{F *}=\bar{P}^{*}=1,
\end{aligned}
$$

based on the steady state money supply in each country.

Finally, I can take another look at the real trade balance per capita given in (6.1.27) and conclude that,

$$
\frac{\overline{T B}}{\bar{P}}=\left[\xi^{*}(1-n)-(1-\xi) n\right] \frac{1}{n} \bar{C},
$$

which is equal to zero whenever,

$$
(1-n) \xi^{*}=n(1-\xi) \Longleftrightarrow \xi=1-\left(\frac{1-n}{n}\right) \xi^{*}
$$


This is exactly the same condition that I derived for the irrelevance of the asset markets. This means that the normalization proposed ensures that international trading of assets is irrelevant in steady state without requiring that the intertemporal elasticity of substitution, $\frac{1}{\gamma}$, and the elasticity of substitution across domestic and foreign bundles, $\sigma$, be equal to one. This normalization makes the nominal and real trade balance equal to zero, so the allocation (in steady state at least) is not distorted by the asset availability for international trading or lack thereof.

\section{The Linearized Equilibrium Conditions}

From this point on, I assume that fiscal policy is always set at $\phi_{t}=\phi_{t}^{*}=\frac{-1}{\theta}$. I take as given that fiscal policy eliminates the mark-up distortion, and do not discuss the subject any further ${ }^{27}$. In order to explore the first-order effects of the different shocks on the dynamics of the economy, the international literature has often relied on log-linearizations. Here I do the same, I log-linearize the equilibrium conditions around the deterministic zero-inflation steady state. I denote $\widehat{x}_{t} \equiv \ln X_{t}-\ln \bar{X}$ the deviation of a variable in $\operatorname{logs}$ from its steady state. For more details on this approach, see Martínez-García (2007) and its corresponding companion technical appendix.

\subsection{Some Preliminaries}

Let me start by describing the log-linearization of the domestic and foreign CPI indexes defined in (3.2.13) and (3.2.15). Given the normalized steady state, it must hold true that $\bar{P}^{H}=\bar{P}^{F}$ and $\bar{P}^{H *}=\bar{P}^{F *}$. Hence, taking a first-order approximation of the CPIs I derive that,

$$
\begin{aligned}
& \widehat{p}_{t} \approx \xi \widehat{p}_{t}^{H}+(1-\xi) \widehat{p}_{t}^{F} \\
& \widehat{p}_{t}^{*} \approx \xi^{*} \widehat{p}_{t}^{H *}+\left(1-\xi^{*}\right) \widehat{p}_{t}^{F *}
\end{aligned}
$$

I define the domestic and foreign inflation rates in deviations as $\widehat{\pi}_{t} \equiv \widehat{p}_{t}-\widehat{p}_{t-1}$ and $\widehat{\pi}_{t}^{*} \equiv \widehat{p}_{t}^{*}-\widehat{p}_{t-1}^{*}$, respectively. I define the real exchange rate in equation (3.2.19) and describe the relative exchange prices in the home and foreign country respectively in (3.2.20). Therefore, it immediately follows that the $R S$ equation of the model is equal to,

$$
\begin{aligned}
\widehat{r s}_{t} & =\widehat{s}_{t}+\widehat{p}_{t}^{*}-\widehat{p}_{t} \\
& \approx \widehat{s}_{t}+\left(\xi^{*} \widehat{p}_{t}^{H *}+\left(1-\xi^{*}\right) \widehat{p}_{t}^{F *}\right)-\left(\xi \widehat{p}_{t}^{H}+(1-\xi) \widehat{p}_{t}^{F}\right) .
\end{aligned}
$$

And, the $R P$ equations take the form of,

$$
\begin{aligned}
& \widehat{r p}_{t}=\widehat{p}_{t}^{F}-\widehat{p}_{t}^{H}, \\
& \widehat{r p}_{t}^{*}=-\left(\widehat{p}_{t}^{F *}-\widehat{p}_{t}^{H *}\right) .
\end{aligned}
$$

\footnotetext{
${ }^{27}$ In any case, neither the mark-up nor the fiscal policy terms have any impact on the short-run dynamics up to first-order. The mark-up and the fiscal policy only enter in the specification of the long-run steady state.
} 
I denote world relative exchange prices, $\widehat{r p}_{t}^{W}$, and the difference between relative exchange prices across countries, $\widehat{r p}_{t}^{R}$, as follows,

$$
\begin{aligned}
\widehat{r p}_{t}^{W} & \equiv \xi \widehat{r p}_{t}-\left(1-\xi^{*}\right) \widehat{r p}_{t}^{*} \\
\widehat{r p}_{t}^{R} & \equiv \widehat{r p}_{t}+\widehat{r p}_{t}^{*}
\end{aligned}
$$

Hence, the $R P$ equations in the model can also be expressed in terms of $\widehat{r p}_{t}^{W}$ and $\widehat{r p}_{t}^{R}$ as,

$$
\begin{aligned}
\widehat{r p}_{t} & =\frac{1}{\xi-\xi^{*}+1} \widehat{r p}_{t}^{W}+\frac{1-\xi^{*}}{\xi-\xi^{*}+1} \widehat{r p}_{t}^{R}, \\
\widehat{r p}_{t}^{*} & =-\frac{1}{\xi-\xi^{*}+1} \widehat{r p}_{t}^{W}+\frac{\xi}{\xi-\xi^{*}+1} \widehat{r p}_{t}^{R} .
\end{aligned}
$$

Moreover, I define domestic and foreign terms of trade respectively in (3.2.18). Then, I can infer that,

$$
\begin{aligned}
\widehat{\operatorname{tot}}_{t} & \equiv\left(\widehat{p}_{t}^{H}-\widehat{s}_{t}-\widehat{p}_{t}^{H *}\right)+\widehat{r p}_{t}=\left(\widehat{p}_{t}^{F}-\widehat{s}_{t}-\widehat{p}_{t}^{H *}\right) \\
\widehat{\operatorname{tot}}_{t}^{*} & \equiv\left(\widehat{s}_{t}+\widehat{p}_{t}^{F *}-\widehat{p}_{t}^{F}\right)+\widehat{r p}_{t}^{*}=-\widehat{t o t}_{t},
\end{aligned}
$$

which in turn allows me to re-write the real exchange rate as,

$$
\begin{aligned}
\widehat{r s}_{t} & \approx \xi \widehat{r p}_{t}-\left(1-\xi^{*}\right) \widehat{r p}_{t}^{*}-\left[\widehat{p}_{t}^{F}-\widehat{s}_{t}-\widehat{p}_{t}^{H *}\right] \\
& =\widehat{r p}_{t}^{W}-\widehat{t o t}_{t} .
\end{aligned}
$$

These calculations show that fluctuations in the real exchange rate can be thought as cointegrated with world relative exchange prices and domestic terms of trade.

\subsection{The Demand-Side in the Goods Markets}

The IS Equations. The linearization of the Euler equations in (3.2.30) - (3.2.31) applies to the model under complete or incomplete asset markets and characterizes the consumption-savings decisions of the households. This is a crucial margin of choice. I obtain the following system of two linearized Euler equations,

$$
\begin{aligned}
\gamma \mathbb{E}_{t}\left[\Delta \widehat{c}_{t+1}\right] & \approx \widehat{i}_{t}-\mathbb{E}_{t}\left[\widehat{\pi}_{t+1}\right] \\
\gamma \mathbb{E}_{t}\left[\Delta \widehat{c}_{t+1}^{*}\right] & \approx \widehat{i}_{t}^{*}-\mathbb{E}_{t}\left[\widehat{\pi}_{t+1}^{*}\right]
\end{aligned}
$$

which are conventionally denoted as the $I S^{H}$ and $I S^{F}$ equations, respectively. The ex ante Fisher equation requires that the model-based implicit real interest rate be equal to,

$$
\begin{aligned}
\widehat{r}_{t} & \equiv \widehat{i}_{t}-\mathbb{E}_{t}\left[\widehat{\pi}_{t+1}\right], \\
\widehat{r}_{t}^{*} & \equiv \widehat{i}_{t}^{*}-\mathbb{E}_{t}\left[\widehat{\pi}_{t+1}^{*}\right] .
\end{aligned}
$$

Therefore, the expected growth rate of consumption is proportional to this measure of the real interest rate. The constant of proportionality is the intertemporal elasticity of substitution, $\frac{1}{\gamma}$. Using the linearized CPIs 
in (7.1.1) - (7.1.2), I obtain that,

$$
\begin{aligned}
\gamma \mathbb{E}_{t}\left[\Delta \widehat{c}_{t+1}\right] & \approx \widehat{i}_{t}-\mathbb{E}_{t}\left[\xi \widehat{\pi}_{t+1}^{H}+(1-\xi) \widehat{\pi}_{t+1}^{F}\right], \\
\gamma \mathbb{E}_{t}\left[\Delta \widehat{c}_{t+1}^{*}\right] & \approx \widehat{i}_{t}^{*}-\mathbb{E}_{t}\left[\xi^{*} \widehat{\pi}_{t+1}^{H *}+\left(1-\xi^{*}\right) \widehat{\pi}_{t+1}^{F *}\right],
\end{aligned}
$$

where $\widehat{\pi}_{t+1}^{H} \equiv \widehat{p}_{t+1}^{H}-\widehat{p}_{t}^{H}$ and $\widehat{\pi}_{t+1}^{F} \equiv \widehat{p}_{t+1}^{F}-\widehat{p}_{t}^{F}$.

In the literature is often preferred to express the consumption-savings margin in terms of the world $I S$ equation, $I S^{W}$, and the relative $I S$ equation, $I S^{R}$. These two equations represent the dynamics of world consumption (defined as a weighted average of domestic and foreign consumption), i.e. $\widehat{c}_{t}^{W} \equiv n \widehat{c}_{t}+(1-n) \widehat{c}_{t}^{*}$, and the dynamics of relative consumption, i.e. $\widehat{c}_{t}^{R} \equiv \widehat{c}_{t}-\widehat{c}_{t}^{*}$. World and relative consumption are sufficient to describe domestic and foreign consumption because it can be easily shown that,

$$
\begin{aligned}
\widehat{c}_{t} & \equiv \widehat{c}_{t}^{W}+(1-n) \widehat{c}_{t}^{R}, \\
\widehat{c}_{t}^{*} & \equiv \widehat{c}_{t}^{W}-n \widehat{c}_{t}^{R} .
\end{aligned}
$$

These dynamics can be derived by computing $n \cdot(7.2 .1)+(1-n) \cdot(7.2 .2)$ and (7.2.1) $-(7.2 .2)$. The world IS equation, $I S^{W}$, is obtained as,

$$
\gamma \mathbb{E}_{t}\left[\Delta \widehat{c}_{t+1}^{W}\right] \approx \widehat{i}_{t}^{W}-\mathbb{E}_{t}\left[\widehat{\pi}_{t+1}^{W}\right]
$$

where $\widehat{i}_{t}^{W} \equiv n \widehat{i}_{t}+(1-n) \widehat{i}_{t}^{*}$ and $\widehat{\pi}_{t+1}^{W} \equiv n \widehat{\pi}_{t+1}+(1-n) \widehat{\pi}_{t+1}^{*}$. The relative IS equation, $I S^{R}$, is obtained as,

$$
\gamma \mathbb{E}_{t}\left[\Delta \widehat{c}_{t+1}^{R}\right] \approx \widehat{i}_{t}^{R}-\mathbb{E}_{t}\left[\widehat{\pi}_{t+1}^{R}\right]
$$

where $\widehat{i}_{t}^{R} \equiv \widehat{i}_{t}-\widehat{i}_{t}^{*}$ and $\widehat{\pi}_{t+1}^{R} \equiv \widehat{\pi}_{t+1}-\widehat{\pi}_{t+1}^{*}$. I interpret the argument on the right-hand side of (7.2.10) as the difference between Fisher's real interest rate at home and abroad.

The UIP Condition. The UIP equation, UIP, comes from the log-linearization of the intertemporal first-order condition in either (3.2.29) or (3.2.27) if markets are complete, and from the log-linearization of the first-order condition in (3.2.32) if markets are incomplete. Under complete asset markets, I obtain that the relative consumption must be proportional to the real exchange rate, i.e.

$$
\widehat{r s}_{t} \approx \gamma \widehat{c}_{t}^{R}
$$

Given this particular equilibrium condition, clearly equation (7.2.10) becomes somewhat redundant in the computation of the equilibrium path. Nonetheless, equation (7.2.10) still has an interesting reading because it implies that,

$$
\widehat{i}_{t}-\mathbb{E}_{t}\left[\widehat{\pi}_{t+1}\right] \approx \widehat{i}_{t}^{*}-\mathbb{E}_{t}\left[\widehat{\pi}_{t+1}^{*}\right]+\mathbb{E}_{t}\left[\Delta \widehat{r s}_{t+1}^{R}\right] .
$$

In other words, the ex ante real interest rates are equalized across countries whenever asset markets are complete, but only if PPP holds. This, obviously, puts a constraint on the behavior of consumption on both countries, but it also shows that violations of PPP can induce different consumption paths across countries.

The UIP condition in its more conventional form holds up to a first-order approximation, and it can be 
expressed as follows,

$$
\mathbb{E}_{t}\left[\Delta \widehat{s}_{t+1}\right] \approx \widehat{i}_{t}-\widehat{i}_{t}^{*} \equiv \widehat{i}_{t}^{R}
$$

where the spread in nominal interest rates reflects movements in the expected exchange rate. Using the definition of the real exchange rate in (7.1.3), I can write a variant of the UIP equation in terms of the real exchange rate as,

$$
\mathbb{E}_{t}\left[\Delta \widehat{r}_{t+1}\right] \approx \widehat{i}_{t}^{R}-\mathbb{E}_{t}\left[\widehat{\pi}_{t+1}^{R}\right],
$$

One way to read this is that the wedge between the real interest rate in the domestic and foreign country is influenced by the real exchange rate, and this is true up to a first-order approximation independently of whether markets are complete or not. Just compare this equation with equation (7.2.12).

Another way to look at this equilibrium condition is by replacing the ex ante real interest rate differential using equation (7.2.10), i.e.

$$
\mathbb{E}_{t}\left[\Delta \widehat{r s}_{t+1}\right] \approx \gamma \mathbb{E}_{t}\left[\Delta \widehat{c}_{t+1}^{R}\right]
$$

The equation reflects how the risk-sharing opportunities change whenever I switch from a world from complete markets to a world with incomplete assets markets (to a bond economy). Under complete asset markets, the relative marginal utility of consumption across countries is equalized to the real exchange rate across all possible states of nature, and I end up with (7.2.11). Under incomplete asset markets, the relationship only holds in expectations because all traded bonds are uncontingent. Hence, I end up with equation (7.2.15) instead.

Equations (7.2.11) and (7.2.15), coupled with the definition of the real exchange rate as given by (7.1.3), are going to be crucial in the determination of the exchange rates. It is also worth noticing that this is the only (log-linearized) equilibrium condition for which there is a difference between the incomplete asset markets model and the complete asset markets model. In summary, the asset market structure is relevant up to a first-order as long as it 'changes' the risk-sharing opportunities available to households, so naturally this effect pops up precisely in the risk-sharing equations.

The MP Equations. A simple log-linearization of the Taylor indexes described in equations (3.4.12) (3.4.13) gives me the MP equations, $M P^{H}$ and $M P^{F}$, as,

$$
\begin{aligned}
& \widehat{i}_{t} \approx \widehat{i}_{t-1}+(1-\rho)\left[\psi_{1} \widehat{\pi}_{t}+\psi_{2}\left(\widehat{y}_{t}-\widehat{\bar{y}}_{t}\right)\right]+\widehat{z}_{t}, \\
& \widehat{i}_{t}^{*} \approx \rho^{*} \widehat{i}_{t-1}^{*}+\left(1-\rho^{*}\right)\left[\psi_{1}^{*} \widehat{\pi}_{t}^{*}+\psi_{2}^{*}\left(\widehat{y}_{t}^{*}-\widehat{\bar{y}}_{t}^{*}\right)\right]+\widehat{z}_{t}^{*},
\end{aligned}
$$

where $\left(\widehat{y}_{t}-\widehat{\bar{y}}_{t}\right)$ and $\left(\widehat{y}_{t}^{*}-\widehat{\bar{y}}_{t}^{*}\right)$ represent the domestic and foreign output gap, respectively, $\widehat{z}_{t}$ denotes the domestic monetary policy shock, and $\widehat{z}_{t}^{*}$ the foreign monetary policy shock. I will derive a characterization of the (first-order) potential output of the economy in subsection (7.7).

Monetary policy affects the demand-side of the economy because it directly 'controls' the nominal interest rate. A monetary policy based on a Taylor rule can be viewed as a relationship that links the ex ante real 
interest rate to inflation, inflation expectations and the output gap, e.g.

$$
\begin{aligned}
& \widehat{r}_{t} \approx \rho \widehat{r}_{t-1}+\rho\left(\mathbb{E}_{t-1}\left[\widehat{\pi}_{t}\right]-\mathbb{E}_{t}\left[\widehat{\pi}_{t+1}\right]\right)+(1-\rho)\left[\left(\psi_{1}-1\right) \mathbb{E}_{t}\left[\widehat{\pi}_{t+1}\right]+\psi_{1}\left(\widehat{\pi}_{t}-\mathbb{E}_{t}\left[\widehat{\pi}_{t+1}\right]\right)+\psi_{2}\left(\widehat{y}_{t}-\widehat{\bar{y}}_{t}\right)\right]+\widehat{z}_{t},(7.2 \\
& \widehat{r}_{t}^{*} \approx \rho^{*} \widehat{r}_{t-1}^{*}+\rho^{*}\left(\mathbb{E}_{t-1}\left[\widehat{\pi}_{t}^{*}\right]-\mathbb{E}_{t}\left[\widehat{\pi}_{t+1}^{*}\right]\right)+\left(1-\rho^{*}\right)\left[\left(\psi_{1}^{*}-1\right) \mathbb{E}_{t}\left[\widehat{\pi}_{t+1}^{*}\right]+\psi_{1}^{*}\left(\widehat{\pi}_{t}^{*}-\mathbb{E}_{t}\left[\widehat{\pi}_{t+1}^{*}\right]\right)+\psi_{2}^{*}\left(\widehat{y}_{t}^{*}-\widehat{\bar{y}}_{t}^{*}\right)\right]
\end{aligned}
$$

where $\mathbb{E}_{t-1}\left[\widehat{\pi}_{t}\right]-\mathbb{E}_{t}\left[\widehat{\pi}_{t+1}\right]$ can be interpreted as sensitivity to inflation expectation jumps. If inflation is thought to be a random walk process, then inflation expectations can be computed as $\widetilde{\mathbb{E}}_{t}\left[\widehat{\pi}_{t+1}\right]=\widehat{\pi}_{t}$. Then, $\widehat{\pi}_{t}-\mathbb{E}_{t}\left[\widehat{\pi}_{t+1}\right]$ can be viewed as the forecasting error relative to the true model. This mispecification error can be eliminated entirely if the monetary authority targets the true inflation expectations, instead of just current inflation.

The real interest rate has the potential to influence the consumption path of households. However, I caution from reading too much into this line of reasoning. The reality is that every market has two sides, a demand-side and a supply-side. The monetary authority may be able to exert some influence on the demand (and the expenditure allocation), but the endogenous equilibrium can only be determined once I add the supply-side of the economy. For example, let me consider an economy that is fully segregated from the rest of the world (autarky) and where prices are flexible. Without frictions, money is neutral and it has no impact on the real output. By the market clearing conditions, however, everything that the economy produces must be consumed by the local households (there is no capital accumulation either). The Euler equations are still satisfied, but that does not mean the consumption path in equilibrium changes in response to a change in the interest rate. In this environment, only nominal variables adjust and they do so to ensure that the resource allocation remains unchanged. In other words, inflation will react to changes in the nominal interest rate to make sure that households are satisfied with the consumption they already have.

The nominal exchange rate is often characterized with a combination of the UIP equation in (7.2.13) and the $M P$ equations described in $(7.2 .16)-(7.2 .17)$. The impact of monetary policy on the determination of the nominal exchange rate becomes easier to grasp if I make the assumption that the reaction functions of the monetary authority are identical in both countries (i.e., $\rho=\rho^{*}, \psi_{1}=\psi_{1}^{*}$, and $\psi_{2}=\psi_{2}^{*}$ ). If I combine the UIP equation and the $M P$ equations, it follows immediately that,

$$
\mathbb{E}_{t}\left[\Delta \widehat{s}_{t+1}\right] \approx \widehat{i}_{t}-\widehat{i}_{t}^{*}=\rho\left(\widehat{i}_{t-1}-\widehat{i}_{t-1}^{*}\right)+(1-\rho)\left[\psi_{1}\left(\widehat{\pi}_{t}-\widehat{\pi}_{t}^{*}\right)+\psi_{2}\left(\left(\widehat{y}_{t}-\widehat{\bar{y}}_{t}\right)-\left(\widehat{y}_{t}^{*}-\widehat{\bar{y}}_{t}^{*}\right)\right)\right]+\left(\widehat{z}_{t}-\widehat{z}_{t}^{*}\right)
$$

Using the definition of the real exchange rate from (7.1.3) and the assumption that $(1-\rho) \psi_{1}>1$, this equation has a unique bounded solution for the depreciation of the nominal exchange rate which can be expressed as,

$$
\Delta \widehat{s}_{t} \approx \sum_{j=0}^{\infty}\left(\frac{1}{(1-\rho) \psi_{1}}\right)^{j+1} \mathbb{E}_{t}\left[\begin{array}{c}
(1-\rho)\left(\psi_{2}\left(\left(\widehat{y}_{t+j}^{*}-\widehat{\bar{y}}_{t+j}^{*}\right)-\left(\widehat{y}_{t+j}-\widehat{\bar{y}}_{t+j}\right)\right)-\psi_{1} \Delta \widehat{r s}_{t+j}\right)+ \\
+\rho\left(\widehat{i}_{t+j-1}^{*}-\widehat{i}_{t+j-1}\right)+\left(\widehat{z}_{t+j}^{*}-\widehat{z}_{t+j}\right)
\end{array}\right]
$$

This equation is a version of the often-cited and widely-used present-value model of the nominal exchange rate.

In very simple terms, this equation shows how the nominal exchange rate depreciates (i.e., $\left.\uparrow \Delta \widehat{s}_{t}\right)$ in response to monetary policy shocks, a depreciation of the real exchange rate (i.e., $\downarrow \Delta \widehat{r s} s_{t}$ ), or a broadening of the output gap differential across countries. The term $\widehat{i}_{t-1}^{*}-\widehat{i}_{t-1}$ accounts for the inertia in monetary 
policy and gives past shocks an impact on current and future fluctuations of the nominal rate. The monetary authority may have an impact on the size of the output only if money has real effects. However, even if that is the case, a successful monetary policy should imply that output fluctuates around its potential over time. Therefore, if all economic agents anticipate a successful monetary policy, the contribution of the output gap to the determination of the nominal exchange rate is likely to be 'limited'. Therefore, it seems that the most crucial linkage between monetary policy and the nominal exchange rate comes from the discretionary component of monetary policy, $\widehat{z}_{t}^{*}-\widehat{z}_{t}$, and the indirect influence it may have on the real exchange rate.

I see that what matters for the determination of the nominal exchange rate is not the interest rate itself, but the monetary shocks. That is, the unpredictable part of the policy rule. If the domestic interest rate decreases but the policy shock is positive keeping the interest rates above what the Taylor rule prescribes, then the nominal exchange rate appreciates (everything else equal). Otherwise it will depreciate. This is true only if the future expectations of the monetary policy shock remain unchanged. In any event, it is perfectly possible to rationalize a depreciation of the nominal exchange rate simultaneously with a cut in the nominal interest rate. In this sense, I don't think we should be surprised to find those patterns in the data.

\subsection{The Supply-Side in the Goods Markets}

In the workhorse model, the Phillips curve is explicitly derived from the pricing decisions of firms. One advantage of this approach is that the relationship has a structural interpretation, and serves to analyze the transmission mechanism from shocks into inflation. The Phillips curve is no longer a mere 'black box' that summarizes certain empirical regularities. But if there are structural changes in the economy, such as the move to a low-inflation environment witnessed since the 1990s, the price-setting behavior of firms is likely to change and with it the inflation dynamics.

From a policy perspective, therefore, two important issues arise. First, how sensitive are the short-run inflation dynamics to such shifts in the economic environment? Particularly whenever the structure of the Phillips curve is tied to the ad hoc characterization of price stickiness proposed by Calvo (1983). Second, how well does a Phillips curve based on the assumption of unchanged price-setting behavior of firms (including infrequent price changes at constant rates and pricing-to-market) describe the inflation dynamics of an economy thought to be in continuous evolution and adaptation to new circumstances?

The $\boldsymbol{A S}$ Equations ${ }^{28}$. The AS equations, $A S^{H}, A S^{H *}, A S^{F}$ and $A S^{F *}$, come from a model with Calvostyle price-setting firms and LCP pricing. The pair of equations $A S^{H}$ and $A S^{H *}$ is obtained from the $\log$ linearization of the optimal price-setting rules, equations (3.3.20) and (3.3.21), and the home and foreign price sub-indexes of the domestic bundle, equations (3.2.16) and (3.2.17). Similarly, I derive the pair $A S^{F}$ and $A S^{F *}$ from the log linearization of the foreign firms' first-order conditions, equations (3.3.26) and (3.3.27), and the price sub-indexes of the foreign bundle of goods, equations (3.2.16) and (3.2.17).

The Optimal Pricing in the Domestic Market for the Domestic Firm. I can log-linearize the optimal pricing equation in (3.3.20) as in Martínez-García (2007). Accordingly, in steady state the Dixit-

\footnotetext{
${ }^{28} \mathrm{An}$ important feature of the workhorse model is that while technologies are symmetric, the nominal side (pricing contracts) and the consumption preferences are asymmetric. This shows up on the aggregate supply (or $A S$ ) equations.
} 
Stiglitz pricing rule holds, then the log-linearization around the steady state can be expressed as,

$$
\mathbb{E}_{t}\left\{\sum_{\tau=0}^{\infty}(\beta \alpha)^{\tau}\left[\hat{f}_{t+\tau}^{H}-\widehat{g}_{t+\tau}^{H}\right]\right\} \approx 0,
$$

where the approximations are as follows,

$$
\begin{aligned}
& \widehat{f}_{t+\tau}^{H} \equiv \widehat{\widetilde{p}}_{t}(h)-\widehat{p}_{t+\tau}^{H}, \\
& \widehat{g}_{t+\tau}^{H} \equiv\left(\widehat{w}_{t+\tau}-\widehat{p}_{t+\tau}-\widehat{a}_{t+\tau}\right)+\left(\widehat{p}_{t+\tau}-\widehat{p}_{t+\tau}^{H}\right)
\end{aligned}
$$

I can re-write the optimal pricing equation simply as,

$$
\mathbb{E}_{t}\left\{\sum_{\tau=0}^{\infty}(\beta \alpha)^{\tau}\left[\left(\widehat{\widetilde{p}}_{t}(h)-\widehat{p}_{t+\tau}^{H}\right)-\left(\widehat{w}_{t+\tau}-\widehat{p}_{t+\tau}-\widehat{a}_{t+\tau}\right)-\left(\widehat{p}_{t+\tau}-\widehat{p}_{t+\tau}^{H}\right)\right]\right\} \approx 0 .
$$

Notice that I can re-express the price indexes $\widehat{p}_{t+\tau}^{H}$ and $\widehat{p}_{t+\tau}^{H *}$ respectively as $\widehat{p}_{t+\tau}^{H}=\widehat{p}_{t-1}^{H}+\sum_{i=0}^{\tau} \widehat{\pi}_{t+i}^{H}$ and $\widehat{p}_{t+\tau}^{H *}=\widehat{p}_{t-1}^{H *}+\sum_{i=0}^{\tau} \widehat{\pi}_{t+i}^{H *}$. Hence, the optimal pricing equation becomes,

$$
\widehat{\widetilde{p}}_{t}(h)-\widehat{p}_{t-1}^{H} \approx(1-\beta \alpha) \mathbb{E}_{t}\left\{\sum_{\tau=0}^{\infty}(\beta \alpha)^{\tau}\left[\sum_{i=0}^{\tau} \widehat{\pi}_{t+i}^{H}+\left(\widehat{w}_{t+\tau}-\widehat{p}_{t+\tau}^{H}-\widehat{a}_{t+\tau}\right)\right]\right\} .
$$

In other words, the difference between the price charged by a firm that can reset prices and the average price of all the firms who cannot re-optimize is given by a weighted function of current and future inflation expectations and the marginal costs.

The nominal marginal cost net of (constant) labor subsidies from (3.3.3) can be expressed as,

$$
\begin{aligned}
\widehat{m c}_{t} & \equiv\left(\widehat{w}_{t}-\widehat{a}_{t}\right), \\
\widehat{m c}_{t}^{*} & \equiv\left(\widehat{w}_{t}^{*}-\widehat{a}_{t}^{*}\right) .
\end{aligned}
$$

Furthermore, after a little bit of algebra, I also find out that,

$$
\sum_{\tau=0}^{\infty}(\beta \alpha)^{\tau}\left(\sum_{i=0}^{\tau} \widehat{\pi}_{t+i}^{H}\right)=\left(\sum_{j=0}^{\infty}(\beta \alpha)^{j}\right)\left(\sum_{\tau=0}^{\infty}(\beta \alpha)^{\tau} \widehat{\pi}_{t+\tau}^{H}\right)=\frac{1}{1-\beta \alpha}\left[\sum_{\tau=0}^{\infty}(\beta \alpha)^{\tau} \widehat{\pi}_{t+\tau}^{H}\right] .
$$

Therefore, the optimal pricing equation can be generically written as,

$$
\widehat{\widetilde{p}}_{t}(h)-\widehat{p}_{t-1}^{H} \approx \mathbb{E}_{t}\left[\sum_{\tau=0}^{\infty}(\beta \alpha)^{\tau} \widehat{\pi}_{t+\tau}^{H}\right]+(1-\beta \alpha) \mathbb{E}_{t}\left[\sum_{\tau=0}^{\infty}(\beta \alpha)^{\tau}\left(\widehat{m c}_{t+\tau}-\widehat{p}_{t+\tau}^{H}\right)\right],
$$

which is clearly a function of current and future marginal costs. I can easily re-write the above expression under rational expectations as follows,

$$
\widehat{\widetilde{p}}_{t}(h)-\widehat{p}_{t-1}^{H} \approx \widehat{\pi}_{t}^{H}+(1-\beta \alpha)\left(\widehat{m c}_{t}-\widehat{p}_{t}^{H}\right)+\beta \alpha \mathbb{E}_{t}\left(\widehat{\widetilde{p}}_{t+1}(h)-\widehat{p}_{t}^{H}\right) .
$$

Equation (7.3.9) is the forward-looking (no-bubbles) solution to this equation. 
The Optimal Pricing in the Foreign Market for the Domestic Firm. In steady state the DixitStiglitz pricing rule holds, then the log-linearization around the steady state can be expressed as,

$$
\mathbb{E}_{t}\left\{\sum_{\tau=0}^{\infty}(\beta \alpha)^{\tau}\left[\widehat{f}_{t+\tau}^{H *}-\widehat{g}_{t+\tau}^{H *}\right]\right\} \approx 0,
$$

where the approximations are as follows,

$$
\begin{aligned}
& \widehat{f}_{t+\tau}^{H *} \equiv \widehat{\widetilde{p}}_{t}^{*}(h)-\widehat{p}_{t+\tau}^{H *}+\left(\widehat{s}_{t+\tau}+\widehat{p}_{t+\tau}^{H *}-\widehat{p}_{t+\tau}^{H}\right) \\
& \widehat{g}_{t+\tau}^{H *} \equiv\left(\widehat{w}_{t+\tau}-\widehat{p}_{t+\tau}-\widehat{a}_{t+\tau}\right)+\left(\widehat{p}_{t+\tau}-\widehat{p}_{t+\tau}^{H}\right)
\end{aligned}
$$

I can re-write the optimal pricing equation simply as,

$$
\mathbb{E}_{t}\left\{\sum_{\tau=0}^{\infty}(\beta \alpha)^{\tau}\left[\left(\widehat{\vec{p}}_{t}^{*}(h)-\widehat{p}_{t+\tau}^{H *}\right)+\left(\widehat{s}_{t+\tau}+\widehat{p}_{t+\tau}^{H *}-\widehat{p}_{t+\tau}^{H}\right)-\left(\widehat{w}_{t+\tau}-\widehat{p}_{t+\tau}-\widehat{a}_{t+\tau}\right)-\left(\widehat{p}_{t+\tau}-\widehat{p}_{t+\tau}^{H}\right)\right]\right\} \approx 0 .
$$

Notice that I can re-express the price indexes $\widehat{p}_{t+\tau}^{H}$ and $\widehat{p}_{t+\tau}^{H *}$ respectively as $\widehat{p}_{t+\tau}^{H}=\widehat{p}_{t-1}^{H}+\sum_{i=0}^{\tau} \widehat{\pi}_{t+i}^{H}$ and $\widehat{p}_{t+\tau}^{H *}=\widehat{p}_{t-1}^{H *}+\sum_{i=0}^{\tau} \widehat{\pi}_{t+i}^{H *}$. Hence, the optimal pricing equation becomes,

$$
\widehat{\widetilde{p}}_{t}^{*}(h)-\widehat{p}_{t-1}^{H *} \approx(1-\beta \alpha) \mathbb{E}_{t}\left\{\sum_{\tau=0}^{\infty}(\beta \alpha)^{\tau}\left[\sum_{i=0}^{\tau} \widehat{\pi}_{t+i}^{H *}+\left(\widehat{w}_{t+\tau}-\widehat{p}_{t+\tau}^{H *}-\widehat{s}_{t+\tau}-\widehat{a}_{t+\tau}\right)\right]\right\} .
$$

In other words, the difference between the price charged by a firm that can reset prices and the average price of all the local firms that cannot re-optimize is given by a weighted function of current and future inflation expectations and the marginal costs.

The nominal marginal cost net of (constant) labor subsidies from (3.3.3) can be expressed as,

$$
\begin{aligned}
\widehat{m c}_{t} & \equiv\left(\widehat{w}_{t}-\widehat{a}_{t}\right), \\
\widehat{m c}_{t}^{*} & \equiv\left(\widehat{w}_{t}^{*}-\widehat{a}_{t}^{*}\right) .
\end{aligned}
$$

Furthermore, after a little bit of algebra, I also find out that,

$$
\sum_{\tau=0}^{\infty}(\beta \alpha)^{\tau}\left(\sum_{i=0}^{\tau} \widehat{\pi}_{t+i}^{H *}\right)=\left(\sum_{j=0}^{\infty}(\beta \alpha)^{j}\right)\left(\sum_{\tau=0}^{\infty}(\beta \alpha)^{\tau} \widehat{\pi}_{t+\tau}^{H *}\right)=\frac{1}{1-\beta \alpha}\left[\sum_{\tau=0}^{\infty}(\beta \alpha)^{\tau} \widehat{\pi}_{t+\tau}^{H *}\right] .
$$

Therefore, the optimal pricing equation can be generically written as,

$$
\widehat{\widetilde{p}}_{t}^{*}(h)-\widehat{p}_{t-1}^{H *} \approx \mathbb{E}_{t}\left[\sum_{\tau=0}^{\infty}(\beta \alpha)^{\tau} \widehat{\pi}_{t+\tau}^{H *}\right]+(1-\beta \alpha) \mathbb{E}_{t}\left[\sum_{\tau=0}^{\infty}(\beta \alpha)^{\tau}\left(\widehat{m c}_{t+\tau}-\widehat{p}_{t+\tau}^{H *}-\widehat{s}_{t+\tau}\right)\right],
$$

which is clearly a function of current and future marginal costs. I can easily re-write the above expression under rational expectations as follows,

$$
\widehat{\widetilde{p}}_{t}^{*}(h)-\widehat{p}_{t-1}^{H *} \approx \widehat{\pi}_{t}^{H *}+(1-\beta \alpha)\left(\widehat{m c}_{t}-\widehat{p}_{t}^{H *}-\widehat{s}_{t}\right)+\beta \alpha \mathbb{E}_{t}\left(\widehat{\widetilde{p}}_{t+1}^{*}(h)-\widehat{p}_{t}^{H *}\right) .
$$

Equation (7.3.19) is the forward-looking (no-bubbles) solution to this equation. 
The Optimal Pricing in the Domestic Market for the Foreign Firm. In steady state the DixitStiglitz pricing rule holds, then the log-linearization around the steady state can be expressed as,

$$
\mathbb{E}_{t}\left\{\sum_{\tau=0}^{\infty}\left(\beta \alpha^{*}\right)^{\tau}\left[\hat{f}_{t+\tau}^{F}-\widehat{g}_{t+\tau}^{F}\right]\right\} \approx 0
$$

where the approximations are as follows,

$$
\begin{aligned}
\widehat{f}_{t+\tau}^{F} & \equiv \widehat{\widetilde{p}}_{t}(f)-\widehat{p}_{t+\tau}^{F}+\left(\widehat{p}_{t+\tau}^{F}-\widehat{p}_{t+\tau}^{F *}-\widehat{s}_{t+\tau}\right) \\
\widehat{g}_{t+\tau}^{F} & \equiv\left(\widehat{w}_{t+\tau}^{*}-\widehat{p}_{t+\tau}^{*}-\widehat{a}_{t+\tau}^{*}\right)+\left(\widehat{p}_{t+\tau}^{*}-\widehat{p}_{t+\tau}^{F *}\right)
\end{aligned}
$$

I can re-write the optimal pricing equation simply as,

$\mathbb{E}_{t}\left\{\sum_{\tau=0}^{\infty}\left(\beta \alpha^{*}\right)^{\tau}\left[\left(\widehat{\widetilde{p}}_{t}(f)-\widehat{p}_{t+\tau}^{F}\right)+\left(\widehat{p}_{t+\tau}^{F}-\widehat{p}_{t+\tau}^{F *}-\widehat{s}_{t+\tau}\right)-\left(\widehat{w}_{t+\tau}^{*}-\widehat{p}_{t+\tau}^{*}-\widehat{a}_{t+\tau}^{*}\right)-\left(\widehat{p}_{t+\tau}^{*}-\widehat{p}_{t+\tau}^{F *}\right)\right]\right\} \approx 0$.

Notice that I can re-express the price indexes $\widehat{p}_{t+\tau}^{F}$ and $\widehat{p}_{t+\tau}^{F *}$ respectively as $\widehat{p}_{t+\tau}^{F}=\widehat{p}_{t-1}^{F}+\sum_{i=0}^{\tau} \widehat{\pi}_{t+i}^{F}$ and $\widehat{p}_{t+\tau}^{F *}=\widehat{p}_{t-1}^{F *}+\sum_{i=0}^{\tau} \widehat{\pi}_{t+i}^{F *}$. Hence, the optimal pricing equation becomes,

$$
\widehat{\widetilde{p}}_{t}(f)-\widehat{p}_{t-1}^{F} \approx\left(1-\beta \alpha^{*}\right) \mathbb{E}_{t}\left\{\sum_{\tau=0}^{\infty}\left(\beta \alpha^{*}\right)^{\tau}\left[\sum_{i=0}^{\tau} \widehat{\pi}_{t+i}^{F}+\left(\widehat{w}_{t+\tau}^{*}-\widehat{p}_{t+\tau}^{F}+\widehat{s}_{t+\tau}-\widehat{a}_{t+\tau}^{*}\right)\right]\right\} .
$$

In other words, the difference between the price charged by a firm that can reset prices and the average price of all the local firms that cannot reset their prices is given by a weighted function of current and future inflation expectations and the marginal costs.

The nominal marginal cost net of (constant) labor subsidies from (3.3.3) can be expressed as,

$$
\begin{aligned}
\widehat{m c}_{t} & \equiv\left(\widehat{w}_{t}-\widehat{a}_{t}\right), \\
\widehat{m c}_{t}^{*} & \equiv\left(\widehat{w}_{t}^{*}-\widehat{a}_{t}^{*}\right) .
\end{aligned}
$$

Furthermore, after a little bit of algebra, I also find out that,

$$
\sum_{\tau=0}^{\infty}\left(\beta \alpha^{*}\right)^{\tau}\left(\sum_{i=0}^{\tau} \widehat{\pi}_{t+i}^{F}\right)=\left(\sum_{j=0}^{\infty}\left(\beta \alpha^{*}\right)^{j}\right)\left(\sum_{\tau=0}^{\infty}\left(\beta \alpha^{*}\right)^{\tau} \widehat{\pi}_{t+\tau}^{F}\right)=\frac{1}{1-\beta \alpha^{*}}\left[\sum_{\tau=0}^{\infty}\left(\beta \alpha^{*}\right)^{\tau} \widehat{\pi}_{t+\tau}^{F}\right] .
$$

Therefore, the optimal pricing equation can be generically written as,

$$
\widehat{\widetilde{p}}_{t}(f)-\widehat{p}_{t-1}^{F} \approx \mathbb{E}_{t}\left[\sum_{\tau=0}^{\infty}\left(\beta \alpha^{*}\right)^{\tau} \widehat{\pi}_{t+\tau}^{F}\right]+\left(1-\beta \alpha^{*}\right) \mathbb{E}_{t}\left[\sum_{\tau=0}^{\infty}\left(\beta \alpha^{*}\right)^{\tau}\left(\widehat{m c}_{t+\tau}^{*}-\widehat{p}_{t+\tau}^{F}+\widehat{s}_{t+\tau}\right)\right]
$$

which is clearly a function of current and future marginal costs. I can easily re-write the above expression under rational expectations as follows,

$$
\widehat{\widetilde{p}}_{t}(f)-\widehat{p}_{t-1}^{F} \approx \widehat{\pi}_{t}^{F}+\left(1-\beta \alpha^{*}\right)\left(\widehat{m c}_{t}^{*}-\widehat{p}_{t}^{F}+\widehat{s}_{t}\right)+\beta \alpha^{*} \mathbb{E}_{t}\left(\widehat{\widetilde{p}}_{t+1}(f)-\widehat{p}_{t}^{F}\right) .
$$

Equation (7.3.29) is the forward-looking (no-bubbles) solution to this equation. 
The Optimal Pricing in the Foreign Market for the Foreign Firm. In steady state the Dixit-Stiglitz pricing rule holds, then the log-linearization around the steady state can be expressed as,

$$
\mathbb{E}_{t}\left\{\sum_{\tau=0}^{\infty}\left(\beta \alpha^{*}\right)^{\tau}\left[\hat{f}_{t+\tau}^{F *}-\widehat{g}_{t+\tau}^{F *}\right]\right\} \approx 0
$$

where the approximations are as follows,

$$
\begin{aligned}
\widehat{f}_{t+\tau}^{F} & \equiv \widehat{\widetilde{p}}_{t}^{*}(f)-\widehat{p}_{t+\tau}^{F *}, \\
\widehat{g}_{t+\tau}^{F} & \equiv\left(\widehat{w}_{t+\tau}^{*}-\widehat{p}_{t+\tau}^{*}-\widehat{a}_{t+\tau}^{*}\right)+\left(\widehat{p}_{t+\tau}^{*}-\widehat{p}_{t+\tau}^{F *}\right)
\end{aligned}
$$

I can re-write the optimal pricing equation simply as,

$$
\mathbb{E}_{t}\left\{\sum_{\tau=0}^{\infty}\left(\beta \alpha^{*}\right)^{\tau}\left[\left(\widehat{\widetilde{p}}_{t}^{*}(f)-\widehat{p}_{t+\tau}^{F *}\right)-\left(\widehat{w}_{t+\tau}^{*}-\widehat{p}_{t+\tau}^{*}-\widehat{a}_{t+\tau}^{*}\right)-\left(\widehat{p}_{t+\tau}^{*}-\widehat{p}_{t+\tau}^{F *}\right)\right]\right\} \approx 0
$$

Notice that I can re-express the price indexes $\widehat{p}_{t+\tau}^{F}$ and $\widehat{p}_{t+\tau}^{F *}$ respectively as $\widehat{p}_{t+\tau}^{F}=\widehat{p}_{t-1}^{F}+\sum_{i=0}^{\tau} \widehat{\pi}_{t+i}^{F}$ and $\widehat{p}_{t+\tau}^{F *}=\widehat{p}_{t-1}^{F *}+\sum_{i=0}^{\tau} \widehat{\pi}_{t+i}^{F *}$. Hence, the optimal pricing equation becomes,

$$
\widehat{\widetilde{p}}_{t}^{*}(f)-\widehat{p}_{t-1}^{F *} \approx\left(1-\beta \alpha^{*}\right) \mathbb{E}_{t}\left\{\sum_{\tau=0}^{\infty}\left(\beta \alpha^{*}\right)^{\tau}\left[\sum_{i=0}^{\tau} \widehat{\pi}_{t+i}^{F *}+\left(\widehat{w}_{t+\tau}^{*}-\widehat{p}_{t+\tau}^{F *}-\widehat{a}_{t+\tau}^{*}\right)\right]\right\} .
$$

In other words, the difference between the price charged by a firm that can reset prices and the average price of all the local firms who cannot reset their prices is given by a weighted function of current and future inflation expectations and the marginal costs.

The nominal marginal cost net of (constant) labor subsidies from (3.3.3) can be expressed as,

$$
\begin{aligned}
\widehat{m c}_{t} & \equiv\left(\widehat{w}_{t}-\widehat{a}_{t}\right), \\
\widehat{m c}_{t}^{*} & \equiv\left(\widehat{w}_{t}^{*}-\widehat{a}_{t}^{*}\right)
\end{aligned}
$$

Furthermore, after a little bit of algebra, I also find out that,

$$
\sum_{\tau=0}^{\infty}\left(\beta \alpha^{*}\right)^{\tau}\left(\sum_{i=0}^{\tau} \widehat{\pi}_{t+i}^{F *}\right)=\left(\sum_{j=0}^{\infty}\left(\beta \alpha^{*}\right)^{j}\right)\left(\sum_{\tau=0}^{\infty}\left(\beta \alpha^{*}\right)^{\tau} \widehat{\pi}_{t+\tau}^{F *}\right)=\frac{1}{1-\beta \alpha^{*}}\left[\sum_{\tau=0}^{\infty}\left(\beta \alpha^{*}\right)^{\tau} \widehat{\pi}_{t+\tau}^{F *}\right]
$$

Therefore, the optimal pricing equation can be generically written as,

$$
\widehat{\widetilde{p}}_{t}^{*}(f)-\widehat{p}_{t-1}^{F *} \approx \mathbb{E}_{t}\left[\sum_{\tau=0}^{\infty}\left(\beta \alpha^{*}\right)^{\tau} \widehat{\pi}_{t+\tau}^{F *}\right]+\left(1-\beta \alpha^{*}\right) \mathbb{E}_{t}\left[\sum_{\tau=0}^{\infty}\left(\beta \alpha^{*}\right)^{\tau}\left(\widehat{m c}_{t+\tau}^{*}-\widehat{p}_{t+\tau}^{F *}\right)\right],
$$

which is clearly a function of current and future marginal costs. I can easily re-write the above expression under rational expectations as follows,

$$
\widehat{\widetilde{p}}_{t}^{*}(f)-\widehat{p}_{t-1}^{F *} \approx \widehat{\pi}_{t}^{F *}+\left(1-\beta \alpha^{*}\right)\left(\widehat{m c}_{t}^{*}-\widehat{p}_{t}^{F *}\right)+\beta \alpha^{*} \mathbb{E}_{t}\left(\widehat{\widetilde{p}}_{t+1}^{*}(f)-\widehat{p}_{t}^{F *}\right) .
$$

Equation (7.3.39) is the forward-looking (no-bubbles) solution to this equation. 
The Price Sub-Indexes of Home and Foreign Bundles. In a symmetric equilibrium under sticky prices, the aggregate price sub-indexes in (3.2.16) - (3.2.17) can be expressed as follows,

$$
\begin{aligned}
P_{t}^{H} & =\left[\alpha\left(P_{t-1}^{H}\right)^{1-\theta}+(1-\alpha)\left(\widetilde{P}_{t}(h)\right)^{1-\theta}\right]^{\frac{1}{1-\theta}}, \\
P_{t}^{H *} & =\left[\alpha\left(P_{t-1}^{H *}\right)^{1-\theta}+(1-\alpha)\left(\widetilde{P}_{t}^{*}(h)\right)^{1-\theta}\right]^{\frac{1}{1-\theta}}, \\
P_{t}^{F} & =\left[\alpha^{*}\left(P_{t-1}^{F}\right)^{1-\theta}+\left(1-\alpha^{*}\right)\left(\widetilde{P}_{t}(f)\right)^{1-\theta}\right]^{\frac{1}{1-\theta}}, \\
P_{t}^{F *} & =\left[\alpha^{*}\left(P_{t-1}^{F *}\right)^{1-\theta}+\left(1-\alpha^{*}\right)\left(\widetilde{P}_{t}^{*}(f)\right)^{1-\theta}\right]^{\frac{1}{1-\theta}},
\end{aligned}
$$

which accounts for the fact that a proportion of firms maintain their prices while the remaining firms reoptimize. The re-optimizing firms also use a symmetric pricing rule. In a zero-inflation steady state, it must hold that $\bar{P}^{H}=\widetilde{\widetilde{P}}(h), \bar{P}^{H *}=\overline{\widetilde{P}}^{*}(h), \bar{P}^{F}=\overline{\widetilde{P}}(f)$ and $\bar{P}^{F *}=\overline{\widetilde{P}}^{*}(f)$. Hence, the log-linear approximation of these price sub-indexes becomes simply,

$$
\begin{aligned}
\widehat{p}_{t}^{H} & \approx \alpha \widehat{p}_{t-1}^{H}+(1-\alpha) \widehat{\widetilde{p}}_{t}(h), \\
\widehat{p}_{t}^{H *} & \approx \alpha \widehat{p}_{t-1}^{H *}+(1-\alpha) \widehat{\widetilde{p}}_{t}^{*}(h), \\
\widehat{p}_{t}^{F} & \approx \alpha^{*} \widehat{p}_{t-1}^{F}+\left(1-\alpha^{*}\right) \widehat{\widetilde{p}}_{t}(f), \\
\widehat{p}_{t}^{F *} & \approx \alpha^{*} \widehat{p}_{t-1}^{F *}+\left(1-\alpha^{*}\right) \widehat{\widetilde{p}}_{t}^{*}(f) .
\end{aligned}
$$

A straightforward manipulation of these equations tells me that the difference between the optimal pricing rules, $\widehat{\widetilde{p}}_{t}(h)$ and $\widehat{\widetilde{p}}_{t}^{*}(h)$, and the price sub-indexes, $\widehat{p}_{t}^{H}$ and $\widehat{p}_{t}^{H *}$, is proportional to the inflation rate in logs, i.e.

$$
\left[\widehat{\widetilde{p}}_{t}(h)-\widehat{p}_{t-1}^{H}\right] \approx\left(\frac{1}{1-\alpha}\right) \widehat{\pi}_{t}^{H},\left[\widehat{\widetilde{p}}_{t}^{*}(h)-\widehat{p}_{t-1}^{H *}\right] \approx\left(\frac{1}{1-\alpha}\right) \widehat{\pi}_{t}^{H *} .
$$

Similarly, the difference between the optimal pricing rule, $\widehat{\widetilde{p}}_{t}(f)$ and $\widehat{\widetilde{p}}_{t}^{*}(f)$, and the price sub-indexes, $\widehat{p}_{t}^{F}$ and $\widehat{p}_{t}^{F *}$, is proportional to the inflation rate in logs, i.e.

$$
\left[\widehat{\widetilde{p}}_{t}(f)-\widehat{p}_{t-1}^{F}\right] \approx\left(\frac{1}{1-\alpha^{*}}\right) \widehat{\pi}_{t}^{F},\left[\widehat{\widetilde{p}}_{t}^{*}(f)-\widehat{p}_{t-1}^{F *}\right] \approx\left(\frac{1}{1-\alpha^{*}}\right) \widehat{\pi}_{t}^{F *}
$$

The Aggregate-Supply Equations for the Domestic Firm: $\boldsymbol{A} S^{H}$ and $\boldsymbol{A} \boldsymbol{S}^{\boldsymbol{H} *}$ The aggregate supply equations can be derived from the optimal pricing rules in (7.3.10) and (7.3.20), and the aggregation rules in (7.3.49). If I combine these results, I obtain the dynamics of inflation on domestically-produced goods in the model as,

$$
\begin{aligned}
\left(\frac{1}{1-\alpha}\right) \widehat{\pi}_{t}^{H} & \approx \widehat{\pi}_{t}^{H}+(1-\beta \alpha)\left(\widehat{m c}_{t}-\widehat{p}_{t}^{H}\right)+\beta \alpha\left(\frac{1}{1-\alpha}\right) \mathbb{E}_{t}\left(\widehat{\pi}_{t+1}^{H}\right), \\
\left(\frac{1}{1-\alpha}\right) \widehat{\pi}_{t}^{H *} & \approx \widehat{\pi}_{t}^{H *}+(1-\beta \alpha)\left(\widehat{m c}_{t}-\widehat{p}_{t}^{H *}-\widehat{s}_{t}\right)+\beta \alpha\left(\frac{1}{1-\alpha}\right) \mathbb{E}_{t}\left(\widehat{\pi}_{t+1}^{H *}\right),
\end{aligned}
$$


or, more compactly,

$$
\begin{aligned}
\widehat{\pi}_{t}^{H} & \approx \beta \mathbb{E}_{t}\left(\widehat{\pi}_{t+1}^{H}\right)+\frac{(1-\alpha)(1-\beta \alpha)}{\alpha}\left(\widehat{m c}_{t}-\widehat{p}_{t}^{H}\right) \\
\widehat{\pi}_{t}^{H *} & \approx \beta \mathbb{E}_{t}\left(\widehat{\pi}_{t+1}^{H *}\right)+\frac{(1-\alpha)(1-\beta \alpha)}{\alpha}\left(\widehat{m c}_{t}-\widehat{p}_{t}^{H *}-\widehat{s}_{t}\right) .
\end{aligned}
$$

These equations are central in my derivations of the Phillips curve for both economies.

The Aggregate-Supply Equations for the Foreign Firm: $\boldsymbol{A} \boldsymbol{S}^{\boldsymbol{F}}$ and $\boldsymbol{A} \boldsymbol{S}^{\boldsymbol{F} *}$ The aggregate supply equations can be derived from the optimal pricing rules in (7.3.30), and (7.3.40), and the aggregation rules in (7.3.50). If I combine these results, I obtain the dynamics of inflation on foreign-produced goods in the model as,

$$
\begin{aligned}
\left(\frac{1}{1-\alpha^{*}}\right) \widehat{\pi}_{t}^{F} & \approx \widehat{\pi}_{t}^{F}+\left(1-\beta \alpha^{*}\right)\left(\widehat{m c}_{t}^{*}-\widehat{p}_{t}^{F}+\widehat{s}_{t}\right)+\beta \alpha^{*}\left(\frac{1}{1-\alpha^{*}}\right) \mathbb{E}_{t}\left(\widehat{\pi}_{t+1}^{F}\right), \\
\left(\frac{1}{1-\alpha^{*}}\right) \widehat{\pi}_{t}^{F *} & \approx \widehat{\pi}_{t}^{F *}+\left(1-\beta \alpha^{*}\right)\left(\widehat{m c}_{t}^{*}-\widehat{p}_{t}^{F *}\right)+\beta \alpha^{*}\left(\frac{1}{1-\alpha^{*}}\right) \mathbb{E}_{t}\left(\widehat{\pi}_{t+1}^{F *}\right)
\end{aligned}
$$

or, more compactly,

$$
\begin{aligned}
\widehat{\pi}_{t}^{F} & \approx \beta \mathbb{E}_{t}\left(\widehat{\pi}_{t+1}^{F}\right)+\frac{\left(1-\alpha^{*}\right)\left(1-\beta \alpha^{*}\right)}{\alpha^{*}}\left(\widehat{m c}_{t}^{*}-\widehat{p}_{t}^{F}+\widehat{s}_{t}\right), \\
\widehat{\pi}_{t}^{F *} & \approx \beta \mathbb{E}_{t}\left(\widehat{\pi}_{t+1}^{F *}\right)+\frac{\left(1-\alpha^{*}\right)\left(1-\beta \alpha^{*}\right)}{\alpha^{*}}\left(\widehat{m c}_{t}^{*}-\widehat{p}_{t}^{F *}\right) .
\end{aligned}
$$

These equations are central in my derivations of the Phillips curve for both economies too.

The Relative $\boldsymbol{A S}$ Equations. It follows from the two domestic aggregate supply curves in (7.3.53) and (7.3.54) that,

$$
\widehat{\pi}_{t}^{H}-\widehat{\pi}_{t}^{H *} \approx \beta \mathbb{E}_{t}\left(\widehat{\pi}_{t+1}^{H}-\widehat{\pi}_{t+1}^{H *}\right)+\frac{(1-\alpha)(1-\beta \alpha)}{\alpha}\left[\widehat{s}_{t}-\left(\widehat{p}_{t}^{H}-\widehat{p}_{t}^{H *}\right)\right] .
$$

It follows from the two domestic aggregate supply curves in (7.3.53) and (7.3.54) that,

$$
\widehat{\pi}_{t}^{F}-\widehat{\pi}_{t}^{F *} \approx \beta \mathbb{E}_{t}\left(\widehat{\pi}_{t+1}^{F}-\widehat{\pi}_{t+1}^{F *}\right)+\frac{\left(1-\alpha^{*}\right)\left(1-\beta \alpha^{*}\right)}{\alpha^{*}}\left[\widehat{s}_{t}-\left(\widehat{p}_{t}^{F}-\widehat{p}_{t}^{F *}\right)\right] .
$$

In either case the structure of the pricing equations is such that marginal cost (whatever that might be) completely drops out of the equation. This explains why pricing differences in the workhorse international macro model are closely linked to the nominal exchange rate, and why the standard model has such a hard time explaining the low degree of pass-through found in the data.

The Aggregate $\boldsymbol{A} \boldsymbol{S}$ Equations: The Inflation Dynamics. The inflation dynamics in the domestic country can be derived by applying the aggregation rule in (7.1.1) to equations (7.3.53) and (7.3.57). Simple algebra gives me the following expression,

$$
\widehat{\pi}_{t} \approx \beta \mathbb{E}_{t}\left(\widehat{\pi}_{t+1}\right)+\frac{(1-\alpha)(1-\beta \alpha)}{\alpha} \xi\left(\widehat{m c}_{t}-\widehat{p}_{t}^{H}\right)+\frac{\left(1-\alpha^{*}\right)\left(1-\beta \alpha^{*}\right)}{\alpha^{*}}(1-\xi)\left(\widehat{m c}_{t}^{*}-\widehat{p}_{t}^{F}+\widehat{s}_{t}\right) .
$$


Whenever the Calvo contracts are symmetric across countries, i.e. $\alpha=\alpha^{*}$, it follows that the inflation dynamics take a more conventional form,

$$
\widehat{\pi}_{t} \approx \beta \mathbb{E}_{t}\left(\widehat{\pi}_{t+1}\right)+\frac{(1-\alpha)(1-\beta \alpha)}{\alpha}\left[\xi \widehat{m c}_{t}+(1-\xi) \widehat{m c}_{t}^{*}-\widehat{p}_{t}+(1-\xi) \widehat{s}_{t}\right]
$$

This shows that the direct effect on inflation from fluctuations of the nominal exchange rate depends on the proportion of foreign goods in the domestic consumption basket, $\xi$, as well as the degree of price stickiness, $\alpha$, and the subjective discount factor, $\beta$.

The inflation dynamics in the foreign country can be derived by applying the aggregation rule in (7.1.2) to equations (7.3.54) and (7.3.58). Simple algebra gives me the following expression,

$$
\widehat{\pi}_{t}^{*} \approx \beta \mathbb{E}_{t}\left(\widehat{\pi}_{t+1}^{*}\right)+\frac{(1-\alpha)(1-\beta \alpha)}{\alpha} \xi^{*}\left(\widehat{m c}_{t}-\widehat{p}_{t}^{H *}-\widehat{s}_{t}\right)+\frac{\left(1-\alpha^{*}\right)\left(1-\beta \alpha^{*}\right)}{\alpha^{*}}\left(1-\xi^{*}\right)\left(\widehat{m c}_{t}^{*}-\widehat{p}_{t}^{F *}\right) .
$$

Whenever the Calvo contracts are symmetric across countries, i.e. $\alpha=\alpha^{*}$, it follows that the inflation dynamics take their more conventional form,

$$
\widehat{\pi}_{t}^{*} \approx \beta \mathbb{E}_{t}\left(\widehat{\pi}_{t+1}^{*}\right)+\frac{(1-\alpha)(1-\beta \alpha)}{\alpha}\left[\xi^{*} \widehat{m c}_{t}+\left(1-\xi^{*}\right) \widehat{m c}_{t}^{*}-\widehat{p}_{t}^{*}-\xi^{*} \widehat{s}_{t}\right] .
$$

This shows that the direct effect on inflation from fluctuations of the nominal exchange rate depends on the proportion of domestic goods in the foreign consumption basket, $\xi^{*}$, as well as the degree of price stickiness, $\alpha$, and the subjective discount factor, $\beta$.

\subsection{The Labor Market Equilibrium Conditions and Marginal Costs}

The $\boldsymbol{L} \boldsymbol{M}$ Equations. The LM equations, $L M^{H}$ and $L M^{F}$, are easily derived from the first-order conditions of the household's problem in (3.2.38) - (3.2.39), the labor market clearing conditions in (3.3.12) - (3.3.13), and the linear-in-labor technologies in (3.3.1)-(3.3.2). Log-linearizing the labor supply functions in (3.2.38)(3.2.39) it follows that,

$$
\begin{aligned}
\widehat{w}_{t}-\widehat{p}_{t} & \approx \gamma \widehat{c}_{t}+\varphi \widehat{l}_{t}^{s}, \\
\widehat{w}_{t}^{*}-\widehat{p}_{t}^{*} & \approx \gamma \widehat{c}_{t}^{*}+\varphi \widehat{l}_{t}^{s *} .
\end{aligned}
$$

The combination of the labor market clearing conditions and the linear-in-labor technologies in (3.3.28) (3.3.29) (or in $(3.3 .12)$ - (3.3.13) and (3.3.1) - (3.3.2)) can be used to derive that,

$$
\begin{aligned}
& \widehat{y}_{t} \approx \widehat{a}_{t}+\widehat{l}_{t}^{s}, \\
& \widehat{y}_{t}^{*} \approx \widehat{a}_{t}^{*}+\widehat{l}_{t}^{s *} .
\end{aligned}
$$

Naturally, putting all these results together helps me characterize the path of real wages both in the domestic and foreign country. It follows that,

$$
\begin{aligned}
\widehat{w}_{t}-\widehat{p}_{t} & \approx \gamma \widehat{c}_{t}+\varphi \widehat{y}_{t}-\varphi \widehat{a}_{t}, \\
\widehat{w}_{t}^{*}-\widehat{p}_{t}^{*} & \approx \gamma \widehat{c}_{t}^{*}+\varphi \widehat{y}_{t}^{*}-\varphi \widehat{a}_{t}^{*} .
\end{aligned}
$$


These are the $L M^{H}$ and $L M^{F}$ equations of the model, and they are both instrumental in the determination of the marginal costs faced by firms in the economy.

The $\boldsymbol{Y}$ Equations. The output equations, $Y^{H}$ and $Y^{F}$, are easily derived from the aggregate goods market clearing conditions in (3.3.32) - (3.3.33). Almost mechanically, the aggregate market clearing conditions can be log-linearized to obtain that ${ }^{29}$,

$$
\begin{aligned}
\widehat{y}_{t} & \approx \frac{n\left(\frac{\xi}{n}\right)}{n\left(\frac{\xi}{n}\right)+(1-n)\left(\frac{\xi^{*}}{n}\right)}\left[-\theta\left[\int_{0}^{n}\left(\widehat{p}_{t}(h)-\widehat{p}_{t}^{H}\right) d h\right]-\sigma\left(\widehat{p}_{t}^{H}-\widehat{p}_{t}\right)+\widehat{c}_{t}\right]+ \\
& +\frac{(1-n)\left(\frac{\xi^{*}}{n}\right)}{n\left(\frac{\xi}{n}\right)+(1-n)\left(\frac{\xi^{*}}{n}\right)}\left[-\theta\left[\int_{0}^{n}\left(\widehat{p}_{t}^{*}(h)-\widehat{p}_{t}^{H *}\right) d h\right]-\sigma\left(\widehat{p}_{t}^{H *}-\widehat{p}_{t}^{*}\right)+\widehat{c}_{t}^{*}\right], \\
\widehat{y}_{t}^{*} & \approx \frac{n\left(\frac{1-\xi}{1-n}\right)}{n\left(\frac{1-\xi}{1-n}\right)+(1-n)\left(\frac{1-\xi^{*}}{1-n}\right)}\left[-\theta\left[\int_{n}^{1}\left(\widehat{p}_{t}(f)-\widehat{p}_{t}^{F}\right) d f\right]-\sigma\left(\widehat{p}_{t}^{F}-\widehat{p}_{t}\right)+\widehat{c}_{t}\right]+ \\
& +\frac{(1-n)\left(\frac{1-\xi^{*}}{1-n}\right)}{n\left(\frac{1-\xi}{1-n}\right)+(1-n)\left(\frac{1-\xi^{*}}{1-n}\right)}\left[-\theta\left[\int_{n}^{1}\left(\widehat{p}_{t}^{*}(f)-\widehat{p}_{t}^{F *}\right) d f\right]-\sigma\left(\widehat{p}_{t}^{F *}-\widehat{p}_{t}^{*}\right)+\widehat{c}_{t}^{*}\right] .
\end{aligned}
$$

Let me point out that the relative price dispersion has no first-order impact on the production in either country. This is because, up to a first-order approximation it follows that,

$$
\int_{0}^{n}\left(\widehat{p}_{t}(h)-\widehat{p}_{t}^{H}\right) d h=\int_{0}^{n}\left(\widehat{p}_{t}^{*}(h)-\widehat{p}_{t}^{H *}\right) d h=\int_{n}^{1}\left(\widehat{p}_{t}(f)-\widehat{p}_{t}^{F}\right) d f=\int_{n}^{1}\left(\widehat{p}_{t}^{*}(f)-\widehat{p}_{t}^{F *}\right) d f=0 .
$$

Therefore, I can re-write the domestic and foreign output as follows,

$$
\begin{aligned}
\widehat{y}_{t} & \approx \eta\left[-\sigma\left(\widehat{p}_{t}^{H}-\widehat{p}_{t}\right)+\widehat{c}_{t}\right]+(1-\eta)\left[-\sigma\left(\widehat{p}_{t}^{H *}-\widehat{p}_{t}^{*}\right)+\widehat{c}_{t}^{*}\right], \\
\widehat{y}_{t}^{*} & \approx \eta^{*}\left[-\sigma\left(\widehat{p}_{t}^{F}-\widehat{p}_{t}\right)+\widehat{c}_{t}\right]+\left(1-\eta^{*}\right)\left[-\sigma\left(\widehat{p}_{t}^{F *}-\widehat{p}_{t}^{*}\right)+\widehat{c}_{t}^{*}\right],
\end{aligned}
$$

where $\eta \equiv \frac{n\left(\frac{\xi}{n}\right)}{n\left(\frac{\xi}{n}\right)+(1-n)\left(\frac{\xi^{*}}{n}\right)}$ and $\eta^{*} \equiv \frac{n\left(\frac{1-\xi}{1-n}\right)}{n\left(\frac{1-\xi}{1-n}\right)+(1-n)\left(\frac{1-\xi^{*}}{1-n}\right)}$. Notice that $\eta=\eta^{*}=n$ whenever $\xi=\xi^{*}$, while $\eta=\xi$ and $\eta^{*}=\xi^{*}$ if $(1-n) \xi^{*}=n(1-\xi)$. Per capita output can also be conveniently re-written if I use the log-linearization of the CPI in (7.1.1) and (7.1.2) $\mathrm{as}^{30}$,

$$
\begin{aligned}
\widehat{y}_{t} & \approx-\sigma\left[\eta(1-\xi)\left(\widehat{p}_{t}^{H}-\widehat{p}_{t}^{F}\right)+(1-\eta)\left(1-\xi^{*}\right)\left(\widehat{p}_{t}^{H *}-\widehat{p}_{t}^{F *}\right)\right]+\left[\eta \widehat{c}_{t}+(1-\eta) \widehat{c}_{t}^{*}\right], \\
\widehat{y}_{t}^{*} & \approx \sigma\left[\eta^{*} \xi\left(\widehat{p}_{t}^{H}-\widehat{p}_{t}^{F}\right)+\left(1-\eta^{*}\right) \xi^{*}\left(\widehat{p}_{t}^{H *}-\widehat{p}_{t}^{F *}\right)\right]+\left[\eta^{*} \widehat{c}_{t}+\left(1-\eta^{*}\right) \widehat{c}_{t}^{*}\right],
\end{aligned}
$$

or, based on the log-linearization of the definition of relative exchange prices,

$$
\begin{aligned}
\widehat{y}_{t} & \approx \sigma\left[\eta(1-\xi) \widehat{r p}_{t}-(1-\eta)\left(1-\xi^{*}\right) \widehat{r p}_{t}^{*}\right]+\left[\eta \widehat{c}_{t}+(1-\eta) \widehat{c}_{t}^{*}\right], \\
\widehat{y}_{t}^{*} & \approx \sigma\left[-\eta^{*} \xi \widehat{r p}_{t}+\left(1-\eta^{*}\right) \xi^{*} \widehat{r p}_{t}^{*}\right]+\left[\eta^{*} \widehat{c}_{t}+\left(1-\eta^{*}\right) \widehat{c}_{t}^{*}\right],
\end{aligned}
$$

\footnotetext{
${ }^{29}$ The log-linearization is attained based on the normalization of the steady state that I discussed before in subsection 6.1 .

${ }^{30}$ It is necessary to check that these formulas are consistent with the approximation of the market clearing condition in (3.5.19). I do not check this consistency condition here, but I will discuss it later in the paper where it applies to the frictionless economy (subsection 7.7).
} 
where

$$
\begin{aligned}
\widehat{r p}_{t} & =\widehat{p}_{t}^{F}-\widehat{p}_{t}^{H} \\
\widehat{r p}_{t}^{*} & =-\left(\widehat{p}_{t}^{F *}-\widehat{p}_{t}^{H *}\right) .
\end{aligned}
$$

The $Y^{H}$ and $Y^{F}$ equations of the model are also instrumental in the determination of the marginal costs faced by firms in the economy.

The dispersion in relative prices that affects the output levels supplied by each firm is of second-order importance as noted in my comments before. Indeed, this claim has become part of the jargon used in the literature. I think, however, that it is a somewhat misleading statement based on partial analysis. It does not take into account the endogeneity of the right-hand side variables and the general equilibrium effects of price stickiness that pop-up (even for a first-order approximation) from a fully-specified DSGE model. In the workhorse model, this is quite easy to understand. After all, price stickiness still has a first-order impact on the pricing decision of firms and, therefore, alters both the path of inflation and output in this economy. The impact of price stickiness on the short-run dynamics of output is non-trivial, and can be measured relative to the frictionless allocation by the size of the output gap!

The Marginal Costs. The combination of the $L M$ and $Y$ equations allows me to characterize the marginal cost functions that are relevant for the pricing decisions of firms and for the dynamics of inflation. If I put all these equations together, I can re-write the nominal marginal costs as follows,

$$
\begin{aligned}
& \widehat{m c}_{t}-\widehat{p}_{t}^{H} \equiv\left(\widehat{w}_{t}-\widehat{a}_{t}\right)-\widehat{p}_{t}^{H} \\
& \quad \approx \gamma \widehat{c}_{t}+\varphi \eta\left[-\sigma\left(\widehat{p}_{t}^{H}-\widehat{p}_{t}\right)+\widehat{c}_{t}\right]+\varphi(1-\eta)\left[-\sigma\left(\widehat{p}_{t}^{H *}-\widehat{p}_{t}^{*}\right)+\widehat{c}_{t}^{*}\right]-(1+\varphi) \widehat{a}_{t}+\widehat{p}_{t}-\widehat{p}_{t}^{H}, \\
& \widehat{m c}_{t}^{*}-\widehat{p}_{t}^{F *} \equiv\left(\widehat{w}_{t}^{*}-\widehat{a}_{t}^{*}\right)-\widehat{p}_{t}^{F *} \\
& \quad \approx \gamma \widehat{c}_{t}^{*}+\varphi \eta^{*}\left[-\sigma\left(\widehat{p}_{t}^{F}-\widehat{p}_{t}\right)+\widehat{c}_{t}\right]+\varphi\left(1-\eta^{*}\right)\left[-\sigma\left(\widehat{p}_{t}^{F *}-\widehat{p}_{t}^{*}\right)+\widehat{c}_{t}^{*}\right]-(1+\varphi) \widehat{a}_{t}^{*}+\widehat{p}_{t}^{*}-\widehat{p}_{t}^{F *},
\end{aligned}
$$

Alternatively, using the log-linearization of the definition of relative exchange prices, I can re-label the marginal cost functions as follows,

$$
\begin{aligned}
& \widehat{m c}_{t}-\widehat{p}_{t}^{H} \approx \gamma \widehat{c}_{t}+\varphi \widehat{y}_{t}+(1-\xi) \widehat{r p}_{t}-(1+\varphi) \widehat{a}_{t} \\
& \approx \gamma \widehat{c}_{t}+\varphi \sigma\left[\eta(1-\xi) \widehat{r p}_{t}-(1-\eta)\left(1-\xi^{*}\right) \widehat{r p}_{t}^{*}\right]+\varphi\left[\eta \widehat{c}_{t}+(1-\eta) \widehat{c}_{t}^{*}\right]+(1-\xi) \widehat{r p}_{t}-(1+(7 \varphi t) . \\
& \widehat{m c}_{t}^{*}-\widehat{p}_{t}^{F *} \approx \gamma \widehat{c}_{t}^{*}+\varphi \widehat{y}_{t}^{*}+\xi^{*} \widehat{r p}_{t}^{*}-(1+\varphi) \widehat{a}_{t}^{*} \\
& \approx \gamma \widehat{c}_{t}^{*}+\varphi \sigma\left[-\eta^{*} \xi \widehat{r p}_{t}+\left(1-\eta^{*}\right) \xi^{*} \widehat{r}_{t}^{*}\right]+\varphi\left[\eta^{*} \widehat{c}_{t}+\left(1-\eta^{*}\right) \widehat{c}_{t}^{*}\right]+\xi^{*} \widehat{r p}_{t}^{*}-(1+\varphi) \widehat{a}_{t}^{*} \text {. }
\end{aligned}
$$


Based on this equation, it clearly follows that the marginal cost is a function of relative exchange prices and aggregate consumption. More generally, I can infer that,

$$
\begin{aligned}
& \widehat{m c}_{t}-\widehat{p}_{t}^{H} \approx \gamma \widehat{c}_{t}+\varphi\left[\eta \widehat{c}_{t}+(1-\eta) \widehat{c}_{t}^{*}\right]+\varphi \sigma\left[\eta(1-\xi) \widehat{r p}_{t}-(1-\eta)\left(1-\xi^{*}\right) \widehat{r p}_{t}^{*}\right]+(1-\xi) \widehat{r p}_{t}- \\
& -(1+\varphi) \widehat{a}_{t}, \\
& \left.\widehat{m c}_{t}-\widehat{p}_{t}^{H *}-\widehat{s}_{t} \approx \gamma \widehat{c}_{t}+\varphi\left[\eta \widehat{c}_{t}+(1-\eta) \widehat{c}_{t}^{*}\right]+\varphi \sigma\left[\eta(1-\xi) \widehat{r p}_{t}-(1-\eta)\left(1-\xi^{*}\right) \widehat{r p}_{t}^{*}\right]+\widehat{\operatorname{tot}}_{t}-\xi \widehat{r p}_{t}-{ }_{4.21}\right) \\
& -(1+\varphi) \widehat{a}_{t}, \\
& \widehat{m c}_{t}^{*}-\widehat{p}_{t}^{F}+\widehat{s}_{t} \approx \gamma \widehat{c}_{t}^{*}+\varphi\left[\eta^{*} \widehat{c}_{t}+\left(1-\eta^{*}\right) \widehat{c}_{t}^{*}\right]+\varphi \sigma\left[-\eta^{*} \xi \widehat{r p}_{t}+\left(1-\eta^{*}\right) \xi^{*} \widehat{r p}_{t}^{*}\right]-\widehat{t o t}_{t}-\left(1-\xi^{*}\right) \widehat{r p}_{t}^{*}-{ }_{7.22} \\
& -(1+\varphi) \widehat{a}_{t}^{*}, \\
& \widehat{m c}_{t}^{*}-\widehat{p}_{t}^{F *} \approx \gamma \widehat{c}_{t}^{*}+\varphi\left[\eta^{*} \widehat{c}_{t}+\left(1-\eta^{*}\right) \widehat{c}_{t}^{*}\right]+\varphi \sigma\left[-\eta^{*} \xi \widehat{p}_{t}+\left(1-\eta^{*}\right) \xi^{*} \widehat{r}_{t}^{*}\right]+\xi^{*} \widehat{r}_{t}^{*}- \\
& -(1+\varphi) \widehat{a}_{t}^{*} \text {. }
\end{aligned}
$$

Therefore, the inflation dynamics of the price sub-indexes in (7.3.53), (7.3.54), (7.3.57) and (7.3.58) are determined as follows,

$$
\begin{aligned}
& \widehat{\pi}_{t}^{H} \approx \beta \mathbb{E}_{t}\left[\widehat{\pi}_{t+1}^{H}\right]+\frac{(1-\alpha)(1-\beta \alpha)}{\alpha}\left[\begin{array}{c}
\gamma \widehat{c}_{t}+\varphi\left(\eta \widehat{c}_{t}+(1-\eta) \widehat{c}_{t}^{*}\right)+ \\
+\varphi \sigma\left(\eta(1-\xi) \widehat{r p}_{t}-(1-\eta)\left(1-\xi^{*}\right) \widehat{r p}_{t}^{*}\right)+(1-\xi) \widehat{r p}_{t}-(1+\varphi){\stackrel{(7.4}{a_{t}}}^{(7.4}
\end{array}\right] \\
& \widehat{\pi}_{t}^{H *} \approx \beta \mathbb{E}_{t}\left[\widehat{\pi}_{t+1}^{H *}\right]+\frac{(1-\alpha)(1-\beta \alpha)}{\alpha}\left[\begin{array}{c}
\gamma \widehat{c}_{t}+\varphi\left(\eta \widehat{c}_{t}+(1-\eta) \widehat{c}_{t}^{*}\right)+ \\
+\varphi \sigma\left(\eta(1-\xi) \widehat{r p}_{t}-(1-\eta)\left(1-\xi^{*}\right) \widehat{r p}_{t}^{*}\right)+\widehat{t o t}_{t}-\xi \widehat{r p}_{t}-(1+\varphi)(7.4 .25)
\end{array}\right]
\end{aligned}
$$

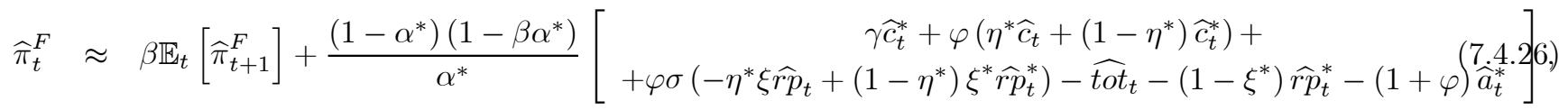

$$
\begin{aligned}
& \widehat{\pi}_{t}^{F *} \approx \beta \mathbb{E}_{t}\left[\widehat{\pi}_{t+1}^{F *}\right]+\frac{\left(1-\alpha^{*}\right)\left(1-\beta \alpha^{*}\right)}{\alpha^{*}}\left[\begin{array}{c}
\gamma \widehat{c}_{t}^{*}+\varphi\left(\eta^{*} \widehat{c}_{t}+\left(1-\eta^{*}\right) \widehat{c}_{t}^{*}\right)+ \\
+\varphi \sigma\left(-\eta^{*} \xi \widehat{r p}_{t}+\left(1-\eta^{*}\right) \xi^{*} \widehat{r p}_{t}^{*}\right)+\xi^{*} \widehat{r p}_{t}^{*}-(1+\varphi) \widehat{a}
\end{array}\right] .
\end{aligned}
$$

This system of four equations suffices to characterizes the dynamics of inflation in both the domestic and foreign economies when combined with the log-linearized CPI indexes in (7.1.1) and (7.1.2). The structure of these equations is the same independently of whether the asset markets are complete or incomplete in the model.

\subsection{The Equilibrium Trade Balance}

The $\boldsymbol{T B}$ Equation. The real trade balance equation, $T B$, comes from the log-linearization of equation (3.5.38) by parts, which holds whether asset markets are complete or incomplete. What I do is I log-linearize $n \frac{P P I_{t}}{P_{t}} Y_{t}$ and $n C_{t}$, and I define the log-linear approximation of the real trade balance as the difference. Then, it follows immediately that,

$$
\begin{aligned}
& \widehat{t b}_{t}-\widehat{p}_{t} \equiv \frac{\xi^{*}(1-n)}{\xi n+\xi^{*}(1-n)} \widehat{r s}_{t}+(1-\sigma) \frac{\xi n}{\xi n+\xi^{*}(1-n)}\left(\widehat{p}_{t}^{H}-\widehat{p}_{t}\right)+ \\
& \quad+(1-\sigma) \frac{\xi^{*}(1-n)}{\xi n+\xi^{*}(1-n)}\left(\widehat{p}_{t}^{H *}-\widehat{p}_{t}^{*}\right)-\frac{\xi^{*}(1-n)}{\xi n+\xi^{*}(1-n)} \widehat{c}_{t}^{R}
\end{aligned}
$$

where $\widehat{c}_{t}^{R} \equiv \widehat{c}_{t}-\widehat{c}_{t}^{*}$. I use the normalization of the steady state discussed in subsection 6.1 , which implies that $(1-n) \xi^{*}=n(1-\xi)$ ensures a zero trade balance in steady state, in order to simplify the equation 
above as,

$$
\widehat{t b}_{t}-\widehat{p}_{t} \equiv(1-\xi) \widehat{r s}_{t}+(1-\sigma)\left(\xi\left(\widehat{p}_{t}^{H}-\widehat{p}_{t}\right)+(1-\xi)\left(\widehat{p}_{t}^{H *}-\widehat{p}_{t}^{*}\right)\right)-(1-\xi) \widehat{c}_{t}^{R} .
$$

Finally, if I use the log-linearization of the CPI in (7.1.1) and (7.1.2), I am able to write the trade balance more compactly as,

$$
\widehat{t b}_{t}-\widehat{p}_{t} \equiv(1-\eta) \widehat{r s}_{t}+(\sigma-1)\left(\eta(1-\xi) \widehat{r p}_{t}-(1-\eta)\left(1-\xi^{*}\right) \widehat{r p}_{t}^{*}\right)-(1-\eta) \widehat{c}_{t}^{R},
$$

where the composite parameter is $\eta \equiv \frac{n\left(\frac{\xi}{n}\right)}{n\left(\frac{\xi}{n}\right)+(1-n)\left(\frac{\xi^{*}}{n}\right)}$ and the relative exchange prices are defined as,

$$
\begin{aligned}
\widehat{r p}_{t} & =\widehat{p}_{t}^{F}-\widehat{p}_{t}^{H}, \\
\widehat{r p}_{t}^{*} & =-\left(\widehat{p}_{t}^{F *}-\widehat{p}_{t}^{H *}\right) .
\end{aligned}
$$

In this equation, $\widehat{t b}_{t}$ measures the per capita nominal trade balance, and $\widehat{r p}_{t}^{W} \equiv \eta \xi(1-\xi) \widehat{r p}_{t}-(1-\eta) \xi\left(1-\xi^{*}\right) \widehat{r p}_{t}^{*}$ tracks the world relative exchange prices ${ }^{31}$.

It also shows that the trade balance expressed in real terms (in units of the domestic consumption basket of goods) depends on consumption in both countries as well as on changes in the real exchange rate and world relative exchange prices. If PPP holds, then expenditure switching across countries comes exclusively from fluctuations of the world relative exchange prices. If PPP does not hold, then, expenditure switching will no longer depend on the world relative exchange prices alone.

\subsection{The Money Market Equilibrium Conditions}

The $M M$ Equations. The MM equations, $M M^{H}$ and $M M^{F}$, are easily derived from the money-market clearing conditions in (3.4.8) - (3.4.9). Log-linearizing these equations it follows that ${ }^{32}$,

$$
\begin{aligned}
\widehat{m}_{t}-\widehat{p}_{t} & \approx \frac{\gamma}{\zeta} \widehat{c}_{t}-\frac{1}{\zeta}\left(\frac{\beta}{1-\beta}\right) \widehat{i}_{t}, \\
\widehat{m}_{t}^{*}-\widehat{p}_{t}^{*} & \approx \frac{\gamma}{\zeta} \widehat{c}_{t}^{*}-\frac{1}{\zeta}\left(\frac{\beta}{1-\beta}\right) \widehat{i}_{t}^{*},
\end{aligned}
$$

The equations say that the real balances are cointegrated with the nominal interest rate and with aggregate consumption (instead of aggregate output as in Cagan's money demand functions). Taking the difference between (7.6.1) and (7.6.2) and using the definition of the real exchange rate is easy to derive an expression for the nominal interest rate spread across both countries as,

$$
\widehat{i}_{t}-\widehat{i}_{t}^{*} \approx \zeta\left(\frac{1-\beta}{\beta}\right)\left[-\widehat{m}_{t}^{R}+\frac{\gamma}{\zeta} \widehat{c}_{t}^{R}+\widehat{p}_{t}^{R}\right]
$$

\footnotetext{
${ }^{31}$ Whenever $\widehat{r p}_{t}^{W}>0$, then foreign-produced goods are relatively more expensive and world demand is shifted towards home-produced goods.

${ }^{32}$ The approximation is calculated relative to gross interest rates, not relative to net interest rates.
} 
where $\widehat{c}_{t}^{R} \equiv \widehat{c}_{t}-\widehat{c}_{t}^{*}, \widehat{m}_{t}^{R} \equiv \widehat{m}_{t}-\widehat{m}_{t}^{*}$, and $\widehat{p}_{t}^{R} \equiv \widehat{p}_{t}-\widehat{p}_{t}^{*}=\widehat{s}_{t}-\widehat{r}_{t}$. This implies that,

$$
\widehat{i}_{t}^{R} \approx \zeta\left(\frac{1-\beta}{\beta}\right)\left[-\widehat{m}_{t}^{R}+\frac{\gamma}{\zeta} \widehat{c}_{t}^{R}+\widehat{p}_{t}^{R}\right]
$$

where $\widehat{i}_{t}^{R} \equiv \widehat{i}_{t}-\widehat{i}_{t}^{*}$. In words, this tells me that the interest rate differential is negatively proportional to the money supply differential, and positively proportional to the relative consumption and to the relative CPIs across countries.

\subsection{The Frictionless Allocation for Potential Output}

The labor market equilibrium conditions of the frictionless allocation in equations (4.3) and (4.4) can be easily log-linearized as,

$$
\begin{aligned}
-(1+\varphi) \widehat{a}_{t}+\gamma \widehat{\bar{c}}_{t}+\varphi \widehat{\bar{y}}_{t}-\left(\widehat{\bar{p}}_{t}^{H}-\widehat{\bar{p}}_{t}\right) & \approx 0, \\
-(1+\varphi) \widehat{a}_{t}^{*}+\gamma \widehat{\bar{c}}_{t}^{*}+\varphi \widehat{\bar{y}}_{t}^{*}-\left(\widehat{\bar{p}}_{t}^{F *}-\widehat{\bar{p}}_{t}^{*}\right) & \approx 0 .
\end{aligned}
$$

Similarly, the perfect international risk-sharing condition under complete asset markets described in equation (3.2.29) can be log-linearized to take the form,

$$
\widehat{\bar{c}}_{t} \approx \frac{1}{\gamma} \widehat{\overline{r s}}_{t}+\widehat{\bar{c}}_{t}^{*}
$$

Re-labelling equation (7.1.3) I can express the log-linearized real exchange rate as,

$$
\widehat{\overline{r s}}_{t} \approx \widehat{\bar{s}}_{t}+\left(\xi^{*} \widehat{\bar{p}}_{t}^{H *}+\left(1-\xi^{*}\right) \widehat{\bar{p}}_{t}^{F *}\right)-\left(\xi \hat{\bar{p}}_{t}^{H}+(1-\xi) \widehat{\bar{p}}_{t}^{F}\right),
$$

while the relevant definitions of terms of trade that apply to the frictionless model are $\widehat{\operatorname{tot}}_{t} \equiv \widehat{\bar{p}}_{t}^{F}-\widehat{\bar{p}}_{t}^{H}$ and ${\widehat{\text { tot }_{t}}}^{*} \equiv \widehat{\bar{p}}_{t}^{H *}-\widehat{\bar{p}}_{t}^{F *}=-\widehat{\overline{t o t}}_{t}$. The assumption of the frictionless model is that prices are fully flexible, so the LOOP holds at the variety level and, due to symmetry, also at the level of locally-produced bundles of goods. Hence, manipulating equation (7.1.3) I can re-write the log-linearized real exchange rate as a function of the terms of trade,

$$
\begin{aligned}
\widehat{\overline{r s}}_{t} & \equiv \widehat{\bar{p}}_{t}^{*}+\widehat{\bar{s}}_{t}-\widehat{\bar{p}}_{t} \\
& \approx\left(\xi-\xi^{*}\right)\left(\widehat{\bar{p}}_{t}^{F}-\widehat{\bar{p}}_{t}^{H}\right)=\left(\xi-\xi^{*}\right) \widehat{\overline{t o t}}_{t}
\end{aligned}
$$

In other words, up to a first-order approximation, the real exchange rate is unaffected by the elasticity of substitution across bundles, but depends upon the assumption of home bias in consumption.

Given that the LOOP holds under flexible prices (see equations (3.3.14) - (3.3.15)), it is possible to re-write the output equations for both countries as in (3.3.36) - (3.3.37). After re-labelling those equations to take account of the fact that I am referring to the frictionless allocation, I log-linearize them around the 
normalized steady state to obtain that,

$$
\begin{aligned}
& \widehat{\bar{y}}_{t} \approx-\sigma\left(\widehat{\bar{p}}_{t}^{H}-\widehat{\bar{p}}_{t}\right)+\sigma(1-\eta) \widehat{\overline{r s}}_{t}+\eta \widehat{\bar{c}}_{t}+(1-\eta) \widehat{\bar{c}}_{t}^{*}, \\
& \widehat{\bar{y}}_{t}^{*} \approx-\sigma\left(\widehat{\bar{p}}_{t}^{F *}-\widehat{\bar{p}}_{t}^{*}\right)-\sigma \eta^{*} \widehat{\overline{r s}}_{t}+\eta^{*} \widehat{\bar{c}}_{t}+\left(1-\eta^{*}\right) \widehat{\bar{c}}_{t}^{*},
\end{aligned}
$$

where $\eta \equiv \frac{n\left(\frac{\xi}{n}\right)}{n\left(\frac{\xi}{n}\right)+(1-n)\left(\frac{\xi^{*}}{n}\right)}$ and $\eta^{*} \equiv \frac{n\left(\frac{1-\xi}{1-n}\right)}{n\left(\frac{1-\xi}{1-n}\right)+(1-n)\left(\frac{1-\xi^{*}}{1-n}\right)}$. It must be noted, once again, that the condition on the home bias parameters applied for the irrelevance of asset markets, i.e. $n(1-\xi)=(1-n) \xi^{*}$, implies here that $\eta \equiv \xi$ and $\eta^{*} \equiv \xi^{*}$. Taking the difference between the output level in both countries, I can say that,

$$
\begin{aligned}
\widehat{\bar{y}}_{t}-\widehat{\bar{y}}_{t}^{*} & \approx-\sigma\left(\left(\widehat{\bar{p}}_{t}^{H}-\widehat{\bar{p}}_{t}\right)-\left(\widehat{\bar{p}}_{t}^{F *}-\widehat{\bar{p}}_{t}^{*}\right)\right)+\sigma\left(1-\left(\eta-\eta^{*}\right)\right) \widehat{\overline{r s}}_{t}+\left(\eta-\eta^{*}\right)\left(\widehat{\bar{c}}_{t}-\widehat{\bar{c}}_{t}^{*}\right) \\
& =-\sigma\left(\left(\widehat{\bar{p}}_{t}^{H}-\widehat{\bar{p}}_{t}^{F *}-\widehat{\bar{s}}_{t}\right)-\left(\widehat{\bar{p}}_{t}-\widehat{\bar{p}}_{t}^{*}-\widehat{\bar{s}}_{t}\right)\right)+\sigma\left(1-\left(\eta-\eta^{*}\right)\right) \widehat{\overline{r s}}_{t}+\left(\eta-\eta^{*}\right)\left(\widehat{\bar{c}}_{t}-\widehat{\bar{c}}_{t}^{*}\right) 7.7
\end{aligned}
$$

Using the terms of trade and the real exchange rate definitions, then recalling that under flexible prices the LOOP holds (and $\widehat{\bar{p}}_{t}^{F *}-\widehat{\bar{s}}_{t}=\widehat{\bar{p}}_{t}^{F}$ ), I can re-write the difference above as,

$$
\widehat{\bar{y}}_{t}-\widehat{\bar{y}}_{t}^{*} \approx-\sigma\left(\widehat{\overline{r s}}_{t}-\widehat{\overline{t o t}}_{t}\right)+\sigma\left(1-\left(\eta-\eta^{*}\right)\right) \widehat{\overline{r s}}_{t}+\left(\eta-\eta^{*}\right)\left(\widehat{\bar{c}}_{t}-\widehat{\bar{c}}_{t}^{*}\right) .
$$

Using equations (7.7.3) and (7.7.5), I derive the following expressions for the real exchange rate and terms of trade $^{33}$,

$$
\begin{aligned}
& \widehat{\overline{r s}}_{t} \approx\left[\sigma\left(\frac{1-\left(\xi-\xi^{*}\right)}{\xi-\xi^{*}}\right)+\sigma\left(1-\left(\eta-\eta^{*}\right)\right)+\frac{1}{\gamma}\left(\eta-\eta^{*}\right)\right]^{-1}\left(\widehat{\bar{y}}_{t}-\widehat{\bar{y}}_{t}^{*}\right), \\
& \widehat{\operatorname{tot}}_{t} \approx\left[\sigma\left(1-\left(\xi-\xi^{*}\right)\right)+\sigma\left(\xi-\xi^{*}\right)\left(1-\left(\eta-\eta^{*}\right)\right)+\frac{1}{\gamma}\left(\xi-\xi^{*}\right)\left(\eta-\eta^{*}\right)\right]^{-1}\left(\widehat{\bar{y}}_{t}-\widehat{\bar{y}}_{t}^{*}\right),
\end{aligned}
$$

which indicates that both relative prices are proportional to the output differential across countries.

These equations simplify further if I assume that $n(1-\xi)=(1-n) \xi^{*}$, i.e.

$$
\begin{aligned}
& \widehat{\overline{r s}}_{t} \approx\left[\frac{\xi-\xi^{*}}{\sigma\left(1-\left(\xi-\xi^{*}\right)^{2}\right)+\frac{1}{\gamma}\left(\xi-\xi^{*}\right)^{2}}\right]\left(\widehat{\bar{y}}_{t}-\widehat{\bar{y}}_{t}^{*}\right), \\
& \widehat{\widehat{t o t}}_{t} \approx\left[\frac{1}{\sigma\left(1-\left(\xi-\xi^{*}\right)^{2}\right)+\frac{1}{\gamma}\left(\xi-\xi^{*}\right)^{2}}\right]\left(\widehat{\bar{y}}_{t}-\widehat{\bar{y}}_{t}^{*}\right),
\end{aligned}
$$

where these formulas depend on the home bias parameters but also on a weighted average of the elasticity of substitution across bundles of goods, $\sigma$, and the intertemporal elasticity of substitution, $\frac{1}{\gamma}$. The intertemporal elasticity of substitution, however, only plays a role in determining the sensitivity of the real exchange rate to the output differential whenever I assume home bias in consumption, i.e. $\xi \neq \xi^{*}$. Based on the structure of

\footnotetext{
${ }^{33}$ These calculations do not depend on the assumptions I made regarding the technology used in this economy. Therefore, the same kind of relationships should hold also if I had a production techology that uses other inputs rather than labor alone, specially capital.
} 
the CPIs in (3.2.14) - (3.2.15), and the log-linearization in (7.1.1) and (7.1.2), I can argue that the following price ratios, i.e.

$$
\begin{aligned}
& \widehat{\bar{p}}_{t}^{H}-\widehat{\bar{p}}_{t} \approx(1-\xi)\left(\widehat{\bar{p}}_{t}^{H}-\widehat{\bar{p}}_{t}^{F}\right)=-(1-\xi) \widehat{\operatorname{tot}}_{t}, \\
& \widehat{\bar{p}}_{t}^{F *}-\widehat{\bar{p}}_{t}^{*} \approx-\xi^{*}\left(\widehat{\bar{p}}_{t}^{H *}-\widehat{\bar{p}}_{t}^{F *}\right)=\xi^{*} \widehat{\operatorname{tot}}_{t},
\end{aligned}
$$

are also related to terms of trade.

Then, I combine all these results in order to write domestic and foreign output as,

$$
\begin{aligned}
& \widehat{\bar{y}}_{t} \approx \sigma(1-\xi) \widehat{\operatorname{tot}}_{t}+\sigma(1-\eta) \widehat{\overline{r s}}_{t}+\eta \widehat{\bar{c}}_{t}+(1-\eta) \widehat{\bar{c}}_{t}^{*} \\
& \approx \sigma\left[\frac{1-\xi}{\xi-\xi^{*}}+(1-\eta)\right] \widehat{\overline{r s}}_{t}-(1-\eta)\left(\widehat{\bar{c}}_{t}-\widehat{\bar{c}}_{t}^{*}\right)+\widehat{\bar{c}}_{t}, \\
& \widehat{\bar{y}}_{t}^{*} \approx-\sigma \xi^{*} \widehat{\operatorname{tot}}_{t}-\sigma \eta^{*} \widehat{\overline{r s}}_{t}+\eta^{*} \widehat{\bar{c}}_{t}+\left(1-\eta^{*}\right) \widehat{\bar{c}}_{t}^{*} \\
& \approx-\sigma\left[\frac{\xi^{*}}{\xi-\xi^{*}}+\eta^{*}\right] \widehat{\overline{r s}}_{t}+\eta^{*}\left(\widehat{\bar{c}}_{t}-\widehat{\bar{c}}_{t}^{*}\right)+\widehat{\bar{c}}_{t}^{*} \text {. }
\end{aligned}
$$

Using one more time the perfect risk-sharing condition derived in (7.7.3), I can re-write the domestic and foreign consumption in terms of domestic and foreign output as,

$$
\begin{aligned}
& \widehat{\bar{y}}_{t} \approx\left[\sigma\left(\frac{1-\xi}{\xi-\xi^{*}}+(1-\eta)\right)-\frac{1}{\gamma}(1-\eta)\right] \widehat{\overline{r s}}_{t}+\widehat{\bar{c}}_{t}, \\
& \widehat{\bar{y}}_{t}^{*} \approx-\left[\sigma\left(\frac{\xi^{*}}{\xi-\xi^{*}}+\eta^{*}\right)-\frac{1}{\gamma} \eta^{*}\right] \widehat{\overline{r s}}_{t}+\widehat{\bar{c}}_{t}^{*},
\end{aligned}
$$

and,

$$
\begin{aligned}
\widehat{\bar{c}}_{t} & \approx \widehat{\bar{y}}_{t}-\left[\frac{\sigma\left(\frac{1-\xi}{\xi-\xi^{*}}+(1-\eta)\right)-\frac{1}{\gamma}(1-\eta)}{\sigma\left(\frac{1-\left(\xi-\xi^{*}\right)}{\xi-\xi^{*}}\right)+\sigma\left(1-\left(\eta-\eta^{*}\right)\right)+\frac{1}{\gamma}\left(\eta-\eta^{*}\right)}\right]\left(\widehat{\bar{y}}_{t}-\widehat{\bar{y}}_{t}^{*}\right) \\
& =\left[\frac{\sigma\left(\frac{\xi^{*}}{\xi-\xi^{*}}+\eta^{*}\right)+\frac{1}{\gamma}\left(1-\eta^{*}\right)}{\sigma\left(\frac{1}{\xi-\xi^{*}}-\left(\eta-\eta^{*}\right)\right)+\frac{1}{\gamma}\left(\eta-\eta^{*}\right)}\right] \widehat{\bar{y}}_{t}+\left[\frac{\sigma\left(\frac{1-\xi}{\xi-\xi^{*}}+(1-\eta)\right)-\frac{1}{\gamma}(1-\eta)}{\sigma\left(\frac{1}{\xi-\xi^{*}}-\left(\eta-\eta^{*}\right)\right)+\frac{1}{\gamma}\left(\eta-\eta^{*}\right)}\right] \widehat{\bar{y}}_{t}^{*}, \\
\widehat{\bar{c}}_{t}^{*} & \approx \widehat{\bar{y}}_{t}^{*}+\left[\frac{\sigma\left(\frac{\xi^{*}}{\xi-\xi^{*}}+\eta^{*}\right)-\frac{1}{\gamma} \eta^{*}}{\sigma\left(\frac{1-\left(\xi-\xi^{*}\right)}{\xi-\xi^{*}}\right)+\sigma\left(1-\left(\eta-\eta^{*}\right)\right)+\frac{1}{\gamma}\left(\eta-\eta^{*}\right)}\right]\left(\widehat{\bar{y}}_{t}-\widehat{\bar{y}}_{t}^{*}\right) \\
& =\left[\frac{\sigma\left(\frac{\xi^{*}}{\xi-\xi^{*}}+\eta^{*}\right)-\frac{1}{\gamma} \eta^{*}}{\sigma\left(\frac{1}{\xi-\xi^{*}}-\left(\eta-\eta^{*}\right)\right)+\frac{1}{\gamma}\left(\eta-\eta^{*}\right)}\right] \widehat{\bar{y}}_{t}+\left[\frac{\sigma\left(\frac{1-\xi}{\xi-\xi^{*}}+(1-\eta)\right)+\frac{1}{\gamma} \eta}{\sigma\left(\frac{1}{\xi-\xi^{*}}-\left(\eta-\eta^{*}\right)\right)+\frac{1}{\gamma}\left(\eta-\eta^{*}\right)}\right] \widehat{\bar{y}}_{t}^{*} .
\end{aligned}
$$


Assuming that $n(1-\xi)=(1-n) \xi^{*}$, the equations can be further simplified as,

$$
\begin{aligned}
\widehat{\bar{c}}_{t} & \approx \widehat{\bar{y}}_{t}-\left[\frac{\sigma(1-\xi)\left(1+\left(\xi-\xi^{*}\right)\right)-\frac{1}{\gamma}(1-\xi)\left(\xi-\xi^{*}\right)}{\sigma\left(1-\left(\xi-\xi^{*}\right)^{2}\right)+\frac{1}{\gamma}\left(\xi-\xi^{*}\right)^{2}}\right]\left(\widehat{\bar{y}}_{t}-\widehat{\bar{y}}_{t}^{*}\right) \\
& =\left[\frac{\sigma \xi^{*}\left(1+\left(\xi-\xi^{*}\right)\right)+\frac{1}{\gamma}\left(1-\xi^{*}\right)\left(\xi-\xi^{*}\right)}{\sigma\left(1-\left(\xi-\xi^{*}\right)^{2}\right)+\frac{1}{\gamma}\left(\xi-\xi^{*}\right)^{2}}\right] \widehat{\bar{y}}_{t}+\left[\frac{\left.\sigma(1-\xi)\left(1+\left(\xi-\xi^{*}\right)\right)-\frac{1}{\gamma}(1-\xi)\left(\xi-\xi^{*}\right)\right]}{\left.\sigma\left(1-\left(\xi-\xi^{*}\right)^{2}\right)+\frac{1}{\gamma}\left(\xi-\xi^{*}\right)^{2}, 4\right)}\right. \\
\widehat{\bar{c}}_{t}^{*} & \approx \widehat{\bar{y}}_{t}^{*}+\left[\frac{\sigma \xi^{*}\left(1+\left(\xi-\xi^{*}\right)\right)-\frac{1}{\gamma} \xi^{*}\left(\xi-\xi^{*}\right)}{\sigma\left(1-\left(\xi-\xi^{*}\right)^{2}\right)+\frac{1}{\gamma}\left(\xi-\xi^{*}\right)^{2}}\right]\left(\widehat{\bar{y}}_{t}-\widehat{\bar{y}}_{t}^{*}\right) \\
& =\left[\frac{\sigma \xi^{*}\left(1+\left(\xi-\xi^{*}\right)\right)-\frac{1}{\gamma} \xi^{*}\left(\xi-\xi^{*}\right)}{\sigma\left(1-\left(\xi-\xi^{*}\right)^{2}\right)+\frac{1}{\gamma}\left(\xi-\xi^{*}\right)^{2}}\right] \widehat{\bar{y}}_{t}+\left[\frac{\sigma(1-\xi)\left(1+\left(\xi-\xi^{*}\right)\right)+\frac{1}{\gamma} \xi\left(\xi-\xi^{*}\right)}{\sigma\left(1-\left(\xi-\xi^{*}\right)^{2}\right)+\frac{1}{\gamma}\left(\xi-\xi^{*}\right)^{2}}\right] \widehat{\bar{y}}_{t}^{*},
\end{aligned}
$$

which tells me that the consumption in each country is a weighted function of the output produced in both countries (weighted according to household's preferences).

Consistency with the Market Clearing Conditions. I know that the sum of the real aggregate output in both countries equals the sum of the real aggregate consumption which follows from the market clearing conditions in (3.5.19). Hence, after log-linearizing it must follow that,

$$
n \widehat{\bar{c}}_{t}+(1-n) \widehat{\bar{c}}_{t}^{*} \approx \frac{\bar{Y}}{n \bar{Y}+(1-n) \bar{Y}^{*}} n \widehat{\bar{y}}_{t}+\frac{\bar{Y}^{*}}{n \bar{Y}+(1-n) \bar{Y}^{*}}(1-n) \widehat{\bar{y}}_{t}^{*},
$$

and it can be shown from the steady state derivations in (6.2.10) and (6.2.11) that,

$$
\begin{aligned}
n \bar{Y} & =\left[\frac{n^{\varphi}}{\kappa}\left(\frac{\xi}{\eta}\right)^{\gamma}\right]^{\frac{1}{\gamma+\varphi}}(A)^{\frac{1+\varphi}{\gamma+\varphi}}, \\
(1-n) \bar{Y}^{*} & =\left[\frac{(1-n)^{\varphi}}{\kappa}\left(\frac{n\left(\frac{1-\xi}{1-n}\right)}{\eta^{*}}\right)^{\gamma}\right]^{\frac{1}{\gamma+\varphi}}\left(A^{*}\right)^{\frac{1+\varphi}{\gamma+\varphi}}, \\
n \bar{Y}+(1-n) \bar{Y}^{*} & =\left[\frac{n^{\varphi}}{\kappa}\left(\frac{\xi}{\eta}\right)^{\gamma}\right]^{\frac{1}{\gamma+\varphi}}(A)^{\frac{1+\varphi}{\gamma+\varphi}}+\left[\frac{(1-n)^{\varphi}}{\kappa}\left(\frac{n\left(\frac{1-\xi}{1-n}\right)}{\eta^{*}}\right)^{\gamma}\right]^{\frac{1}{\gamma+\varphi}}\left(A^{*}\right)^{\frac{1+\varphi}{\gamma+\varphi}} .
\end{aligned}
$$

The steady state normalization, applied to any choice of the consumption bias parameters, requires that,

$$
A=1, A^{*}=\left(\frac{n}{1-n}\right)^{\frac{\varphi}{1+\varphi}}\left[\frac{\frac{n\left(\frac{1-\xi}{1-n}\right)}{\eta^{*}}}{\frac{n\left(\frac{\xi}{n}\right)}{\eta}}\right]^{\frac{\varphi}{1+\varphi}}=\left[\left(\frac{n}{1-n}\right)^{2} \frac{\eta}{\eta^{*}} \frac{(1-\xi)}{\xi}\right]^{\frac{\varphi}{1+\varphi}}
$$


as per (6.2.13). Therefore, it follows that,

$$
\begin{aligned}
n \bar{Y} & =\left[\frac{n^{\varphi}}{\kappa}\left(\frac{\xi}{\eta}\right)^{\gamma}\right]^{\frac{1}{\gamma+\varphi}}, \\
(1-n) \bar{Y}^{*} & =\left[\frac{n^{\varphi}}{\kappa}\left(\frac{\xi}{\eta}\right)^{\gamma}\right]^{\frac{1}{\gamma+\varphi}}\left(\frac{n}{1-n} \frac{\eta}{\eta^{*}} \frac{1-\xi}{\xi}\right), \\
n \bar{Y}+(1-n) \bar{Y}^{*} & =\left[\frac{n^{\varphi}}{\kappa}\left(\frac{\xi}{\eta}\right)^{\gamma}\right]^{\frac{1}{\gamma+\varphi}}\left(1+\frac{n}{1-n} \frac{\eta}{\eta^{*}} \frac{1-\xi}{\xi}\right) .
\end{aligned}
$$

As a result I can express the market clearing condition becomes,

$$
n \widehat{\bar{c}}_{t}+(1-n) \widehat{\bar{c}}_{t}^{*} \approx \frac{\eta^{*}(1-n) \xi}{\eta^{*}(1-n) \xi+\eta n(1-\xi)} \widehat{\bar{y}}_{t}+\frac{\eta n(1-\xi)}{\eta^{*}(1-n) \xi+\eta n(1-\xi)} \widehat{\bar{y}}_{t}^{*} .
$$

I impose on the home bias parameters that $n(1-\xi)=(1-n) \xi^{*}$, which further implies that $\eta \equiv \xi$ and $\eta^{*} \equiv \xi^{*}$. In this case, it must be true that,

$$
\frac{n}{1-n} \frac{\eta}{\eta^{*}} \frac{1-\xi}{\xi}=\frac{n}{1-n} \frac{1-\xi}{\xi^{*}}=1
$$

so $n \bar{Y}=(1-n) \bar{Y}^{*}$, and it holds true that,

$$
n \widehat{\bar{c}}_{t}+(1-n) \widehat{\bar{c}}_{t}^{*} \approx \frac{1}{2} \widehat{\bar{y}}_{t}+\frac{1}{2} \widehat{\bar{y}}_{t}^{*}
$$

If I aggregate equations (7.7.22) and (7.7.23) accordingly, it shall follow that,

$n \widehat{\bar{c}}_{t}+(1-n) \widehat{\bar{c}}_{t}^{*} \approx\left[\frac{\sigma\left(\frac{\xi^{*}}{\xi-\xi^{*}}+\eta^{*}\right)+\frac{1}{\gamma}\left(n\left(1-\eta^{*}\right)-(1-n) \eta^{*}\right)}{\sigma\left(\frac{1}{\xi-\xi^{*}}-\left(\eta-\eta^{*}\right)\right)+\frac{1}{\gamma}\left(\eta-\eta^{*}\right)}\right] \widehat{\bar{y}}_{t}+\left[\frac{\sigma\left(\frac{1-\xi}{\xi-\xi^{*}}+(1-\eta)\right)+\frac{1}{\gamma}((1-n) \eta-n(1-\eta))}{\sigma\left(\frac{1}{\xi-\xi^{*}}-\left(\eta-\eta^{*}\right)\right)+\frac{1}{\gamma}\left(\eta-\eta^{*}\right)}\right] \widehat{\bar{y}}_{t}^{*}$.

Hence, this implies that in order for the approximation to be consistent with the market clearing condition, the elasticity of substitution across bundles of domestic and foreign goods, $\sigma$, and the intertemporal elasticity of substitution, $\frac{1}{\gamma}$, must satisfy the following two parametric conditions,

$$
\begin{gathered}
\frac{\sigma\left(\frac{\xi^{*}}{\xi-\xi^{*}}+\eta^{*}\right)+\frac{1}{\gamma}\left(n\left(1-\eta^{*}\right)-(1-n) \eta^{*}\right)}{\sigma\left(\frac{1}{\xi-\xi^{*}}-\left(\eta-\eta^{*}\right)\right)+\frac{1}{\gamma}\left(\eta-\eta^{*}\right)}=\frac{\eta^{*}(1-n) \xi}{\eta^{*}(1-n) \xi+\eta n(1-\xi)}, \\
\frac{\sigma\left(\frac{1-\xi}{\xi-\xi^{*}}+(1-\eta)\right)+\frac{1}{\gamma}((1-n) \eta-n(1-\eta))}{\sigma\left(\frac{1}{\xi-\xi^{*}}-\left(\eta-\eta^{*}\right)\right)+\frac{1}{\gamma}\left(\eta-\eta^{*}\right)}=\frac{\eta n(1-\xi)}{\eta^{*}(1-n) \xi+\eta n(1-\xi)} .
\end{gathered}
$$

Since there are two restrictions and two degrees of freedom, the parameters $\sigma$ and $\gamma$, it could happen that either no solution exists, that only a solution exists that functionally relates these two elasticities to the home bias parameters, or that these equations are satisfied for any possible choice of the elasticities. I check here only the conditions applying to the special case where $n(1-\xi)=(1-n) \xi^{*}$. Given this parametric 
restriction on the home bias parameters,

$$
\begin{gathered}
\frac{\sigma\left(\frac{\xi^{*}}{\xi-\xi^{*}}+\xi^{*}\right)+\frac{1}{\gamma}\left(n\left(1-\xi^{*}\right)-(1-n) \xi^{*}\right)}{\sigma\left(\frac{1}{\xi-\xi^{*}}-\left(\xi-\xi^{*}\right)\right)+\frac{1}{\gamma}\left(\xi-\xi^{*}\right)}=\frac{1}{2}, \\
\frac{\sigma\left(\frac{1-\xi}{\xi-\xi^{*}}+(1-\xi)\right)+\frac{1}{\gamma}((1-n) \xi-n(1-\xi))}{\sigma\left(\frac{1}{\xi-\xi^{*}}-\left(\xi-\xi^{*}\right)\right)+\frac{1}{\gamma}\left(\xi-\xi^{*}\right)}=\frac{1}{2} .
\end{gathered}
$$

A little bit of manipulation and it follows that,

$$
\begin{aligned}
\frac{\sigma\left(\frac{\xi^{*}}{\xi-\xi^{*}}+\xi^{*}\right)+n \frac{1}{\gamma}\left(\xi-\xi^{*}\right)}{\sigma\left(\frac{1}{\xi-\xi^{*}}-\left(\xi-\xi^{*}\right)\right)+\frac{1}{\gamma}\left(\xi-\xi^{*}\right)} & =\frac{1}{2} \Longleftrightarrow \frac{1}{\gamma}\left[n-\frac{1}{2}\right]\left(\xi-\xi^{*}\right)=\sigma \frac{1}{2}\left[\frac{1-2 \xi^{*}}{\xi-\xi^{*}}-\xi-\xi^{*}\right], \\
\frac{\sigma\left(\frac{1-\xi}{\xi-\xi^{*}}+(1-\xi)\right)+(1-n) \frac{1}{\gamma}\left(\xi-\xi^{*}\right)}{\sigma\left(\frac{1}{\xi-\xi^{*}}-\left(\xi-\xi^{*}\right)\right)+\frac{1}{\gamma}\left(\xi-\xi^{*}\right)} & =\frac{1}{2} \Longleftrightarrow \frac{1}{\gamma}\left[n-\frac{1}{2}\right]\left(\xi-\xi^{*}\right)=\sigma \frac{1}{2}\left[\frac{1-2 \xi^{*}}{\xi-\xi^{*}}-\xi-\xi^{*}\right] .
\end{aligned}
$$

In other words, I end up with one additional parametric constraint which requires that,

$$
\frac{1}{\gamma}\left[n-\frac{1}{2}\right]\left(\xi-\xi^{*}\right)^{2}=\sigma \frac{1}{2}\left[1-2 \xi^{*}-\left(\xi+\xi^{*}\right)\left(\xi-\xi^{*}\right)\right]=\sigma \frac{1}{2}\left[1-2 \xi^{*}-\xi^{2}+\left(\xi^{*}\right)^{2}\right]=\sigma \frac{1}{2}\left[\left(1-\xi^{*}\right)^{2}-\xi^{2}\right],
$$

or, alternatively, that,

$$
\frac{1}{\gamma}\left[n-\frac{1}{2}\right]\left(\xi-\frac{n}{1-n}(1-\xi)\right)^{2}=\sigma \frac{1}{2}\left[\left(1-\frac{n}{1-n}(1-\xi)\right)^{2}-\xi^{2}\right],
$$

where I use once again the fact that $n(1-\xi)=(1-n) \xi^{*}$.

In general, this implies that for internal consistency with the market clearing condition, I cannot pick an arbitrary choice for the two elasticities. At the same time, I can also show that if I choose both countries to be symmetric in size, i.e. $n=\frac{1}{2}$, then the left- and the right-hand side terms of this restriction become zero and that allows me an unrestricted selection of both elasticities. Making both countries symmetric was also a necessary condition in the standard normalization to be able to assume that the steady state productivity levels in both countries are identical and equal to one.

The Potential Output of the Economy. Mindful of the implicit restriction on the elasticity of substitution across bundles of domestic and foreign goods, $\sigma$, and the intertemporal elasticity of substitution, $\frac{1}{\gamma}$, I proceed ahead to derive the implicit relationship between output and productivity shocks. For that, I only have to replace consumption, prices and terms of trade in the log-linearized equilibrium labor market clearing conditions derived in (7.7.1) - (7.7.2) to easily obtain the following system of two equations in two 
unknowns,

$$
\begin{aligned}
& -(1+\varphi) \widehat{a}_{t}+\gamma\left[\left(\frac{\sigma\left(\frac{\xi^{*}}{\xi-\xi^{*}}+\eta^{*}\right)+\frac{1}{\gamma}\left(1-\eta^{*}\right)}{\sigma\left(\frac{1}{\xi-\xi^{*}}-\left(\eta-\eta^{*}\right)\right)+\frac{1}{\gamma}\left(\eta-\eta^{*}\right)}\right) \widehat{\bar{y}}_{t}+\left(\frac{\sigma\left(\frac{1-\xi}{\xi-\xi^{*}}+(1-\eta)\right)-\frac{1}{\gamma}(1-\eta)}{\sigma\left(\frac{1}{\xi-\xi^{*}}-\left(\eta-\eta^{*}\right)\right)+\frac{1}{\gamma}\left(\eta-\eta^{*}\right)}\right) \widehat{\bar{y}}_{t}^{*}\right]+ \\
& +\varphi \widehat{\bar{y}}_{t}+\left[\frac{(1-\xi)}{\sigma\left(1-\left(\xi-\xi^{*}\right)\left(\eta-\eta^{*}\right)\right)+\frac{1}{\gamma}\left(\xi-\xi^{*}\right)\left(\eta-\eta^{*}\right)}\right]\left(\widehat{\bar{y}}_{t}-\widehat{\bar{y}}_{t}^{*}\right) \approx 0 \\
& -(1+\varphi) \widehat{a}_{t}^{*}+\gamma\left[\left(\frac{\sigma\left(\frac{\xi^{*}}{\xi-\xi^{*}}+\eta^{*}\right)-\frac{1}{\gamma} \eta^{*}}{\sigma\left(\frac{1}{\xi-\xi^{*}}-\left(\eta-\eta^{*}\right)\right)+\frac{1}{\gamma}\left(\eta-\eta^{*}\right)}\right) \widehat{\bar{y}}_{t}+\left(\frac{\sigma\left(\frac{1-\xi}{\xi-\xi^{*}}+(1-\eta)\right)+\frac{1}{\gamma} \eta}{\sigma\left(\frac{1}{\xi-\xi^{*}}-\left(\eta-\eta^{*}\right)\right)+\frac{1}{\gamma}\left(\eta-\eta^{*}\right)}\right) \widehat{\bar{y}}_{t}^{*}\right]+ \\
& +\varphi \widehat{\bar{y}}_{t}^{*}-\left[\frac{\xi^{*}}{\sigma\left(1-\left(\xi-\xi^{*}\right)\left(\eta-\eta^{*}\right)\right)+\frac{1}{\gamma}\left(\xi-\xi^{*}\right)\left(\eta-\eta^{*}\right)}\right]\left(\widehat{\bar{y}}_{t}-\widehat{\bar{y}}_{t}^{*}\right) \approx 0,
\end{aligned}
$$

or, expressed more compactly,

$$
\begin{aligned}
& {\left[\varphi+\left(\frac{\gamma \sigma\left(\xi^{*}+\left(\xi-\xi^{*}\right) \eta^{*}\right)+\left(\xi-\xi^{*}\right)\left(1-\eta^{*}\right)+(1-\xi)}{\sigma\left(1-\left(\xi-\xi^{*}\right)\left(\eta-\eta^{*}\right)\right)+\frac{1}{\gamma}\left(\xi-\xi^{*}\right)\left(\eta-\eta^{*}\right)}\right)\right] \widehat{\bar{y}}_{t}+} \\
& \quad+\left[\frac{\gamma \sigma\left((1-\xi)+\left(\xi-\xi^{*}\right)(1-\eta)\right)-\left(\xi-\xi^{*}\right)(1-\eta)-(1-\xi)}{\sigma\left(1-\left(\xi-\xi^{*}\right)\left(\eta-\eta^{*}\right)\right)+\frac{1}{\gamma}\left(\xi-\xi^{*}\right)\left(\eta-\eta^{*}\right)}\right] \widehat{\bar{y}}_{t}^{*} \approx(1+\varphi) \widehat{a}_{t}, \\
& \quad\left[\frac{\gamma \sigma\left(\xi^{*}+\left(\xi-\xi^{*}\right) \eta^{*}\right)-\left(\xi-\xi^{*}\right) \eta^{*}-\xi^{*}}{\sigma\left(1-\left(\xi-\xi^{*}\right)\left(\eta-\eta^{*}\right)\right)+\frac{1}{\gamma}\left(\xi-\xi^{*}\right)\left(\eta-\eta^{*}\right)}\right] \widehat{\bar{y}}_{t}+ \\
& \quad+\left[\varphi+\left(\frac{\gamma \sigma\left((1-\xi)+\left(\xi-\xi^{*}\right)(1-\eta)\right)+\left(\xi-\xi^{*}\right) \eta+\xi^{*}}{\sigma\left(1-\left(\xi-\xi^{*}\right)\left(\eta-\eta^{*}\right)\right)+\frac{1}{\gamma}\left(\xi-\xi^{*}\right)\left(\eta-\eta^{*}\right)}\right)\right] \widehat{\bar{y}}_{t}^{*} \approx(1+\varphi) \widehat{a}_{t}^{*} .
\end{aligned}
$$

The solution to this system of equations gives me the following pair of formulas,

$$
\begin{aligned}
\widehat{\bar{y}}_{t} & \approx \lambda_{a} \widehat{a}_{t}+\lambda_{a^{*}} \widehat{a}_{t}^{*}, \\
\widehat{\bar{y}}_{t}^{*} & \approx \lambda_{a}^{*} \widehat{a}_{t}+\lambda_{a^{*}}^{*} \widehat{a}_{t}^{*},
\end{aligned}
$$

where the coefficients are defined as follows,

$$
\begin{aligned}
& \lambda_{a} \equiv \frac{1+\varphi}{\gamma+\varphi}\left[\begin{array}{c}
\frac{\gamma \xi^{*}+\sigma \gamma^{2}+\varphi \xi^{*} \eta^{*}-\sigma \gamma^{2} \xi^{*}+\sigma \gamma \varphi+\gamma \xi \eta \eta \xi \xi \eta \varphi-\gamma \eta \xi^{*}-\xi \varphi \eta^{*}-\eta \varphi \xi^{*}-\sigma \gamma^{2} \xi \eta}{\gamma+\varphi \xi^{*} \eta^{*}+\sigma \gamma \varphi+\xi \eta \eta-\xi \varphi \eta^{*}-\eta \varphi \xi^{*}+\sigma \gamma \xi \varphi \eta^{*}+\sigma \gamma \eta \varphi \xi^{*}-\sigma \gamma \varphi \xi^{*} \eta^{*}-\sigma \gamma \xi \eta \varphi} \\
+\frac{\sigma \gamma^{2} \eta \xi^{*}+\sigma \gamma \xi \varphi \eta^{*}+\sigma \gamma \eta \xi^{*}-\sigma \gamma \varphi \xi^{*} \eta^{*}-\sigma \gamma \xi \xi \eta \varphi}{\gamma+\varphi \xi^{*} \eta^{*}+\sigma \gamma \varphi+\xi \eta \varphi-\xi \varphi \eta^{*}-\eta \varphi \xi^{*}+\sigma \gamma \xi \varphi \eta^{*}+\sigma \gamma \eta \varphi \xi^{*}-\sigma \gamma \varphi \xi^{*} \eta^{*}-\sigma \gamma \xi \eta \varphi}
\end{array}\right], \\
& \lambda_{a^{*}} \equiv\left(\sigma-\frac{1}{\gamma}\right) \frac{1+\varphi}{\gamma+\varphi}\left[\frac{\xi^{*}+\xi \eta-\eta \xi^{*}-1}{\gamma+\varphi \xi^{*} \eta^{*}+\sigma \gamma \varphi+\xi \eta \varphi-\xi \varphi \eta^{*}-\eta \varphi \xi^{*}+\sigma \gamma \xi \varphi \eta^{*}+\sigma \gamma \eta \varphi \xi^{*}-\sigma \gamma \varphi \xi^{*} \eta^{*}-\sigma \gamma \xi \eta \varphi}\right] \text {, } \\
& \lambda_{a}^{*} \equiv\left(\sigma-\frac{1}{\gamma}\right) \frac{1+\varphi}{\gamma+\varphi}\left[\frac{-\xi^{*}+\xi^{*} \eta^{*}-\xi \eta^{*}}{\gamma+\varphi \xi^{*} \eta^{*}+\sigma \gamma \varphi+\xi \eta \varphi-\xi \varphi \eta^{*}-\eta \varphi \xi^{*}+\sigma \gamma \xi \varphi \eta^{*}+\sigma \gamma \eta \varphi \xi^{*}-\sigma \gamma \varphi \xi^{*} \eta^{*}-\sigma \gamma \xi \eta \varphi}\right], \\
& \lambda_{a^{*}}^{*} \equiv \frac{1+\varphi}{\gamma+\varphi}\left[\begin{array}{c}
\frac{\gamma-\gamma \xi^{*}+\gamma \xi^{*} \eta^{*}+\varphi \xi^{*} \eta^{*}+\sigma \gamma^{2} \xi^{*}+\sigma \gamma \varphi+\xi \eta \varphi-\gamma \xi \eta^{*}-\xi \varphi \eta^{*}-\eta \varphi \xi^{*}-\sigma \gamma^{2} \xi^{*} \eta^{*}}{\gamma+\varphi \xi^{*} \eta^{*}+\sigma \gamma \varphi+\xi \eta \varphi-\xi \varphi \eta^{*}-\eta \varphi \xi^{*}+\sigma \gamma \xi \varphi \eta^{*}+\sigma \gamma \eta \varphi \xi^{*}-\sigma \gamma \varphi \xi^{*} \eta^{*}-\sigma \gamma \xi \eta \varphi} \\
+\frac{\sigma \gamma^{2} \xi \eta^{*}+\sigma \gamma \xi \varphi \eta^{*}+\sigma \gamma \eta \xi^{*}-\sigma \gamma \varphi \xi^{*} \eta^{*}-\sigma \gamma \xi \eta \varphi}{\gamma+\varphi \xi^{*} \eta^{*}+\sigma \gamma \varphi+\xi \eta \varphi-\xi \varphi \eta^{*}-\eta \varphi \xi^{*}+\sigma \gamma \xi \varphi \eta^{*}+\sigma \gamma \eta \varphi \xi^{*}-\sigma \gamma \varphi \xi^{*} \eta^{*}-\sigma \gamma \xi \eta \varphi}
\end{array}\right] .
\end{aligned}
$$

These two equations characterize the potential output of the economy, and implicitly set a reference for the output gap targeted by the monetary authorities.

Let me assume that the usual restriction is imposed on the home bias parameters, i.e. $n(1-\xi)=$ 
$(1-n) \xi^{*}$. Then, operating on (7.7.1) - (7.7.2), I can obtain the following system of equations,

$$
\begin{aligned}
& -(1+\varphi) \widehat{a}_{t}+\gamma\left[\left(\frac{\sigma \xi^{*}\left(1+\left(\xi-\xi^{*}\right)\right)+\frac{1}{\gamma}\left(1-\xi^{*}\right)\left(\xi-\xi^{*}\right)}{\sigma\left(1-\left(\xi-\xi^{*}\right)^{2}\right)+\frac{1}{\gamma}\left(\xi-\xi^{*}\right)^{2}}\right) \widehat{\bar{y}}_{t}+\left(\frac{\sigma(1-\xi)\left(1+\left(\xi-\xi^{*}\right)\right)-\frac{1}{\gamma}(1-\xi)\left(\xi-\xi^{*}\right)}{\sigma\left(1-\left(\xi-\xi^{*}\right)^{2}\right)+\frac{1}{\gamma}\left(\xi-\xi^{*}\right)^{2}}\right) \widehat{\widehat{y}}_{t}^{*}\right]+ \\
& \quad+\varphi \widehat{\bar{y}}_{t}+\left(\frac{1-\xi}{\sigma\left(1-\left(\xi-\xi^{*}\right)^{2}\right)+\frac{1}{\gamma}\left(\xi-\xi^{*}\right)^{2}}\right)\left(\widehat{\bar{y}}_{t}-\widehat{\bar{y}}_{t}^{*}\right) \approx 0, \\
& -(1+\varphi) \widehat{a}_{t}^{*}+\gamma\left[\left(\frac{\sigma \xi^{*}\left(1+\left(\xi-\xi^{*}\right)\right)-\frac{1}{\gamma} \xi^{*}\left(\xi-\xi^{*}\right)}{\sigma\left(1-\left(\xi-\xi^{*}\right)^{2}\right)+\frac{1}{\gamma}\left(\xi-\xi^{*}\right)^{2}}\right) \widehat{\bar{y}}_{t}+\left(\frac{\sigma(1-\xi)\left(1+\left(\xi-\xi^{*}\right)\right)+\frac{1}{\gamma} \xi\left(\xi-\xi^{*}\right)}{\sigma\left(1-\left(\xi-\xi^{*}\right)^{2}\right)+\frac{1}{\gamma}\left(\xi-\xi^{*}\right)^{2}}\right) \widehat{\bar{y}}_{t}^{*}\right]+ \\
& +\varphi \widehat{\bar{y}}_{t}^{*}-\left(\frac{\xi^{*}}{\sigma\left(1-\left(\xi-\xi^{*}\right)^{2}\right)+\frac{1}{\gamma}\left(\xi-\xi^{*}\right)^{2}}\right)\left(\widehat{\bar{y}}_{t}-\widehat{\bar{y}}_{t}^{*}\right) \approx 0,
\end{aligned}
$$

or, expressed more compactly,

$$
\begin{aligned}
& {\left[\varphi+\left(\frac{\gamma \sigma \xi^{*}\left(1+\left(\xi-\xi^{*}\right)\right)+\left(1-\xi^{*}\right)\left(\xi-\xi^{*}\right)+(1-\xi)}{\sigma\left(1-\left(\xi-\xi^{*}\right)^{2}\right)+\frac{1}{\gamma}\left(\xi-\xi^{*}\right)^{2}}\right)\right] \widehat{\bar{y}}_{t}+} \\
& \quad+\left[\frac{\gamma \sigma(1-\xi)\left(1+\left(\xi-\xi^{*}\right)\right)-(1-\xi)\left(\xi-\xi^{*}\right)-(1-\xi)}{\sigma\left(1-\left(\xi-\xi^{*}\right)^{2}\right)+\frac{1}{\gamma}\left(\xi-\xi^{*}\right)^{2}}\right] \widehat{\bar{y}}_{t}^{*} \approx(1+\varphi) \widehat{a}_{t}, \\
& {\left[\frac{\gamma \sigma \xi^{*}\left(1+\left(\xi-\xi^{*}\right)\right)-\xi^{*}\left(\xi-\xi^{*}\right)-\xi^{*}}{\sigma\left(1-\left(\xi-\xi^{*}\right)^{2}\right)+\frac{1}{\gamma}\left(\xi-\xi^{*}\right)^{2}}\right] \widehat{\bar{y}}_{t}+} \\
& \quad+\left[\varphi+\left(\frac{\gamma \sigma(1-\xi)\left(1+\left(\xi-\xi^{*}\right)\right)+\xi\left(\xi-\xi^{*}\right)+\xi^{*}}{\sigma\left(1-\left(\xi-\xi^{*}\right)^{2}\right)+\frac{1}{\gamma}\left(\xi-\xi^{*}\right)^{2}}\right)\right] \widehat{\bar{y}}_{t}^{*} \approx(1+\varphi) \widehat{a}_{t}^{*} .
\end{aligned}
$$

The solution to this system of equations gives me the following pair of formulas,

$$
\begin{aligned}
& \widehat{\bar{y}}_{t} \approx \lambda_{a} \widehat{a}_{t}+\lambda_{a^{*}} \widehat{a}_{t}^{*}, \\
& \widehat{\bar{y}}_{t}^{*} \approx \lambda_{a}^{*} \widehat{a}_{t}+\lambda_{a^{*}}^{*} \widehat{a}_{t}^{*},
\end{aligned}
$$

where the coefficients are defined as follows,

$$
\begin{aligned}
& \lambda_{a} \equiv \frac{1+\varphi}{\gamma+\varphi}\left[\begin{array}{c}
\frac{\varphi\left(\xi^{*}\right)^{2}+\gamma \xi^{*}+\sigma \gamma^{2}+\gamma \xi^{2}+\xi^{2} \varphi-\sigma \gamma^{2} \xi^{*}-\sigma \gamma^{2} \xi^{2}+\sigma \gamma \varphi-\gamma \xi \xi^{*}-2 \xi \varphi \xi^{*}-\sigma \gamma \xi^{2} \varphi}{\gamma+\varphi\left(\xi^{*}\right)^{2}+\xi^{2} \varphi+\sigma \gamma \varphi-2 \xi \varphi \xi^{*}-\sigma \gamma \xi^{2} \varphi-\sigma \gamma \varphi\left(\xi \xi^{*}\right)^{2}+2 \sigma \gamma \xi \varphi \xi^{*}}+ \\
+\frac{\sigma \gamma^{2} \xi \xi^{*}-\sigma \gamma \varphi\left(\xi^{*}\right)+2 \sigma \gamma \xi \varphi \xi^{*}}{\gamma+\varphi\left(\xi^{*}\right)^{2}+\xi^{2} \varphi+\sigma \gamma \varphi-2 \xi \varphi \xi^{*}-\sigma \gamma \xi^{2} \varphi-\sigma \gamma \varphi\left(\xi^{*}\right)^{2}+2 \sigma \gamma \xi \varphi \xi^{*}}
\end{array}\right], \\
& \lambda_{a^{*}} \equiv\left(\sigma-\frac{1}{\gamma}\right) \frac{1+\varphi}{\gamma+\varphi}\left[\frac{(\xi-1)\left(\xi-\xi^{*}+1\right)}{\gamma+\varphi\left(\xi^{*}\right)^{2}+\xi^{2} \varphi+\sigma \gamma \varphi-2 \xi \varphi \xi^{*}-\sigma \gamma \xi^{2} \varphi-\sigma \gamma \varphi\left(\xi^{*}\right)^{2}+2 \sigma \gamma \xi \varphi \xi^{*}}\right], \\
& \lambda_{a}^{*} \equiv\left(\sigma-\frac{1}{\gamma}\right) \frac{1+\varphi}{\gamma+\varphi}\left[\frac{\xi^{*}\left(\xi-\xi^{*}+1\right)}{-\gamma-\varphi\left(\xi^{*}\right)^{2}-\xi^{2} \varphi-\sigma \gamma \varphi+2 \xi \varphi \xi^{*}+\sigma \gamma \xi^{2} \varphi+\sigma \gamma \varphi\left(\xi^{*}\right)^{2}-2 \sigma \gamma \xi \varphi \xi^{*}}\right], \\
& \lambda_{a^{*}}^{*} \equiv \frac{1+\varphi}{\gamma+\varphi}\left[\begin{array}{c}
\frac{\gamma+\gamma\left(\xi^{*}\right)^{2}+\varphi\left(\xi^{*}\right)^{2}-\gamma \xi^{*}+\xi^{2} \varphi+\sigma \gamma^{2} \xi^{*}+\sigma \gamma \varphi-\sigma \gamma^{2}\left(\xi^{*}\right)^{2}-\gamma \xi \xi^{*}-2 \xi \varphi \xi^{*}-\sigma \gamma \xi^{2} \varphi}{\gamma+\varphi\left(\xi^{*}\right)^{2}+\xi^{2} \varphi+\sigma \gamma \varphi-2 \xi \varphi \xi^{*}-\sigma \gamma \xi^{2} \varphi-\sigma \gamma \varphi\left(\xi^{*}\right)^{2}+2 \sigma \gamma \xi \varphi \xi^{*}} \\
+\frac{\sigma \gamma^{2} \xi \xi^{*}-\sigma \gamma \varphi\left(\xi^{*}\right)^{2}+2 \sigma \gamma \xi \varphi \xi^{*}}{\gamma+\varphi\left(\xi^{*}\right)^{2}+\xi^{2} \varphi+\sigma \gamma \varphi-2 \xi \varphi \xi^{*}-\sigma \gamma \xi^{2} \varphi-\sigma \gamma \varphi\left(\xi^{*}\right)^{2}+2 \sigma \gamma \xi \varphi \xi^{*}}
\end{array}\right] .
\end{aligned}
$$

Using the structure of the linear-in-labor technology functions, it is possible to approximate aggregate output as,

$$
\begin{aligned}
\widehat{\bar{y}}_{t} & \approx \widehat{\bar{l}}_{t}+\widehat{a}_{t}, \\
\widehat{\bar{y}}_{t}^{*} & \approx \widehat{\bar{l}}_{t}^{*}+\widehat{a}_{t}^{*},
\end{aligned}
$$

therefore, the equilibrium level of employment follows easily from here. 
I already argued, while discussing the irrelevance of asset markets, that under certain special conditions ${ }^{34}$ the foreign shocks have no direct impact on the domestic output. That was true because under those conditions the nominal trade balance was equal to zero. However, in my previous calculations appears an interesting fact which is true independently of the choice of home bias parameters. If the elasticity of substitution across domestic and foreign bundles is identical to the intertemporal elasticity of substitution, i.e.

$$
\sigma=\frac{1}{\gamma}
$$

then local employment and output will only depend on local productivity shocks up to a first-order approximation. Arguably, this is a knife-edge case. However, these two parameters have very important implications for the way labor reacts to shocks coming from abroad. In fact, it can be said that these two parameters regulate whether the wealth effects or the substitution effects dominate on the employment decisions (and, hence, translate into a higher or lower equilibrium output level). This can be seen from the fact that the sign of $\left(\sigma-\frac{1}{\gamma}\right)$ determines the sign of $\lambda_{a^{*}}$ and $\lambda_{a}^{*}$.

The Output Gap and Monetary Policy. If monetary policy targets deviations of output from its potential, as posited by the Taylor rule, it can no longer ignore the foreign productivity shocks except whenever $\sigma=\frac{1}{\gamma}$. My previous derivations show that potential output in either country is a function of both productivity shocks. On one hand, it indicates that potential output can be affected by the productivity shock of the other country (if international trade in goods is feasible). On the other hand, it shows that the monetary authority has no influence whatsoever on potential output. This should not be surprising since the potential output of the economy is the output that would prevail in a frictionless economy, which is precisely the type of economy where money is neutral.

The Taylor monetary policy rules also suggest that errors in the estimation of potential output could be perceived or misinterpreted as monetary policy shocks, while in reality they are truly supply (or real) shocks. For example, let me suppose that the domestic monetary authority believes the economy to be closed or the foreign productivity shocks to be unimportant and estimates the domestic potential output as $\widehat{\bar{y}}_{t} \approx \lambda_{a} \widehat{a}_{t}$. Depending on the sign of $\lambda_{a}$ and the realization of the foreign shock, the output gap may be either overestimated or underestimated by the monetary authority. That means the interest rates might be either too high or too low relative to what the correctly-specified Taylor rule would prescribe in order to drive the economy closer to the frictionless allocation. Hence, this specification error can be detrimental for the goals of the policy-maker.

Let me suppose now, as an alternative example, that the monetary authority follows the Taylor rules prescribed in (7.2.16) - (7.2.17). But an econometrician does not know how to correctly estimate the potential output that is being targeted. Then, the differences between the econometrician's conjecture and the true output gap of the economy will be interpreted as monetary policy shocks. While, in fact, these specification errors should be functionally related to productivity shocks, because potential output only depends on real shocks. Because these output gap errors are misconstrued as monetary policy shocks, econometrician's may use them to conclude that monetary policy shocks are correlated with real shocks, even though that is not the case. These errors could also lead the econometrician to conclude that Taylor rules have real effects,

${ }^{34}$ That is, whenever $\sigma=\gamma=1, n(1-\xi)=(1-n) \xi^{*}$ and the net debt in the initial conditions is zero. 
even when there is little truth to that (if anything at all).

\subsection{The Linearized Equilibrium Conditions: Revisited}

The workhorse model is build around a log-linearized set of equilibrium conditions. It has been shown that asset prices, the nominal interest rate and the nominal exchange rate particularly, can be pin down with the current framework. Moreover, this first-order approximation is sufficient to close the model and determine the relevant allocations based on a small number of Euler equations, pricing equations and asset pricing equations. For instance, I derive aggregate output and consumption, inflation, as well as the trade balance based on these equations only.

However, the portfolio allocation is indeterminate up to a first-order approximation. The composition of assets in each country's portfolio cannot be determined in this way. One way to attain a determinate portfolio allocation would be to produce a second-order approximation of the asset pricing equations. This is precisely the approach that Evans and Hnatkovska $(2005,2007)$ follow. Portfolio determination is crucial for our macro models to be able to say something interesting on the home bias in equity portfolios puzzle or regarding the role of financial globalization.

However, it seems important to emphasize that asset prices, not portfolio quantities, is all that is needed to determine the allocations (even the trade balance) in the workhorse model. On one hand, portfolio allocations are only of second-order importance to help us understand the behavior of the economy. On the other hand, the asset market structure is quite important still in as much as determines the risk-sharing opportunities available and, therefore, the efficiency with which households pool their risks and trade.

What does this mean for monetary policy? The asset market structure influences decisively the risksharing that occurs across countries. Therefore, it changes the financial environment in which monetary policy is conducted and through which it is implemented. It also introduces a potential role for monetary policy to promote better risk pooling across countries (insurance), which is not clear whether it conflicts or not with the objective of price stability. I argue that portfolio allocations are of second-order importance for the determination of those variables (primarily inflation and output/consumption) that are thought to be of relevance for the monetary authority. Up to a first-order effect, only certain asset prices like the short-term nominal rates, the consumption-saving decision of households and the pricing decisions of firms matter in the context of the workhorse model. Nonetheless, the asset market structure cannot be ignored by policy-makers as exemplified by the distinction between a complete asset markets economy and a 'bond economy' in this paper.

Finally, it is worth always keeping an open mind on these topics and financial globalization is no exception. In a slightly more complex model with borrowing constraints, differential trading costs across asset types or segmented markets and different degrees of asset substitutability, the claim that portfolio allocations are of second-order importance may no longer be true. Certainly, more research needs to be done along these lines. 


\section{Concluding Remarks}

First, monetary policy is neutral if prices are flexible, firms are competitive and asset markets are complete. In this context, it makes little sense for the monetary authority to worry about output fluctuations over the business cycle because it is outside the set of things monetary policy can actually accomplish. In the presence of nominal rigidities in the goods markets (and possibly other frictions), monetary policy may have real effects because the price level can be manipulated to alter some relative prices. Monetary policy can play a role in dampening the relative price distortions implied by these frictions. However, even if monetary policy was fully effective in eliminating these distortions, its real effects may only be modest.

After controlling for other sources of heterogeneity across firms, large real distortions depend on the existence of very large relative price differences. In Calvo's (1983) world with nominal rigidities, these relative price disparities are only possible if inflation is quite sizeable. But it is unlikely that firms will make their pricing decisions only sporadically if inflation is pushing the relative prices rapidly far apart. The firms being hurt by the resulting misallocation of spending would endogenously re-price their goods (and will do so frequently) to mitigate the decline in the expenditure share they get. Therefore, this should keep relative price differences 'contained'. That's what logic dictates. Therefore, I should not anticipate a very large real effects. If large relative price differences do exist, that may have to be explained by some other feature that this simple model of sticky price contracts cannot either capture or approximate sensibly.

Second, independently of the magnitude of the real effects of monetary policy, one of the underlying themes of this paper is how to conduct monetary policy in this environment with nominal rigidities. I would argue that, at least conceptually, the Taylor-type policy rule should be 'robust' to model uncertainty. If you believe that the frictionless model best describes the economy, then you must believe that output is most of the time at its 'potential'. Therefore, on the basis of a simple Taylor rule, you should set the shortterm interest rate to determine the inflation rate. Monetary policy only affects nominal variables, and the objective of price stability seems a perfectly reasonable criteria. If you believe that nominal rigidities (or other frictions) are pushing the economy away from its potential, then a Taylor rule has real effects and can be used to force the economy to revert back to the frictionless allocation. Inflation targeting ensures that relative price distortions are minimized and, in doing so, it 'reduces' the welfare loss for consumers.

Third, price stability is the ultimate goal of the monetary authority whether you believe that money is neutral or not. The discrepancy in the implementation of the Taylor policy rule arises because economists do not seem to agree on the potential output of the economy (even if they agree to adopt exactly the same policy rule). Conventional measures of output gap make critical assumptions on what potential output is likely to be. However, it is not necessarily obvious that observable output is not equal (or closely matches) the potential output. This is where model uncertainty becomes a contentious issue, and this is why most of the policy debate seems to move these days around the challenge of how to best estimate the output gap.

Finally, as I have shown in this paper, inflation and prices are an essentially monetary phenomenon. But even in the frictionless economy, where I have analytical solutions, it is clear that consumption prices are influenced by monetary shocks. However, it is also obvious that consumption prices are affected by other shocks to the economy (including productivity shocks). It is necessary to dispel the myth that lower inflation and more stable prices necessarily implies that monetary policy has become 'better' or 'tighter'. It is perfectly possible to be running a loose monetary policy while (either domestic or foreign) productivity

shocks are pushing inflation down. In fact, that might even be the correct policy prescription at the time to 
maintain price stability without the perils of deflation. In other words, inflation reflects more than just the impact of monetary shocks.

The problem with a situation like this is that the monetary authorities may 'get accustomed' to run a loose monetary policy. Then, it may be costly to re-set monetary policy towards a tighter phase whenever the inflation downward bias caused by productivity shocks wanes down or disappears. We may keep running a loose monetary policy for too long and, hence, end up feeding the inflation 'monster' in the process. 


\section{References}

[1] Backus, David K. and Gregor W. Smith (1993): "Consumption and Real Exchange Rates in Dynamic Economies with Non-traded Goods". Journal of International Economics, vol. 35 (3-4), pp. 297-316.

[2] Backus, David K., Patrick J. Kehoe, and Finn E. Kydland (1992): "International Real Business Cycles". Journal of Political Economy, vol. 100 (4), pp. 745-775.

[3] Backus, David K., Patrick J. Kehoe, and Finn E. Kydland (1994): "Dynamics of the Trade Balance and the Terms of Trade: The J-Curve", American Economic Review, vol. 84 (1), pp. 84-103.

[4] Backus, David K., Patrick J. Kehoe, and Finn E. Kydland (1995): "International Business Cycles: Theory and Evidence", in Frontiers of Business Cycle Research (T. Cooley, Ed.), pp. 331-356. Princeton University Press: Princeton, New Jersey, USA.

[5] Bakhshi, Hasan, Hashmat Khan and Barbara Rudolf (2007): "The Phillips Curve under StateDependent Pricing". Journal of Monetary Economics, vol. 54 (8), pp. 2321-2345.

[6] Bakhshi, Hasan, Pablo Burriel-Llombart, Hashmat Khan and Barbara Rudolf (2007): "The New Keynesian Phillips Curve under Trend Inflation and Strategic Complementarity". Journal of Macroeconomics, vol. 29 (1), pp. 37-59.

[7] Baxter, Marianne and Alan C. Stockman (1989): "Business Cycles and the Exchange Rate Regime: Some International Evidence". Journal of Monetary Economics, vol. 23 (3), pp. 377-400.

[8] Benigno, Pierpaolo (2001): "Price Stability with Imperfect Financial Integration". CEPR Working Paper, No. 2854.

[9] Benigno, Gianluca (2004): "Real Exchange Rate Persistence and Monetary Policy Rules". Journal of Monetary Economics, vol. 51 (3), pp. 473-502.

[10] Blanchard, Olivier Jean (1985): "Debt, Deficits, and Finite Horizons". Journal of Political Economy, vol. 93 (2), pp. 223-247.

[11] Blanchard, Olivier Jean and Nobuhiro Kiyotaki (1987): "Monopolistic Competition and the Effects of Aggregate Demand". American Economic Review, vol. 77 (2), pp. 647-666.

[12] Calvo, Guillermo A. (1983): "Staggered Prices in a Utility-Maximizing Framework". Journal of Monetary Economics, vol. 12 (3), pp. 383-398.

[13] Chari, V. V., Patrick J. Kehoe and Ellen R. McGrattan (2002): "Can Sticky Price Models Generate Volatile and Persistent Real Exchange Rates?". Review of Economic Studies, vol. 69 (3), pp. 533-563.

[14] Clarida, Richard, Jordi Galí, and Mark Gertler (2002): "A Simple Framework for International Monetary Policy Analysis". Journal of Monetary Economics, vol. 49 (5), pp. 879-904.

[15] Cole, Harold L. and Maurice Obstfeld (1991): "Commodity Trade and International Risk Sharing: How Much Do Financial Markets Matter?". Journal of Monetary Economics, vol. 28, pp. 3-24.

[16] Corsetti, Giancarlo and Paolo Pesenti (2001): "Welfare and Macroeconomic Interdependence". Quarterly Journal of Economics, vol. 116 (2), pp. 421-446.

[17] Corsetti, Giancarlo and Paolo Pesenti (2005a): "International Dimensions of Optimal Monetary Policy". Journal of Monetary Economics, vol. 52 (2), pp. 281-305.

[18] Corsetti, Giancarlo and Paolo Pesenti (2005b): "The Simple Geometry of Transmission and Stabilization in Closed and Open Economies". NBER Working Paper, No. 11341, National Bureau of Economic Research, Inc. 
[19] Corsetti, Giancarlo (2006): "Openness and the Case for Flexible Exchange Rates". European University Institute-Economics Working Paper, No. 2005-21.

[20] Crucini, Mario J., Chris I. Telmer and Marios Zachariadis (2005): "Understanding European Real Exchange Rates". American Economic Review, vol. 95 (3), pp. 724-738.

[21] Devereux, Michael B. and Alan Sutherland (2007): "Financial Globalization and Monetary Policy". CEPR Discussion Papers, No. DP6147.

[22] Devereux, Michael B. and Charles Engel (2003): "Monetary Policy in the Open Economy Revisited: Price Setting and Exchange-Rate Flexibility". Review of Economic Studies, vol. 70 (4), pp. 765-783.

[23] Devereux, Michael B. and Charles Engel (2007): "Expectations, Monetary Policy, and the Misalignment of Traded Goods Prices", forthcoming in NBER International Seminar on Macroeconomics 200\%.

[24] di Giorgio, Giorgio, and Salvatore Nisticò (2007): "Monetary Policy and Stock Prices in an Open Economy". Journal of Money, Credit and Banking, vol. 39 (8), pp. 1947-1985.

[25] Dotsey, Michael, Robert G. King, and Alexander L. Wolman (1999): "State-Dependent Pricing and the General Equilibrium Dynamics of Money and Output". Quarterly Journal of Economics, vol. 114 (2), pp. 655-690.

[26] Engel, Charles (1999): "Accounting for U.S. Real Exchange Rate Changes". Journal of Political Economy, vol. 107 (3), pp. 507-538.

[27] Engel, Charles and Kenneth West (2005): "Exchange Rates and Fundamentals". Journal of Political Economy, vol. 113 (3), pp. 485-517.

[28] Engel, Charles and Jian Wang (2007): "International Trade in Durable Goods: Understanding Volatility, Cyclicality, and Elasticities". GMPI Working Paper, No. 3, Federal Reserve Bank of Dallas.

[29] Evans, Carolyn L. (2003): "The Economic Significance of National Border Effects". American Economic Review, vol. 93 (4), pp. 1291-1312.

[30] Evans, Martin D. D. and Viktoria Hnatkovska (2005): "International Capital Flows, Returns and World Financial Integration". Mimeo, Georgetown University.

[31] Evans, Martin D. D. and Viktoria Hnatkovska (2007): "Solving General Equilibrium Models with Incomplete Markets and Many Financial Assets". Mimeo, Georgetown University.

[32] Feldstein, Martin and Charles Horioka (1980): "Domestic Savings and International Capital Flows". Economic Journal, vol. 90 (358), pp. 314-329.

[33] Flood, Robert P. and Andrew K. Rose (1995): "Fixing the Exchange Rate Regime: A Virtual Quest for Fundamentals". Journal of Monetary Economics, vol. 36 (1), pp. 3-37.

[34] French, Kenneth R. and James M. Poterba (1991): "Investor Diversification and International Equity Markets". American Economic Review, vol. 81 (2), pp. 222-226.

[35] Friedman, Milton (1960): "A Program for Monetary Stability". Fordham University Press: New York, New York, USA.

[36] Galí, Jordi and Mark Gertler (2007): "Macroeconomic Modeling for Monetary Policy Evaluation". Journal of Economic Perspectives, vol. 21 (4), pp. 25-45.

[37] Gopinath, Gita and Roberto Rigobon (2007): "Sticky Borders". Mimeo, Harvard University, Economics Department. Also circulated in 2006 as NBER Working Paper, No. 12095, National Bureau of Economic Research, Inc. 
[38] King, Robert G., C. Plosser, and Sergio T. Rebelo (1988): "Production, Growth and Business Cycles: I. The Basic Neoclassical Model". Journal of Monetary Economics, vol. 21 (2-3), pp. 195-232.

[39] Knetter, Michael M. (1993): "International Comparison of Pricing-to-Market Behavior". American Economic Review, vol. 83 (3), pp. 473-486.

[40] Landry, Anthony (2007): "Pricing-to-Market with State-Dependent Pricing". Federal Reserve Bank of Dallas Working Paper, No. 0706, Federal Reserve Bank of Dallas.

[41] Lewis, Karen K. (1999): "Trying to Explain the Home Bias in Equities and Consumption". Journal of Economic Literature, vol. 37 (2), pp. 571-608.

[42] McCallum, John (1995): "National Borders Matter: Canada-U.S. Regional Trade Patterns". American Economic Review, vol. 85 (3), pp. 615-623.

[43] Mankiw, N. Gregory (1987): "The Optimal Collection of Seigniorage Theory and Evidence". Journal of Monetary Economics, vol. 20 (2), pp. 327-341.

[44] Mankiw, N. Gregory and Ricardo Reis (2002): "Sticky Information versus Sticky Prices: A Proposal to Replace the New Keynesian Phillips Curve". Quarterly Journal of Economics, vol. 117 (2), pp. $1295-1328$.

[45] Mankiw, N. Gregory and Ricardo Reis (2006): "Pervasive Stickiness". American Economic Review, vol. 96 (2), pp. 164-169.

[46] Manuelli, Rodolfo and James Peck (1990): "Exchange Rate Volatility in an Equilibrium Asset Pricing Model". International Economic Review, vol. 31 (3), pp. 559-574.

[47] Mark, Nelson C. (2001): "International Macroeconomics and Finance. Theory and Econometric Methods". Blacwell Publishers Inc.: Malden, Massachusetts, USA.

[48] Martínez-García, Enrique (2007): "A Monetary Model of the Exchange Rate with Informational Frictions". GMPI Working Paper, No. 2, Federal Reserve Bank of Dallas.

[49] Martínez-García, Enrique and Jens Sondergaard (2008): "The Real Exchange Rate in Sticky Price Models: Does Investment Matter?". GMPI Working Paper, No. XXXXX, Federal Reserve Bank of Dallas.

[50] Meese, Richard A. and Kenneth Rogoff (1983): "Empirical Exchange Rate Models of the Seventies: Do they Fit Out of Sample?". Journal of International Economics, vol. 14 (1-2), pp. 3-24.

[51] Obstfeld, Maurice and Kenneth Rogoff (1995): "Exchange Rate Dynamics Redux". Journal of Political Economy, vol. 103 (3), pp. 624-660.

[52] Obstfeld, Maurice and Kenneth Rogoff (1996): "Foundations of International Macroeconomics". MIT University Press: Cambridge, Massachusetts, USA.

[53] Obstfeld, Maurice and Kenneth Rogoff (2000a): "The Six Major Puzzles in International Macroeconomics: Is There a Common Cause?", in Ben S. Bernanke and Kenneth Rogoff (eds.) NBER Macroeconomics Annual 2000, vol. 15, pp. 339-390. MIT University Press: Cambridge, Massachusetts, USA.

[54] Obstfeld, Maurice and Kenneth Rogoff (2000b): "New Directions for Stochastic Open Economy Models". Journal of International Economics, vol. 50 (1), pp. 117-153.

[55] Obstfeld, Maurice and Kenneth Rogoff (2002): "Risk and Exchange Rates", in Elhanan Helpman and Effraim Sadka (eds.) Contemporary Economic Policy: Essays in Honor of Assaf Razin. Cambridge University Press: Cambridge, UK. 
[56] Rogoff, Kenneth (1996): "The Purchasing Power Parity Puzzle". Journal of Economic Literature, vol. 34 (2), pp. 647-668.

[57] Rossi, Barbara (2007): "Expectations Hypotheses Tests at Long Horizons". Econometrics Journal, vol. 10 (3), pp. 554-579.

[58] Poole, William (2008): "Inflation Dynamics". The Baldwin Lecture, Truman State University, Kirksville, Mo. February 20, 2008.

[59] Svensson, Lars E. O., and Sweder van Wijnbergen (1989): "Excess Capacity, Monopolistic Competition and International Transmission of Monetary Disturbances". Economic Journal, vol. 99 (397), pp. 785805 .

[60] Taylor, John B. (1993): "Discretion versus Policy Rules in Practice". Carnegie-Rochester Conference Series, vol. 39, pp. 195-214.

[61] Taylor, John B. (2006): "Implications of Globalization for Monetary Policy". Prepared for the academic consultants meeting, Federal Reserve Board.

[62] Thoenissen, Christoph (2003): "Real Exchange Rates, Current Accounts and the Net Foreign Asset Position". Mimeo, University of St. Andrews.

[63] Trefler, Daniel (1995): "The Case of the Missing Trade and other Mysteries". American Economic Review, vol. 85 (5), pp. 1029-1046.

[64] Warnock, Francis E. (2003): "Exchange Rate Dynamics and the Welfare Effects of Monetary Policy in a Two-Country Model with Home-Product Bias". Journal of International Money and Finance, vol. 22 (3), pp. 343-363.

[65] Warnock, Frank and Veronica Cacdac Warnock (2006): "International Capital Flows and U.S. Interest Rates". Mimeo, University of Virginia-Darden Business School. Revised version of International Finance Discussion Paper, No. 840, Federal Reserve Board.

[66] Woodford, Michael (2003): "Interest and Prices. Foundations of a Theory of Monetary Policy". Princeton University Press: Princeton, New Jersey, USA.

[67] Woodford, Michael (2007): "Globalization and Monetary Control". NBER Working Paper, No. 13329, National Bureau of Economic Research, Inc.

[68] Yaari, Menahem E. (1965): "Uncertain Lifetime, Life Insurance, and the Theory of the Consumer". Review of Economic Studies, vol. 32 (2), pp. 137-150. 
Appendix 


\section{A The Nonlinear Dynamics}

\section{A.1 The Flexible Price, Complete Asset Markets Model}

\begin{tabular}{cc}
\hline \hline $\mathbf{I S}^{\mathbf{H}}$ & $\bar{Q}_{t}\left(\omega_{t+1}\right)=\beta\left(\frac{\overline{\bar{C}}_{t+1}\left(\omega_{t+1}\right)}{\bar{C}_{t}}\right)^{-\gamma} \frac{\bar{P}_{t}}{\overline{\bar{P}_{t+1}\left(\omega_{t+1}\right)}} \mu_{t}\left(\omega_{t+1}\right), \int_{\omega_{t+1} \in \Omega} \bar{Q}_{t}\left(\omega_{t+1}\right)=\frac{1}{1+\bar{i}_{t}}$, \\
$\mathbf{I S} \mathbf{F}$ & $\bar{Q}_{t}^{*}\left(\omega_{t+1}\right)=\beta\left(\frac{\bar{C}_{t+1}^{*}\left(\omega_{t+1}\right)}{\bar{C}_{t}^{*}}\right)^{-\gamma} \frac{\bar{P}_{t}^{*}}{\bar{P}_{t+1}^{*}\left(\omega_{t+1}\right)} \mu_{t}\left(\omega_{t+1}\right), \int_{\omega_{t+1} \in \Omega} \bar{Q}_{t}^{*}\left(\omega_{t+1}\right)=\frac{1}{1+\bar{i}_{t}^{*}}$, \\
$\mathbf{U I P}$ & $\frac{\bar{S}_{t+1}\left(\omega_{t+1}\right)}{\overline{\bar{S}}_{t}}=\frac{\bar{Q}_{t}^{*}\left(\omega_{t+1}\right)}{\overline{\bar{Q}}_{t}\left(\omega_{t+1}\right)}$, \\
$\mathbf{M} \mathbf{P}^{\mathbf{H}}$ & $\frac{1+\bar{i}_{t}}{1+\bar{i}}=\frac{Z_{t}}{Z}\left(\frac{1+\bar{i}_{t-1}}{1+\bar{i}}\right)^{\rho}\left[\bar{\Pi}_{t}^{\psi_{1}}\left(\frac{\bar{Y}_{t}}{\bar{Y}_{t}}\right)^{\psi_{2}}\right]^{1-\rho}$, \\
$\mathbf{M P}$ & $\frac{1+\bar{i}_{t}^{*}}{1+\bar{i}^{*}}=\frac{Z_{t}^{*}}{Z^{*}}\left(\frac{1+\bar{i}_{t-1}^{*}}{1+\bar{i}}\right)^{\rho^{*}}\left[\bar{\Pi}_{t}^{*} \psi_{1}^{*}\left(\frac{\bar{Y}_{t}^{*}}{\bar{Y}_{t}^{*}}\right)^{\psi_{2}^{*}}\right]^{1-\rho^{*}}$, \\
\hline
\end{tabular}

The Supply-Side in the Goods Market:

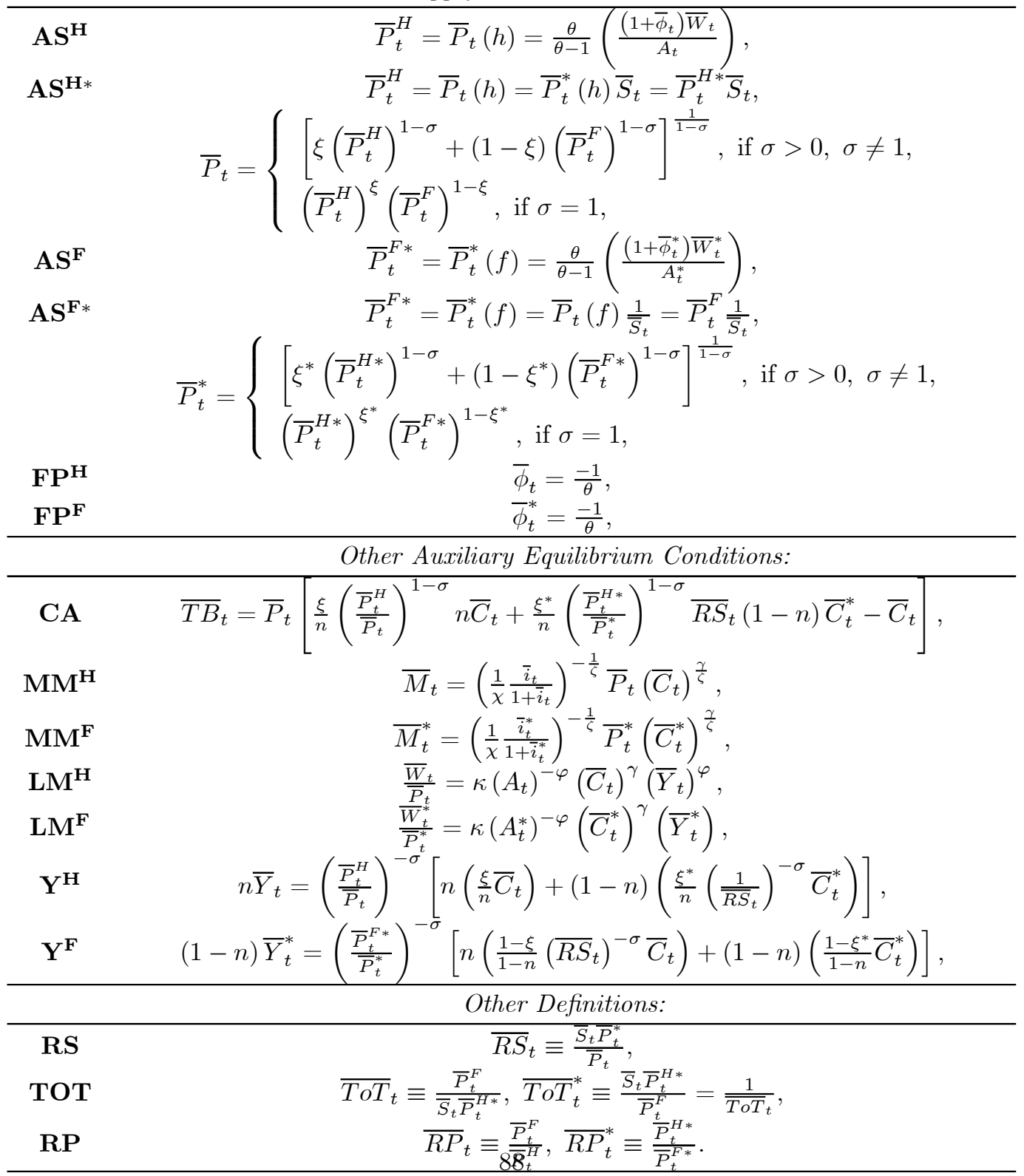




\section{A.2 The Sticky Price, Complete Asset Markets Model}

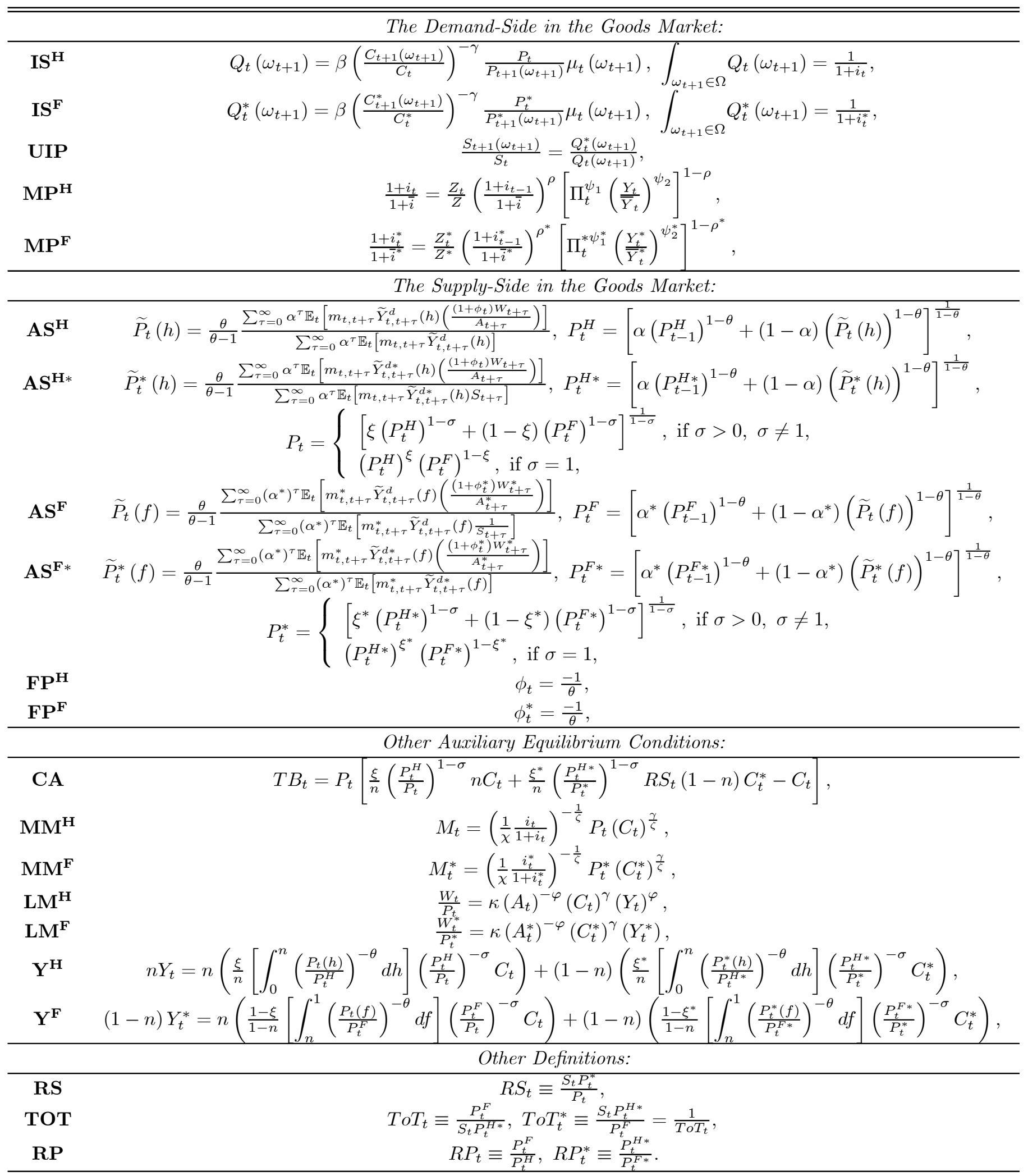




\section{A.3 The Sticky Price, Incomplete Asset Markets Model}

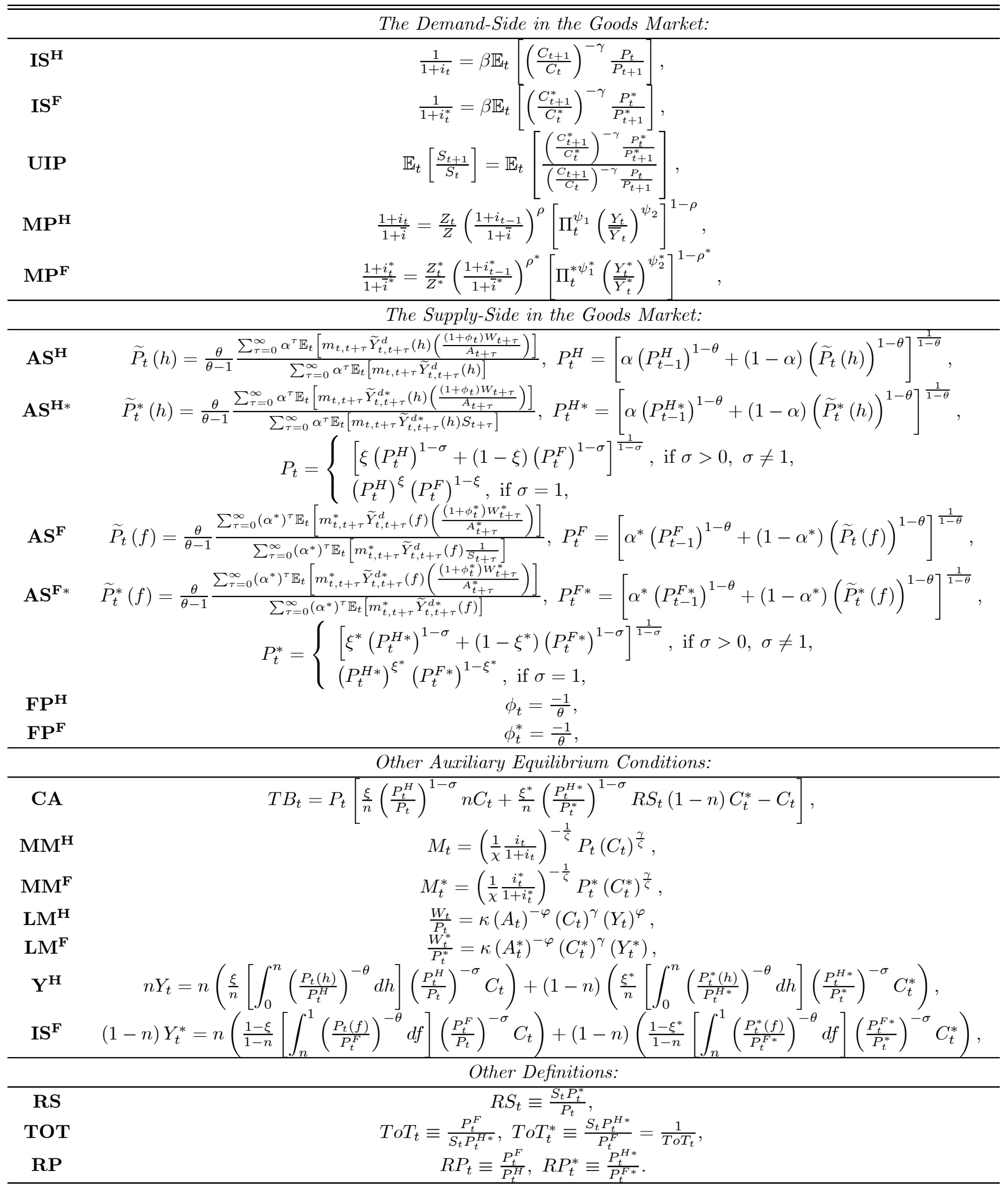




\section{B The Deterministic Steady State}

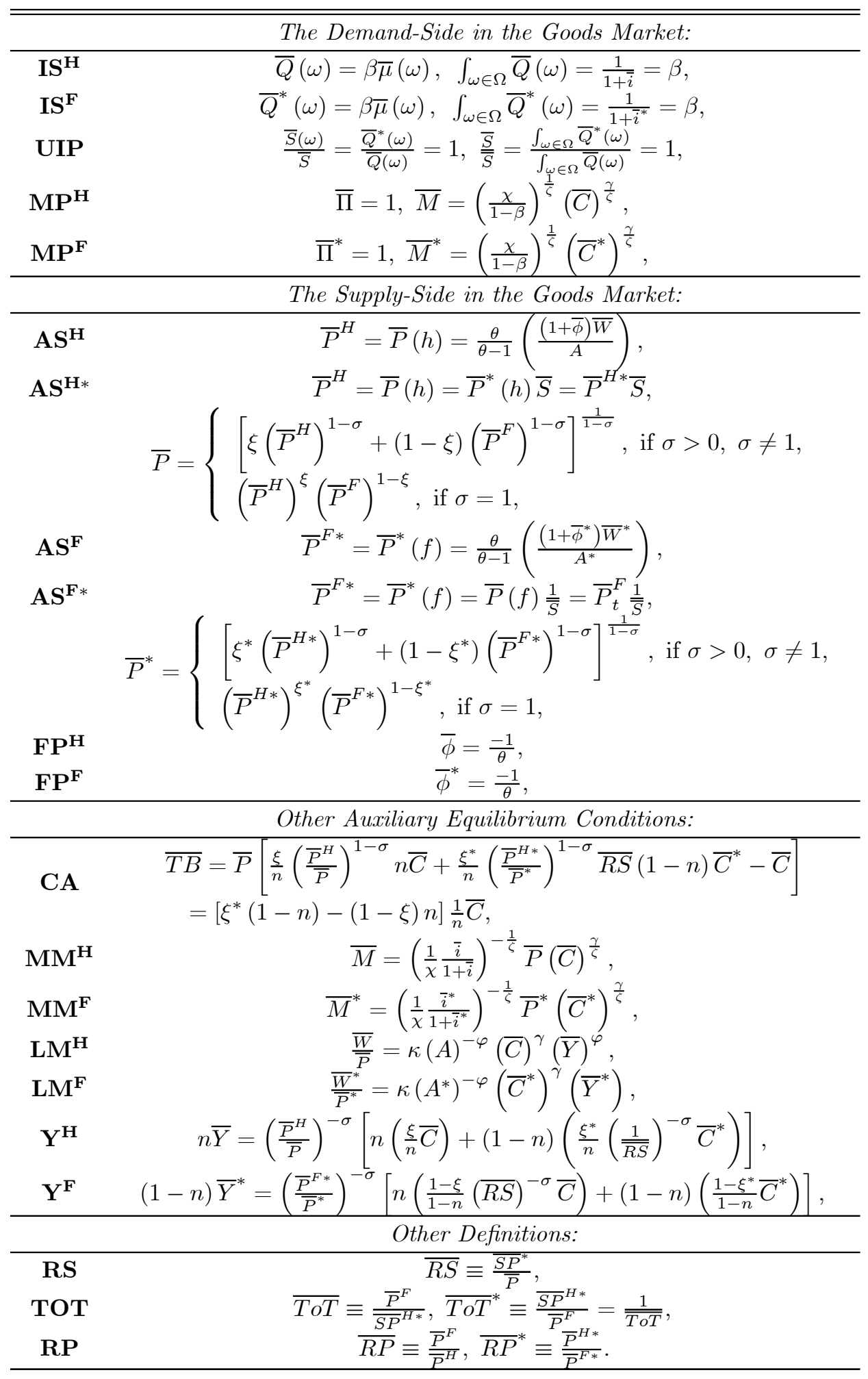




\section{The Log-Linearized Dynamics (A First-Order Approximation)}

\section{C.1 The Flexible Price, Complete Asset Markets Model}

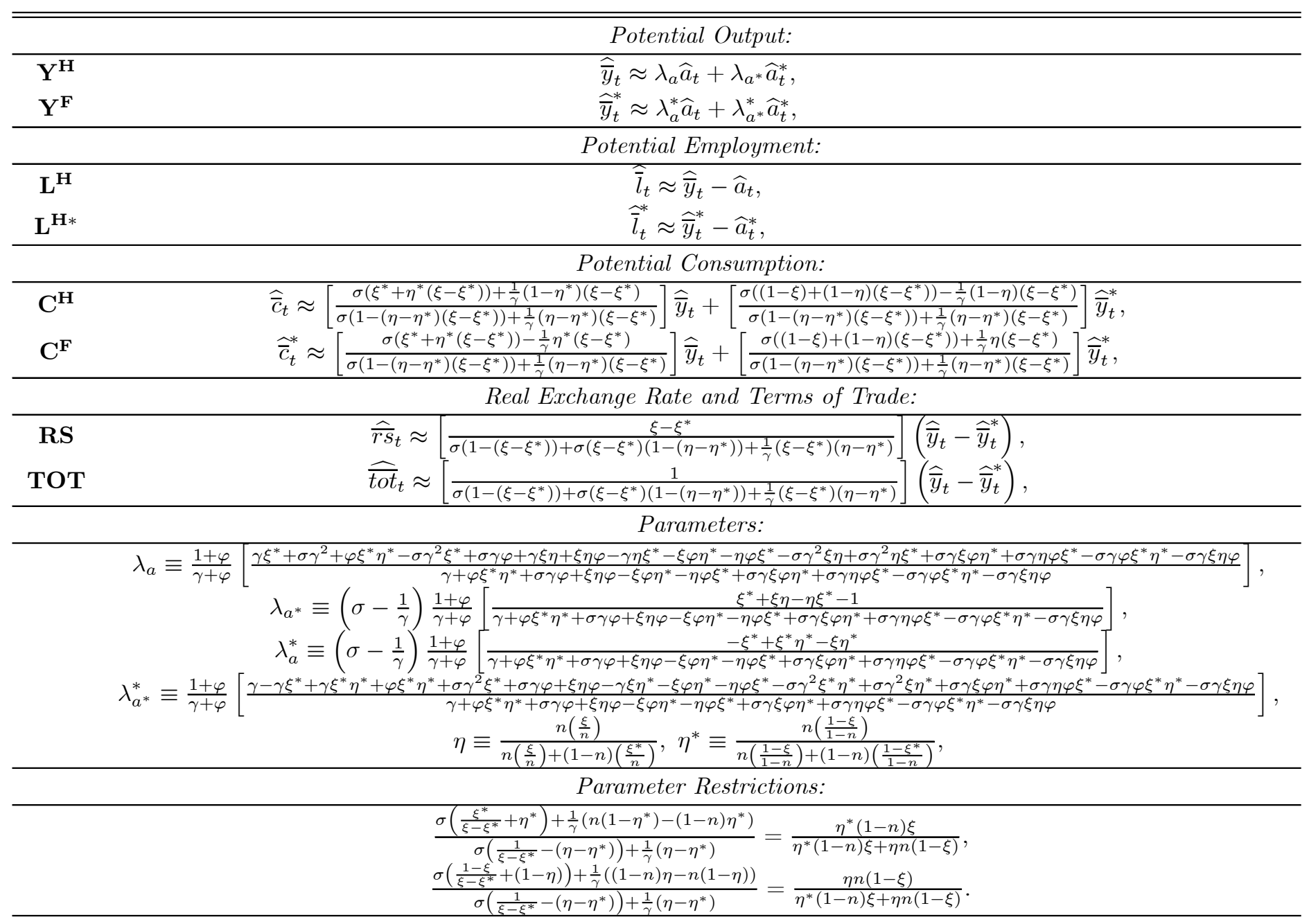




\section{C.2 The Sticky Price, Complete Asset Markets Model}

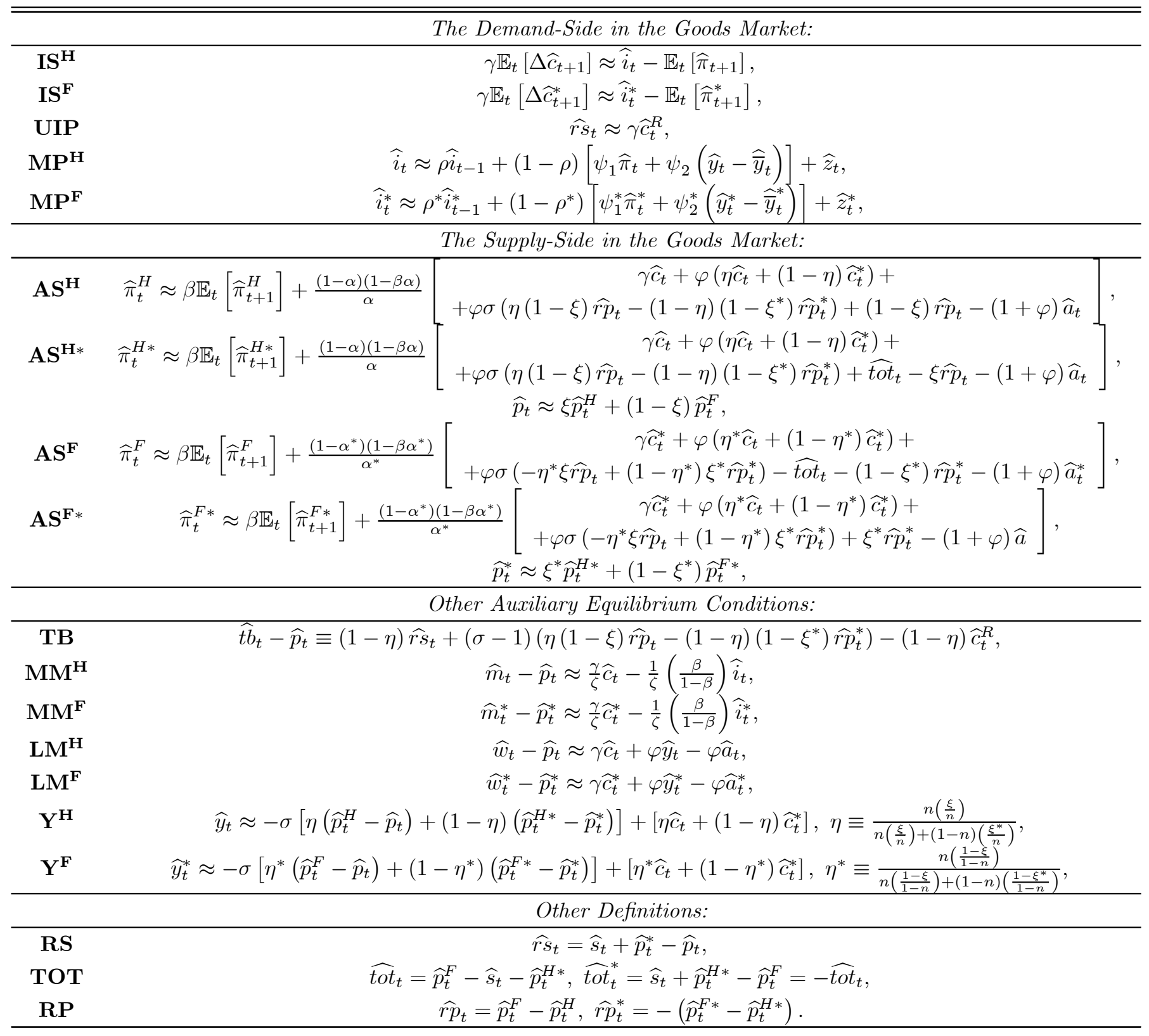




\section{C.3 The Sticky Price, Incomplete Asset Markets Model}

\begin{tabular}{|c|c|}
\hline & The Demand-Side in the Goods Market: \\
\hline $\mathbf{I S}^{\mathbf{H}}$ & $\gamma \mathbb{E}_{t}\left[\Delta \widehat{c}_{t+1}\right] \approx \widehat{i}_{t}-\mathbb{E}_{t}\left[\widehat{\pi}_{t+1}\right]$ \\
\hline $\mathbf{I S}^{\mathbf{F}}$ & $\gamma \mathbb{E}_{t}\left[\Delta \widehat{c}_{t+1}^{*}\right] \approx \widehat{i}_{t}^{*}-\mathbb{E}_{t}\left[\widehat{\pi}_{t+1}^{*}\right]$ \\
\hline UIP & $\mathbb{E}_{t}\left[\Delta \widehat{r s}_{t+1}\right] \approx \gamma \mathbb{E}_{t}\left[\Delta \widehat{c}_{t+1}^{R}\right]$ \\
\hline $\mathbf{M P}^{\mathbf{H}}$ & $\widehat{i}_{t} \approx \rho \widehat{i}_{t-1}+(1-\rho)\left[\psi_{1} \widehat{\pi}_{t}+\psi_{2}\left(\widehat{y}_{t}-\widehat{\bar{y}}_{t}\right)\right]+\widehat{z}_{t}$, \\
\hline \multirow[t]{2}{*}{$\mathrm{MP}^{\mathrm{F}}$} & $\widehat{i}_{t}^{*} \approx \rho^{*} \widehat{i}_{t-1}^{*}+\left(1-\rho^{*}\right)\left[\psi_{1}^{*} \widehat{\pi}_{t}^{*}+\psi_{2}^{*}\left(\widehat{y}_{t}^{*}-\widehat{\bar{y}}_{t}^{*}\right)\right]+\widehat{z}_{t}^{*}$ \\
\hline & The Supply-Side in the Goods Market: \\
\hline $\mathbf{A S} \mathbf{S}^{\mathbf{H}}$ & $\widehat{\pi}_{t}^{H} \approx \beta \mathbb{E}_{t}\left[\widehat{\pi}_{t+1}^{H}\right]+\frac{(1-\alpha)(1-\beta \alpha)}{\alpha}\left[\begin{array}{c}\gamma \widehat{c}_{t}+\varphi\left(\eta \widehat{c}_{t}+(1-\eta) \widehat{c}_{t}^{*}\right)+ \\
+\varphi \sigma\left(\eta(1-\xi) \widehat{r p}_{t}-(1-\eta)\left(1-\xi^{*}\right) \widehat{r p}_{t}^{*}\right)+(1-\xi) \widehat{r p}_{t}-(1+\varphi) \widehat{a}_{t}\end{array}\right.$ \\
\hline $\mathbf{A S} \mathbf{S}^{\mathbf{H *}}$ & $\begin{array}{c}\widehat{\pi}_{t}^{H *} \approx \beta \mathbb{E}_{t}\left[\widehat{\pi}_{t+1}^{H *}\right]+\frac{(1-\alpha)(1-\beta \alpha)}{\alpha}\left[\begin{array}{c}\gamma \widehat{c}_{t}+\varphi\left(\eta \widehat{c}_{t}+(1-\eta) \widehat{c}_{t}^{*}\right)+ \\
+\varphi \sigma\left(\eta(1-\xi) \widehat{r p}_{t}-(1-\eta)\left(1-\xi^{*}\right) \widehat{r p}_{t}^{*}\right)+\widehat{t o t}_{t}-\xi \widehat{r p}_{t}-(1+\varphi) \widehat{a}_{t} \\
\widehat{p}_{t} \approx \xi \widehat{p}_{t}^{H}+(1-\xi) \widehat{p}_{t}^{F}\end{array}\right.\end{array}$ \\
\hline $\mathbf{A} \mathbf{S}^{\mathbf{F}}$ & $\widehat{\pi}_{t}^{F} \approx \beta \mathbb{E}_{t}\left[\widehat{\pi}_{t+1}^{F}\right]+\frac{\left(1-\alpha^{*}\right)\left(1-\beta \alpha^{*}\right)}{\alpha^{*}}\left[\begin{array}{c}\gamma \widehat{c}_{t}^{*}+\varphi\left(\eta^{*} \widehat{c}_{t}+\left(1-\eta^{*}\right) \widehat{c}_{t}^{*}\right)+ \\
+\varphi \sigma\left(-\eta^{*} \xi \widehat{r p}_{t}+\left(1-\eta^{*}\right) \xi^{*} \widehat{r p}_{t}^{*}\right)-\widehat{t o t}_{t}-\left(1-\xi^{*}\right) \widehat{r p}_{t}^{*}-(1+\varphi) \widehat{a}_{t}^{*}\end{array}\right.$ \\
\hline \multirow[t]{2}{*}{$\mathbf{A} \mathbf{S}^{\mathbf{F *}}$} & $\begin{array}{c}\widehat{\pi}_{t}^{F *} \approx \beta \mathbb{E}_{t}\left[\widehat{\pi}_{t+1}^{F *}\right]+\frac{\left(1-\alpha^{*}\right)\left(1-\beta \alpha^{*}\right)}{\alpha^{*}}\left[\begin{array}{c}\gamma \widehat{c}_{t}^{*}+\varphi\left(\eta^{*} \widehat{c}_{t}+\left(1-\eta^{*}\right) \widehat{c}_{t}^{*}\right)+ \\
+\varphi \sigma\left(-\eta^{*} \xi \widehat{r p}_{t}+\left(1-\eta^{*}\right) \xi^{*} \widehat{r p}_{t}^{*}\right)+\xi^{*} \widehat{r p}_{t}^{*}-(1+\varphi) \widehat{a}\end{array}\right] \\
\widehat{p}_{t}^{*} \approx \xi^{*} \widehat{p}_{t}^{H *}+\left(1-\xi^{*}\right) \widehat{p}_{t}^{F *}\end{array}$ \\
\hline & Other Auxiliary Equilibrium Conditions: \\
\hline TB & $\widehat{t b}_{t}-\widehat{p}_{t} \equiv(1-\eta) \widehat{r s}_{t}+(\sigma-1)\left(\eta(1-\xi) \widehat{r p}_{t}-(1-\eta)\left(1-\xi^{*}\right) \widehat{r p}_{t}^{*}\right)-(1-\eta) \widehat{c}_{t}^{R}$ \\
\hline $\mathrm{MM}^{\mathrm{H}}$ & $\widehat{m}_{t}-\widehat{p}_{t} \approx \frac{\gamma}{\zeta} \widehat{c}_{t}-\frac{1}{\zeta}\left(\frac{\beta}{1-\beta}\right) \widehat{i}_{t}$ \\
\hline $\mathrm{MM}^{\mathrm{F}}$ & $\widehat{m}_{t}^{*}-\widehat{p}_{t}^{*} \approx \frac{\gamma}{\zeta} \widehat{c}_{t}^{*}-\frac{1}{\zeta}\left(\frac{\beta}{1-\beta}\right) \widehat{i}_{t}^{*}$ \\
\hline $\mathbf{L} \mathbf{M}^{\mathbf{H}}$ & $\widehat{w}_{t}-\widehat{p}_{t} \approx \gamma \widehat{c}_{t}+\varphi \widehat{y}_{t}-\varphi \widehat{a}_{t}$ \\
\hline $\mathbf{L M}^{\mathrm{F}}$ & $\widehat{w}_{t}^{*}-\widehat{p}_{t}^{*} \approx \gamma \widehat{c}_{t}^{*}+\varphi \widehat{y}_{t}^{*}-\varphi \widehat{a}_{t}^{*}$ \\
\hline $\mathbf{Y}^{\mathbf{H}}$ & $\widehat{y}_{t} \approx-\sigma\left[\eta\left(\widehat{p}_{t}^{H}-\widehat{p}_{t}\right)+(1-\eta)\left(\widehat{p}_{t}^{H *}-\widehat{p}_{t}^{*}\right)\right]+\left[\eta \widehat{c}_{t}+(1-\eta) \widehat{c}_{t}^{*}\right], \eta \equiv \frac{n\left(\frac{\xi}{n}\right)}{n\left(\frac{\xi}{n}\right)+(1-n)\left(\frac{\xi^{*}}{n}\right)}$, \\
\hline \multirow[t]{2}{*}{$\mathbf{Y}^{\mathbf{F}}$} & $\widehat{y}_{t}^{*} \approx-\sigma\left[\eta^{*}\left(\widehat{p}_{t}^{F}-\widehat{p}_{t}\right)+\left(1-\eta^{*}\right)\left(\widehat{p}_{t}^{F *}-\widehat{p}_{t}^{*}\right)\right]+\left[\eta^{*} \widehat{c}_{t}+\left(1-\eta^{*}\right) \widehat{c}_{t}^{*}\right], \eta^{*} \equiv \frac{n\left(\frac{1-\xi}{1-n}\right)}{n\left(\frac{1-\xi}{1-n}\right)+(1-n)\left(\frac{1-\xi^{*}}{1-n}\right)}$, \\
\hline & Other Definitions: \\
\hline RS & $\widehat{r s}_{t}=\widehat{s}_{t}+\widehat{p}_{t}^{*}-\widehat{p}_{t}$ \\
\hline TOT & $\widehat{t o t}_{t}=\widehat{p}_{t}^{F}-\widehat{s}_{t}-\widehat{p}_{t}^{H *}, \widehat{t o t}_{t}^{*}=\widehat{s}_{t}+\widehat{p}_{t}^{H *}-\widehat{p}_{t}^{F}=-\widehat{t o t}_{t}$ \\
\hline $\mathbf{R P}$ & $\widehat{r p}_{t}=\widehat{p}_{t}^{F}-\widehat{p}_{t}^{H}, \widehat{r p}_{t}^{*}=-\left(\widehat{p}_{t}^{F *}-\widehat{p}_{t}^{H *}\right)$ \\
\hline
\end{tabular}

